\title{
The acquisition of morphology in a corpus of secondary school EFL learners: a focus on possessive ' $-s$ '
}

\section{Elpiniki Atzolidaki}

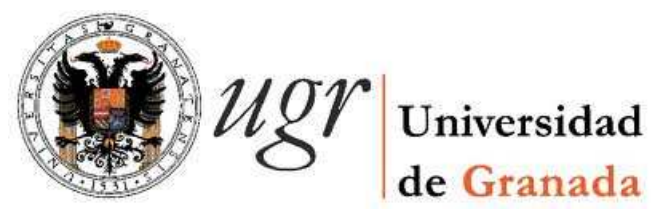

Supervisor: Cristóbal Lozano

Trabajo Fin de Máster (TFM) del Máster de profesorado de educación secundaria obligatoria y bachillerato, formación professional y enseñanza de idiomas

\author{
Universidad de Granada
}


To my parents 


\section{Acknowledgements}

The present paper is based on a research project conducted as part of the Master's Degree in Education and Foreign Language Teaching at the University of Granada.

This study owes a lot to the support and collaboration of my supervisor Dr. Cristóbal Lozano. Without his insightful comments, the seminars he organised and the material he facilitated me with, I would not have completed this three-fold project. In the same line, I would like to give special thanks to Dr. Ana Díaz Negrillo for her assistance in elaborating the learner corpus and the tagging scheme used in this study.

Additionally, I gratefully acknowledge the support of my family and friends. Their help, patience and encouragement were vital for the completion of this project.

I am also grateful to the students that participated in this study and to the schools IES Pedro soto de Rojas, IES Padre Suarez and the Centro de Lenguas Modernas (UGR) for giving me their permission to conduct my research in their premises and for all the help and support of the relevant teachers.

Finally, I would like to thank all those people (professors, fellow students, family, friends) that have been a great source of inspiration in my life. 
Table of contents

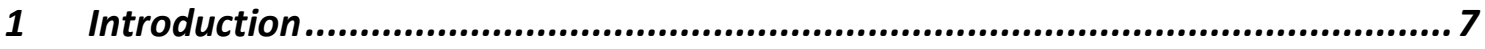

$2 \quad$ Linguistic structures under investigation ................................................... 9

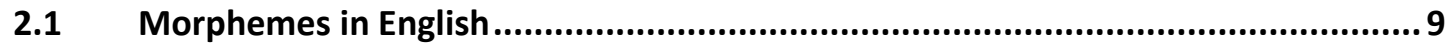

2.2 The expression of possession in English and in German ......................................11

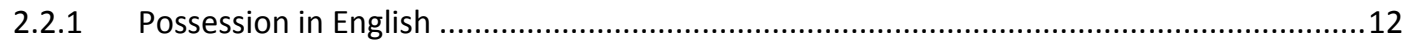

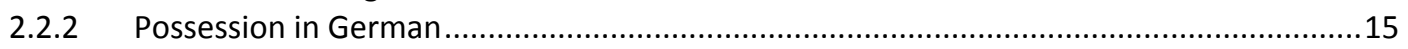

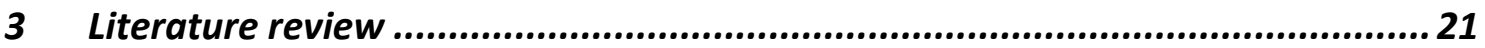

3.1 Morpheme order studies (MOS) ............................................................ 22

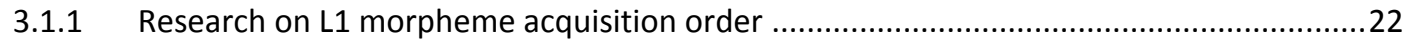

3.1.2 Research in L2 morpheme acquisition order..............................................................25

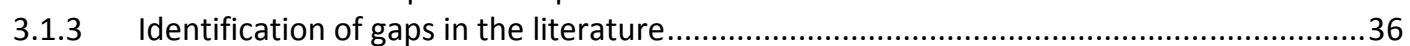

3.2 Learner Corpora and Learner Corpus Research .................................................. 40

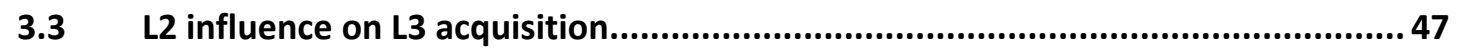

4 Research Questions and Hypotheses.......................................................... 52

4.1 Study I: MOS and Learner Corpus in L2 English .................................................52

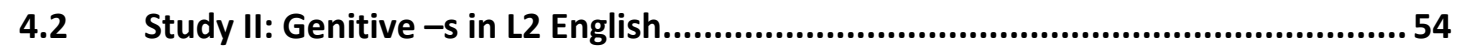

4.3 Study III: Possessive structures in L3 German ....................................................55

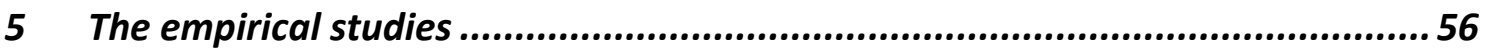

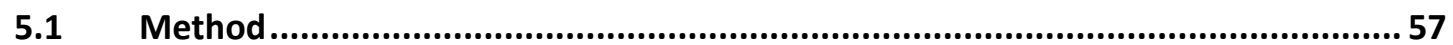

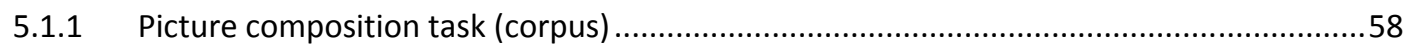

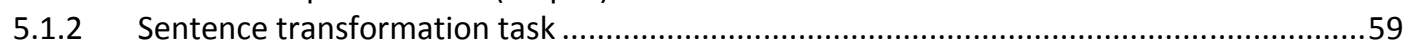

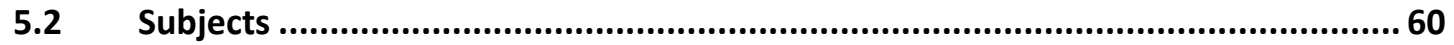

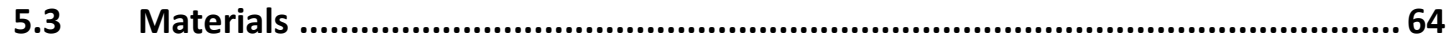

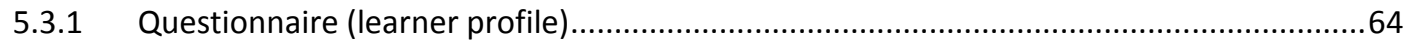

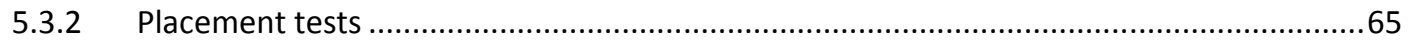

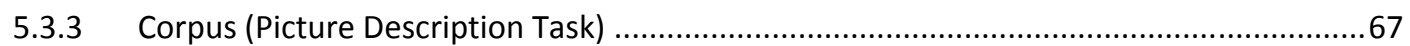

5.3.4 Experimentally elicited language (Sentence Transformation Task) .................................68

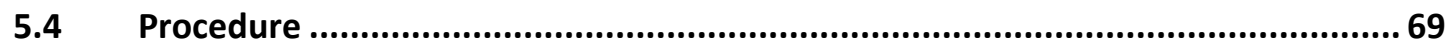

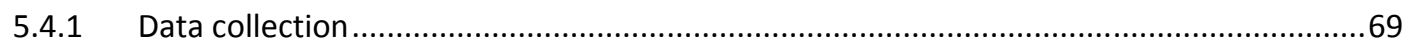

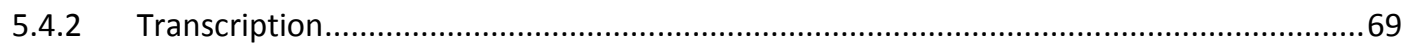

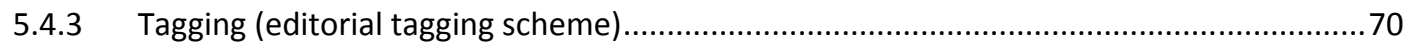

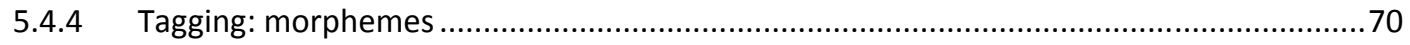

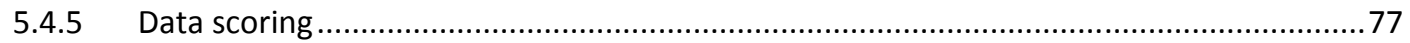

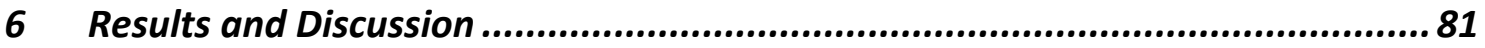

6.1 Morpheme Order Study in L2 English .................................................................... 81

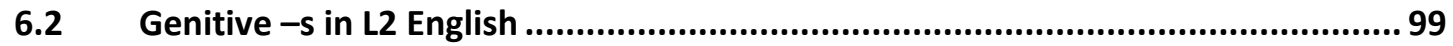

6.3 Possessive structures in L3 German ............................................................... 106

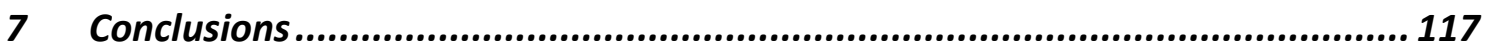

7.1 Study I: MOS \& Learner Corpus in L2 English .................................................. 117 


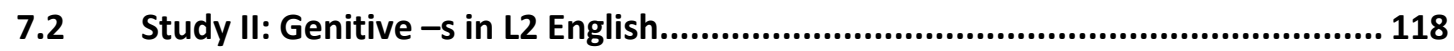

7.3 Study III: Possessive structures in L3 German ................................................. 119

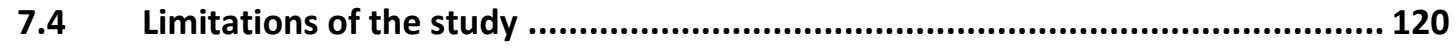

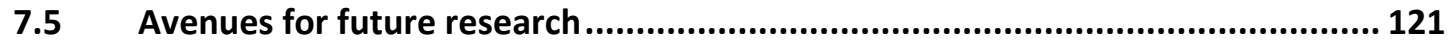

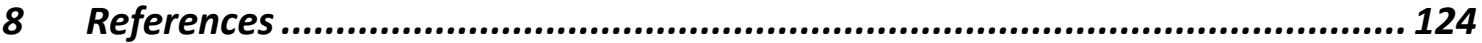

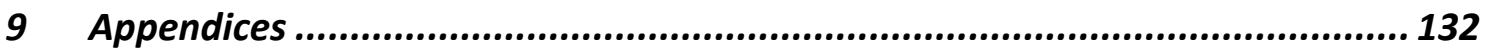

9.1 Learner Profile for L2 English and for L3 German ........................................... 132

$9.2 \quad$ Proficiency test: L2 English ............................................................................. 134

9.3 Proficiency Level Test: L3 German ...................................................................... 139

9.4 Elicitation of Learner Language: Picture Composition Task ................................. 145

9.5 Experimental Elicitation of Learner Language: Sentence Transformation Task:

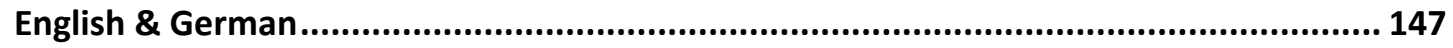

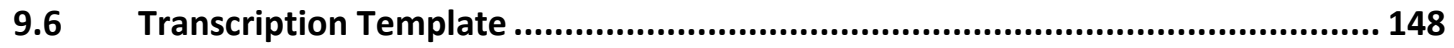

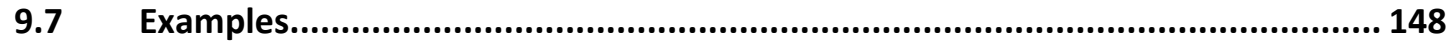

9.7.1 Learner Corpus Transcribed File .................................................................. 148

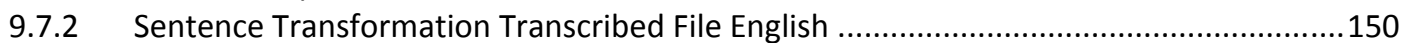

9.7.3 Sentence Transformation Transcribed File German .........................................................151

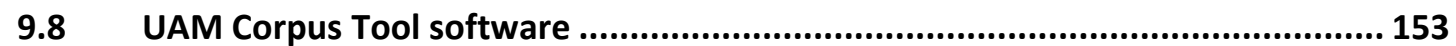

9.9 Tagging Manual: Learners' correction tagging scheme..................................... 153

9.10 Tagging Manual: MOS Project ....................................................................... 156

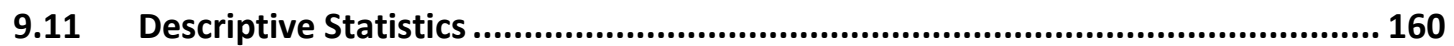

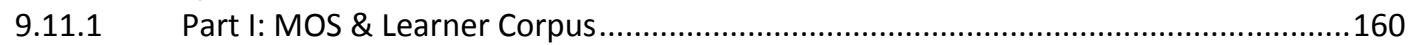

9.11.1.1 Specific Descriptive Statistics (grouping criterion: proficiency level) .....................160

9.11.1.2 General Descriptive Statistics (grouping criterion: none) .....................................217

9.11.2 Part II: The use of the possessive $-\mathrm{s}$ by L2 English learners: an experimentally elicited data study 231

9.11.3 Part III: The use of the possessive structures by L3 German learners: an experimentally

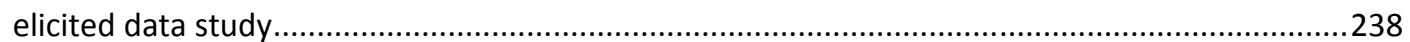

9.11.3.1 The relative frequency of the various possession constructions in German by L1

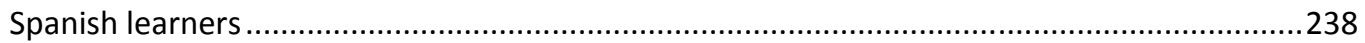

9.11.3.2 The relative frequency of the various possession constructions in German by L1

Spanish and L2 English learners 247 


\section{Abstract}

This paper consists of three separate studies. The principal one is a morpheme order study (MOS) based on our own learner corpus which contains learner language from secondary school students. For this study we were partly based on previous relevant projects, but our research is distinct in two core points. The first relates to the data elicitation instrument (learner corpus) which is a novel and promising approach in the field of second language acquisition research. The second regards the scoring method used in our project in order to establish the accuracy rates for each of the grammatical morphemes at issue. Regarding this, our study's novelty relies on the combination of the most accurate relevant scoring models that have been previously suggested. Our second study focuses on a specific functor, namely the possessive $-s$. In this regard we have studied not only the accuracy rates of the aforementioned inflectional possession structure, but also its frequency of use in relation to the other possession forms in English. In keeping with the perceived importance of the data elicitation instrument, we have decided to use two different methods (a learner corpus and an experiment) with our L2 English learners and thus deliver more accurate results. Our final study accounts for the use of the various possession forms in L3 German. This study has two distinct focal points. The first refers to the learners' preference for one of the possessive forms available in German as seen by our subjects' corresponding choices. In this regard, we have also compared the frequency of use of each of the possession structures in both L2 English and L3 German. The other point of interest of our third study was the possible influence of our students' L2 (English) on the acquisition of their L3 (German) as seen by our subjects' use of the various possessive forms. In all our studies we have classified our subjects according to their proficiency level, which we determined by means of a corresponding test. This is a very distinctive feature of our study since most previous studies on this field have either not considered the subjects' level of proficiency or they have determined it based on criteria other than an actual proficiency test. 


\section{Introduction}

The description of learners' language (i.e., their interlanguage) has been of particular interest to second language acquisition research. This interest in language learners' interlanguage stems from the idea that its analysis may provide researchers with enriching insights into the process of language acquisition in general and second language acquisition in particular.

Ellis (1994) claimed that, by collecting and analysing samples of learner language, SLA researchers can achieve two goals:

(a) a description of the subjects' linguistic systems, i.e. their interlanguages and

(b) an explanation of the processes and factors involved in acquiring a foreign language.

Hence interlanguage research is only the first step. If we manage to understand the process of second language acquisition, then we will be able to apply the findings to a variety of practical aspects of language teaching: syllabus design, materials development, task design, and language testing.

Researchers' focus on the acquisition of morphemes started in the 1970s when they were investigating the "independent grammars assumption" (Cook, 1993). It soon evolved into the so-called "natural order" studies due to the majority of the researchers" interest in confirming the innatist view of language acquisition. In 1973 Roger Brown observed that when children start learning their first language they omit mainly grammatical rather than lexical morphemes, which eventually appear in their language in subsequent developmental stages. That prompted language acquisition researchers to check whether there is a consistency in the order of L1 and L2 acquisition of grammatical morphemes. A more detailed account of the aforementioned types of morphemes can be found in section 2.1 . 
The underpinning idea of comparing $\mathrm{L} 1$ and $\mathrm{L} 2$ morpheme acquisition orders was that if a universal morpheme acquisition order could be established, then the process of acquisition would be proved to be internally driven. Accordingly, it could be argued that second language acquisition is independent of external factors such as the age, the teaching method, the type of exposure (naturalistic vs. instructed) or the L1.

In the same line a number of different theoretical frameworks have been put forth as explanatory patterns. Ellis (1994:44) identifies four major approaches:

1. the study of learners' errors;

2. the study of developmental patterns;

3. the study of variability;

4. the study of pragmatic features.

In our study we have been guided mainly by the approach that focuses on the study of developmental patterns by investigating the acquisition of morphology (both the correct suppliance of morphemes as well as the errors produced). We do consider that MO studies have to offer the SLA researcher with valuable information regarding the process of second language acquisition. First, because, as Ellis and Barkhuizen (2005) put it, "the descriptive information it provides serves as a basis for testing the validity of different explanations of the order of acquisition" (p.79). Second, because, although the so-called "natural order" approach has received a lot of criticism, many methodologically rigorous studies show sufficiently consistent general findings. Nevertheless, the reason why we consider morpheme order studies to be valuable for SLA research is the general degree of commonalities that previously conducted morpheme studies have shown. This, as Larsen-Freeman and Long (1991) noted, provides strong evidence that interlanguages exhibit common accuracy/acquisition orders. 


\section{Linguistic structures under investigation}

In this chapter we will outline the theoretical background that relates to the various studies of our project. Our principal study, as illustrated in our project's title, is the acquisition of morphological structures in L2 English. Therefore, in the first section of the present chapter (2.1) we will provide a definition and a brief description of the English morphemes in general and the English grammatical morphemes in particular. However, our project also focuses on the expression of possession in L2 English and L3 German. Hence in section 2.2 we outline the various structures of possession expression in English and in German. Additionally, we describe and exemplify the restrictions that each of these possession structures has. As we will see, the differences in the choice of possessive structures that English and German present will guide us in our research on the influence of the L2 English on the acquisition of the L3 German.

\subsection{Morphemes in English}

Morphemes are usually defined as the "smallest meaningful constituents of words that can be identified" (Haspelmath, 2002:3). In the same line, every lexical item that "[...] cannot be split into meaningful smaller units" (Cook, 1993:25) is a morpheme. Consequently, morphology contains the rules that concern these minimal meaningful units of a language and the way in which morphemes are combined to make up words. Morphemes may be free or bound. The former can stand on their own (e.g. the word boy), whereas the latter are attached to other items (e.g. the genitive $-s$ in the boy's book). Bound morphemes are further divided into inflectional and derivational. Regarding nouns, for example, we can say that they allow "[...] various suffix morphemes -called inflections- to be appended to indicate 
plurality (dogs), possession (dog's), and both plurality and possession (dogs')" (Butters, 2001:325). Bound morphemes are derivational if their use results in the formation of a new word, that is, if "they derive one word from another" (Cook, 1993:25). Quite often appears in the relevant literature a distinction between lexical and grammatical morphemes. Lexical morphemes are also known as "content words" (Cook, 1993:25), e.g. dog, boy, book, whereas grammatical morphemes are also known as functors. Brown (1973) defines the latter as:

[...] forms that do not, in any simple way, make reference. They mark grammatical structures and carry subtle modulatory meanings. The word classes or parts of speech involved (inflections, auxiliary verbs, articles, prepositions, and conjunctions) all have few members and do not readily admit new members (p.75).

Natural order studies are mainly concerned with grammatical morphemes as we mentioned at the beginning of this section. The following table presents a list of the grammatical morphemes under examination in the first study of this paper. Note that each of our studies is presented in detail in chapter 4 . In the list presented below each of the morphemes is illustrated by an example.

\section{Functor}

Past regular -ed

Past irregular

Third person singular -s (3SG)

Progressive -ing

Be copula

Be auxiliary

Plural

Possessive $-s$

\section{Example}

She smiled.

Then, she stood up and left.

The baby cries.

He is playing the guitar.

She is happy .

He is always eating chocolate.

The children were standing still. Then some of the boys and girls left.

This is John's car./ She was shown to the girls' changing 
room.

Articles

The room was cold./ An apple is enough./ Men drive fast.

Table 1: List of the nine functors studied in this paper

\subsection{The expression of possession in English and in German}

As we stated at the beginning of this chapter, in our study we do not only investigate the acquisition of morphology in English, but we also focus on the accuracy rates of the inflectional forms of possession expression in both L2 English and L3 German. For the study of the acquisition of the English morphology by L2 language learners we used exclusively the data found in our learner corpus. On the contrary, the study of the expression of possession in English and in German required the use of additional data that we collected by means of an experimental method. Note that the methods used in our project are presented in detail in chapter 5 that regards our empirical studies and thus includes information about the methods and the materials used for the elicitation and the collection of the data. Naturally, in subsequent chapters we will also be giving more explanation as to the reasons that prompted our special interest on the expression of possession in these two linguistically related languages. But before we start studying the relative frequency with which our language learners used the various possession structures in both English and German, we should present the corresponding systems of possession expression.

Possession is the relation between two entities. Most specifically it is a relational concept that can express the conceptual relations between entities. McGregor (2009) suggests that possession should be defined on grounds of the linguistic factors implied rather than conceptually. In keeping with this proposal we can claim that possession is a relational concept that regards the relationship(s) between the possessum (henceforth PM) and the possessor (henceforth PR) as illustrated in the following examples: 


\begin{tabular}{|c|}
\hline $\begin{array}{c}\text { 1. John's book. } \\
\text { PR PM }\end{array}$ \\
\hline 2. The book of John. \\
PM PR \\
\hline 3. His book. \\
PR PM \\
\hline
\end{tabular}

The PM refers to what is possessed, whereas the $\mathbf{P R}$ makes reference to the entity (person, animal, etc.) that possesses the PM. In our examples (1-3), the PM is always "the book", whereas the PR is always "John" although in (3) the reference is realised by means of the possessive pronoun.

\subsubsection{Possession in English}

Following McGregor (2009), we can affirm that three types of possessive construction are distinguished: attributive, predicative and external. In the case of attributive possession, the PM and the PR form a single NP as shown in the examples $(1),(2) \&$ (3) above. Sometimes these constructions are also referred to as adnominal possession. In the predicative possession the possessive relation is expressed in the predicate (e.g. John has a book). In the external possession constructions the possessive relation is expressed "[...] at the level of a clausal construction as in the dog bit cliff on the ankle" (McGregor, 2009:2). In this study we will be looking at the attributive possession.

The attributive possession or possessive NPs have been claimed to (a) be definite (Quirk et al., 1985) and (b) introduce new PM referents into the discourse (Taylor, 1996). Willemse et al. (2009) based on a qualitative and quantitative analysis of a corpus of possessive NPs claim that "[...] many PM referents have a discourse status in between fully given and fully new" (p.13) and thence suggest a continuum-like classification.

Furthermore, within the attributive possession constructions structures like the so-called recursive possessives have been identified. In these multiple possessors can be found in the 
same sequence (e.g.: John's father's book). Although the number of recursion is structurally unlimited, it seems that practically no more than two genitives $-s$ are found in a chain since the opposite would be "[...] stylistically objectionable, comic and difficult to comprehend" (Quirk et al., 1985: section $17.118)$.

For the purposes of this study we should also mention that several studies of the English possession system have identified a number of factors that determine the choice of the possessive construction. Some studies have focused on phonological, pragmatic, syntactic and morphological factors (Hawkins, 1994; Quirk et al., 1985). Other researchers have focused on the cognitive and psychological factors (Taylor, 1989; Heine, 1997; Rosenbach, 2005).

In this regard we present the results of the study by Rosenbach (2005) in Figure 3. This chart shows the relative frequency of the s-genitive and the of-genitive according to four factors related to animacy and weight.

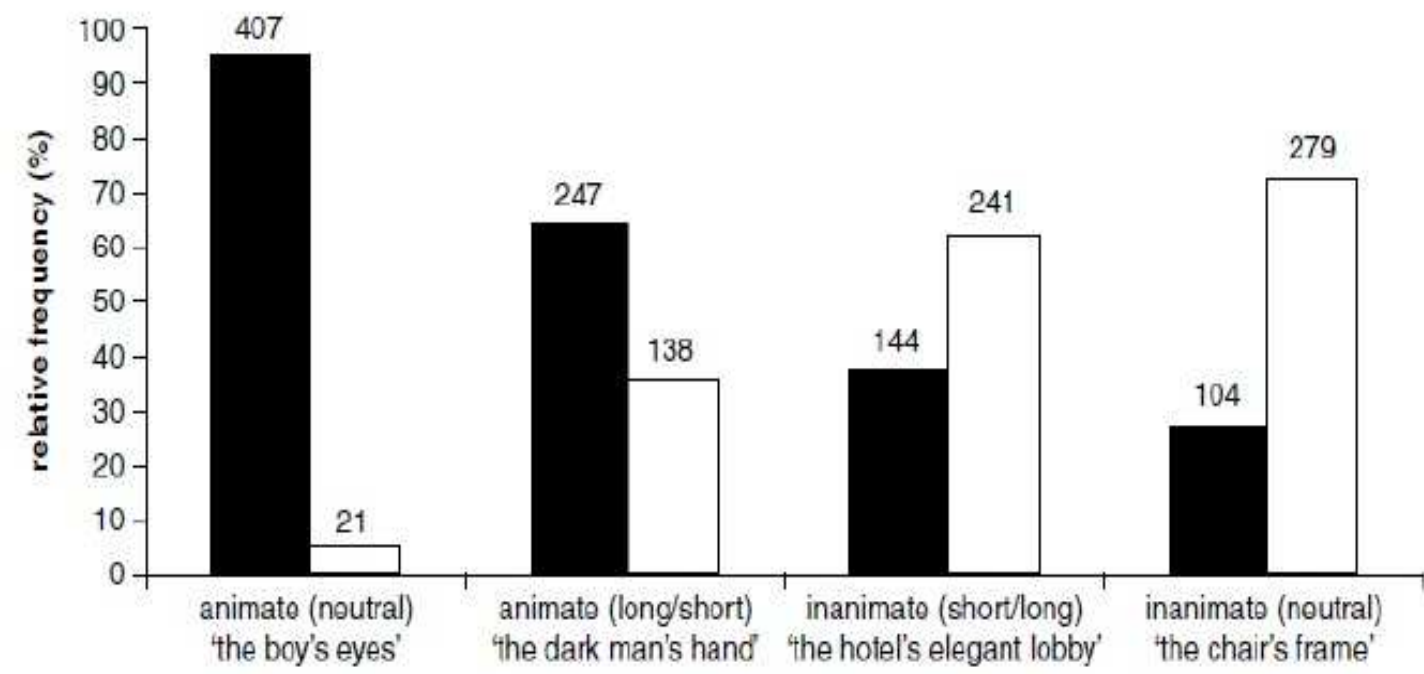

s-genitive $\square$ of-genitive

Figure 3: Relative frequency of the s-genitive and the ofgenitive (from Rosenbach, 2005:620). 
Rosenbach's (2005) study provides evidence from both a corpus analysis and an experimental study that animacy is a processing factor that influences the grammatical variation and it dominates the syntactic weight. She used a questionnaire based on a short text passage that provided context for both sgenitive and of-genitive constructions that included four conditional factors, two animate and two inanimate. The term "animacy" distinguishes between the animate referents and the inanimate referents. It has been defined as a dominant factor that causes variation between the s-genitive and the of-genitive constructions (Rosenbach, 2005). Her study includes 39 native speakers of American English, but the results are nevertheless interesting. As seen in Figure 3 native speakers of English prefer s-genitive constructions for animate possessors while ofgenitive for inanimate possessors.

In our study we do not distinguish between animate and inanimate entities. In order to include this further distinction we would need additional data and time. Nevertheless, we understand that the results of Rosenbach's (2005) study are important for any further investigation related to the results of the present study. More details are presented in sections 7.4 and 7.5 where we regard the limitations of this paper and suggest possible avenues for future research. What is more, the outcomes of Rosenbach's (2005) study may not directly relate to our project but they do so inasmuch as they highlight yet another significant difference between the possession systems in English and in German (for the possession system in German see section 2.2.2). Indeed, it is this particular difference in the factors that influence the choice of the possessive form in English and in German that enables us to detect possible influences of the L2 English on the acquisition of L3 German but we will be looking into this in detail in section 6.3 .

In the present study we are interested in investigating the use of the synthetic/inflectional vs. the analytic/periphrastic form of attributive possession. We decided to use the possessive 
pronouns as a possession construction trigger in our sentence transformation task. That enabled us to check the L2 English learners preferences regarding both the other inflectional form (i.e. the possessive $-s$ ) and the periphrastic form (i.e. the prepositional phrase). Examples 4, 5 \& 6 illustrate each of the aforementioned possessive forms.

4) This is his car. (inflectional/pronoun) ${ }^{1}$

5) This is my father's car. (inflectional/possessive -s)

6) This is the car of my father. (periphrastic/prepositional phrase)

\subsubsection{Possession in German}

It has already been mentioned that our study focuses also on another target language, namely, German. Therefore, we should now turn to the description of the expression of possession in German.

The first relevant point, that we would like to draw the reader's attention to, is that in German the expression of possession can be realised by four different structures. In English there are three forms of expressing possession, namely the possessive pronoun (ex.5), the possessive $-s$ (ex.6), and the genitive -of (ex.7). The system of possession expression in German includes yet another inflectional form, that is, the genitive case as illustrated in the following example:

8) Das Auto meines Vaters.

The.nom car.nom my.gen father.gen.

Another major difference is that in German there are certain structural constraints that determine the choice of possessive form. This condition is absent from the English possession

1 Note that the students were told to rewrite the sentence using the NP my father instead of the possessive pronoun his. This example is actually taken from our sentence transformation task a full account of which can be found in Appendix 9.5 (A for English and B for German) 
system. In English, as we mentioned in section 2.1, the choice of the $P R>P M$ and $P M>P R$ orders and the subsequent use of the equivalent possessive form has been explained on grounds of either phonological, pragmatic, syntactic and morphological factors (Hawkins, 1994; Quirk et al., 1985) or of cognitive and psychological factors (Taylor, 1989; Heine, 1997; Rosenbach, 2005). Rosenbach (2005) for instance claims that it is principally the animacy that prompts the use of a specific order $(\mathrm{PR}>\mathrm{PM}$ or $\mathrm{PM}>\mathrm{PR})$ and thence the use of the equivalent possession form (see section 2.1 for more details on Rosenbach's study). In keeping with Rosenbach's (2005) findings we can claim that native speakers would prefer to use the PR>PM order and hence the possessive $-s$ in those cases where the PR is an animate entity. In German, on the contrary, the PR>PM and PM PR orders are not determined by conceptual factors. In that vein, both the $\mathrm{PR}>\mathrm{PM}$ and the $\mathrm{PM}>\mathrm{PR}$ orders are equally used. This difference is illustrated in the examples below.

English 9) My father's car.

German 10) Vaters Auto.

Father.gen car.nom

11) Das Auto meines Vaters.

The.nom car.nom my.gen father.gen

12) Das Auto von meinem Vater.

The.nom car.nom of my.dat father.dat

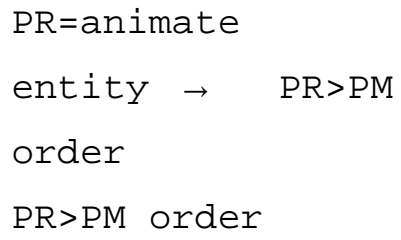

$\mathrm{PM}>\mathrm{PR}$ order

$\mathrm{PM}>\mathrm{PR}$ order

Nevertheless, German, unlike English, does not allow the possessive $\boldsymbol{s}$ to be attached to any noun. In German the possessive $-s$ is affixed only to proper names and a few kinship terms (Eisenbeiß 2009) as examples 13.1, 14.1 \& 14.2 below illustrate. Note that whenever the name ends in "s" an apostrophe is added instead of the possessive $-s$. This is the only difference between examples 14.1 and 14.2 below. 


\begin{tabular}{|l|l|}
\hline $\begin{array}{l}\text { 13.1) Vaters Auto. } \\
\text { Father's car.nom }\end{array}$ & $\begin{array}{l}\text { PR + possessing }-\mathrm{s}+\mathrm{PM} \\
\text { PR: kinship }\end{array}$ \\
\hline & PR + possessing $-\mathrm{s}+\mathrm{PM}$ \\
14.1) Marias Schwester. & PR: proper name \\
Maria's sister.nom & b) does not end in s \\
14.2) Tobias' Bruder. & possessing $-\mathrm{s}$ \\
Tobias' brother.nom & c) ends in $\mathrm{s} \rightarrow$ apostrophe
\end{tabular}

However if the $\mathbf{P R}$, realised by either a kinship term or a proper name, is modified by an article or any other modifier, then the $\mathrm{PM}>\mathrm{PR}$ order is required and hence the use of the possessive -s is incorrect. That is to say, if the PR in example number 13 was "my father" instead of "father" then we should use the PM $>$ PR order and hence either the genitive case or the prepositional phrase would be required in order to express possession. Both cases are exemplified below.

13.2) Das Auto meines Vaters.

The.nom car.nom my.gen father.gen.

13.3) Das Auto von meinem Vater.

The.nom car.nom of my.dat father.dat

PR: modified $\quad$ kinship
term $\rightarrow$ PM>PR order $\rightarrow$
genitive case

PR: $\quad$ modified kinship term $\rightarrow$ PM>PR order $\rightarrow$ prepositional phrase

At this point we would like to foreground that in German articles agree in number, gender and case with the nouns that they accompany. Nouns can also undergo some modification when the possession is expressed by means of the genitive case. Indeed, when the noun has a masculine or a neutral grammatical gender, then the suffix -s/-es is added in the formation of the genitive as seen in example 13.2 above.

Tables 2 and 3 illustrate all the cases of the expression of possession in German that we have described up to here. 


\begin{tabular}{|c|c|c|c|}
\hline Possessive -s & & & \\
\hline $\begin{array}{l}\text { a) Vaters Auto } \\
\text { Father's car }\end{array}$ & $\begin{array}{l}P R+\text { possessing }-s+P M \\
P R: \text { kinship }\end{array}$ & & \\
\hline $\begin{array}{l}\text { b) Marias Schwester } \\
\text { Maria's sister } \\
\text { c) Tobias' Bruder } \\
\text { Tobia's brother }\end{array}$ & $\begin{array}{l}\mathrm{PR}+\text { possessing }-\mathrm{s}+\mathrm{PM} \\
\mathrm{PR} \text { : name } \\
\text { b) does not end in } \\
\text { possessing }-\mathrm{s} \\
\text { C) ends in } \mathrm{s} \rightarrow \text { apostrophe }\end{array}$ & & \\
\hline
\end{tabular}

Table 2: Structural constraints: the use of the possessor $-s$

\section{2) $\mathrm{PM}>\mathrm{PR}$ order}

\section{Genitive Case (GC)}

a) Das Auto meines Vaters. PM Pron:GC PR:GC

The.nom car.nom my.gen

father.gen

b) Der Computer der Frau.

PM Def.Art:GC PR:GC

The.nom computer.nom the.gen woman.gen

C) Das Fenster eines Autos.

PM Indef.Art:GC PR:GC

The.nom window.nom a.gen

car.gen

P.P.: von + Dat.

a) Das Auto von meinem Vater. $\mathrm{PM}+\mathrm{PP}=$ von $+\mathrm{NP}$ : mod. $=$ Pron (dat)

The.nom car.nom of my.dat

father.dat

b) Der Computer von einer Frau (a): $\quad[\mathrm{PR}=$ masculine $\rightarrow-\mathrm{s} /$-es suffix $]+[P R=$ kinship noun + modifier $\rightarrow$ possessive $-s \neq$ possible]

(b) $: \quad \mathrm{PR}=$ feminine $\rightarrow$ no modification applied on the noun .

(c) $]: \quad[P R=$ neutral $\rightarrow-$ s/-es suffix $]+[P R=$ common noun $\rightarrow$ possessive $-s \neq$ possible]

(a): $\mathrm{PR}=$ kinship noun + modifier $\rightarrow$ possessive $-s \neq$ possible 


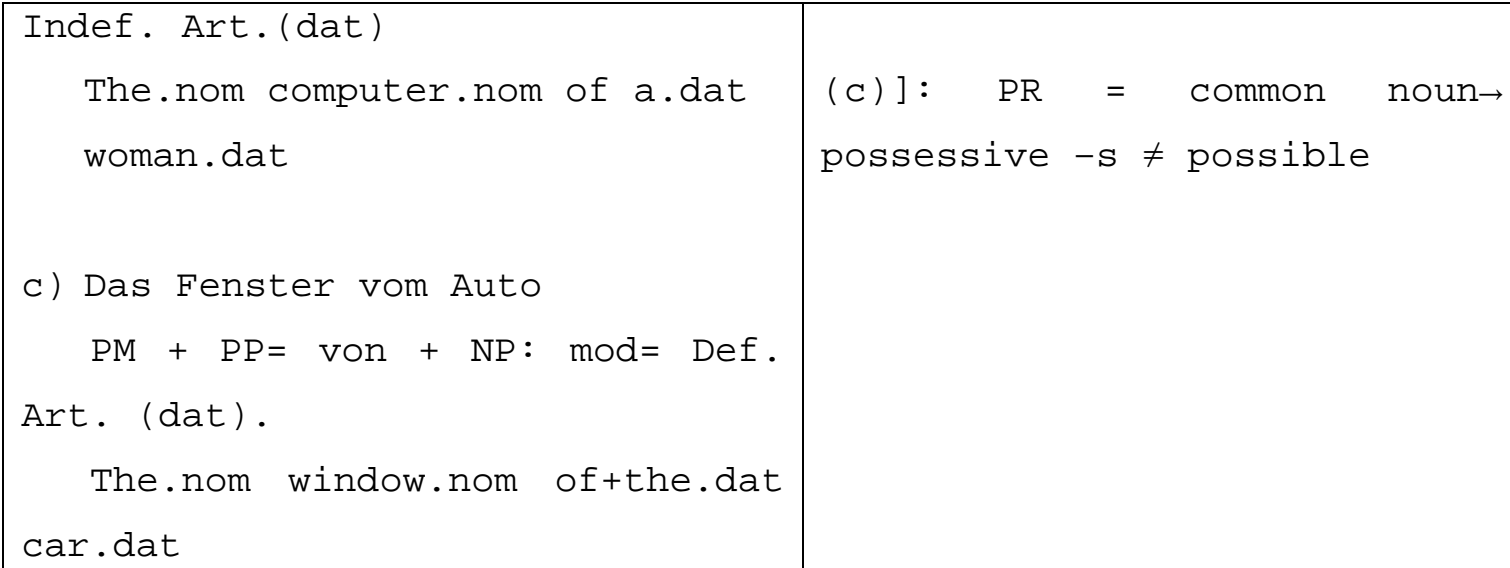

c) Das Fenster vom Auto

$\mathrm{PM}+\mathrm{PP}=\mathrm{Von}+\mathrm{NP}: \bmod =$ Def.

Art. (dat).

The.nom window.nom oftthe.dat car.dat

Table 3: Structural constraints: The use of the genitive case or the prepositional phrase

To sum up chapter 2 regards the linguistic features studied in this paper. In the same line, section 2.1 contains information about the morphemes in general and the grammatical morphemes that have been the pivot of our morpheme order study (i.e., the first of the three studies included in this paper). On the other hand, in section 2.2 we outlined the basic aspects of the possession expression systems in English and in German. We understand this theoretical background to be important for two reasons. First, because the second study of this project focuses on the use of the possessive -s by L2 English language learners. As we will see in the following section the majority of the morpheme order studies have identified low accuracy rates for the possessive $-s$. This prompted our interest to study further the use of the inflectional form of possession especially because English is an analytic language. In the same line we wished to check the frequency of use of the synthetic (inflectional) possessive forms by learners whose target language is German. We chose German not only because it is a synthetic language, but also because it is also a West Germanic language. That induced the third study of our project in which we check the frequency of use of each of the possessive structures by our L3 German learners. The accurate knowledge of the structural restrictions outlined above is crucial in order to recognise the correct and the incorrect uses of the various possessive forms by our L3 German learners. Additionally, the 
theoretical background that we present in section 2.2 enables us to recognise the commonalities, but also to distinguish the differences that the German and the English possession systems present. Indeed, these two systems are different not only in terms of the structures available for the expression of possession, but mainly regarding the way(s) that these forms are used. As we saw in sub-section 2.2.2 in German there are some structural restrictions regarding the choice of each possession form. The latter is a highly important point, as it is the one that defines the area where we actually see the influence of the previously learnt languages (L2 English) on the acquisition of a new foreign language (L3 German). Nevertheless, we will deal in depth with this issue in section 6.3 where we present the relevant results and comment upon their significance and possible explanation. 


\section{Literature review}

This chapter is dedicated on the brief review of some major previous studies relevant to the research lines of our project. The first section focuses on the ones that relate to our principal study, that is, the acquisition of some grammatical morphemes by $\mathbf{L}$ 2 English language learners. Since this is a historical overview we have decided to also include the two major works that regard the acquisition of morpheme in L1 English. Our decision is justified on the basis that these generated all the subsequent MOS. Furthermore, the L1 morpheme acquisition studies, and especially Brown's (1973) study, include elements that we have incorporated in our project, such as the use of corpus and the list of functors studied. In keeping with this decision we will start the first section of this chapter with a sub-section on the L1 MOS, which will be followed by a separate sub-section (3.1.2) in which we outline the major findings in relation to the acquisition of morphemes in foreign languages. Nevertheless, since the MO studies have received a lot of critique we have decided to include an additional sub-section (3.1.3) where we outline the major voices of criticism on the previously conducted MOS. The information found in this sub-section is also vital since it has guided our decisions regarding our data collection instruments and the scoring methods.

Decisions made on methodological issues are crucial and can determine the rigour of a study. In keeping with the perceived importance of the data elicitation method, we recognise the value of authentic learner language in SLA research. In the same vein we have dedicated a separate section within this chapter (3.2) to our principal elicitation instrument, that is, the learner corpus. Note that in section 3.2, except for occasional comments, we do not provide information regarding our own learner corpus. A full account of the latter along with 
additional data regarding the instruments used and the procedures followed in the present study can be found in chapter 5 .

The final section of chapter 3 regards the main studies on the influence of any previously learnt language on the acquisition of a new foreign language. Section 3.3 thus provides us with a review of the studies that have been conducted in relation to the other focal point of our study, that is, the influence of the $\mathbf{L} \mathbf{2}$ on the acquisition of an $\mathbf{L} 3$.

\subsection{Morpheme order studies (MOS)}

\subsubsection{Research on L1 morpheme acquisition order}

As we said in the introduction, morpheme acquisition research was partly prompted by the debate over behaviourist and nativist theories of language acquisition. The starting point was Brown's (1973) longitudinal study of three children who were native speakers of American English. Data for two of the children were collected over a five-year period, whereas for the third child the data were collected over a period of one year. At the beginning of Brown's study, the first two children were 27 months old, whereas the third was only 18 months old. For the analysis of the collected data, Brown studied the subjects' utterances in order to determine to which extent the grammatical morphemes in question were supplied in contexts where they were required or not. The underpinning idea was that certain contexts, also known as obligatory occasions, i.e. occasions when a native speaker is obliged to use particular morphemes, trigger the use of specific morphemes. The accurate use of the correspondent morpheme was thence seen as an indication of that morpheme's acquisition. As Brown (1973) put it:

[...] grammatical morphemes are obligatory in certain contexts, and so one can set an acquisition criterion not simply in terms of output, but in terms of output-where-required. Each obligatory context can be regarded as a kind of test item 
which the child passes by supplying the required morpheme or fails by supplying none or one that is not correct. This performance measure, the percentage of morphemes supplied in obligatory contexts, should not be dependent on the topic of conversation or the character of the interaction (p.255).

However, suppliance in obligatory contexts is not enough in order to decide whether a morpheme has been acquired or not. Another aspect that has to be taken into account is the level of accuracy of use that a learner must achieve in order to confirm the morpheme's acquisition. Brown (1973) set the level at 90 per cent on the grounds that it constitutes a level close to 100 per cent and corresponds to the level achieved by native speakers (Ellis \& Barkhuizen, 2005).

Brown's study revealed a similar order of acquisition for grammatical morphemes in obligatory contexts for all three children although acquisition was not achieved at the same age, which indicates that the route (=order) of acquisition is similar to all children, but there may be variations in their rate (=speed) of acquisition. Table 4 presents the mean order of acquisition of L1 English morphemes according to Brown's findings. It is important to highlight that Brown (1973) was the first to use corpus data to study the L1 acquisition of morphology. The rest of the studies on L1 and L2 acquisition reviewed below, have used more controlled instruments. In this paper, we have also used L2 corpus data, in line with Brown's original study on L1. 


\begin{tabular}{|c|c|c|}
\hline ORDER & MORPHEME & EXAMPLE \\
\hline 1 & Present Progressive '-ing' & He is eating \\
\hline $2 \& 3$ & Prepositions 'in-on' & $\mathrm{He}$ is in the park \\
\hline 4 & Plural '-s' & Two birds \\
\hline 5 & Past Irregular & He went \\
\hline 6 & Possessive '-s' & Daddy's book \\
\hline 7 & Uncontractible Copula & She is good \\
\hline 8 & Articles & The ice-cream \\
\hline 9 & Past Regular & She looked \\
\hline 10 & Third person singular '-s' & She looks \\
\hline 11 & Third person singular irregular & She has \\
\hline 12 & Auxiliary Be & She is walking \\
\hline 13 & Contractible Copula & She's good \\
\hline 14 & Contractible Auxiliar & She's walking \\
\hline
\end{tabular}

Table 4: Order of Ll Acquisition of English Morphemes (from Brown, 1973:275)

At around the same period de Villers and de Villers (1973) conducted a cross-sectional study in which they elicited spontaneous L1 speech data using Brown's 14 functors (see Table 4 ) and his coding rules to identify obligatory contexts. Speech samples were taken by 21 children aged 16-40 months. However, de Villers and de Villers (1973) did not set their cut-off point for acquisition at the 90\% of accuracy. They simply ranked the functors according to the relative accuracy of use in obligatory occasions. Their findings were then compared to the acquisition order found by Brown (1973) for his three subjects. Their crosssectional study revealed the same order of acquisition and came thus as a response to the critique that Brown (1973) based his conclusions on the observations of just three children. 


\subsubsection{Research in L2 morpheme acquisition order}

As pointed out in the introduction the interest on morpheme acquisition orders was soon extended to L2 and second language acquisition research (henceforth SLA). As we will see most of the L2 studies in this field have used some variant of the obligatory occasion analysis.

Dulay and Burt (1973; 1974b) conducted two L2 morpheme acquisition studies. In their first study (1973) they studied three groups of L1 Spanish child learners of English. The first group, the 'East Harlem (New York)' group, received a bilingual (English and Spanish) education at school, but no formal instruction in English. The second group, the 'Sacramento (California)' group received only English education at school and formal instruction in English. The third group, the 'San Ysidro (Mexico)' group, crossed the border to attend an English school, but returned home daily where they spoke Spanish. Dulay and Burt focused on the acquisition of eight of the 14 functors proposed by Brown (1973) and found a consistent order across all the groups. Each obligatory context for a functor was scored according to the following schema (from Dulay \& Burt, 1973:254):

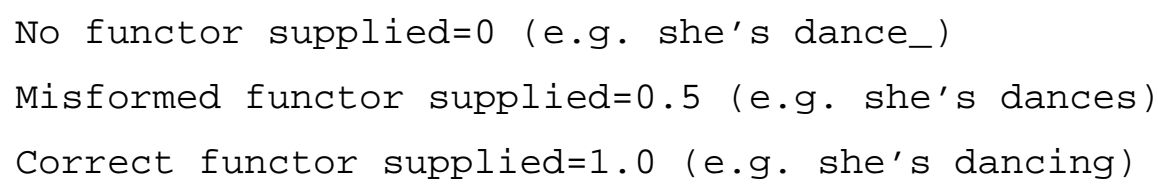

The accuracy score for each functor was then calculated as a ratio of the sum of the scores for each obligatory context for that functor across the whole group. According to this model we could then calculate the accuracy rate for the three examples given above. In this case the total number of examples determined the OC which is hence equal to three. Applying the calculation process described above we end up with the following: 


$$
\frac{(1 \times 0)+(1 \times 0.5)+(1 \times 1)}{3} \times 100=\frac{1.5}{3} \times 100=50 \%
$$

Although each of Dulay and Burt's (1973) groups showed different rates of accuracy, they all followed the same route. Accordingly, they concluded that L2 morpheme acquisition order is not influenced by exposure to the target language (henceforth TL) .

In 1974 Dulay and Burt conducted a second study (1974b) observing two groups of 6-8 year-old children learning English as a second language in the USA. The first group consisted of 60 children native speakers of Spanish and the second consisted of 55 children whose L1 was Cantonese. In this study the authors found a similar developmental pattern for both groups regardless of their L1.

Like most L2 morpheme studies and unlike L1 morpheme studies, Dulay and Burt used controlled tasks. This decision was based on the fact that elicited L2 language is rarely spontaneous. The instrument they used was the Bilingual Syntax Measure (BSM) which is a syntax-based test of L2 proficiency designed for use with young children. The BSM was not designed to test order of acquisition but rather proficiency level. Nevertheless, according to Dulay and Burt (1974b), the value of this method is that the researcher "[...] can look to see how the child forms simple finite clauses (word order, gender, number and case for the pronoun, agreement for the verb, the form of the qualifier, etc)" (p.40). Additionally, the BSM was used as a measure by most researchers and that facilitated comparisons. The instrument consists of some cartoon pictures and questions. These prompts are used to elicit roughly predictable responses that include various obligatory contexts for grammatical morphemes. For instance the researcher may point to a very fat cartoon character and ask: "why is he so fat?" The expected answer is "Because he eats too much/a lot". Figure 1 exemplifies a case of the BSM. Children's errors were then placed into three categories: developmental, interference, and unique. Dulay and 
Burt (1974b), based on the fact that the majority of errors fell in the developmental category, hypothesised that second language acquisition is similar to first language acquisition.

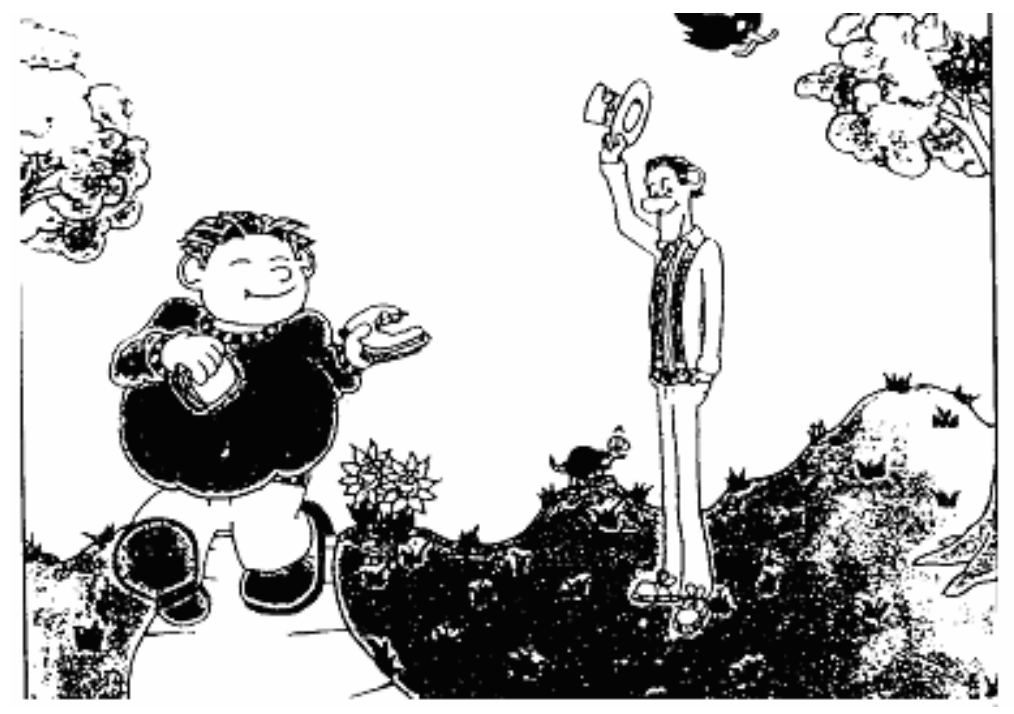

Figure 1: Example from the Bilingual Syntax Measure (from Dulay and Burt, 1974b:37-53)

Bailey et al. (1974) generalised the results of Dulay and Burt's studies to adults learning an L2 and found a similar order of acquisition for the same set of English morphemes. They studied 73 adults of distinct L1 backgrounds, 33 were native speakers of Spanish and 40 had different first languages (Greek, Persian, Turkish, etc.). They also used the BSM as elicitation method. The developmental patterns of both groups correlated significantly among them and with the patterns found in children learners of L2 English in Dulay and Burt's studies. Krashen (1977) suggested later that is was possible to group certain morphemes together on the basis of accuracy and create thus an acquisition hierarchy as shown in Figure 2. This organisational pattern states that the order of acquisition will progress from one group to the other, but makes no comment in relation to the acquisition order of the morphemes within each group. 


\begin{tabular}{|c|}
\hline $\begin{array}{l}\text { Plural -s } \\
\text { Progressive -ing } \\
\text { Copula be }\end{array}$ \\
\hline$\downarrow$ \\
\hline $\begin{array}{l}\text { Auxiliary be } \\
\text { Articles }\end{array}$ \\
\hline$\downarrow$ \\
\hline Irregular past \\
\hline 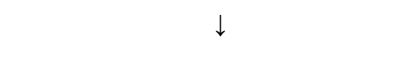 \\
\hline $\begin{array}{l}\text { Regular Past Tense } \\
3^{\text {rd }} \text { person sing. } \\
\text { Present -s } \\
\text { Possessive -'s }\end{array}$ \\
\hline
\end{tabular}

Figure 2: Order of Grammatical Morpheme Acquisition for L2 Learners of English, Krashen (1977)

In 1975 Fathman carried out a cross-sectional study in order to investigate the relationship between age on one hand and rate as well as order of acquisition of English structures on the other. She studied 140 children aged 6-15 years, who had been in the USA for less than three years $(70$ had been there for one year, 40 for two years and 30 for three years) and had all been immersed in the verbal environment of the school. Fathman (1975) introduced the Second Language Oral Production English (SLOPE) test, which has twenty sections (each involving three items) designed to test 20 different grammatical phenomena (article, negation, wh-questions, etc.). The test usually consisted of two pictures and one question. For example, in order to elicit plural $-s$ the researcher points to a picture of a boy and says "Here is a boy", then to a picture of two boys and asks "Here are two ... ?". Both the SLOPE test and the BSM aim to the production of spontaneous language related to the L2 acquisition of grammatical knowledge. Fathman (1975) divided her subjects into two age groups $(6-10 \& 11-15$ years) and then observed the changes between these two groups in terms of rate and order of acquisition of 20 morpheme categories or syntactic patterns. 
Additionally, her subjects described orally a composite picture for which they were rated for correctness of grammar, pronunciation and general fluency. Fathman (1975), based on the results of her study, concluded that L2 acquisition process changes with the age in terms of success in learning, with the younger children showing higher pronunciation abilities and the older children higher morphological and syntactic abilities. In terms of order of acquisition the study revealed no changes and thence Fathman (1975) affirmed that L2 acquisition order remains constant.

Perkins and Larsen-Freeman (1975) performed a cross-sectional study of adults using multiple tasks in order to check the validity of the single task-based studies and found that the order of acquisition was similar to that of previous single-task studies. Indeed, they found significant correlations between the morpheme sequences produced by adult learners in the two oral production tasks and the morpheme sequences produced by child learners in Dulay and Burt's study. For the written task there were some differences such as a rise in the rank order of plural $-s$ and third person $-s$. However, Ellis (1994) points out that these can be explained by the production conditions in the sense that speaking and writing are influenced by different sociolinguistic and psycholinguistic conditions, and they thence do not imply a different morpheme acquisition order. Additionally, Perkins and Larsen-Freeman (1975) investigated L2 acquisition in relation to the type of instruction. According to their study's results, when learners were exposed to naturalistic input, formal language instruction did not seem to affect accuracy orders. As Perkins and Larsen-Freeman (1975) put it: "[...] instruction does not radically alter order of acquisition" (p.241).

In 1978 Andersen altered slightly the principal subject of morpheme order ${ }^{2}$ research by focusing on the investigation of the

\footnotetext{
Note that in this paper we will be using morpheme order and MO interchangeably. In the same line we use the acronym MOS when making reference to a Morpheme Order Study.
} 
actual explanation of the "natural order" that previous studies had shown in both the L1 and the L2 morpheme acquisition. Unlike the explanations that had been proposed until then, mainly based on a nativist assumption, Andersen tried to account for the accuracy profiles of $L 2$ learners in relation to the acquisition of underlying syntactic knowledge. He divided the data on the acquisition of English grammatical morphemes into two syntactic classes: verb-related morphemes and noun-related morphemes and analysed the accuracy rates accordingly. Although he based his data collection on the soc model introduced by Brown (1973), he analysed the results using the implicational scale as scoring method. This technique is based on the idea that "[...] if a learner is accurate on a 'difficult' morpheme, she will also perform accurately on some 'easier' morpheme [...] the reverse is not necessarily the case" (Hawkins, 2001:47). Andersen (1978) noted that the degree of difficulty could depend on the underlying syntactic properties of the morphemes, rather than on the actual morphemes. Said in other words, Andersen (1978) argued that in order to use accurately a morpheme the I2 student must have previously acquired the underlying property of that the specific morpheme. That is, the L2 learner must fully understand not only what a specific morpheme stands for, but also comprehend its underlying syntactic properties as such. In the same line, in order to accurately use the structure "be + Ving" the L2 learner must have previously acquired what this morpheme represents, i.e. the progressive aspect and hence the difference between progressive and non-progressive (e.g. Mary is reading vs. Mary reads).

Makino (1979) attempted a morpheme order study with English learners in Japan in order to test the acquisition order hypothesis for EFL learners. He tested 777 adolescents using fill-in-the blank tests and stratified the data according to the subjects' grade level, English textbook used and location of the school (urban or rural). The order of acquisition correlated significantly with the orders obtained in most of the studies that had looked at ESL learners and thus supported the 
hypothesis that all I2 learners follow the same route in terms of morpheme acquisition despite the learning environment.

Pica (1983) investigated the effects of formal classroom instruction on one hand and the influence of learning in a naturalistic environment on the other. The subjects of her study formed three groups. The first consisted of classroom-instructed adults, the second was formed by a group of adults who lived in an English-speaking environment in the absence of formal instruction and the third was a 'mixed' group that received both classroom instruction and input from native speakers in a naturalistic environment. All three groups had the same L1, namely Spanish. Ellis and Barkhuizen (2005) argue that Pica's study is "methodologically more sophisticated [...] in that she examined learners' oversuppliance [...] through a target-like use analysis as well as suppliance in obligatory contexts ${ }^{3}$ (p.87). Pica (1983) concluded that "different conditions of exposure to L2 English do not significantly alter the accuracy order in which grammatical morphemes are produced" (p.465). Conditions of exposure, however, do influence the learners' interlanguages. Pica found that learners with instructed exposure oversupplied morphemes in non-obligatory, and hence inappropriate, contexts. By contrast it was omission errors that were higher among those with naturalistic exposure. That indicates that different conditions of L2 exposure affect learners' hypotheses about the target language and their strategies for using it (Pica, $1983: 495)$.

Lightbown (1983) in an attempt to determine what factors may affect the order of acquisition performed a study in which she investigated frequency as putative determinant. She looked at the relationship between the frequency of appearance of certain forms in the classroom and the frequency of their accurate use. Her subjects were instructed learners of English in Quebec aged between 11 and 17 years. They were asked to perform an oral task

\footnotetext{
3 More details regarding the Suppliance in Obligatory Context (SOC) and the Target Like Use (TLU) are provided in section 3.1.3.
} 
twice in two consecutive years. The results suggested that there is no direct relationship between input frequency and the accurate use of the morphemes.

After Andersen's (1978) study, most researchers were looking to establish not only a descriptive but also a solid explanatory model. That tendency is especially prominent in the studies conducted after the 1980s. As mentioned above, some explanation of the observed phenomena regarding order of acquisition had been previously attempted as well. For example Brown (1973), following a nativist perspective, argued that "some factor or some set of factors caused these grammatical morphemes to evolve in an approximately consistent order in these children" (p.272). In the same vein, during the $1970 \mathrm{~s}$ a series of putative determinants have been suggested by L1 and L2 researchers including the following: (a) perceptual salience (Larsen-Freeman, 1976), (b) morphophonological regularity, (c) syntactic complexity, (d) frequency (Larsen-Freeman, 1976), (e) semantic complexity (Larsen-Freeman, 1976; Andersen, 1978), (f) native language transfer (Andersen, 1978), (g) individual variances (Andersen, 1978).

Ellis and Barkhuizen (2005) recognize two key studies in this account after the change of the researchers' focal point from description to explanation. The first is the study by zobl and Liceras (1994) and the second is the one conducted by Goldschneider and Dekeyser (2001).

Zobl and Liceras (1994) observe that L1 acquisition order is characterized by nominal categories preceding verbal categories, whereas I2 acquisition order is cross-categorical. They suggested that this is explained by abstract cognitivelinguistic principles. Indeed, they argue that the Nominal $\rightarrow$ Verbal pattern observed in L1 acquisition stems from the gradual maturation of functional categories in young children. Thence the difference in L1 and L2 acquisition patterns can be 
explained by the fact that functional categories are already available from the beginning in L2 learning.

In keeping with this preference to find an explanation based on purely linguistic criteria, Hawkins (2001) has studied the patterns of acquisition order following the division between verb-related and noun-related morphemes put forth by Andersen (1978). Hawkins (2001) in his interpretation of Andersen's (1978) results argues that the scale of difficulty of the verb-related morphemes exhibit the addition of the following syntactic properties:

\section{Copula $\rightarrow$ aspect ( \pm progressive) $\rightarrow$ tense ( \pm past) $\rightarrow$ subject-verb agreement $\left( \pm 3^{\text {rd }}\right.$ person singular) (Hawkins, 2001:48).}

Hawkins (2001) claims that this result is interesting mainly because it poses certain questions the answer to which may help our understanding of L2 morpheme acquisition patterns. As he put it "Why should a copular construction (John's hungry [...]) become established in the mental grammar more accurately, apparently, than an aspectual one (John is cooking) [...]" (Hawkins, 2001:48). He also suggested a working theory, called "modulated structure building" (2001:73), which includes insights from two theories known as "minimal trees" and "full transfer/full access". According to this model learners' initial L2 grammars consist of lexical projections like VP, NP, AP, PP and these have the structural properties of their L1 grammars (i.e. the position of the head, complement and specifier are initially determined by the L1). Initial L2 grammars consist of lexical projections only in principle since restructuring towards the L2 may be very rapid. Functional projections are established later than lexical projections (i.e. the establishment of English inflection and its projection IP appear after a VP-only stage). Finally, it is only once functional categories are established in the L2 grammar that the influence of L1 functional categories becomes evident. For example in initial stages L1 verb-subject agreement pattern is not relevant "because learners are not at the point 
of development where they need to have a representation for specifier-head agreement" (Hawkins, 2001:74). But, as soon as they reach that point their L1 becomes influential and hence Spanish learners have an asset and indeed produce more accurately specifier-head agreement than Japanese students whose L1 does not have such agreement as the study by stauble (1984) confirms. That is why Hawkins calls his structure building pattern 'modulated', because it "is influenced by properties of the $\mathbf{L} \mathbf{1}$ at the relevant point in the construction of a grammar and not before" (Hawkins, 2001:74). The influence of the L1 on the acquisition of the TL has been criticised, as we will see later.

Goldschneider and Dekeyser (2001) carried out a meta-analysis of all the accuracy results obtained for oral production data in twelve studies involving 924 learners. They then suggested that the L2 acquisition order pattern can be explained by a combination of five putative determinants (i.e. functors features): perceptual salience, semantic complexity, morphophonological regularity, syntactic category and frequency. Other external factors such as L1 transfer could also be influential but their multiple-regression study did not allow them to take it into consideration. Goldschneider and Dekeyser highlight that only a combination of variables can account for the "natural order" and remark that the revision of these 12 studies concludes that the commonalities in their findings cannot be ignored. Additionally their study suggests that "L2 acquisition is the product of an interaction between the learner's internal mechanisms and the input" (Ellis \& Barkhuizen, 2005:77). As Hawkins and Lozano (2006) put it: "The picture of SLA that emerges is one of a complex interaction among innate knowledge, previous knowledge from the $\mathbf{L} \mathbf{1}$, and input from the L2" (p.73).

In 2006 Muñoz carried out a cross-sectional study in order to check the effects of the age of onset, i.e. the age in which the subjects started learning the L2, the amount of exposure to the 
target language and the proficiency levels on both the order and rate of acquisition of English as a foreign language. She studied 6 groups of instructed learners of English who were asked to perform two oral tasks, a picture-elicited story and a semi-structured interview. Table 5 shows the composition in terms of onset age, time of exposure to the L2, test age and number of participants.

\begin{tabular}{|l|c|c|c|c|c|c|}
\cline { 2 - 7 } \multicolumn{1}{c|}{} & \multicolumn{2}{c|}{ Group $\mathrm{AAO}=8$} & \multicolumn{2}{c|}{ Group $\mathrm{BAO}=\mathbf{1 1}$} & \multicolumn{2}{c|}{ Group DAO $=18+$} \\
\hline $\begin{array}{l}\text { Time 1 } \\
200 \mathrm{~h}\end{array}$ & $\mathrm{~A} 1$ & $\begin{array}{c}\mathrm{AT}=10 ; 9 \\
N=30\end{array}$ & $\mathrm{~B} 1$ & $\begin{array}{c}\mathrm{AT}=12 ; 9 \\
N=30\end{array}$ & $\mathrm{D} 1$ & $\begin{array}{c}\mathrm{AT}=28 ; 9 \\
N=20\end{array}$ \\
\hline $\begin{array}{l}\text { Time 2 } \\
\text { 416 h }\end{array}$ & - & - & - & - & D2 & $\begin{array}{c}\mathrm{AT}=30 ; 4 \\
N=15\end{array}$ \\
\hline $\begin{array}{l}\text { Time 3 } \\
726 \mathrm{~h}\end{array}$ & $\mathrm{~A} 3$ & $\begin{array}{c}\mathrm{AT}=16 ; 9 \\
N=30\end{array}$ & $\mathrm{~B} 3$ & $\begin{array}{c}\mathrm{AT}=17 ; 9 \\
N=30\end{array}$ & - & - \\
\hline
\end{tabular}

Table 5: Groups' composition (Muñoz, 2006:116)

Muñoz (2006) performed an Obligatory Occasion analysis of the data and scored the responses following Pica's (1983) guidelines ( 2 points for the suppliance of the correct functor, 1 point for each incorrect functor supplied and 0 points when no morpheme was supplied). The results of her study confirmed the findings of earlier "natural sequence" studies in three points (Muñoz, 2006: 121-123): (a) that a similar route is to be found independently of learner's age, although the age seems to influence the rate of acquisition since older learners showed higher rates of accuracy in the use of morphological functors especially in initial stages of language acquisition, (b) that proficiency level plays a bigger role than first language and (c) learning context does not affect accuracy orders as much as proficiency level does, at least not until the learners have progressed beyond the very elementary levels of proficiency. As she put it "foreign language learners present accuracy orders that approach the average order once they have had a certain amount of exposure to the target language and have progressed beyond the very elementary levels of proficiency" (Muñoz, 2006:123). Proficiency has been proved influential in the acquisition of derivational morphology too. Muñoz's finding is 
thus in keeping with other studies (Lardiere, 1995; Lardiere \& Schwartz, 1997 cited in Muñoz 2006) which argue that L1 affects the acquisition of derivational morphology "in early L2 development, but this influence disappears with proficiency" (Hawkins \& Lozano, 2006:71).

\subsubsection{Identification of gaps in the literature}

Morpheme order studies have been questioned in relation to some methodological presuppositions and techniques.

A fundamental point of the overall critique relates to the basic assumption of morpheme studies that accuracy equals acquisition. It has been argued that, from a conceptual point of view, accuracy cannot be equated with acquisition. That is, suppliance of a morpheme does not imply necessarily that the morpheme has been acquired. As this is a two-fold criticism we will present its points separately.

The first inadequacy seems to stem from the incapability of the SOC to take into consideration a number of data that are also significant in terms of language acquisition. The fact that the learner uses a morpheme correctly in an obligatory context does not imply that the learner has acquired that particular morpheme because the subject may as well incorrectly overuse it in other occasions. That led scholars to establish the concept of targetlike use (henceforth TLU) which implies a weighted scoring as well. TLU takes into account correct suppliance in both obligatory contexts and non-obligatory context. Researchers can thus account not only for the correct uses (TLU) but also for the incorrect uses, i.e. the non target-like uses (henceforth NTLU). The NTLU includes the cases of underuse, misuse, and overuse and thus enables the researcher to tag and analyse a greater variety of morpheme uses. Therefore, scholars can draw a more complete image of the process of grammatical morpheme acquisition. 
At this point we would like to give an example to illustrate the difference between the soc and the TLU models in terms of the results obtained. Suppose that we wish to measure the accurate use of the progressive -ing morpheme in the following text:

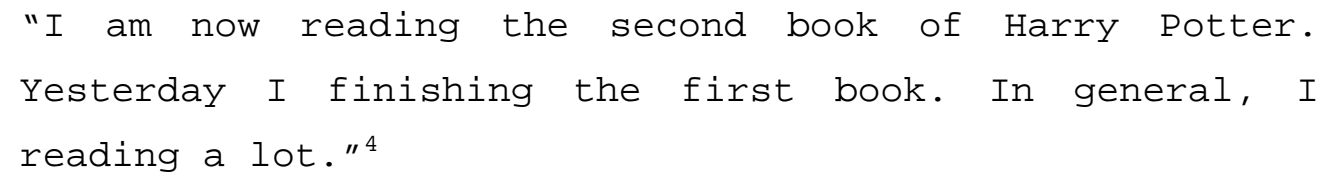

Following Brown's soc model we should check for the correct suppliance of the -ing in obligatory context, which is only one in our example, and then divide the number of the correct suppliance by the number of the obligatory contexts, which is, again, just one in our example (i.e., 1:1). We would then have to conclude that the accuracy rate for the progressive -ing morpheme obtained by this (hypothetical) L2 learner is (1:1) x $100=100 \%$. According to this accuracy rate we would be bound to affirm that our hypothetical I2 learner has acquired the progressive -ing. However, the learner's actual production clearly indicates the contrary.

The TLU model, on the contrary, enables us to take into account the remaining two cases where our hypothetical student has used the -ing. These instances reveal an incorrect use of the morpheme in question since they represent non-obligatory contexts for the progressive -ing. So, following the TLU model we would divide the number of correct suppliance of the -ing in obligatory context by the sum of the total number of oc and the number of NTLU cases, i.e. the incorrect use in non-obligatory contexts. On these grounds we would conclude that the accurate rate of the progressive -ing is [1:(1+2)] $\times 100=33 \%$.

Clearly the difference between the results produced by Brown's (1973) SOC and Pica's (1983) TLU models is highly significant. Considering the huge influence of the scoring method on the actual results, as reflected in our example, along with the

\footnotetext{
4 This example is totally invented.
} 
rationale behind the TLU we have decided to use this model in the analysis of our data.

Resuming our account of the critiques of the first mo studies, we should say that the central point of morpheme studies fails to cover phenomena proper of the acquisition development of certain morphemes. Indeed, the first morpheme studies disregarded the fact that some morphemes display a U-shape pattern of development. That is particularly observed with the acquisition of regular and irregular past in English. At the initial stages of irregular past acquisition, learners go through an early stage in which they use the forms of the irregular past correctly. Based on the suppliance in obligatory context condition, the researcher should conclude that by that moment the learner has acquired the irregular past forms. However, such assumption would be wrong as we now know that right after that initial stage of correct use learners experience a stage of over-generalized -ed forms, during which they replace the supposedly previously acquired past irregular forms with the past regular morpheme. That is, at the beginning of the acquisition of the past irregular morpheme our hypothetical L2 learner would produce a sentence like "Yesterday I went to school". In the immediately following stage, nonetheless, the same hypothetical L2 learner would regularise the past tense of the verb "to go" and hence produce the incorrect sentence "Yesterday I goed to school". Obviously longitudinal studies do not face the danger of not accounting for these developmental stages since they are based on data that refer to and reflect each subject's acquisition process for longer periods. Cases like over-generalisation are thus evident in this type of studies. Cross-sectional studies, on the other hand, can easily leave the aforementioned phenomenon unaccounted for. However, if their subjects are grouped according to their level of proficiency and the accuracy rates calculated separately for each group, then the developmental stages we described above become evident in cross-sectional studies as well. As Ellis and Barkhuizen (2005) put it, grouping on the 
basis of the subjects" proficiency level "[...] will enable researchers to investigate proficiency as a covariate of accuracy order and to identify which morphemes display a lower level of accuracy at higher levels of proficiency"(p.78). In line with this suggestion we have decided to group our subjects on the basis of their proficiency level and give thus a more accurate and complete image of the accuracy orders displayed for each morpheme at each level. We give a full account of this procedure as well as of the way we measured our subjects' proficiency level in section 5.3.2.

Another criticism relates to the small number of morphemes that have been investigated in most morpheme order studies. Most morpheme studies have followed Brown's (1973) methodological guidelines and thence have investigated the whole or part of his list of functors. Ellis and Barkhuizen (2005) argue that the set of morphemes could be expanded but that would depend on whether the instrument used could ensure "a sufficient number of obligatory contexts for each morpheme" (p.78).

In the same line, both the SOC and the TLU studies have been criticized for focusing mainly on the grammatical morphemes and "thus ignoring the functional use of the language" (Muñoz, 2006:109). Along this line of thought another critique on natural order studies was developed. According to this, Mos should not extend the implications found for a set of morphemes to acquisition in general. We would like to point out that a study based on corpus data, presents certain advantages in this respect since it provides the researchers with additional information and hence enables them not only to regard the functional nature of language but also to extend their study to the other aspects of acquisition (e.g. regarding the stylistic aspects of language use).

Additionally, some categories include various disparate features such as case features, features of the verb phrase, features of the noun-phrase, etc. For example, all morpheme studies place 
indefinite and definite articles in the same category when they do not constitute discrete features but rather cluster of forms. Nevertheless, this problem can be overcome though a methodological adaptation in order to group the morphemes on grounds of a specific principle. J.D. Brown (1983) suggested that morphemes should be classified into open and bound classes. Andersen (1978) distinguished into verb-related and noun-related classes and demonstrated thus an implicational ordering within each class as explained in the previous section.

Finally, morpheme order studies and their results have been questioned in terms of their validity since most natural order studies were cross-sectional and used the BSM (Bilingual syntax Measure) as data elicitation instrument. Larsen-Freeman (1975), for example, believed that the sequence was an artefact of the BSM. Indeed, Rosansky's longitudinal study (1976) shows that the relative accuracy that has been obtained in cross-sectional studies does not predict the sequence of acquisition for groups of individuals. Krashen (1978), on the contrary, argued that spontaneous language will always reveal the order of acquisition, whereas language elicited by means of controlled activities such as discrete-point grammar tests, in which learners' formal knowledge is tapped, will show the order of learning, which according to Krashen will be different to the order of acquisition. We should mention, however, that data obtained from children (Fathman, 1975; Kjarsgaard, 1979) and adults (Krashen, Sferlazza, Feldman, \& Fathman, 1976) showed that for structures present in both the SLOPE and BSM a similar order was found despite the differences in the task and scoring method.

\subsection{Learner Corpora and Learner Corpus Research}

As we saw, Morpheme Order Studies were criticised on the grounds that their findings were based on very few samples of L2 learner language elicited in many cases through very controlled means. Recently the use of corpus known as learner corpus has been introduced in the SLA research providing thus a more ample 
database of language produced by $\mathbf{L} 2$ learners. In that sense, we understand that learner corpora represent a very useful instrument of data collection. Additionally, learner corpora contain authentic $\mathbf{L} 2$ production which presents a twofold advantage. First, it reflects more accurately the acquisition process. Second it enables the researcher to account for other aspects of the language such as the functional or the pragmatic. In line with this thought we have decided to compile our own learner corpus, a detailed analysis of which can be found in chapter 5. In this section we will limit ourselves to the review of language corpus in general and learner corpora in particular.

Before proceeding with the actual description of the learner corpus, we should define what a language corpus is. According to McEnery (2003) a language corpus is:

a well-organized collection of data, collected within the boundaries of a sampling frame designed to allow the exploration of a certain linguistic feature (or set of features) via the collected data (p.449).

The term learner corpus was first used for Longman's learner dictionaries, in which the information on EFL learners' common mistakes was provided, based upon the Longman Learners' Corpus. In 1990 a project called the International Corpus of Learner English (ICLE) was launched as part of the ICE (International Corpus of English) in order to collect L2 data (Granger, 1998 cited in Tono, 2000:124-125).

Learner corpora are defined by Granger (2008) as "[...] electronic collections of texts produced by language learners" (p. 259). Hence learner corpora differ from language corpora in that the data come from foreign language learners. It is important to highlight that the learner language included in the learner corpora reflects language learnt in instructional environments, not in naturalistic ones. That is, the learners do not live in a 
country where the target language is spoken. ${ }^{5}$ However, further classification in relation to the speakers involved and the type of data they produce is not only possible but also necessary.

Regarding the status of the learners involved two comments can be made. First, language learners whose linguistic performance is included in learner corpora are foreign language learners. That, apart from the implications outlined in the previous paragraph, also means that the data included in English learner corpora cannot come from speakers that belong to Kachru's (1985) outer circle (e.g. India or Nigeria where English has achieved the status of official language and/or language of education or administration). Secondly, the distinction made sometimes between learner corpora and ELF (English as a Lingua Franca) corpora is based on the "[...] researchers' orientation towards the data and the purposes they intend the corpora to serve" (Seidlhofer, 2004:224). That is, if the subjects are still in the process of learning then the researcher's focus will be the progress of the speaker's interlanguage and the gap that needs to be filled in order for the learner to become proficient speaker. On the contrary, if the subject is a proficient nonnative speaker of English then the focus will be more on how they are able to communicate (Seidlhofer, 2004).

In terms of the learner data the most distinguishing feature that has been put forth by Sinclair (1996) is authenticity in the sense that they represent material gathered from the genuine communication of people. This feature raises a problem for learner corpus data as learners do not often use a foreign language in their genuine communication with other people. In order to overcome this obstacle, Granger (2008:261) suggests we should include in learner corpora only the learner production data that display a medium degree of naturalness such as that produced by picture description, summary or translation. In

\footnotetext{
5 Since our corpus is a learner corpus and hence the data collected represent by definition language acquired in instructional environments, we will be using L2 and FL interchangeably in the chapters dedicated to the analysis of our data, the discussion and the conclusion. The same is true for the terms L2 learner and FL learner.
} 
keeping with the importance of natural language for SLA research and following Granger's advice we have decided to compile our learner corpus based on language elicited by means of a picture description task. More information is provided in sections 5.1.1 and 5.3 .3 .

According to Granger (2008: 261-263), learner corpora can be divided in various types according to the underpinning criteria one uses for their typology. On these grounds learner corpora can be:

\section{i. Commercial or academic}

Commercial learner corpora are started by major publishing companies, whereas academic learner corpora are compiled in educational settings. In that sense, our learner corpus is academic.

\section{ii. Big or small}

Learner corpora that contain millions of words are naturally considered big and they do present an asset regarding representativeness of the data. However, small learner corpora that contain thousands or hundreds of words also are valuable. As pointed out by Granger (2008) "[a] detailed longitudinal study of one single learner is of great value if the focus is on individual language development" (p.262). The learner corpus used in our study is relatively small but it is our own learner corpus and this has other advantages such as the learner profile that we have included for each of our subjects and which gives us additional information (e.g. the learner's mother tongue, the hours of tuition received, additional FL spoken etc.; for more details please refer to sections 5.1.1 and 5.3.3.).

\section{iii. English or non-English}

English learner corpus is by far the largest collection of learner corpora nowadays. Only the International Corpus of Learner English (ICLE) contains 2.5 millions of words and covers learners from 11 different mother tongue backgrounds. 


\section{iv. Writing vs. speech}

There are more written than spoken learner corpora. This is not surprising if we take into account that the major difficulties of "[...] collecting and transcribing speech is multiplied by a factor of 10 in the case of learner data [...]" (Granger, 2008:263). In our study we have also opted for the written learner corpus, because we consider that it has certain advantages. First, it enables the researcher to collect a considerably larger amount of data in less time. Second, oral samples are not always clear for all the participants or in every environment. Finally, written corpora have an advantage bearing on the learner reaction to the means of data collection. As Ellis and Barkhuizen (2005) put it "[...] the presence of a cassette recorder may induce self-consciousness in learner's speech, thus making it less likely that the resulting samples will reflect their vernacular style" (p.27).

\section{v. Longitudinal or cross-sectional}

According to Granger the majority of learner corpora that focus on interlanguage are cross-sectional, that is, they contain data collected by various learners at a single point in time. Genuine longitudinal corpora, i.e. data from the same learners collected over time, are very difficult to compile. Therefore, researchers prefer the so-called quasi-longitudinal corpora that contain data gathered at a single point in time but from learners of different proficiency levels. In the same line we have opted for the compilation of a quasi-longitudinal corpus insofar as we have included language produced by learners of different proficiency levels (see section 5.2 for more details on the synthesis of our subjects).

\section{vi. Immediate vs. delayed pedagogical use}

Corpora compiled for delayed pedagogical use are not used directly as teaching/learning materials. They rather provide us with insights into learners' interlanguage and/or into the pedagogical tools used, which are thought to benefit similar- 
type future learners. Learner corpora for immediate pedagogical use are, on the contrary, used directly by the learners who produced them.

Although the use of learner corpora in SLA and language teaching is quite recent, there are several reasons that explain researchers' growing interest in this field. Below we present the ones that we consider central and which justify our decision to compile and use our own learner corpus for the first part of our project that regards the morpheme accuracy rates obtained by our L2 English learners.

i. Learner corpora respond to the necessity of obtaining quantitative data in SIA (MCEnery and Wilson, 1996:18). According to Granger (2009:16) one of the main assets of learner corpora is that it provides the SLA research with a much wider empirical basis. Additionally, by being systematic, and thus include data collected according to a number of criteria, learner corpora allow for diversified material (Díaz Negrillo, 2007:85). Therefore learner corpora, i.e. large systematically compiled databases of learners' language production, can be established as representative and thus support generalisations.

ii. Learner corpora contain basically authentic language and hence contextualised discourse. On one hand, this feature enables researchers to observe various aspects of learners' interlanguage (Granger, 2009:16). On the other hand, as Housen (2002) remarks, learner corpora make it possible to "empirically validate previous research findings obtained from smaller transcripts, as well as to test explanatory hypotheses about pace-setting factors in SLA" (p.108).

iii. Learner corpora are computerised and the amount of data available in machine-readable forms increases every year. That facilitates researchers' studies in many ways. First, it provides them with great amount of learner language data as seen by the fact that the CHILDES corpus is used in 3200 research 
papers (Lozano \& Mendikoetxea, forthcoming 2012). Secondly, computerization not only makes it possible for the researchers to manage large amounts of data, but it also provides them with tools of analysis. As Tono (2000) put it:

The use of learner corpora opens up the possibility of filling the gap between small-scale, tightly controlled experimental research and large-scale, but impressionistic, survey-questionnaire type research (p. 132).

In line with this idea we have decided to found the principal study of our project on our own learner corpus. This has provided us with larger amounts of learner language, which, as Granger (2009:16) has claimed, provided us with a solid empirical base on which we observed the acquisition process of certain morpho-syntactic features. The fact that the elicitation method was systematically designed enabled us, as Díaz-Negrillo (2007:85) points out, to reach conclusions that we can claim valid for a relatively large amount of L2 learners. The importance of founding our research on authentic language has been emphasized many times in the previous section. We shall, therefore, simply repeat here that authentic language offers us insights into the learners actual interlanguage the description of which is crucial for SLA research in that they "[...] provide the evidence by which theories of L2 can be developed and tested"(Ellis and Barkhuizen, 2005:21). In this paper we have used our learner corpus to check the morpheme acquisition orders suggested by some previous MO studies. In the same line, we have tried to check the influence of the data collection method on the learner language by comparing the results of our corpus to the ones obtained by means of a controlled activity bearing on the possessive $-s$. In sections 5.1 and 5.4 we provide more information regarding the controlled data elicitation method used in our project. 


\section{3 L2 influence on L3 acquisition}

At the beginning of this chapter we stated that we aim to review the major studies previously conducted in relation to every study of our project. Therefore, in section 3.1 we outlined the outcomes of some major MO studies and in section 3.2 we described the main characteristics of learner corpora emphasizing its importance as an instrument for SLA research. In the same line of thought, we have decided to devote the last section of chapter 3 to the review of the major findings regarding the influence of any previously learnt language on the acquisition of a new foreign language. As pointed out at the end of chapter 2, the last study of our project regards the influence of L2 English on the acquisition of the expression of possession in L3 German. Our initial idea was to check the accuracy rates of the synthetic possessive forms in German by learners of German as a foreign language and then compare it to the corresponding accuracy rates of the possessive $-s$ by L2 learners of English. However, the results of our study indicated a possible influence of the English system of possession on the acquisition of the German expression of possession in those subjects that had learnt English as an L2 and were currently learning German as an L3. On these grounds we decided to investigate further on the effects of L2 on L3 acquisition. Therefore we would like to provide more information in relation to this area of research before proceeding with the presentation and analysis of our corresponding findings (section 6.3). In the present section we will present some previously conducted studies in this field as well as the three major explanatory models that have been put forth.

The influence that second or other background languages exert on the acquisition of a new target language is a very recent area of research. However, various studies have been conducted up to now, which have prompted the formulation of three major relevant models: the Cumulative Enhancement Model (CEM) (Flynn et al., 
2004), the Typological Primacy Model (TPM) (Rothman, 2010) and the L2 Status Factor Hypothesis (LSFH) (Bardel and Falk, 2007).

The CEM (Flynn et al., 2004) suggests that all previously learnt languages can influence L3 acquisition. It claims that in principle the L1 is the primary source of transfer. The L2 will have an influential role only if the feature in scope (i.e. the feature to be acquired) is not present in the L1. This model takes only syntactic overlap into consideration, that is, transfer is seen as a facilitating factor in TL acquisition. Hence the CEM suggests that language acquisition is a cumulative process according to which the learner can decide to use not only one, but all, previously acquired languages in L3 acquisition.

The TPM (Rothman, 2010) suggests that (psycho)typology determines whether the L1 or the L2 will be transferred in L3 acquisition. The term (psycho)typology can refer either to the proximity of the languages involved based on genetic relatedness, to a typological similarity of a particular structure, or to the learner's perception regarding languages' similarity. If a learner perceives the one or the other language to be "closer" to the L3, this particular language will be transferred. The difference between this hypothesis and the CEM is that the former recognises the possibility of non target-like use structures resulting from this transfer process, whereas, the CEM, as we said, assumes that the transfer is facilitating.

The LSFH (Bardel and Falk, 2007) claims that in an L3 acquisition process the primary source of transfer is always the L2 regardless of the similarity, actual or assumed, between the L2 and the L3. The L2 status hypothesis is based on the study conducted by Williams and Hammarberg (1998) regarding L3 acquisition of the lexicon. They claimed that there is a general tendency to activate a previously learnt language, rather than to activate the L1 in the acquisition of a third, which they called L2 status factor. In 2007 Bardel and Falk conducted a 
study in which they found that Williams and Hammarberg's observations in SLA coincided with their findings regarding the acquisition of L3 syntax and thence proposed the LSFH as an explanatory factor to the findings.

These hypotheses emerged as a response to the findings of various studies that revealed an $\mathrm{L} 2$ influence on the acquisition of an L3. The first of these studies focused mainly on lexical transfer (e.g. Hammarberg, 1998) but then the scholars' interest extended to the syntax as well. Some of the major studies of syntactic transfer are outlined below.

The first study that looked on the acquisition of L3 syntax was that conducted by zobl (1992). In this study zobl found that multilinguals have broader, in the sense on non-restrictive, IL grammars than monolinguals. In the judgement tests he made he found that multilinguals accept more marked constructions and ungrammatical sentences, since they are being less restrictive in a new language.

Klein (1995) conducted a relevant study in which she tried to address the question of whether multilinguals are different to monolinguals in foreign language acquisition. She investigated the acquisition of English verbs and their prepositional complements as well as the acquisition of preposition stranding. In relation to this she compared a group of 17 L2 English learners with a group of multilingual L3/L4 English learners with various language backgrounds. She also used a group of 15 native speakers of English as a control group. This study confirmed Klein's initial hypothesis that multilinguals would acquire the preposition stranding structure faster, even though a similar structure did not exist in their L1 or their L2. This finding hence suggests that multilinguals are probably going through a less conservative learning procedure benefiting from their higher metalinguistic awareness. As Klein (1995) said, multilinguals have an "enhanced lexical knowledge which may help 
to trigger parameter-setting and this propels Mls [multilinguals] further along the path of acquisition" (p.450).

Dentler (2000) also studied the acquisition of L3 syntax. She investigated the impact of L2 syntax in L3 German by focusing on the production of German main clauses by L1 Swedish and L2 English speakers. Her study's results show that the participants did not apply the V2 rule correctly in L3 German, although this is a feature that German shares with the participants' L1 but not with their L2. Dentler (2000) did not explain this phenomenon on the basis of L2 transfer but she rather sees it as an indication of a certain acquisition order followed by all subjects confirming thus Pienemann's (1998) Processability Theory. This, however, does not imply that her study's results do not indicate an L2 transfer.

Flynn et al. (2004) presented a study of the acquisition of relative clauses by $\mathbf{L}$ 2 English learners with different L1, Spanish and Japanese chosen precisely due to the typological distance that characterises these two native languages. Spanish is a head-initial language and in that sense it is similar to English. Japanese, on the other hand, is a head-final language. Their findings showed that L1 Japanese learners of English performed better than L1 Spanish learners of English. The scholars thence claimed that "both 'determining' and experience with the consequences of the parametric value of this grammatical principle is necessary in acquisition in terms of the development of a language-specific grammar" (Flynn et al. 2004:8). That is, they argue that Japanese L1 speakers act just like monolingual English children. Since they have no previous experience with head-initial languages, they only have to set the correct parametric value for the English L1 or L2. They then compared these findings to others resulting from L3 acquisition studies. They found that "when the L2 is still 'in progress', its influence on $\mathrm{L} 3$ acquisition is not the same as it is when L2 and L3 are sequential" (Flynn et al., 2004:14). 
Indeed, the importance of the TL and the L2 proficiency level has been suggested by other scholars as well. williams and Hammarberg (1998) showed that high proficiency in the L2 will enable this language to influence the acquisition of a new language. However, low proficiency in a background language has also been claimed to be a factor (De Angelis, 2005b). It is generally assumed that the lower the proficiency level in the TL the more the background languages will exert influences in order to solve communicative problems (Ringbom 1987).

In 2007, Bardel and Falk conducted an empirical study in which they compared two groups of learners' acquisition of negation placement. They used both longitudinal Swedish data collected in the Netherlands and cross-sectional data collected in sweden. The L3 Swedish as well as the L3 Dutch learners were at the very initial stage of L3 acquisition. They focused on the negation placement which depends on whether or not the finite verb raises up to the second place in the main clause (the V2 property). One group of learners (the English L2 group) had an L1 with V2 and an L2 without V2, and the other group (the Dutch/German L2 group) had an L1 without V2 and an L2 with V2. They found that the group with the I2 that had the V2 property correctly placed the negation post-verbally from the very initial stages. 


\section{Research Questions and Hypotheses}

Our study is divided in three main parts according to the language at issue and the principal data elicitation method used. We should, therefore, formulate separately our hypotheses and questions that relate to each of these studies. First, we will present the research questions for the acquisition of morphology in a corpus of L2 English collected in an EFL secondary school (study 1). Then, we will focus on a particular morpheme: the expression of possession L2 English via the genitive -s morpheme vs. the analytic $P P$ structure (study 2) and in L3 German via the genitive $-s$ morpheme, the genitive case and the analytic $P P$ structure (study 3 ).

\subsection{Study I: MOS and Learner Corpus in L2 English}

Q1. Our first question concerns the proficiency as an explanatory factor for the observed development of morphology in L2 English, that is, whether low and high proficient learners will display different accuracy orders as previous studies have shown (Muñoz, 2006).

Our first hypothesis is that accuracy does not imply acquisition of the corresponding functor. Evidence from different studies proves that some functors' development does not display a linear evolution and hence accuracy at one stage does not imply that the same accuracy rates will be obtained in subsequent stages. That is, accuracy does not equate acquisition. If grouping our subjects according to their level of proficiency enables us to observe more phenomena of the acquisition process as Ellis and Barkhuizen (2005) have argued, then we will be able to study the different developmental stages of certain 
morphemes (such as the regular past and the irregular past) and thus confirm that we should not assume acquisition has taken place on grounds of the accuracy rates achieved.

Our second hypothesis is that the accuracy orders will display a similar route for all proficiency levels. In relation to this we also argue that our findings will correlate with other EFL findings.

Q2. The second question we wish to answer through the analysis of our learner corpus from a MO perspective is whether Hawkins' (2001) pattern bearing on the difficulty of the morphemes can stand as an explanatory model of our study's findings. Therefore, as we will see in a subsequent section (5.4.4) we also organized our morphemes in verb-related and noun-related classes. Regarding this question we will be examining only the verbrelated functors.

Our third hypothesis, therefore, is that the accuracy orders revealed in our study regarding the verb-related functors will have a pattern similar to the one suggested by Hawkins (2001) and Andersen (1978) ${ }^{6}$. In that vein, the development of the verb-related morphology in L2 English will depend on the difficulty of the underlying grammatical structures of each morpheme. However, we do expect to find some variation within the aforementioned sequence among our groups in accordance with our first hypothesis that regards the subjects' proficiency level. We furthermore argue that this deviation from Hawkins' developmental pattern will appear in relation to the past tense morphemes, that is, it will be influenced by the non-linear development that their acquisition exhibits. See section 3.1 .3 for a discussion on this issue.

\footnotetext{
6 A presentation and brief analysis of this pattern is presented in section
} 3.1.2. 


\subsection{Study II: Genitive $-s$ in L2 English}

21. The first question we wish to investigate in this section regards the influence of the data elicitation instrument on the research's results. In the same line, we will be checking Krashen's (1978) claim that the instrument influences the results and that the accuracy orders displayed in each case will be different according to whether the data come from naturally produced (corpus) or experimentally elicited language. Therefore we will compare the accuracy rates of the possessive -s obtained by the subjects that participated in our picture composition task (corpus) on the one hand and in the sentence transformation task (experiment) on the other. In this respect we will be using the soc scores since it is acquisition we wish to check and hence we have to include both the TLU and the NTLU instances. Note that we do not calculate the soc according to Brown's model, i.e. based only on the OC. More details regarding the model adopted in this study in order to calculate the accuracy rates is presented in the following chapter (section 5.4.5). When investigating the frequency, on the other hand, we shall compare the TLU and the NTLU scores in order to isolate and thus separate the use of the inflectional (TLU) and the periphrastic (NTLU) possession forms. We analyse in detail our tagging schemes for each of our three studies in chapter 5. Although our scoring model is structured on the basis of the TLU model, we call the total accuracy scores SOC instead of TLU in order to distinguish between the total accuracy rates, which contain both the TLU and the NTLU cases, and the actual TLU instances. Both the SOC and the TLU are used in comparisons in the analysis of the accuracy rates and the frequency of use respectively.

Our first hypothesis stems directly from our first question and regards the actual influence of the data collection instrument on the accuracy rates of the possessive $-s$. Following Krashen's idea that experimentally elicited data reflect the learnt but not necessarily the acquired knowledge, we expect to find that the possessive -s has been 
more accurately used in our sentence transformation (experiment) than in the picture description (corpus) task.

Our second hypothesis refers to the relative frequency of the possessive $-s$ in English. We believe that our L2 English learners will show a clear preference towards the use of the periphrastic form confirming thus the findings of previous MOS (Bailey et al., 1974; Larsen-Freeman, 1975; Rosansky, 1976) that rank the inflectional form among the last functors to be acquired.

\subsection{Study III: Possessive structures in I3 German}

Q1. The main question of this study contemplates the relative frequency of each of the possessive forms (i.e., periphrastic as well as inflectional) in our L3 German learners' language. In the same line we wish to compare the corresponding results with the ones obtained for our L2 English learners.

In relation to our previously posed question we cannot form a hypothesis. MO studies previously conducted bearing on the acquisition of L2 English morphology claim that the route is similar regardless of the subject's II (see section 3.1.2). However, research on the acquisition of the possessive construction in German/Dutch ${ }^{7}$ by L2 learners claim that in initial stages students tend to rely on their Ll expression of possession (Van de Craats et al., 2000; Matteini, 2007; Matteini, 2009).

Therefore, our hypothesis for this study regards only the effect that the subjects' $\mathbf{L} 2$ exerts on their acquisition of the I3. In keeping with previous studies on this field (see section 3.3 for more details) our hypothesis predicts that I3 German acquisition is influenced by the learners' L2 English, especially in initial proficiency levels.

7 Please note that the comparison is possible due to the similarities between the German and the Dutch systems of expressing possession. 


\section{The empirical studies}

In this chapter we present the details of our empirical studies. In keeping with the perceived importance of the methodology we have decided to begin by introducing the two methods that we have adopted in this paper. Initially we provide information about the various types of method available. Then we discuss our own methodological options on which we dedicate two separate sub-sections (5.1.1 and 5.1.2).

In section 5.2 we analyse our subjects' composition first according to the educational institution in which they learn the TL (i.e., either English or German) and then in terms of their proficiency level.

The following section of this chapter regards the materials used in our empirical studies. In order to achieve clarity in their presentation we have decided to create one sub-section for each of the data elicitation instruments. In the same line, subsection 5.3.1 refers to the format we used in order to create a learner's profile including thus useful information such as mother tongue, time of exposure to the TL, other FL spoken, etc. In sub-section 5.3.2 we present the placement tests used for the classification of our subjects' proficiency level in both English and German. In the final two sub-sections we describe and analyse the compilation of both our picture description task (corpus) and our sentence transformation task (experiment).

The final section of chapter 5 relates the actual procedures followed for the three studies of our project. Accordingly, we describe how we proceeded with the collection (5.4.1) and the transcription (5.4.2) of our data. After completing these stages we processed our data using an editorial tagging scheme which we present in sub-section 5.4.3. The actual tagging of the morphemes at issue is presented in the following sub-section 
(5.4.4) Note that within this sub-section we distinguish three parts in keeping with the three studies of our project. Accordingly, each of these parts contains the detailed description of the tagging scheme that corresponds to every study. Finally, in sub-section 5.4.5 we introduce the calculation model used for the scoring of our data.

\section{1 Method}

First we should mention that our study is cross-sectional and that it focuses on the accuracy order of nine functors presented in sub-section 5.4.4 as well as on the relative frequency of the functors that relate to the expression of possession in both English and German.

In order to obtain samples of language from L2 learners, researchers can use different methods. Learner language production varies due to both internal and external factors. Research has shown that the order of acquisition of different grammatical structures can vary according to the kind of task used to elicit learners' language. Although some of the first MO studies reached similar conclusions regardless of the method used (see section 3.1), other studies support the hypothesis that the outcomes regarding the accuracy of use are influenced by the elicitation instrument. Indeed, Ellis (1987) found that the accuracy order of two past tense morphemes varied depending on how the data were collected.

In keeping with the perceived relationship between elicitation task and learner language we can distinguish three types of learner language samples corresponding to the three principal methods for collecting data.

The first method is the least controlled one and consists of obtaining samples of language produced in a real-life situation in order to satisfy some communicative need. The other two methods involve elicitation that, following Corder (1976), can 
be distinguished in clinical and experimental. Figure 4 displays the three types of learner language.

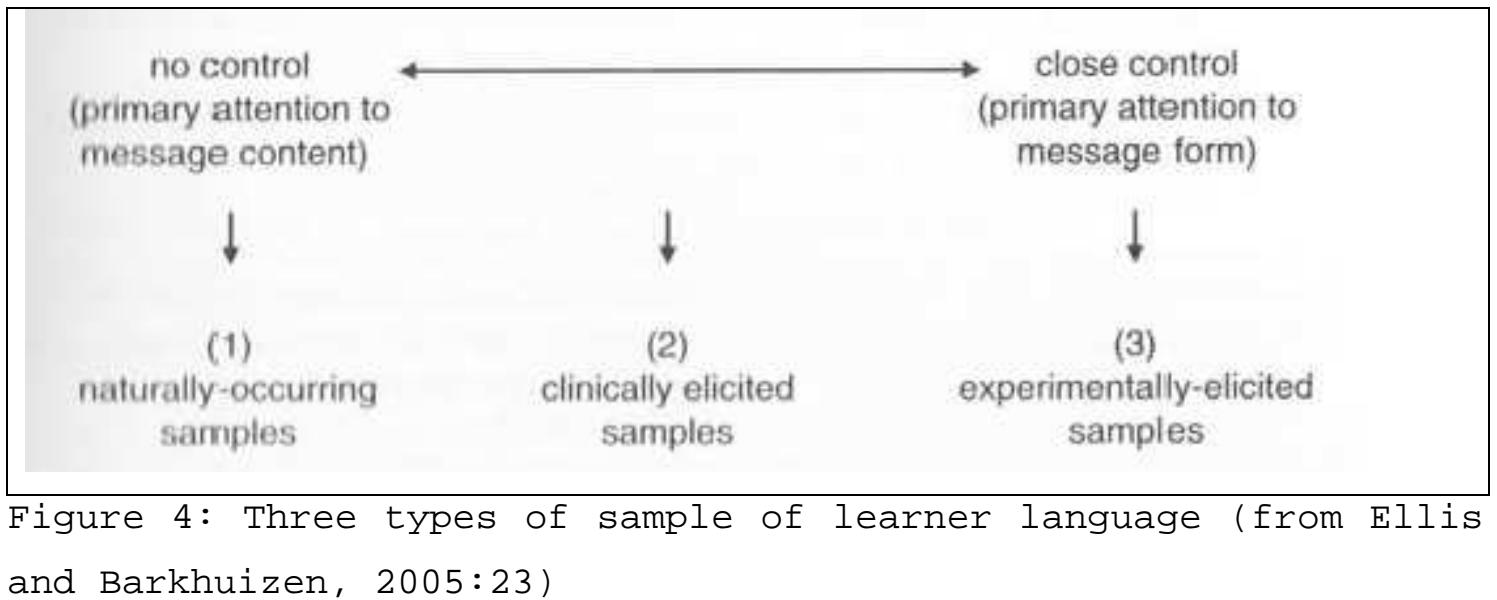

The difference between clinical and experimental elicitation "matches the distinction between task and exercise". (Ellis \& Barkhuizen, 2005:23) Corder (1976) argued that the clinical elicitation is suitable for those studies that do not have a previously well-formed hypothesis and therefore intends to gather data of any sort from the participants. Experimental elicitation, on the other hand, is highly controlled because the researcher wishes to check the usage of a specific linguistic form. Experimentally elicited samples result in a constrained constructed response (Norris \& Ortega, 2001), that is to say, in a short L2 segment.

In our case study we have opted for the use of two methods, ranging from less control (picture composition task: corpus) to more control (sentence transformation task: experiment). In the following sections $(5.1 .1 \& 5.1 .2)$ we provide a detailed description of the aforementioned methodologies.

\subsubsection{Picture composition task (corpus)}

The first method used was a picture composition task which represents clinical elicitation and enabled us to compile our own learner corpus. In fact, picture composition task is very close to naturally occurring samples of language. The only 
difference between them is that the former is collected specifically for the purpose of the research. Additionally, picture composition tasks aim to the elicitation of a general, rather than a focused, sample of learner language. This further distinction is very important since the "learner's orientation to the elicitation task can have a profound effect on the language used" (Ellis and Barkhuizen, 2005:31).

The process we followed was to show the learners the picture composition (see Appendix 9.4) and ask them to write the story in their own words while they were in class. That is to say, our corpus did not result from a take-home composition task as we wanted the language used to be as authentic as possible. Students were allowed 30-45 minutes to complete the task and were provided with the entire series of pictures along with a reduced word-list that included mainly nouns they may not know. Our decision to give our subjects plenty of time is justified by the fact that we did not want them to feel stressed which would obstruct their concentration and probably distort their language. On the other hand, our choice to give learners a reduced list of relevant words was based on our previous decision in relation to the nature of the elicitation task. That is, the task should not be cognitively demanding in order to facilitate the production of authentic learner language. By giving our subjects a list of words we may have influenced the authenticity of the learner language but only in terms of lexical items, which obviously does not influence our research that focuses on functors.

\subsubsection{Sentence transformation task}

The second method was a controlled task, namely, a sentence transformation task intending to elicit the use of possessive -s in the case of L2 English learners and the equivalent synthetic forms for the expression of possession in the case of L3 German learners. Ellis \& Barkhuizen (2005:37) include this type of experimental elicitation in the so-called discrete-points tests with the traditional language exercise format. 
Our decision to use two methods one of which is very controlled is justified by the fact that the possessive $-s$ is not easily elicited in naturally occurring samples. Additionally, it allowed us to check Krashen's argument that discrete-point tests trigger the learners' formal linguistic knowledge that results from the L2 learning process. If Krashen was correct, then the accuracy rates for the possessive $-s$ will be different, and indeed significantly higher, from those found in our corpus analysis. Since the latter is authentic and thus to a high degree spontaneous language, it should show a morpheme accuracy order determined by unconscious acquisition as Krashen (1978) has argued.

\subsection{Subjects}

As we mentioned before, our study is cross-sectional and, as such, it includes a large number of subjects. For both parts of our study a total of 400 examples of learner language were collected.

For the compilation of our learner corpus a total of 95 secondary education students from the High School IES Pedro Soto de Rojas (Granada, Spain) participated in the study.

In the second part of our study consisting of the experimentally elicited data a total of 305 FL learners took part. Out of the total of 305 students 256 were secondary education students from the High School IES Pedro Soto de Rojas (Granada, Spain) and had English as a foreign language whereas 7, also secondary education, students were learning German as an L3 at the High School IES Padre Suarez (Granada, Spain). Due to the scarcity of L3 German learners, we also used samples collected from the language centre Centro de Lenguas Modernas (CLM) in Granada, Spain. Therefore, 42 subjects were not secondary education students. This, however, did not influence our study since we grouped our subjects not according to age but on the basis of their proficiency level which was determined by means of proficiency tests. The process is fully explained in section 
5.3.2 and our L3 German learners' classification in terms of proficiency level is presented in table 6 .

Additionally, a learner's profile was administered. It included information regarding age, gender, L1, proficiency level, etc. following the example that we provide in Appendix 9.1, has been compiled for all our subjects.

The participants were all volunteers who were informed about the objectives of the study from the very beginning.

Table 6 shows the composition of our subjects in terms of their proficiency level in L2 English. We then supply a chart of the aforementioned subjects' synthesis in Figure 5. As we can see the majority of the subjects in both parts of our research project (always in relation to L2 English) have a preintermediate or an intermediate level. Only few have reached the upper-intermediate level whereas just a minority is still at the elementary level. We should also mention that the age range of our L2 English learners was 11-18 years. In terms of educational level we included students from the $2^{\circ} \mathrm{ESO}$ to $1^{\circ}$ Bachillerato.

\begin{tabular}{|l|c|c|c|}
\hline & $\begin{array}{c}\text { Learner } \\
\text { Corpus }\end{array}$ & $\begin{array}{c}\text { Experimentally Elicited } \\
\text { Data: Possessive -s }\end{array}$ & TOTAL \\
\hline Elementary & 5 & 18 & $\mathbf{2 3}$ \\
\hline Pre-Intermediate & 43 & 106 & $\mathbf{1 4 9}$ \\
\hline Intermediate & 39 & 101 & $\mathbf{1 4 0}$ \\
\hline $\begin{array}{l}\text { Upper- } \\
\text { Intermediate }\end{array}$ & 8 & 31 & $\mathbf{3 9}$ \\
\hline
\end{tabular}

Table 6: Distribution of I2 English subjects 


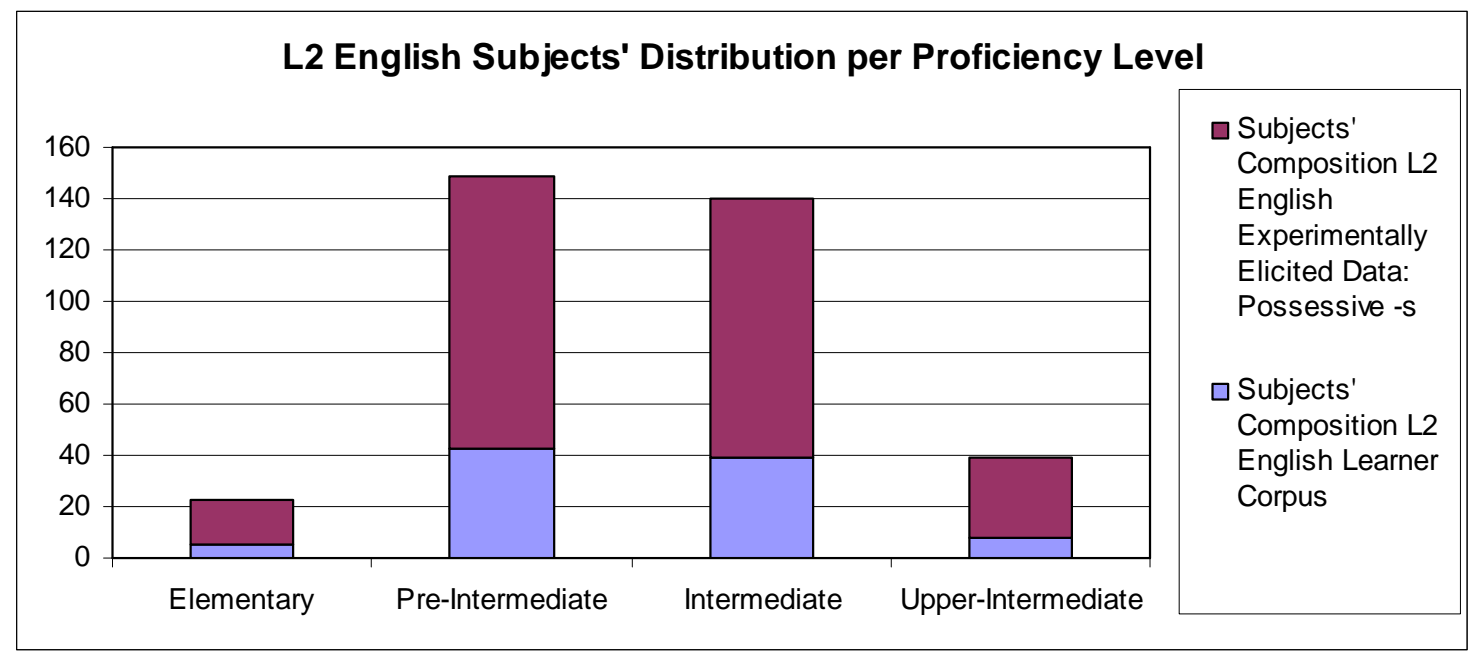

Figure 5: Distribution of the number of subjects per proficiency level in L2 English

Table 7 shows our subjects' distribution according to their proficiency level in L3 German. The chart of the same is presented in Figure 6, where we can observe that the majority of our subjects are at the elementary level. The pre-intermediate and the intermediate levels have almost the same number of students. Finally, we have managed to find only a few students at the upper-intermediate level. We would like to underline that, although some of our subjects come from a high school whereas the rest come from a language centre, a comparison of the final data is possible because in both cases the learning environment is instructional.

\begin{tabular}{|l|c|c|c|}
\hline & $\begin{array}{c}\text { IES Padre } \\
\text { Suarez }\end{array}$ & CIM & TOTAL \\
\hline Elementary & 3 & 17 & $\mathbf{2 0}$ \\
\hline Pre-Intermediate & 4 & 9 & $\mathbf{1 3}$ \\
\hline Intermediate & 0 & 12 & $\mathbf{1 2}$ \\
\hline Upper-Intermediate & 0 & 4 & $\mathbf{4}$ \\
\hline
\end{tabular}

Table 7: Distribution of subjects in I3 German 


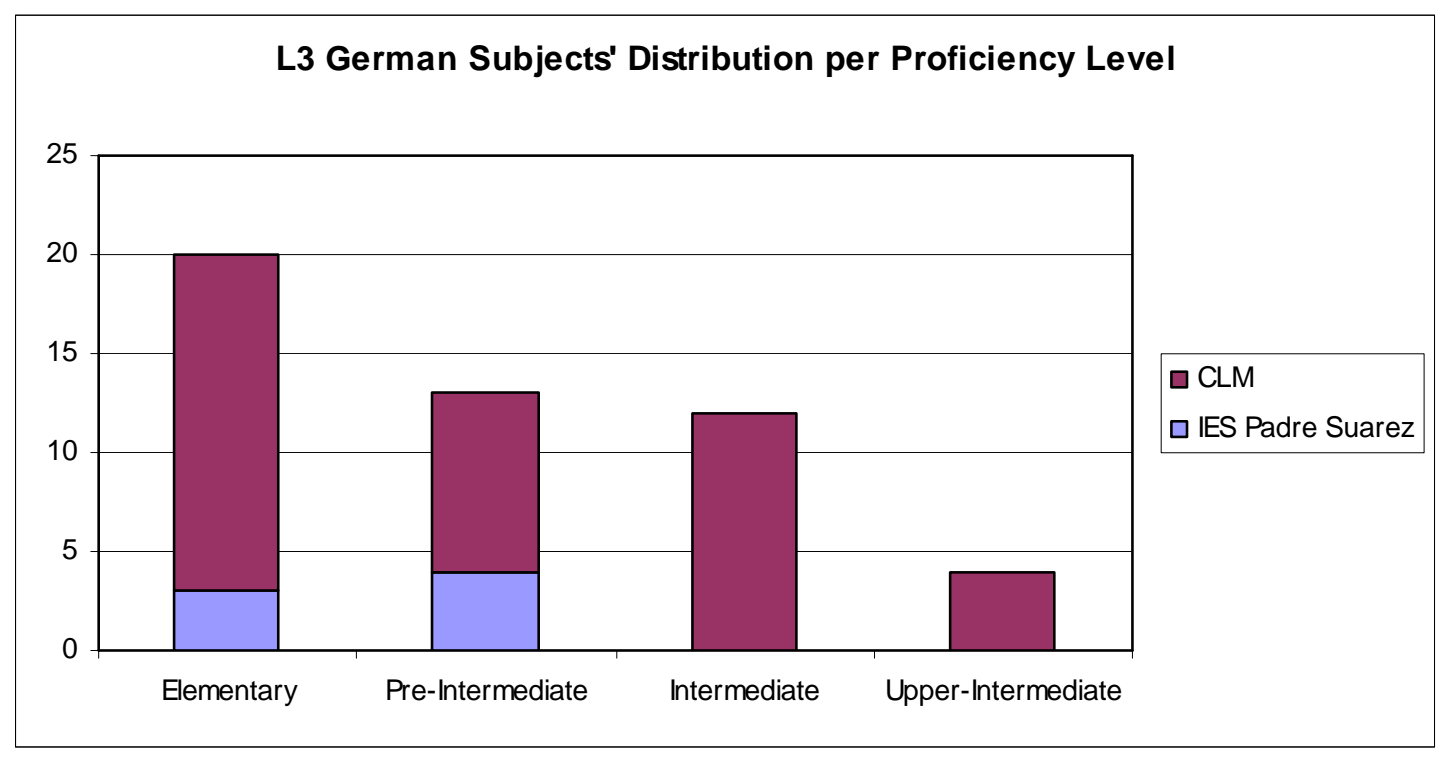

Figure 6: Distribution of the number of subjects per proficiency level in I3 German

Finally Table 8 and Figure 7 show the distribution of our subjects according to their proficiency level in both L2 English and L3 German.

\begin{tabular}{|l|c|c|}
\hline Subjects' Composition L2 English \& I3 German \\
\hline Elementary & German & English \\
\hline Pre-Intermediate & 20 & 23 \\
\hline Intermediate & 13 & 149 \\
\hline Upper-Intermediate & 12 & 140 \\
\hline
\end{tabular}

Table 8: Distribution of subjects in I2 English and L3 German

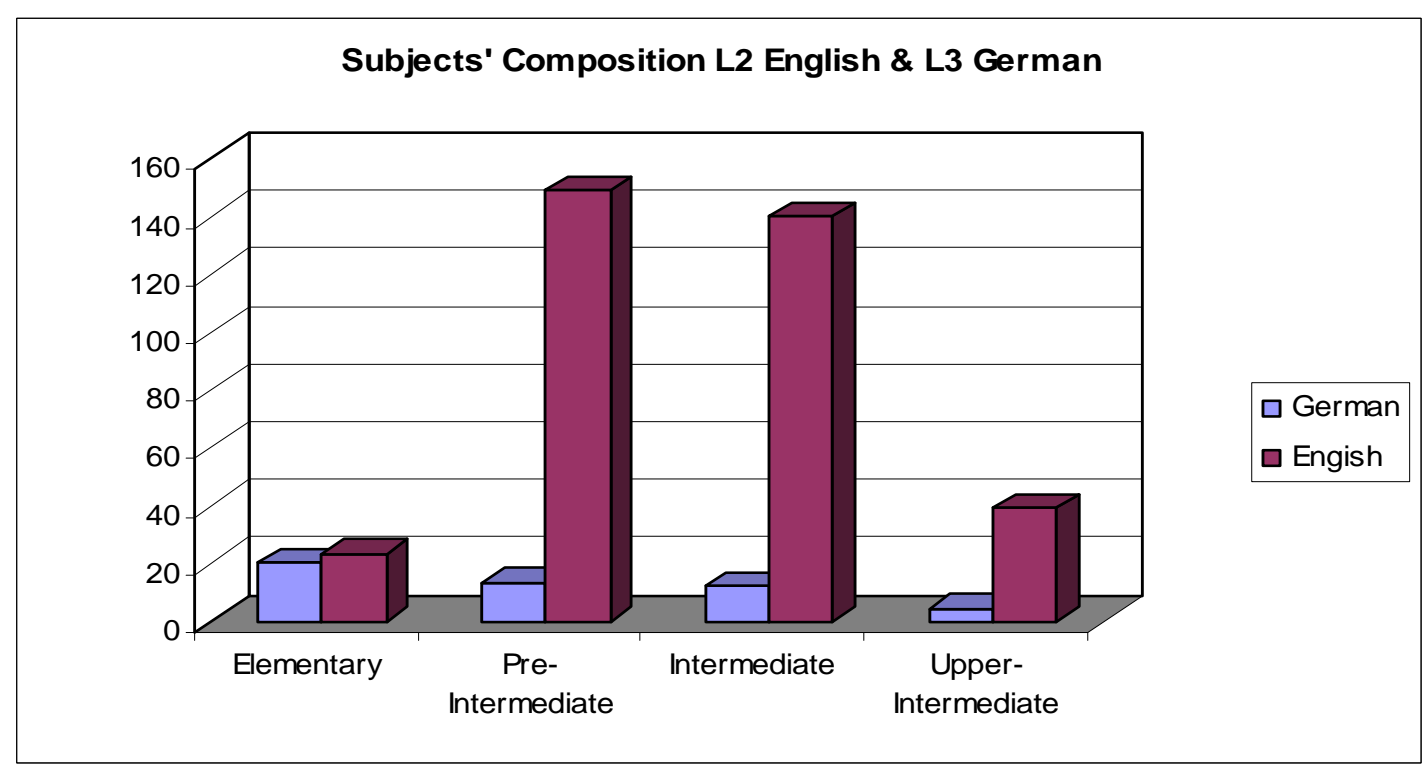

Figure 7: Distribution of our subjects' proficiency level in I2 English and I3 German. 


\section{3 Materials}

In our case study we have used various types of data elicitation instruments.

\subsubsection{Questionnaire (learner profile)}

Learner language is influenced by a wide variety of linguistic, situational and psycholinguistic factors. Indeed, one of the critiques of the cross-sectional SLA studies is that "there is often no detailed information about the learners themselves and the linguistic environment in which production was elicited" (Gass, 2001:33). In that line of thought, we decided to include additional information regarding our subjects. Although Figure 8 shows the major variables that need to be controlled when compiling a learner corpus as traced by Granger (2008:264), we used it as a guideline for the collection of our experimentally elicited data as well. The underpinning idea of this two-part table is the distinction put forth by Ellis (1994:49) between learner variables and task variables. In our case study we have tried to incorporate as many of these variables as possible by creating a quite detailed learner's profile based on a questionnaire, a sample of which can be found in Appendix 9.1.

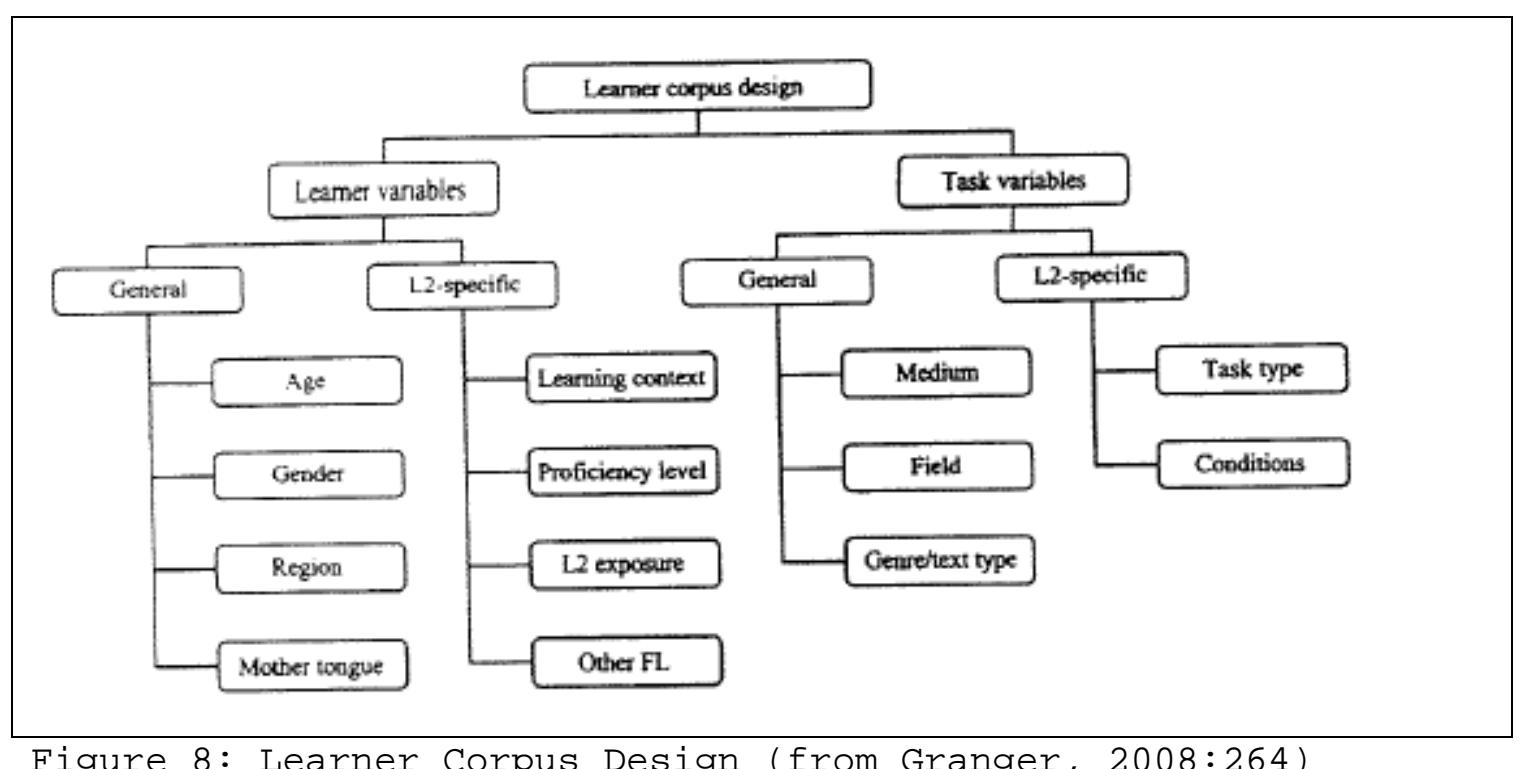

Figure 8: Learner Corpus Design (from Granger, 2008:264) 
In the compilation of our learner profile we have been based on the learner variables as outlined in Figure 8. Indeed, we have included both the General and the TL-specific variables. Our subjects were asked to provide information about their age and gender. The variable region was not explicitly included in our learner profile since all our subjects were residents of Granada, Spain. Regarding the variable mother tongue the students had to explicitly state their mother tongue, their mother's native language, their father's mother tongue, as well as the language spoken at home. In relation to the learning context and the exposure to the $T L$ we asked our subjects to provide all the relevant information in. That is, whether they have been in a country where the TL is spoken (and if yes, where and for how long), if they take part in a bilingual programme (and if yes, since when, for which subjects and how many hours per week), and finally whether they receive additional tuition on the TL or if they do other activities in the TL (e.g. watching films, reading books, etc.). Our subjects were also asked to state whether they speak or not other foreign languages and which. Finally, bearing on the subjects' proficiency level not only we conducted a placement test, but we also asked our students to give us their opinion regarding their proficiency level in each of the four areas (i.e. listening, reading, speaking and writing).

\subsubsection{Placement tests}

Granger (2008:264) mentions that of all the L2-specific learner variables, the proficiency level is the most important but also the most difficult to establish. Indeed, until now no L2 English learner corpus includes a proficiency test. Even the ICLE created by Granger et al. (see section 3.2) is a corpus that includes data from low advanced L2 English learners. In our learner corpus we have incorporated not only the learner profile described above but also a proficiency test. Accordingly, our learner corpus contains four sub-corpora according to the proficiency level (ranging from elementary to upperintermediate). 
We would like to emphasize that our decision to test our subjects' proficiency level helped us overcome the inconsistency provoked by the fact that "one researcher's advanced category may correspond to another's intermediate category" (Gass, 2001:37). Additionally, it allowed us to classify the subjects into different groups according to their level of proficiency and thus observe other phenomena within the SLA process such as the U-shape developmental pattern that certain morphemes present.

Our subjects' proficiency level was decided on grounds of each student's results on a placement test that we distributed before proceeding with the elicitation process.

In relation to $\mathbf{L} 2$ English placement test, we used the written placement test of the English Unlimited Test published by Cambridge University Press in 2010. This consists of 120 multiple-choice questions, 20 at each level from starter to Advanced (covering CEF levels A1 to C1). We used the first 100 questions since it was a test given out to secondary education students, that is, we excluded CEF level C1. However, no student reached the upper limits of the upper-intermediate level. Students were asked to start at the beginning of the written test and stop when the questions became too difficult. We allowed 45 minutes for the test. A sample of the adapted placement test along with the teacher's guide can be found in Appendix 9.2 .

Let us consider now the $\mathbf{L} 3$ German proficiency test. In order to check the proficiency level in German of the secondary education students of the High School "IES Padre Suarez" we adapted the placement test provided by the centre of modern languages (Escuela Oficial de Idiomas) in the Basque Country. Following the guidelines given out by the Escuela Oficial de Idiomas (henceforth EOI) we considered that a proficiency level was reached when the student had made at least 19 correct choices out of the 24 for each level. In keeping with our decision to conduct only a written test in English we excluded the reading 
part that was originally found in the placement test of the aforementioned centre of modern languages. A sample of this can be found in Appendix 9.3. We did not apply that test to the students of the language centre Centro de Lenguas Modernas in Granada since the subjects are already grouped on the basis of a placement test compiled according to the Common European Framework of Reference for Languages (CEFR) by the Centro de Lenguas Modernas (henceforth CLM) in Granada. Although our L3 German subjects' proficiency level is defined on the basis of two different tests we consider that their classification is comparable and hence reliable for two reasons. First because the placement test of the EOI that we used with the students of the High School IES Padre Suarez and the placement test used by the CLM are compiled on the basis of the CEFR guidelines and thus share a common theoretical framework. Second because both the EOI and the CLM are certified FL examination centres.

\subsubsection{Corpus (Picture Description Task)}

According to Corder (1976), clinical elicitation suits best a generally formed hypothesis. Since our first aim is to check the accuracy order that previous L2 morpheme acquisition studies have put forth, we considered a clinically elicited language sample to be the most adequate option. As described in subsection 5.1.1, our corpus was compiled on the basis of a picture composition task a sample of which can be found in Appendix 9.4. This sample is an adaptation of the elicitation task titled "Frog, where are you?" originally created by Mayer (1969). We decided to use a version of this picture composition task mainly because it has been used in other learner corpus based studies (e.g. CHILDES), as well as in one of the key studies on morpheme acquisition in L2 English (Muñoz 2006), which we reviewed above (sub-section 3.1.2).

Up to this point we have presented various reasons that support the usefulness of learner corpora even when they consist of raw data, that is to say, learner language with no added linguistic annotation. However, it is even more useful when it contains 
extra information. Annotation, both grammatical and error, is a highly challenging and time-consuming process and hence researchers may choose to use the ready-made annotating tools. However, as Granger (2008) points out, these tools have been created on the basis of L1 corpora and "[...] there is no guarantee that they will perform as accurately when confronted with learner data" (p.265). In our attempt to deliver as reliable data as possible we have done all the grammatical annotation manually. The process is described in sub-section 5.4.4 where we outline the procedures of the present study.

\subsubsection{Experimentally elicited language (Sentence Transformation Task)}

The second question we wished to give answer to regards the socalled Anglo-Saxon genitive. Most previous studies have placed its accurate use, and thus assumed acquisition, at very low levels. We wanted to check the validity of this previously given position and also compare it to the expression of the genitive by means of the inflectional possession structures in another West Germanic language, namely in German.

Since the elicitation of the possessive $-s$ is very difficult and we could not assure its use in our corpus, we decided to use an experimental elicitation as well. This instrument consists of 6 sentences that the students should transform in order to express possession. Note that in the given sentences the possession was expressed by means of the possessive pronouns. We used the sentence transformation test instead of the fill-in-the-blank questions that have been used in the study conducted by Wagner (2005) regarding the acquisition of the possessive -s because we considered that the latter actually leads the learner to use either the possessive $-s$ or nothing. But it does not give the subject the option of selection between the synthetic form, i.e. the possessive $-s$, and the analytic form, that is, the prepositional phrase (introduced by the preposition of). We considered that the learner's choice between these two forms is significant in terms of acquisition of the inflectional 
possessive form. We used the same sentences in both English and German. A sample of them can be found in Appendix 9.5.

Furthermore, the combination of both clinically and experimentally elicited data gave us some insight regarding the influence of the instrument on the results of morpheme studies and thus a way to check Krashen's hypothesis in relation to the elicitation of learned vs. acquired L2 knowledge. Note that this combination is justified since it has been recently argued that combining corpus and experimental data always provides better insights into the nature of interlanguage grammars (Gilquin \& Gries 2009; Lozano \& Mendikoetxea, forthcoming 2013; Mendikoetxea \& Lozano, forthcoming 2013).

\section{4 Procedure}

\subsubsection{Data collection}

First we asked the subjects of our study to complete the learner profile. The following step was to carry out the placement tests which we then corrected and scored according to the guidelines of their creators as explained in section 5.3.2 and exemplified in Appendices $9.2 \& 9.3$. At the same time we asked the learners to complete the sentence transformation task. Then we did the picture composition task (corpus) for 95 secondary education students (from $2^{\circ}$ ESO to $1^{\circ}$ Bachillerato).

\subsubsection{Transcription}

After having collected the data, we typed each sentence transformation test and each composition in plain text format in order to avoid automatic corrections of the students' errors that "Word documents" usually perform. A sample of a transcribed file can be found in Appendix 9.6. In the same text we also included all the learner variables (see section 5.3.1), that is, the information found in the learner's profile regarding age, nationality, L1, etc. as well as the subject's proficiency level according to the placement test. Appendices 9.7.1, 9.7.2 and 9.7.3 contain examples of transcribed files that we then used to 
compile our learner corpus and our sentence transformation task database for both English and German.

\subsubsection{Tagging (editorial tagging scheme)}

An editorial tagging scheme was used to code the learners' editions of their own writing. That is, we also coded rewritten material whether legible or illegible. In the first case we used the code \$_RWR_ (the rewritten element). In the second case the code was $\$$ RWU_i. The tagging scheme for the learner's corrections is shown in Appendix 9.9. Table 9 shows the data that we included in each transcribed file name along with an example. From this the researcher can obtain information regarding the proficiency level that the specific student obtained in the placement test, the course in which the subject is at the moment of the data collection, the subject's age, the researcher's identification and the subject's initial. Accordingly, in our example below we can immediately see that our subject is at the upper-intermediate level, attends the 4 ESO course and is 15 years old.

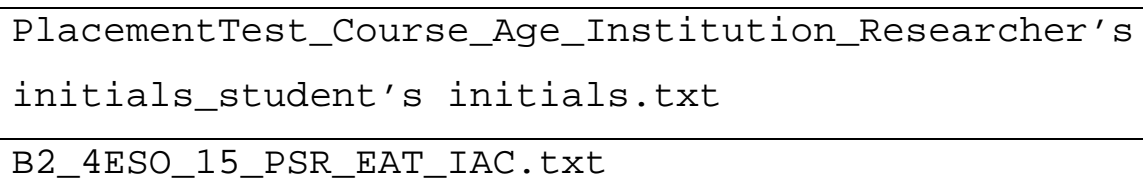

\subsubsection{Tagging: morphemes}

After having transcribed all the texts, we used the UAM Corpus Tool software in order to code the data, i.e., to tag the morphemes. An example of the UAM Corpus Tool can be found in Appendix 9.8. In relation to the learner corpus we should mention that we tagged a set of morphemes based on the list found in previous morpheme studies. Table 10 presents the list of the morphemes investigated in the present study. 


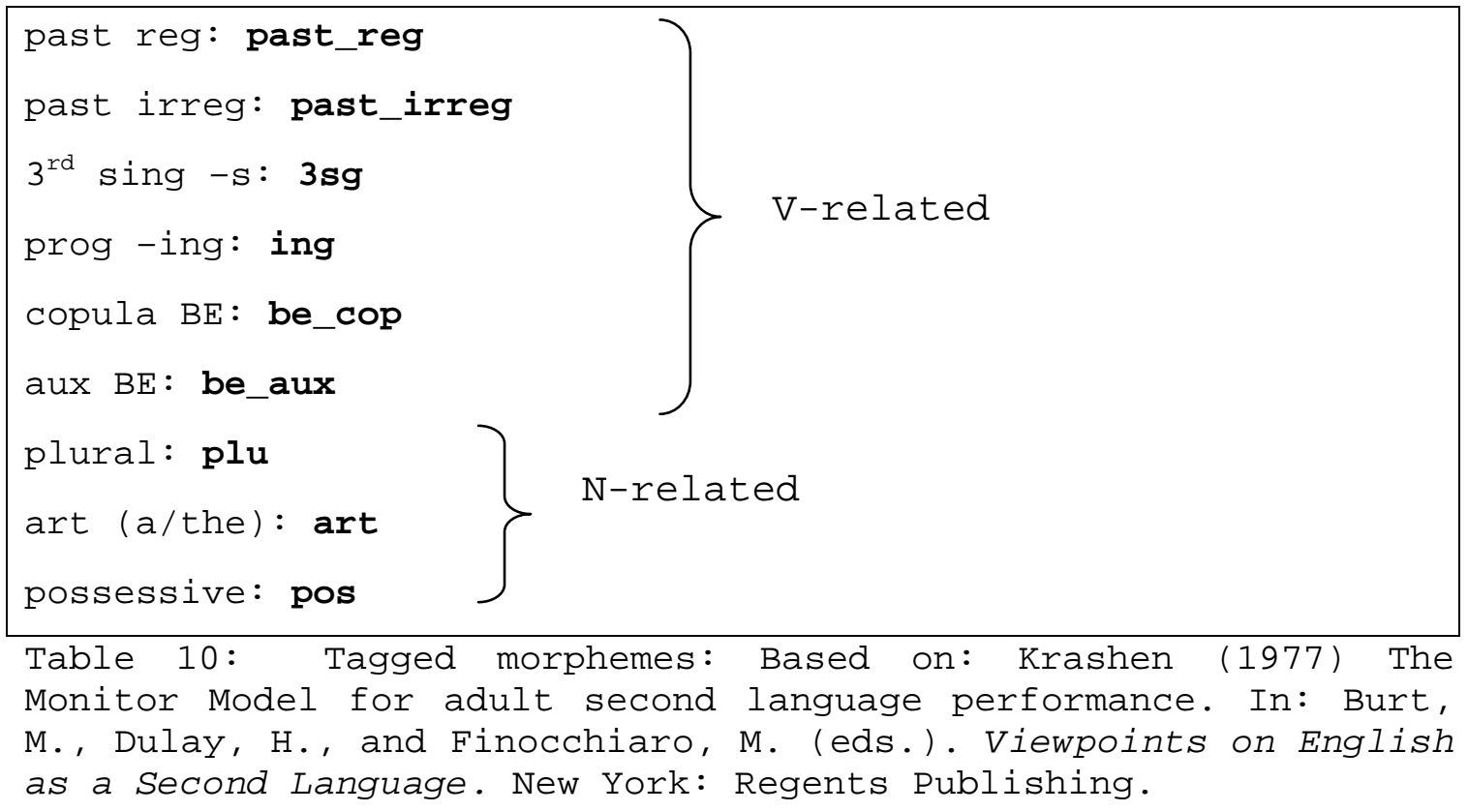

Based on one of the first MOS' critiques regarding the shortcomings of the soc method, we decided to include in our tagging scheme not only the soc (Suppliance in obligatory Context) but also the sNoc (Suppliance in Non-obligatory Context). Therefore both the Target-Like Use and the Non-TargetLike Use of each of the aforementioned morphemes have been examined. That enabled us to account also for the cases of incorrect use of the morphemes by the learners (that is, underuse, misuse and overuse, whose differences will be explained later) and thus trace a more complete picture of the actual accuracy rates. Our analysis of the subjects' performance in relation to the nine morphemes shown in Table 10 involved the following steps:

1. Identification of the obligatory contexts for the use of each of these morphemes and

2. identification of the cases of target-like-use and nontarget-like-use of each morpheme for each learner.

\section{OPart I: Tagging scheme in the MOS Learner Corpus}

In Table 11 we present the tagging scheme in UAM Corpus Tool for progressive -ing as used in the mo study. Following this pattern, the use of a morpheme can be classified as either target-like, which corresponds to Brown's (1973) idea of suppliance in 
obligatory contexts, or non-target-like. Within the latter we further distinguish between underuse, that corresponds to the lack of suppliance, misuse, which may be a misselection (the use of an incorrect morpheme instead of the target morpheme in the obligatory context) or a misrealisation (the erroneous realisation of the morpheme required in a obligatory context), and overuse, which corresponds to what is also known as SNOC (suppliance in non-obligatory context). Through this scheme we could trace a more complete and hence more accurate image of each learner's interlanguage. The aforementioned categories are exemplified for progressive -ing in Table 12. Examples of the tagging scheme described above for each of the investigated morphemes can be found in Appendix 9.10.

\begin{tabular}{|c|c|c|c|}
\hline \multirow{5}{*}{ ing $\frac{\text { ING- }}{\text { TYPE }}$} & \multicolumn{3}{|l|}{ [target_like_use } \\
\hline & & & 「underuse \\
\hline & & NON TARGET LIKE USE- & misuse MISUSE- misselection \\
\hline & non_target_like_use & TYPE & $\begin{array}{l}\text { TYPE } \\
\text { - overuse(snoc) }\end{array}$ \\
\hline & & & - unclassified \\
\hline
\end{tabular}

Table 11: Tagset for UAM Corpus Tool_MOS

\begin{tabular}{|c|c|c|c|}
\hline \multicolumn{3}{|c|}{ OC:Progr. -ing (She is reading) } & S: Supplied form \\
\hline \multicolumn{3}{|c|}{$\begin{array}{l}\text { Target-like Use (TLU) } \\
\text { (correct form supplied) }\end{array}$} & She is reading \\
\hline \multirow[t]{3}{*}{$\begin{array}{l}\text { Non-target- } \\
\text { like Use }\end{array}$} & \multicolumn{2}{|c|}{$\begin{array}{l}\text { Underuse } \\
\text { (no form supplied) }\end{array}$} & She is read_ \\
\hline & \multirow[t]{2}{*}{ Misuse } & $\begin{array}{l}\text { Misselection } \\
\text { (form exists) }\end{array}$ & She reads \\
\hline & & $\begin{array}{l}\text { Misrealisation } \\
\text { (form doesn't } \\
\text { exist) }\end{array}$ & She is reads. \\
\hline \multicolumn{3}{|c|}{ OC: $3^{\text {rd }}$ Sing (She reads a lot) } & SNOC \\
\hline & & $\begin{array}{l}\text { Overuse } \\
\text { (correct form } \\
\text { supplied in NOC) }\end{array}$ & She reading a lot. \\
\hline
\end{tabular}


The data elicited through the sentence transformation task were also introduced in the UAM Corpus Tool in which we tagged it according to the rationale presented below.

\section{Part II: Tagging scheme in the Possession Expression and the Experimentally Elicited Data in L2 English}

All the cases that require a possession construction were considered as obligatory contexts (OC). This in English can be expressed by means of both the possessive $-s$ and the prepositional phrase introduced by the preposition 'of' (see discussion in section 2.2.1).

We decided to use the UAM tool for the tagging of the possessive $-s$ for our experimentally elicited data as well. Although the latter do not present a corpus, we opted for the use of the corpus-software for various reasons. First and foremost, because we decided to maintain the formatting and thus facilitate the process of the tagging and the analysis for the researcher. Second, because it allowed us to introduce the additional data from the learner profile and create a separate file for each student but within the same project. Finally, because the UAM Corpus Tool gives the researcher the opportunity to add extra tagging schemes at any time and thus investigate other aspects and then contrast the elements studied.

For the purposes of our study we called TLU the use of the possessive -s and "NTLU: misuse: misselection" the use of the prepositional phrase. This decision is justified by the fact that we investigate the accuracy rates for the possessive $-s$ only and not for the possession construction in general. Hence if the use of the possessive $-s$ is the TLU then anything else should be classified as NTLU. We specifically tagged the $P P$ as "NTLU: misuse: misselection" so that we could also take into consideration the accuracy rates of the $P P$. We wish to clarify that our tagging scheme does not imply that the students have not acquired the possession construction in English. It rather indicates the preference of our subjects towards the use of 
either the analytic $(P P)$ or the synthetic (pos. -s) form of the attributive construction.

In Table 13 we present the tagging scheme used for the tagging of the possessive $-s$ in our L2 English collected by means of the sentence transformation task (experiment). Note that each of the categories that appear in it is illustrated in the examples presented in Table 14 .

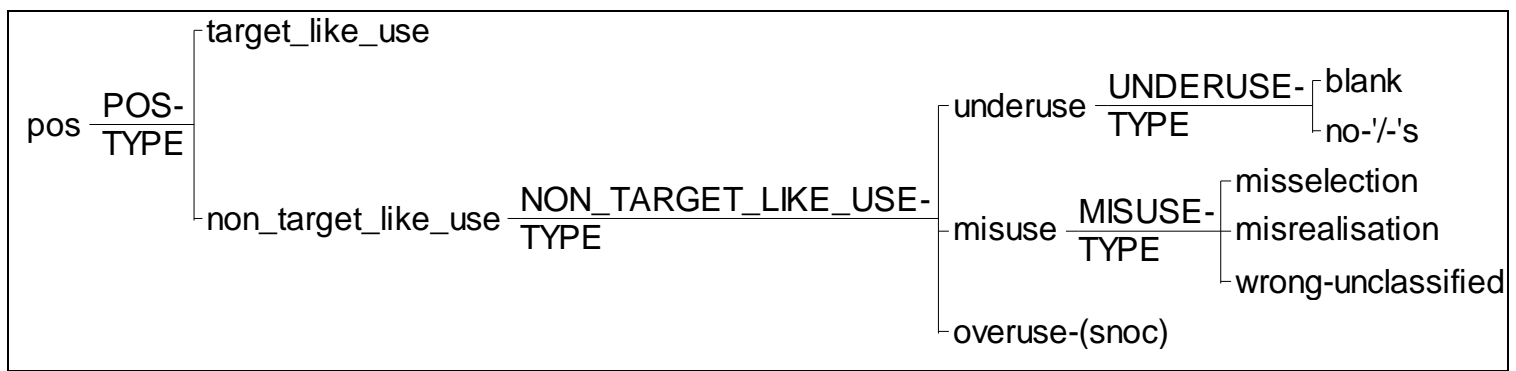

Table 13: Tagset for UAM Corpus Tool_POS_L2 English

\begin{tabular}{|c|c|c|c|}
\hline \multicolumn{3}{|c|}{ OC: Possessive -s (My father's car) } & S: Supplied form \\
\hline \multicolumn{3}{|c|}{$\begin{array}{l}\text { Target-like Use } \\
\text { (correct form supplied) }\end{array}$} & My father's car \\
\hline \multirow{5}{*}{$\begin{array}{l}\text { Non-target-like } \\
\text { Use }\end{array}$} & \multirow{2}{*}{$\begin{array}{l}\text { Underuse } \\
\text { (no form } \\
\text { supplied) }\end{array}$} & Blank & \\
\hline & & No $/ /$ 's & $\begin{array}{l}\text { The boys_- shoes. } \\
\text { My father_ car. }\end{array}$ \\
\hline & \multirow{3}{*}{$\begin{array}{l}\text { Misuse } \\
\text { (incorrect form } \\
\text { supplied) }\end{array}$} & $\begin{array}{l}\text { Misselection } \\
\text { (form exists) }\end{array}$ & $\begin{array}{l}\text { The car of my } \\
\text { father. }\end{array}$ \\
\hline & & $\begin{array}{l}\text { Misrealisation } \\
\text { (form does not } \\
\text { exist) }\end{array}$ & $\begin{array}{l}\text { The boys's } \\
\text { shoes. }\end{array}$ \\
\hline & & $\begin{array}{l}\text { Wrong- } \\
\text { unclassified }\end{array}$ & The shoes boys. \\
\hline \multicolumn{3}{|c|}{ OC: Plural (Kids like toys) } & SNOC \\
\hline & & $\begin{array}{lr}\text { Overuse } & \\
\text { (correct } & \text { form } \\
\text { supplied } & \text { in } \\
\text { NOC) } & \end{array}$ & Kid's like toys. \\
\hline Table & tagging & scheme for & expression \\
\hline
\end{tabular}

possession in L2 English 
3Part III: Tagging scheme in the Possession Expression and the Experimentally Elicited Data in L3 German

In keeping with our choice regarding the tagging scheme in English, we decided to call TLU the use of the synthetic possessive forms in German. That is, both the possessive $-\boldsymbol{s}$ and the genitive case have been tagged as TLU. Our tagging scheme is presented in table 15 below. Accordingly, each of the tagging categories included is exemplified in table 16. The NTLU is further divided into three categories. We called the first underuse to follow the model we used in our learner corpus study. This category marks the lack of use of any possession construction, either synthetic or analytic, in the identified OC. Under the label misuse we have distinguished three subcategories.

(i) The first is called misselection and includes, just like in the case of L2 English, the use of the PP instead of the genitive case. But in German, as we mentioned in section 2.2.2, the use of one of the three forms of attributive possession has specific structural constraints. Therefore, in German, unlike English, we recognise yet another case of misselection, that is, the ungrammatical use of the possessive $-\boldsymbol{s}$ in the cases where a $P P$ or a genitive case is required. The same label (i.e., NTLU: misuse: misselection: possessive $-s$ ) has been attributed also to the cases where the learner has opted for the $\mathrm{PR}>\mathrm{PM}$ instead of the $\mathrm{PM}>\mathrm{PR}$ order (see section 2.2.2 for the significance of these orders in the possession system of German), even if the student has not added the suffix " $-s$ ".

(ii) The second subcategory of misuse includes the two cases of misrealisation, that is the wrong realisation of the possessive $-s$ in German (i.e., -'s) and the wrong genitive form.

(iii) The last subcategory of misuse was called wrongunclassified and includes some exceptional cases that do not fit any other tag. 
The final category of the NTLU is called overuse (also known as sNoc), that contains the cases of correct use of the possession construction in incorrect contexts.

Table 15 presents the tagging scheme in UAM Corpus Tool for the possession in L3 German. As mentioned above, each of the categories is exemplified in Table 16.

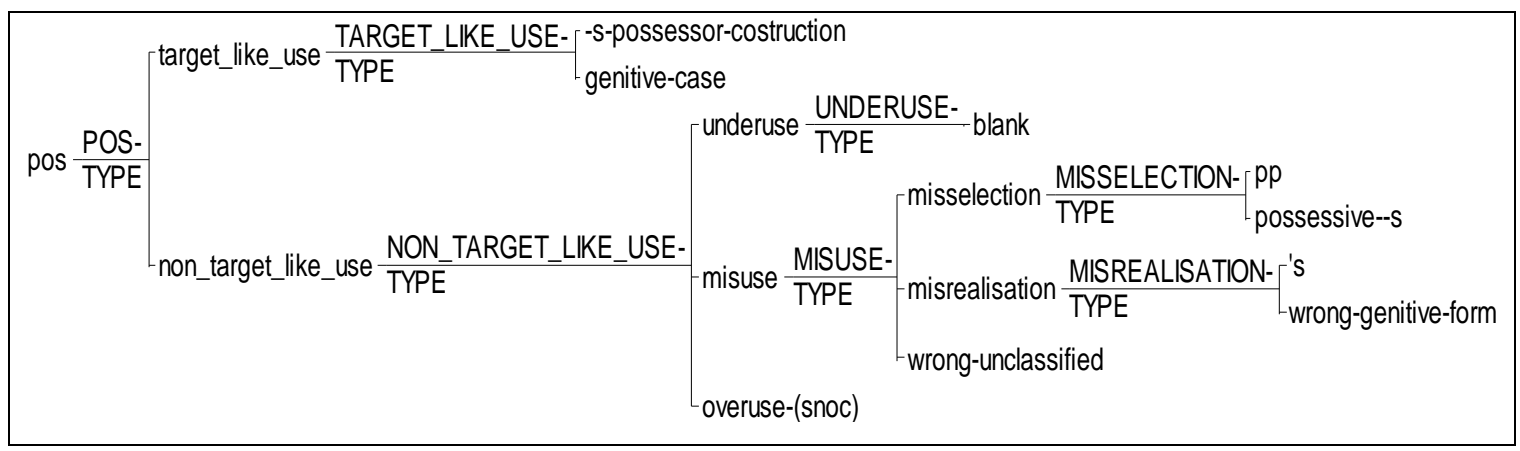

Table 15: Tagset for UAM Corpus Tool_POS_L3 German

\begin{tabular}{|c|c|c|c|c|}
\hline \multicolumn{4}{|c|}{ OC: Possessive -s (My father's car) } & S: Supplied form \\
\hline \multirow{2}{*}{\multicolumn{2}{|c|}{$\begin{array}{l}\text { Target-like Use } \\
\text { (correct form } \\
\text { supplied) }\end{array}$}} & \multicolumn{2}{|c|}{-s-possessor construction } & $\begin{array}{l}\text { Marias Schwester } \\
\text { Lit: Maria's } \\
\text { sister.nom }\end{array}$ \\
\hline & & \multicolumn{2}{|c|}{ Genitive case } & $\begin{array}{l}\text { Der Computer der } \\
\text { Frau } \\
\text { Lit: The.nom } \\
\text { computer.nom } \\
\text { the.gen } \\
\text { woman.gen }\end{array}$ \\
\hline \multirow[t]{3}{*}{$\begin{array}{l}\text { Non-target- } \\
\text { like Use }\end{array}$} & $\begin{array}{l}\text { Underuse } \\
\text { (no form } \\
\text { supplied) }\end{array}$ & \multicolumn{2}{|l|}{ Blank } & $\begin{array}{l}\text { Maria Schwester. } \\
\text { Lit: Maria } \\
\text { sister.nom }\end{array}$ \\
\hline & \multirow[t]{2}{*}{$\begin{array}{l}\text { Misuse } \\
\text { (incorrect } \\
\text { form } \\
\text { supplied) }\end{array}$} & \multirow[t]{2}{*}{$\begin{array}{l}\text { Misselection } \\
\text { (form exists) }\end{array}$} & PP & $\begin{array}{l}\text { Der Computer von } \\
\text { der Frau. } \\
\text { Lit: The.nom } \\
\text { computer.nom of } \\
\text { the.dat } \\
\text { woman.dat }\end{array}$ \\
\hline & & & Pos $-\mathbf{s}$ & Kinders \\
\hline
\end{tabular}




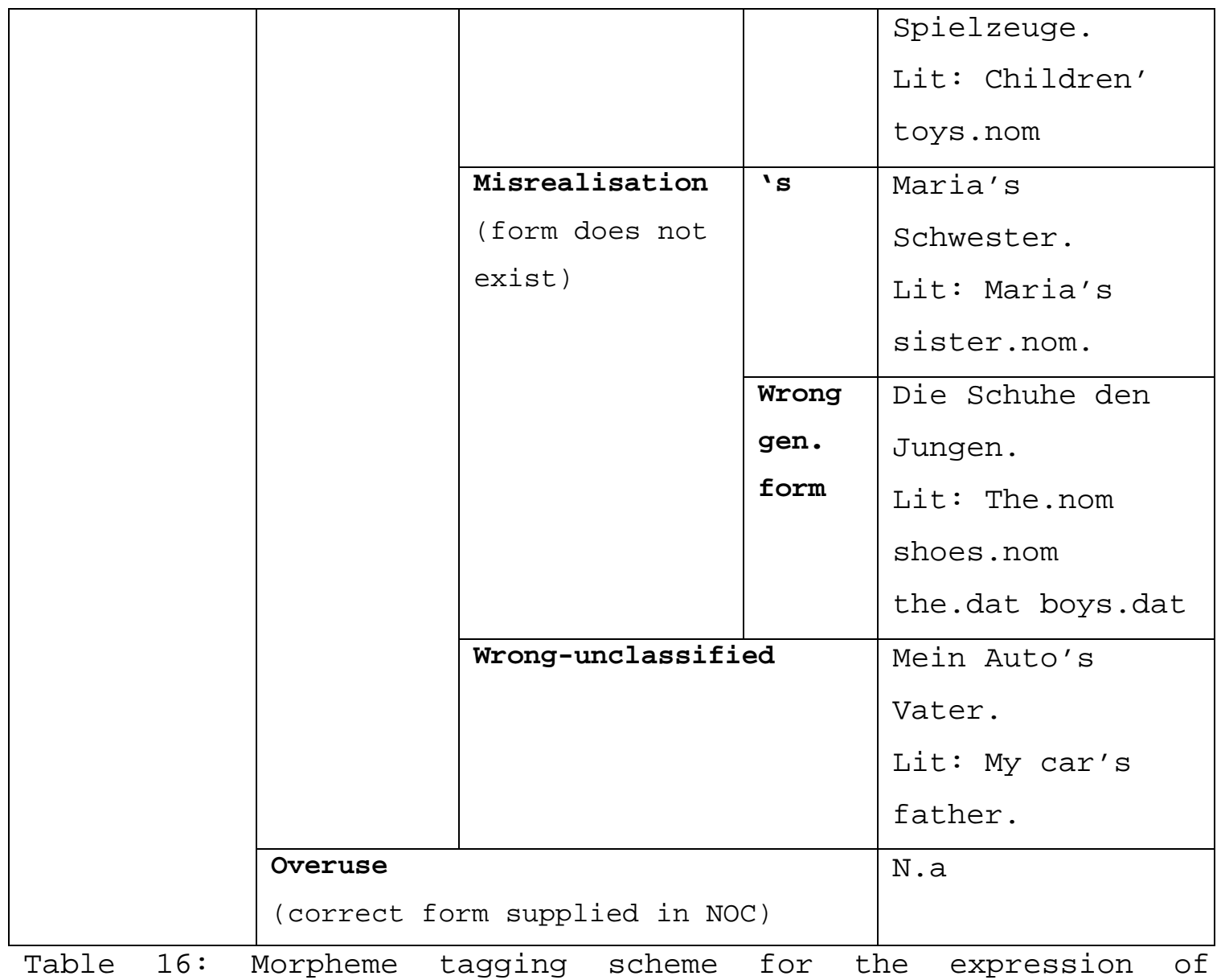

possession in L3 German

\subsubsection{Data scoring}

In order to score our data we followed the guidelines suggested by both Dulay \& Burt (1973) and Pica (1983), that is, we combined the scoring of each suppliance suggested by Dulay and Burt (1973) and the TLU model put forth by Pica (1983). The former implied a weighted scoring according to the following schema :

- 0 points: No suppliance

(he walk__ yesterday) (two child_)

- 0.5 points: Wrong morpheme supplied

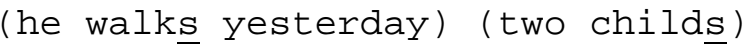

- 1 point: Correct suppliance (he walked yesterday) (two children) 
This was used in the calculation of the suppliance in obligatory context (SOC) and enabled us to include in the accuracy rates the cases of both underuse and misuse. The latter was included because its presence indicates that the student recognises the context as an obligatory one although he/she fails to make the correct choice. In our understanding this implies that the student has initiated the process of acquisition of that particular morpheme and in any case it indicates that his/her interlanguage is undergoing some change, which we consider important to account for.

More specifically, when working with the picture composition task we decided to tag the use of past regular/past irregular or $3^{\text {rd }}$ person singular $-s$ according to the student's initial choice regarding the use of past or present for the narration of the story. So, if the student started narrating using the present tense and then changed to the past tense, we tagged the use of the past as "NTLU: misuse: misselection". To illustrate this we present a short extract from our corpus:

FILE_NAME: B1_2ESO_14_PSR_EAT_APL.txt

This story begins \$_RWU_i at the night \$_RWU_i in Ben's house. Ben is seven years old and he has got a frog and a dog. [...] And he decided to find the frog, because he was sad and alone. [...]

In this regard we also find what Muñoz (2006) observed in her study, that is, students "with higher levels of proficiency tended to narrate the story but often mixing tenses" (p.116). This can be seen in the following section where we present the features of the NTLU for past and present for all proficiency levels.

In our attempt to be as accurate as possible we decided to distinguish between the use of the indefinite vs. definite article, although both are included in one category. Therefore, we tag as "NTLU: misuse: misselection" the use of the definite article when the indefinite article should have been provided, and vice versa. 
Pica's (1983:474) proposal refers to the general calculation pattern, also known as TLU (Target-Like Use), which "penalises" the cases of overuse by including them in the denominator.

$$
\mathrm{TLU}=\frac{\mathrm{SOC}}{\mathrm{OC}+\mathrm{SNOC}}
$$

Thence, after having calculated the suppliance of each morpheme in the corresponding obligatory context following Dulay and Burt's model, we proceeded with calculating the level of targetlike use (TLU) for each morpheme. Note that for the purposes of this study we will be calling soc the final score achieved after having applied the aforementioned calculation processes proposed by Dulay and Burt (1973) and Pica (1983). When we make reference to Brown's (1973) SOC model that will be always accompanied by Brown's name. In the same line, we will be using the term TLU when we study the relative frequency of the morpheme at issue and hence the cases of misuse are not included. As described in section 4.2, we have decided to use this distinction because we will be studying accuracy rates in relation to the acquisition process, as well as accuracy rates in relation to the frequency of use in which we cannot include neither the cases of misuse, which are included in the weighted scoring proposed by Dulay and Burt (1973), nor the cases of overuse, which represent the SNOC in Pica's model.

That is, we ended up with two accuracy indices for measuring the accuracy rates obtained for each morpheme: SOC and TLU. In our study the first is calculated on the basis of the following pattern:

SOC $=\frac{\text { weighted scoring (according to the model of Dulay \& Burt) }}{\text { OC }+ \text { SNOC }} \times 100$ 
The TLU scores indicate the rates of target-like use instances as defined in our tagging schemes in section 5.4.4. In Appendix 9.11 we present in detail the descriptive statistics for each morpheme in all three studies of our project. The aforementioned accuracy indices, i.e. the SOC and the TLU, are also presented there.

Since we had already grouped our subjects according to their proficiency level, we did not calculate a target-like use score for each student but rather for each level. The same process was then followed for the experimentally elicited data in L2 English as well as in L3 German. 


\section{Results and Discussion}

In this section we will present the outcomes of our study and comment on them. That is, we have decided to present the results together with the discussion so as to facilitate the reader's task, given that presenting the results for the three studies, plus a separate section with the implications of each study, would be too distracting.

Consequently, we have divided this chapter in three parts according to the instrument used for the data elicitation and the subjects' L2/L3. In the first part we make reference to the results of our learner corpus study and thence comment on our subjects' accuracy rates and the corresponding morpheme orders. In the second section we present the results of the possessive s accuracy rates in $\mathbf{2}$ English for all proficiency levels. In the final section we present the results of our project that deals with the accuracy rates of each of the three investigated forms of possession constructions in L3 German.

\subsection{Morpheme Order Study in L2 English}

In order to explore the progression followed by subjects with different proficiency levels, comparisons are made between the accuracy rates obtained by each of the following groups: elementary, pre-intermediate, intermediate and upperintermediate. Table 17 shows the accuracy rates and the corresponding rank for each morpheme obtained by each proficiency-level group. The accuracy rates are determined on the basis of our soc formula as described in section 5.4 .5 and are thus indicative of the acquisition level for each morpheme obtained by our subjects. Although accuracy does not equate 
acquisition, we consider that our accuracy rates can be indicative of the latter because we do take into account the cases of misuse, underuse and overuse. Additionally, since we have calculated the accuracy rates for each proficiency level, we are able to check the acquisition process for those morphemes that do not present a linear developmental pattern. For more details regarding the aforementioned features see our discussion in section 3.1.3. Based on the accuracy rates we have determined the rank that each morpheme occupies in each proficiency level. The rank simply indicates that the accuracy rates obtained for one morpheme by one proficiency group are higher (or lower) than the accuracy rates obtained for another morpheme by the same proficiency group. It is in the same way that Brown (1973) defined the mean order of acquisition of L1 English morphemes presented in Table 4 (section 3.1.1). The same is true for the results of every previously conducted MOS bearing on L2/FL English (section 3.1.2). In our study we have found, for example, that our pre-intermediate group obtained higher accuracy rates for the be_copula morpheme than for the be_auxiliary morpheme. According to the percentages obtained the former is ranked in the first position whereas the second in the seventh (see Table 17 below). Note that whenever a "tie", i.e. two identical values, appeared in the data, a joined rank appears in Table 17. This represents the average of the ranks that they would otherwise occupy. Regarding the information displayed in Table 17, we would like to foreground that the empty slots do not imply absence of data, but rather reflect our decision to exclude the cases where our samples were less than 10 (OC>10) according to the criteria followed in previous studies (Muñoz, 2006; Goldschneider \& Dekeyser, 2001), given that a group production of a morpheme lower than 10 is not sufficient data to reach a definite conclusion. Apart from table 17, for a detailed description of the accuracy rates for each morpheme by each of the four proficiency-level groups the reader is referred to Appendix 9.11.1. Note that these are also divided according to the proficiency level of the group studied. Additionally, each 
of these descriptions contains a chart of the relation between TLU and NTLU (as defined in section 5.4.4) for every morpheme.

\begin{tabular}{|c|c|c|c|c|c|c|c|c|}
\hline & \multicolumn{2}{|c|}{ EI } & \multicolumn{2}{c|}{ PI } & \multicolumn{2}{c|}{ I } & \multicolumn{2}{c|}{ UI } \\
\hline FUNCTOR & SOC & Rank & SOC & Rank & SOC & Rank & SOC & Rank \\
\hline ART & 63,63 & $\mathbf{1}$ & 84,05 & $\mathbf{2}$ & 91,74 & $\mathbf{2}$ & 96,53 & $\mathbf{2}$ \\
\hline PAST_IRREG & 44,44 & $\mathbf{2}$ & 55,27 & $\mathbf{5}$ & 71,29 & $\mathbf{6}$ & 88,8 & $\mathbf{4 , 5}$ \\
\hline PAST_REG & 38,46 & $\mathbf{3}$ & 57,18 & $\mathbf{4}$ & 70,79 & $\mathbf{7}$ & 88,8 & $\mathbf{4 , 5}$ \\
\hline 3SG & 5,5 & $\mathbf{4}$ & 21,86 & $\mathbf{9}$ & 17,9 & $\mathbf{9}$ & 0 & $\mathbf{7}$ \\
\hline BE_COP & - & - & 92,46 & $\mathbf{1}$ & 95,67 & $\mathbf{1}$ & 100 & $\mathbf{1}$ \\
\hline ING & - & - & 46,55 & $\mathbf{8}$ & 82,05 & $\mathbf{4}$ & 94,11 & $\mathbf{3}$ \\
\hline BE_AUX & - & - & 47,25 & $\mathbf{7}$ & 79,23 & $\mathbf{5}$ & 100 & $\mathbf{1}$ \\
\hline POS & - & - & 48,61 & $\mathbf{6}$ & 58,57 & $\mathbf{8}$ & 54,54 & $\mathbf{6}$ \\
\hline PLU & - & - & 67,36 & $\mathbf{3}$ & 86,04 & $\mathbf{3}$ & 84,09 & $\mathbf{5}$ \\
\hline
\end{tabular}

Table 17: SOC (accuracy rate) and rank orders for each proficiency level: El (elementary), PI (pre-intermediate), I (intermediate), UI (upper intermediate)

In the above table we can observe how the accuracy order for each morpheme (rank) changes according to the proficiency level. In that respect our study's results agree with Muñoz's (2006) findings that confirmed the influence of the proficiency level on the order of acquisition. In order to check Muñoz's (2006) claim that the accuracy orders of the foreign learners approach the average order "once they have progressed beyond the very elementary levels of proficiency" (p.123), we have compared the ranks achieved by each group to the ones achieved by the sum of all our subjects irrespective of their proficiency level. The results of this comparison are presented in Tables $18(a)$ and 18 (b). The latter displays the soc and rank orders for each group sorted by functor.

\begin{tabular}{|c|c|c|c|c|c|c|}
\hline FUNCTOR & $\begin{array}{c}\text { All } \\
\text { groups } \\
\text { SOC }\end{array}$ & $\begin{array}{c}\text { All } \\
\text { groups } \\
\text { Rank }\end{array}$ & $\begin{array}{c}\text { Elem } \\
\text { Rank }\end{array}$ & $\begin{array}{c}\text { Pre-Int } \\
\text { Rank }\end{array}$ & $\begin{array}{c}\text { Int } \\
\text { Rank }\end{array}$ & $\begin{array}{c}\text { Upper- } \\
\text { Int } \\
\text { Rank }\end{array}$ \\
\hline ART & 87,6 & 2 & 1 & 2 & 2 & 2 \\
\hline PAST_IRREG & 73,7 & 4 & 2 & 5 & 6 & 4,5 \\
\hline PAST_REG & 67,81 & 5 & 3 & 4 & 7 & 4,5 \\
\hline 3SG & 19,96 & 9 & 4 & 9 & 9 & 7 \\
\hline
\end{tabular}




\begin{tabular}{|c|c|c|c|c|c|c|}
\hline BE_COP & 93,95 & 1 & - & 1 & 1 & 1 \\
\hline ING & 67,56 & 6 & - & 8 & 4 & 3 \\
\hline BE_AUX & 65,02 & 7 & - & 7 & 5 & 1 \\
\hline POS & 53,52 & 8 & - & 6 & 8 & 6 \\
\hline PLU & 75,8 & 3 & - & 3 & 3 & 5 \\
\hline
\end{tabular}

Table 18(a): SOC and rank orders comparison

\begin{tabular}{|l|l|l|l|l|}
\hline All groups & $\begin{array}{c}\text { Elementary } \\
\text { Group }\end{array}$ & $\begin{array}{c}\text { Pre- } \\
\text { Intermediate } \\
\text { Group }\end{array}$ & $\begin{array}{l}\text { Intermediate } \\
\text { Group }\end{array}$ & $\begin{array}{r}\text { Upper- } \\
\text { Intermediate } \\
\text { Group }\end{array}$ \\
\hline BE_COP & ART & $\begin{array}{l}\text { BE_COP } \\
\text { ART }\end{array}$ & $\begin{array}{l}\text { BE_COP } \\
\text { ART } \\
\text { PLU }\end{array}$ & PLU \\
PAST_IRREG & PAST_IRREG & PAST_REG & ING & BE_COP/AUX \\
PAST_REG & PAST_REG & PAST_IRREG & BE AUX \\
ING & & POS & PAST_IRREG & PLU \\
\hline BE_AUX & & BE_AUX & PAST_REG & PAST_IRREG \\
\hline POS & & ING & POS & POS \\
\hline 3SG & 3SG & 3SG & $3 S G$ & 3SG \\
\hline
\end{tabular}

Table $18(\mathrm{~b})$ : SOC and Rank orders comparison (sorted by functor)

In Table $18(\mathrm{~b})$ we can see that the be-copula morpheme comes first for all groups except for the Elementary Level group for which we had not enough examples and hence excluded it from our study. The article and the 3SG morphemes on the other hand seem to be stable in all groups, including the generic one (i.e., the group in which no distinction on grounds of the subjects' proficiency level was made). Past regular and past irregular appear simultaneously and occupy close positions in all groups. We will consider these two morphemes in detail below, but we wish to make a comment here bearing on the influence of the proficiency level. If we check the ranks occupied by past irregular and past regular in the generic group, we see that the former presents higher accuracy rates. This, however, can be misleading since the regular and the irregular morphology of the past tense in English interchange in a way their positions in 
the different proficiency levels as our other groups rates reveal.

We can, therefore, claim that Tables $18(\mathrm{a})$ and $18(\mathrm{~b})$ show the influence that the proficiency level exerts on the rank orders. Apart from our comment on the regular past and the irregular past ranks, we can also appreciate that there is a difference between the accuracy rates obtained by all our subjects (i.e. if we do not group them by proficiency level) and the corresponding rates obtained by the proficiency-level groups. Indeed, only the be-copula, the article and the $3 S G$ functors are ranked in similar positions by all proficiency-level groups and by the generic group. Note that although the $3 S G$ morpheme is ranked fourth (4) in our Elementary Group, it is still the morpheme with the least accuracy rates. To that observation we would like to add that there seems to be a high correlation between the average order, as presented by the results of our generic group, and the ones achieved by the more advanced students especially those that belong to the intermediate level. We can not consider the total number of subjects as an influential factor here, mainly because both the pre-intermediate and the upperintermediate groups include an equally high number of participants as shown in Table 6(section 5.2). In that line we can argue that our study confirms Muñoz's claim that the average order appears beyond the elementary level.

Perhaps a more interesting conclusion can be reached through the observation of the data shown in Tables 17 \& 18 regarding the Ushape development of the past irregular morpheme. Obviously, this observation can be made only when the proficiency level is taken into account, proving thus the relevant criticism of the first MO studies right. This, as we already mentioned, was related to the central assumption of Brown's (1973) SoC model that when a morpheme is being accurately used then it is also acquired (see sections 3.1 .1 and 3.1.3). In relation to this developmental pattern Ellis and Barkhuizen (2005) say that 
[...] when learners acquire English past irregular they frequently pass through an early stage of acquisition where they use some irregular forms correctly only to replace these later on with overgeneralised -ed forms [...] (p.77)

The results of our study yield a similar pattern. Indeed, in the elementary level the $\operatorname{SOC}^{8}$ percentage of the past regular morpheme is lower than that of the past irregular morpheme. In the following stage (pre-intermediate) the regular morphology surpasses the SOC percentage of the past irregular morpheme, only to fall back to a lower rank in the intermediate level. In the upper-intermediate level the differences are nil; indeed the percentage is exactly the same for both morphemes. The movement we just described can be appreciated in the Figure 9.

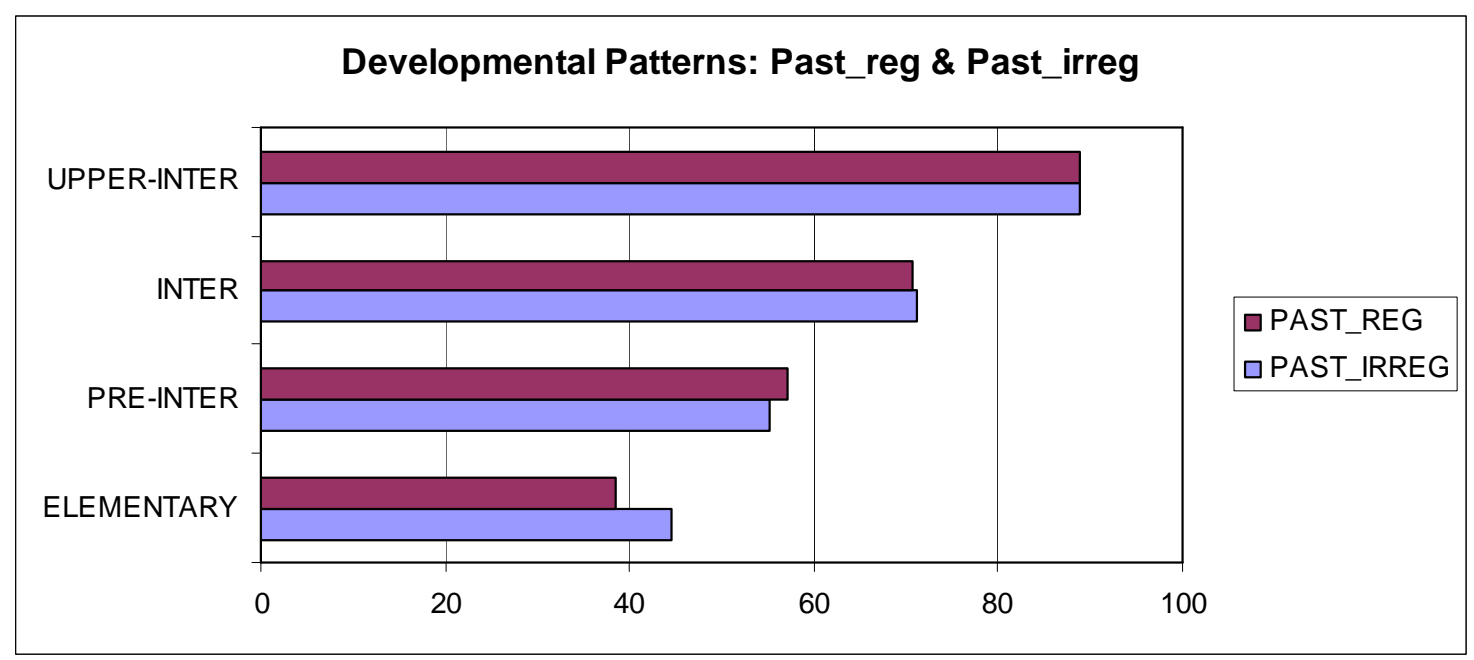

Figure 9: U-shape movement of the past irregular morpheme as seen by the comparison of the past regular and the past irregular accuracy rates.

Another interesting finding that results from our MOS project regards the morpheme accuracy orders for each proficiency level. We will not call it acquisition, as we just described that accuracy does not necessarily imply acquisition. We shall repeat, however, that the similarities in the route followed can be indicative of the acquisition order at each proficiency level

8 Note that we refer to the soc percentages calculated according to our scoring formula which includes Dulay and Burt's (1973) weighted scoring and uses Pica's (1983) TLU model. For more details we refer the reader to our section 5.4 .5 . 
since we count with a large number of learner language data (corpus) and we have taken into account features that most of the first MO studies ignored (such as the cases of underuse, misuse and overuse or the subjects' proficiency level). If we observe the accuracy rates for each of our four groups (i.e. from Elementary to Upper-Intermediate) in Table 17 we can see that there are certain commonalities in the development of the morpheme accuracy orders obtained by each proficiency group. This similar way of development is perhaps easier to appreciate in the chart displayed in Figure 10 .

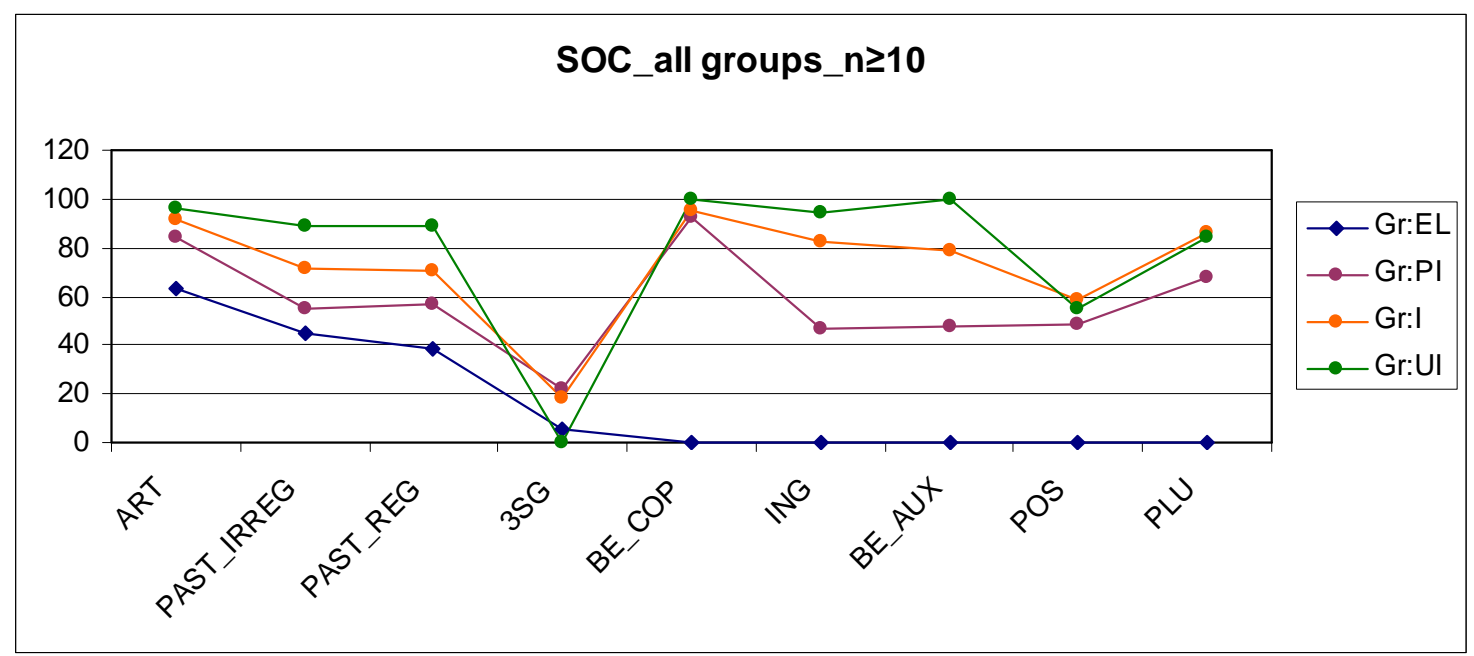

Figure 10: Accuracy order for each group (note that $\mathrm{n} \geq 10$ )

In the above figure we can appreciate that the development of the morphemes' accuracy is similar for all four groups. There are differences in the rates obtained but in terms of the route followed the pattern displayed by each group is similar. We wish thus to repeat here the quote by Larsen-Freeman and Long (1991) where they affirmed that the observed similarities can not be ignored since they imply that "There is something moving in the bushes" (p.92).

The only significant differences are to be found in relation to the past irregular and the past regular morphemes on one hand and the progressive -ing and be auxiliary morphemes on the other. The former is explained by the U-shape developmental pattern as described above. The latter, however, requires our attention. In 
relation to the progressive -ing and the be_auxiliary morphemes we only have data for the three more advanced groups, that is, the pre-intermediate (PI), the intermediate (I) and the upperintermediate (UI). The last two groups exhibit the same accuracy order. In other words, at the intermediate and upperintermediate levels students seem to use more accurately the progressive -ing and be auxiliary morphemes than the past irregular and the past regular morphemes. On the contrary, students at the pre-intermediate level seem to use more accurately the past irregular and the past regular morphemes than the progressive -ing and be auxiliary. So, we could say that, in relation to these four morphemes, the pre-intermediate group follows the route: "past_reg" $\rightarrow$ "past_irreg" $\rightarrow$ "be_aux" $\rightarrow$ "-ing", the intermediate group follows the route "be_aux" $\rightarrow$ "ing" $\rightarrow$ "past_irreg" $\rightarrow$ "past_reg" and the upper-intermediate group follow the route: "-ing" $\rightarrow$ "be_aux" $\rightarrow$ "past_reg"/"past_irreg". Table 19 displays the routes described for each group.

\begin{tabular}{|l|l|l|l|l|}
\hline Level & Morpheme & Morpheme & Morpheme & Morpheme \\
\hline PI & past_reg & past_irreg & be_aux & Progr_ing \\
\hline I & be_aux & progr_ing & past_irreg & past_reg \\
\hline UI & Progr_ing & Be_aux & past_irreg/reg \\
\hline
\end{tabular}

Table 19: Route of accuracy obtained in four morphemes (past_reg, past_irreg, be_aux, progr_ing)

If we add to that route the accuracy rates of the copula be and the 3SG, then we can create a table exhibiting the accuracy order for all the verb-related morphemes studied in our project.

\begin{tabular}{|l|l|l|l|l|l|l|}
\hline Level & Morpheme & Morpheme & Morpheme & Morpheme & Morpheme & Morpheme \\
\hline PI & Cop_be & $\begin{array}{l}\text { Past_ } \\
\text { Reg }\end{array}$ & $\begin{array}{l}\text { Past_ } \\
\text { Irreg }\end{array}$ & Be_aux & $\begin{array}{l}\text { Progr_ } \\
\text { Ing }\end{array}$ & 3SG \\
\hline I & Cop_be & Be_aux & $\begin{array}{l}\text { Progr_ } \\
\text { Ing }\end{array}$ & $\begin{array}{l}\text { Past_ } \\
\text { irreg }\end{array}$ & $\begin{array}{l}\text { Past_ } \\
\text { reg. }\end{array}$ & $3 \mathrm{SG}$ \\
\hline UI & Cop_be & $\begin{array}{l}\text { Progr_ } \\
\text { Ing }\end{array}$ & Be_aux & $\begin{array}{l}\text { Past_ } \\
\text { irreg/ } \\
\text { reg }\end{array}$ & & 3SG \\
\hline
\end{tabular}

Table 20: Route of accuracy of the verb-related morphemes 
If we transcribe the route shown in Table 20 according to the syntactic properties of each of the morphemes we will end up having the following schema:

(1) PI: Copula $\rightarrow$ tense ( \pm past) $\rightarrow$ aspect ( \pm progressive) $\rightarrow$ subject-verb agreement ( \pm 3 rd person singular)

(2) I/UI: Copula $\rightarrow$ aspect ( \pm progressive) $\rightarrow$ tense ( \pm past) $\rightarrow$ subject-verb agreement ( \pm 3 rd person singular)

The second pattern clearly fits to the schema proposed by Hawkins (2001) and Andersen (1978). The first, however, is slightly different, exhibiting higher accuracy levels in the use of the tense (tpast) in comparison to the accurate use of the aspect ( \pm progressive). Two explanations could be suggested for this phenomenon. The first would argue that the pattern displayed above by the students of the pre-intermediate level is due to the fact that our data elicitation task implied the telling of a story and thus directed the students towards the use of the past tense morphemes. Although we do admit that the instrument drastically influences the results, we do not consider this explanation to be very solid for two reasons. First, because the aforementioned accuracy rates are calculated as percentages after we assured that for each of the morphemes the minimum number of samples would be equal or higher than 10 and thence the assumed difference caused by the number of oc for each morpheme would immediately vanish. Second, because the same instrument was used with all our groups and yet the intermediate and the upper-intermediate level groups exhibit a different pattern. Therefore, the first option, although rational, cannot stand alone as an explanatory model of the described difference in route between the pre-intermediate group on the one hand and the intermediate and the upper-intermediate groups on the other.

We believe that our second explanation can more adequately account for this variance in route. It is related to the actual process of L2 acquisition. In that sense the aforementioned difference could be explained by the fact that in initial stages 
L2 students produce output based on rote memory of individual words containing the past tense morpheme, that is, they learn the past forms as chunks. But when their IL goes through a restructuring period to accommodate additional features related to the expression of the past tense they incorrectly omit it. The same was argued by Lightbown (1983) in relation to the accurate use of the progressive morpheme. This idea proves Andersen's (1978) and Hawkins' (2001) claim right. Since the underlying syntactic properties related to the tense ( \pm past) are more difficult than the ones found in the aspect ( \pm progressive), as soon as the learner passes the stage of the memorization the accuracy order is reversed and fits the pattern proposed by Hawkins (2001) and Andersen (1978) and found in our study for the intermediate and the upper-intermediate levels.

This claim is also supported by the dual-system model suggested by Ullman $(2001 ; 2005)$ in relation to the use of declarative and the procedural memory system in language acquisition. The former "[...] underlies the mental lexicon, whereas the procedural system subserves aspects of the mental grammar" (Ullman, 2001:718). His study shows that the forms of the irregular past are stored in the declarative memory, whereas the composition of regular forms is subserved by the procedural memory. Obviously, this does not imply that the declarative memory is not in use, but rather that the composition of the regular forms requires the activation of the memory system responsible for the mental grammar, i.e. the procedural memory. Ullman's model is supported by the U-shape pattern that the acquisition of the past irregular follows. The latter indicates that in initial stages students memorize, using their declarative memories, and are therefore more accurate in the production of the irregular forms, whereas in higher proficiency levels this is reversed because students proceed in the actual manipulation of the language by means of the procedural memory system. In that higher stage the aspect ( \pm progressive) based on a more regular and thus easier set of rules, displays high accuracy rates, whereas the tense ( \pm past) based on a more complex and hence difficult set of rules 
exhibits low accuracy rates. On the contrary, in initial stages the use of the aspect and the tense morphemes rely on the use of the declarative memory and on which of the morphemes the student has best memorized.

If this rationale is right then the elementary group should display a similar pattern. As we mentioned before, we have decided to exclude the rates for those morphemes of which the overall number of samples was lower than $10(n<10)$. At the elementary level these also included the use of the morphemes related to the aspect. However, we will present them in the following Table (No 21) and the corresponding chart (Figure 11) in order to see the elementary students' performance in relation to the verb-related morphemes.

\begin{tabular}{|l|c|c|c|c|}
\hline Functor & Gr:El & Gr:PI & Gr:I & Gr:UI \\
\hline BE_COP & 75 & 92,46 & 95,67 & 100 \\
\hline PAST_IRREG & 44,44 & 55,27 & 71,29 & 88,8 \\
\hline PAST_REG & 38,46 & 57,18 & 70,79 & 88,8 \\
\hline ING & 33,3 & 46,55 & 82,05 & 94,11 \\
\hline BE_AUX & 33,3 & 47,25 & 79,23 & 100 \\
\hline 3SG & 5,5 & 21,86 & 17,9 & 0 \\
\hline
\end{tabular}

Table 21: Accuracy rates (SOC) of the verb-related morphemes obtained by all four groups

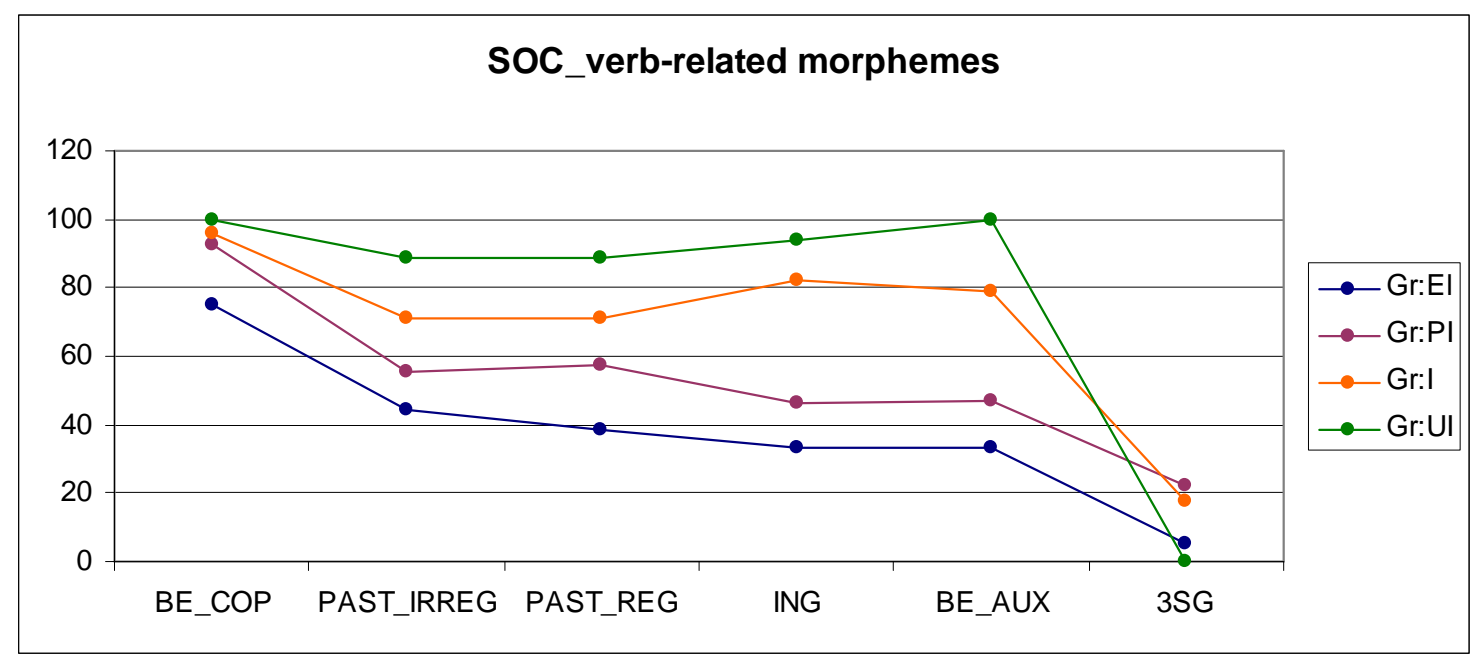

Figure 11: Accuracy rates (SOC) of the verb-related morphemes obtained by all four groups 
Indeed, as we can see in Table 21 and in its chart (fig. 11), the very initial stages, namely the elementary and the preintermediate display the same route regarding the use of the verb-related morphemes as shown in the SOC scores. The same is true for the two higher levels, that is, the intermediate and the upper-intermediate. Hence we can affirm that Hawkins' (2001) schema works in higher proficiency levels since it is there that students actually proceed in the composition of linguistic forms. In former stages, Hawkins' (2001) pattern is observed only partly due to the extended use of the declarative memory system, which disregards the actual difficulty of each morpheme based on the underlying structural properties.

Salience could account for the perceived "preference" of the students to memorize irregular past first, then regular past and finally the aspect. Note that this was one of the variables predicting accuracy in MO studies that Goldschneider and Dekeyser (2001) included in their meta-analysis as mentioned in section 3.1.2. In their study salience is defined as the ease with which a morpheme is perceived. They state that the perceptual salience of the morphemes reviewed in their metaanalysis was calculated on the basis of "[...] the number of phones, the presence/absence of a vowel in the surface form, and the total relative sonority of the functor" (Goldschneider and Dekeyser, 2005:23). They also mention "stressed/unstressed and serial position" (Goldschneider and Dekeyser, 2005:23) as possible subfactors composing the score of perceptual salience, but they do not include them in their study. In our study we do not determine the score of perceptual salience for each of the aforementioned morphemes but we understand that they all share these factors. It may be true that progressive -ing and past -ed are placed at the end and that gives them an asset in comparison to the irregular past morpheme as argued by Slobin (1971, cited by Goldschneider and Dekeyser, 2005:22). Nevertheless, irregular past is stressed and that could counterbalance the effect of serial position exhibited by the progressive -ing and the past regular. In order to conclude regarding the role of perceptual 
salience on the accuracy rates obtained for each of the verbrelated morphemes at issue, we need to determine the score of the perceptual salience according each of the aforementioned subfactors. We consider that this surpasses the limits of the present paper, and hence would have to deal with it in a separate study. Another possible explanation is classroom input, in that in initial stages most of the classroom talk relates to what students did, saw, etc., and thus provides the learners with more opportunities not only to receive input in relation to the past tense morphemes but also to use them and hence memorize them. That would partly correspond to what Goldschneider and Dekeyser call frequency in the input which is defined as "[...] the number of times a given structure occurs in speech addressed to the learner" (Goldschneider and Dekeyser, 2001:29). In the same line, the irregular past morpheme is more likely to receive frequent teacher feedback. This would probably correspond to the "other factors that cause some parts of the input to become salient" as Dulay and Burt suggested (1978, cited by Goldschneider and Dekeyser, 2001:22). We do agree with Goldschneider and Dekeyser (2001) in that a combination of factors is responsible for the accuracy rates in each morpheme obtained by L2/FL students (see section 3.1.2 for more details), but, as we mentioned above, the determination and study of each of the proposed factors exceeds the scope of this paper.

\section{Additional morpheme order analysis: our study compared to previous research}

In the first part of the present sub-section we have presented and commented only on our study's results. We would like to compare our learner corpus-based study to the findings of previous morpheme order studies. For this purpose we will use the studies by Muñoz (2006), Lightbown (1983), Dulay and Burt (1974) and Krashen et al. (1977). The last two are included as representative of the first MO studies in EsL contexts. The other two are included because they are both MO studies of EFL and in that aspect they share a fundamental element with our 
study. Additionally, our study and Muñoz's study also share the distinction between proficiency levels and the subjects' L1 (Spanish).

The following table includes the results of each of these studies as well as of our study. We should remind here that Muñoz's groups A1, B1, D1, D2, A3 \& B3 were constructed on the basis of the onset age and their proficiency level according to the hours they had been exposed to English.

\begin{tabular}{|c|c|c|c|c|c|c|}
\hline FUNCTOR & $\begin{array}{c}\text { Krashen 's } \\
\text { rank }\end{array}$ & $\begin{array}{c}\text { Dulay\& } \\
\text { Burt's } \\
\text { rank }\end{array}$ & $\begin{array}{c}\text { Light } \\
\text { bown' } \\
\text { s } \\
\text { rank }\end{array}$ & $\begin{array}{c}\text { Muñoz's } \\
\text { A1 rank }\end{array}$ & $\begin{array}{c}\text { Muñoz's } \\
\text { B1 rank }\end{array}$ & $\begin{array}{c}\text { Elem } \\
\text { rank }\end{array}$ \\
\hline ING & 1 & 3 & 3,5 & 3 & 5 & - \\
\hline PLU & 2 & 8 & 3,5 & 1 & 1,5 & - \\
\hline BE_COP & 3 & 2 & 2 & 2 & 1,5 & - \\
\hline BE_AUX & 4 & 5 & 5 & - & 4 & - \\
\hline ART & 5 & 1 & 1 & 4 & 3 & 1 \\
\hline PAST_IRREG & 6 & 7 & - & - & - & 2 \\
\hline PAST_REG & 7 & 6 & - & - & - & 3 \\
\hline 3SG & 8 & 9 & 6 & 5 & 6 & 4 \\
\hline POS & - & 8 & - & - & - & - \\
\hline
\end{tabular}

\begin{tabular}{c|c|c|c|c|c|c|c|c|}
\hline FUNCTOR & $\begin{array}{l}\text { Muñoz's } \\
\text { A3 rank }\end{array}$ & $\begin{array}{l}\text { Muñoz's } \\
\text { D1 rank }\end{array}$ & $\begin{array}{l}\text { Muñoz's } \\
\text { B3 rank }\end{array}$ & $\begin{array}{c}\text { Muñoz's } \\
\text { D2 rank }\end{array}$ & $\begin{array}{c}\text { Pre- } \\
\text { inter } \\
\text { rank }\end{array}$ & $\begin{array}{c}\text { Inter } \\
\text { rank }\end{array}$ & $\begin{array}{c}\text { Upper- } \\
\text { inter } \\
\text { rank }\end{array}$ \\
\hline ING & 5 & 5 & 5 & 4 & 8 & 4 & 3 \\
\hline PLU & 2 & 2 & 1 & 2 & 3 & 3 & 5 \\
\hline BE_COP & 1 & 1 & 2 & 1 & 1 & 1 & 1 \\
\hline BE_AUX & 3 & 4 & 3,5 & 5 & 7 & 5 & 1 \\
\hline ART & 4 & 3 & 3,5 & 3 & 2 & 2 & 2 \\
\hline PAST_IRREG & 6 & 6 & 6 & 6 & 5 & 6 & 4,5 \\
\hline PAST_REG & 7 & 7 & 7 & 7 & 4 & 7 & 4,5 \\
\hline 3SG & 8 & 8 & 8 & 8 & 9 & 9 & 7 \\
\hline POS & - & - & - & - & 6 & 8 & 6 \\
\hline
\end{tabular}

level groups, Muñoz's groups, Lightbown's group and Krashen's average order. 
DComparison between Muñoz's (2006) data and our data:

At first it seems that our accuracy orders are very different from the findings of the other studies. Nonetheless, a more careful examination of the data reveals a correlation especially between the accuracy rates of our pre-intermediate to upperintermediate groups and those found in Muñoz's A3, B3, and D2 groups. There are only a few differences, like the order for the be_auxiliary in which our groups and Muñoz's groups do not correlate, or the rank of the progressive -ing functor in our pre-intermediate group which is different, but the rest of the groups do correlate.

The upper-intermediate group in our case also shows orders different to those of Muñoz's high proficiency level group. Two explanations could be offered for such a divergence. The first is the small number of upper-intermediate items that we have obtained in our study. The second explanation is that Muñoz (2006) determines the proficiency level of her subjects on the basis of the hours of exposure to the target language according to which the most proficient group has been exposed to English during 726 hours. This could correspond to our intermediate group. Indeed, Muñoz (2006) presents three proficiency levels starting from the elementary one. Therefore, we can assume that there is a correspondence, in terms of proficiency level, between Muñoz's (2006) groups and our groups as seen in Table 23. The chart of the accuracy rates for each proficiency correspondence displayed in Table 23 is seen in Figure 12 .

\begin{tabular}{|l|l|}
\hline Muñoz's (2006) groups & Our groups \\
\hline $\begin{array}{l}\text { A1, B1, D1: 200h of exposure to } \\
\text { the target language }\end{array}$ & $\begin{array}{l}\text { Elementary Group (El) } \\
\text { Elementary level scored in the } \\
\text { placement test }\end{array}$ \\
\hline $\begin{array}{l}\text { D2: 416h of exposure to the } \\
\text { target language }\end{array}$ & $\begin{array}{l}\text { Pre-intermediate Group (PI) } \\
\text { Pre-intermediate level achieved } \\
\text { in the placement test }\end{array}$ \\
\hline A3, B3: 726h of exposure to the & Intermediate Group (I) \\
target language & Intermediate level scored in \\
\hline
\end{tabular}




\begin{tabular}{|l|l|}
\hline & the placement test \\
\hline- & Upper-intermediate Group \\
& Upper-intermediate level scored \\
& in the placement test \\
\hline
\end{tabular}

Table 23: A comparison of our subjects' composition and the one found in Muñoz's (2006) study
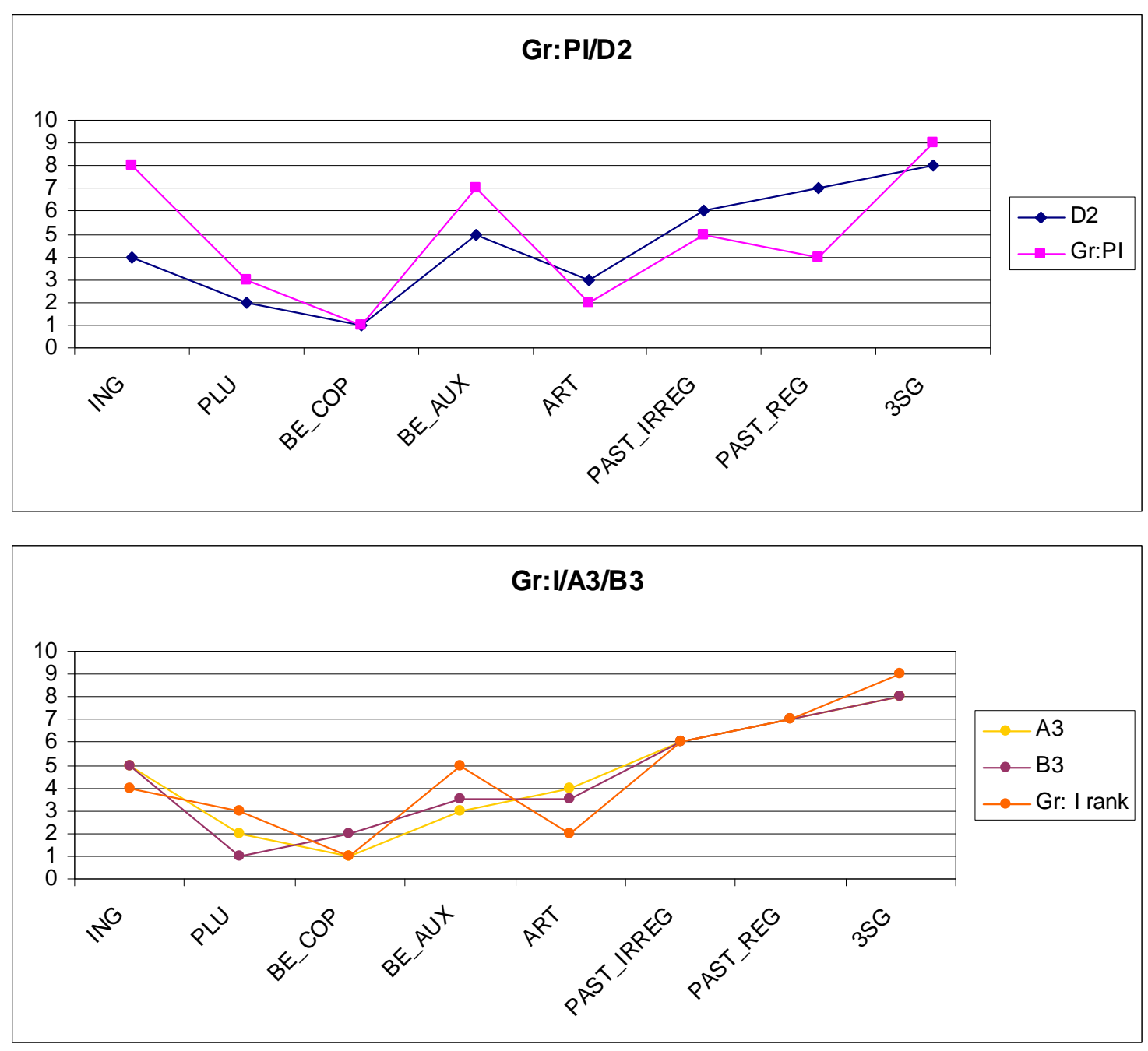

Figure 12: Comparison of the accuracy rates obtained by the preintermediate and the intermediate groups in Muñoz's study and in our project

In Figure 12 we can better appreciate the commonalities in the orders that each group exhibits. There are differences in the actual rates obtained but in general the routes are similar. Note that our upper-intermediate group had no equivalent in Muñoz's study, since we brought Muñoz's groups together on the basis of the hours of exposure to the target language. Additionally, we do not present a comparison between our 
elementary group and Muñoz's A1, B1 and D1 groups because in every case there are many rates that have been excluded (due to the " $n \geq 10$ " condition followed in both studies) so an actual chart is impossible. Furthermore, we have already proved, as Muñoz did before, that proficiency level is highly influential and the average rates appear beyond the very initial stages.

We could therefore say that our study does correlate with the results of the other EFL study that grouped the subjects according to proficiency level. Any differences found could be explained by the fact that we have not grouped our subjects according to the onset age, which could have influenced the final data. Additionally, the difference displayed in relation to certain verb-related morphemes among our pre-intermediate group and Muñoz's D2 group could probably have been caused by the difference on the two groups' age of onset as well as age of testing. For more details we refer the reader to section 5.2 where we present the subjects of our learner corpus as well as to the relevant discussion previously displayed (section 6.1). Another explanatory factor could be the data collection method: oral in Muñoz's study and written in our case. Differences between previous studies (see for example Perkins \& LarsenFreeman vs. Dulay \& Burt, section 3.1.2) have been explained in a similar way based on the fact that speaking and writing are influenced by different sociolinguistic and psycholinguistic conditions (Ellis: 1994).

\section{Comparison between Lightbown's (1983) data and our data:}

A first comparison of our findings with Lightbown's rank would yield a sole correlation between her group's orders and our elementary group's orders for just two functors. On the other hand, these are the only two functors with data that are common in both studies. That is, the only two functors common in the data for our elementary group and in Lightbown's study are the article and the 3SG. For both groups (i.e., our elementary group and Lightbown's group) the article morpheme comes first in rank, whereas the $3 S G$ morpheme comes last. Indeed, further examination 
of Lightbown's findings in relation to our other groups' orders leads to the conclusion that there is no correlation. This could be explained by the fact that Lightbown's group consists only of Grade 6 learners but no further distinction is made with regard to the subjects' proficiency level.

3Comparison between Dulay \& Burt's (1974) and Krashen's (1977a) data and our data:

In relation to the correspondence between our orders and those suggested by the first MO studies as seen by Dulay \& Burt's and Krashen's example, we should say that our findings do not generally support the order suggested by these scholars. It is true that regarding some functors we do find similarities in the accuracy rates, but that cannot be regarded as significant of the overall order suggested. In that sense, we disagree with Wagner's (2005) claim that her study provides evidence that "the acquisition order of the grammatical morphemes by English as a Foreign Language learners is similar to the order of English as a Second Language learners" (p.34). Wagner compares her findings with those put forth in the study of Dulay and Burt (1974) and she indeed finds a significant correlation between the two studies' findings. But that correlation regards only 3 out of the 9 morphemes investigated by Dulay and Burt. Hence, even though there is a significant correlation regarding these 3 morphemes, we disagree with her decision to extend said relationship to the accuracy order of the grammatical morphemes in EFL as the aforementioned quote suggests. Indeed, we also find commonalities between our findings and the ones suggested by Dulay and Burt (1974b) regarding three morphemes (3SG, Art, Pos). Furthermore, we could say that there is a relative correlation between our findings and the order suggested by Krashen (1977a) as displayed in Figure 2. We say that there is a relative correlation because again there are similarities in relation to some morphemes only. We shall, however, say that the difference between the average orders proposed by Krashen and Dulay and Burt, on the one hand, and our orders, on the other hand, can probably be explained by the fact that their study was 
an ESL study whereas ours was an EFL study. The proficiency level does not seem to be influential since, if we compare Krashen's average order (Table 22) and the orders of our general group for which we have not taken into account the subjects' proficiency level (Table 18a), we see that there is still no correlation except maybe for the case of the 3 SG functor. Another possible explanation could be the influence of the data elicitation instrument or even the scoring method. Indeed, Pica's (1983) calculation model (included in our study's scoring) gives lower scores than those achieved by Brown's (1973) model (used in the other two studies). For more details regarding Brown's (1973), Pica's (1983) and our calculation model see section 5.4.5. In relation to the influence of the scoring method on the accuracy rates and thus the morpheme orders obtained we refer the reader to our discussion in section 3.1 .3 .

Let us focus now in more detail on the results regarding the genitive $-s$ morpheme in the L2 English sentence transformation task.

\section{2 Genitive $-s$ in I2 English}

Before presenting the results of our second study, we would like to remind that the majority of our findings regarding the accuracy rates of the possessive $-s$ have resulted from our sentence transformation task and hence represent experimentally elicited data (see sections 5.1, 5.1.1 \& 5.1.2 for a discussion of corpus vs. experimental data). Recall that the idea of using an elicitation task like this was justified by the low rates of genitive $-s$ produced in the corpus, due to the nature of the corpus task. In this section, we shall present the results of our experimentally elicited data and then compare them to the corresponding findings from our learner corpus.

In relation to the use of the possessive -s morpheme we wish to investigate two issues:

(i) The first is Krashen's (1978) claim that discretepoint grammar tests, in which learners' formal 
knowledge is appointed, will show the order of learning, whereas the naturally produced language will be displaying different order of acquisition (that is, different according to Krashen). If his claim is right then the soc rates for the possessive $-s$ in our learner corpus will be significantly different from those obtained in our sentence transformation task.

(ii) The second question relates to the $\mathbf{L} \mathbf{2}$ learner preference for the analytic form of expressing the possession, that is to say, the use of the $\boldsymbol{P} \boldsymbol{P}$ construction. This preference is assumed by the fact that in the first MO studies the synthetic form of possession, i.e. the possessive $-s$, occupies one of the last position in their morpheme acquisition orders.

Note that regarding the first question we will be comparing the soc scores since we wish to check the acquisition order, whereas the TLU scores will be contrasted to the NTLU rates in relation to our second question, where we will be studying the frequency rates (for more details regarding this distinction please check section 5.4 .5$)$.

Question 1 (Will different methods yield different soc rates?). Table 24 displays the accuracy rates of the possessive -s obtained by all our groups in the sentence transformation task. A detailed description of the TLU and NTLU rates along with their chart and a full account of the NTLU types are displayed in Appendix 9.11.2. 


\begin{tabular}{|l|l|l|}
\hline \multicolumn{1}{c|}{ Group } & SOC & OC \\
\hline Gr: El & 44,44 & 108 \\
\hline Gr: PI & 67,92 & 636 \\
\hline Gr: I & 90,09 & 606 \\
\hline \multirow{2}{*}{ Table } & 90,59 & 186 \\
\cline { 2 - 4 } & Gr: UI SOC Scores for possessive $-s$ in the sentence
\end{tabular}

transformation task

Based on the data presented in the table above we can affirm that the accuracy orders for the possessive $-s$ are very high in the three groups that correspond to higher proficiency levels. In that sense, Muñoz's (2006) claim that the proficiency level is "a stronger determinant factor" (p.122) is confirmed also by the results of our experimentally elicited data. However, if we wish to check the influence of the instrument on the actual results and hence study Krashen's hypothesis on the learning/acquisition distinction we should compare the results displayed in Table 24 to the relevant accuracy rates obtained by our subjects that participated in the learner corpus study. Table 25 shows the corresponding contrast.

\begin{tabular}{|l|c|c|c|}
\hline Group & $\begin{array}{c}\text { SOC in sentence } \\
\text { transformation } \\
\text { task }\end{array}$ & $\begin{array}{c}\text { SOC in story } \\
\text { narration } \\
\text { (corpus) }\end{array}$ & Difference \\
\hline Gr: EI & 44,44 & 0 & 44,44 \\
\hline Gr:PI & 67,92 & 48,61 & 19,31 \\
\hline Gr: I & 90,09 & 58,57 & 31,52 \\
\hline Gr: UI & 90,59 & 54,54 & 36,05 \\
\hline
\end{tabular}

Table 25: SOC of the possessive $-s$ in the two tasks

As we can observe in the above table the accuracy rates obtained by the participants of the sentence transformation task surpass the results obtained by the learner corpus groups. Since the SOC rates and the corresponding difference are calculated as a percentage we consider that the difference is significant in all cases. The least significant difference is to be found among the learners of the pre-intermediate level, but mainly due to the 
low accuracy rates found in the experimentally elicited data. This could be explained by the plateau effect (Richards, 2008) in SLA. Indeed, that seems to be the right explanation in this case since it is only in the transition from the elementary to the pre-intermediate level that the progress rate seems to be significantly low. The difference in accuracy rates between the intermediate and the upper-intermediate group is also low, but this is due to high accuracy scores in both cases (>90\%).

Going back to the comparison of the data elicited by means of the two different tasks and the relevant question we posed in the beginning regarding the influence of the research instrument on the results we can affirm that there is a clear correlation and that Krashen's claim is right. That is to say, it seems that discrete-point grammar tasks indeed trigger the subjects' learnt rules, i.e. formal knowledge, and hence the accuracy rates obtained are significantly higher than those found in naturally produced language.

Question 2 (Will rates for the analytic genitive $P P$ be higher than for the synthetic -s morpheme?).

Before dealing with the second issue we wished to investigate, that is, the choice of the L2 English learners between the analytic and the synthetic forms in order to express possession in English, we should repeat our initial hypothesis. According to this L2 English learners will exhibit a clear preference for the analytic form especially in the initial stages.

In order to (dis)confirm this hypothesis, we should compare not only the TLU and NTLU rates but also the types of NTLU found in each proficiency level. We remind here that we have tagged the use of the analytic possession construction (i.e. the $P P$ ) as "NTLU: misuse: misselection" in order to be able to identify it and thus make the comparison. Recall that this does not imply low rates of accuracy in the use of the possession structure in general. These rates are represented by the SOC, as shown in Table 24. The following table (no. 26) displays the TLU and the 
NTLU rates obtained by the students that participated in our sentence transformation task. In Figure 13 we can see the chart of these results.

\begin{tabular}{|l|c|c|}
\hline Group & TLU & NTLU \\
\hline Gr: EI & 25 & 75 \\
\hline Gr: PI & 58,6 & 16,7 \\
\hline Gr: I & 83,3 & 10,8 \\
\hline Gr: UI & 89,2 & $-S$ by \\
Table 26: TLU and NTLU rates in the use of the possessive -
\end{tabular}

L2 learners of English (sentence transformation task)

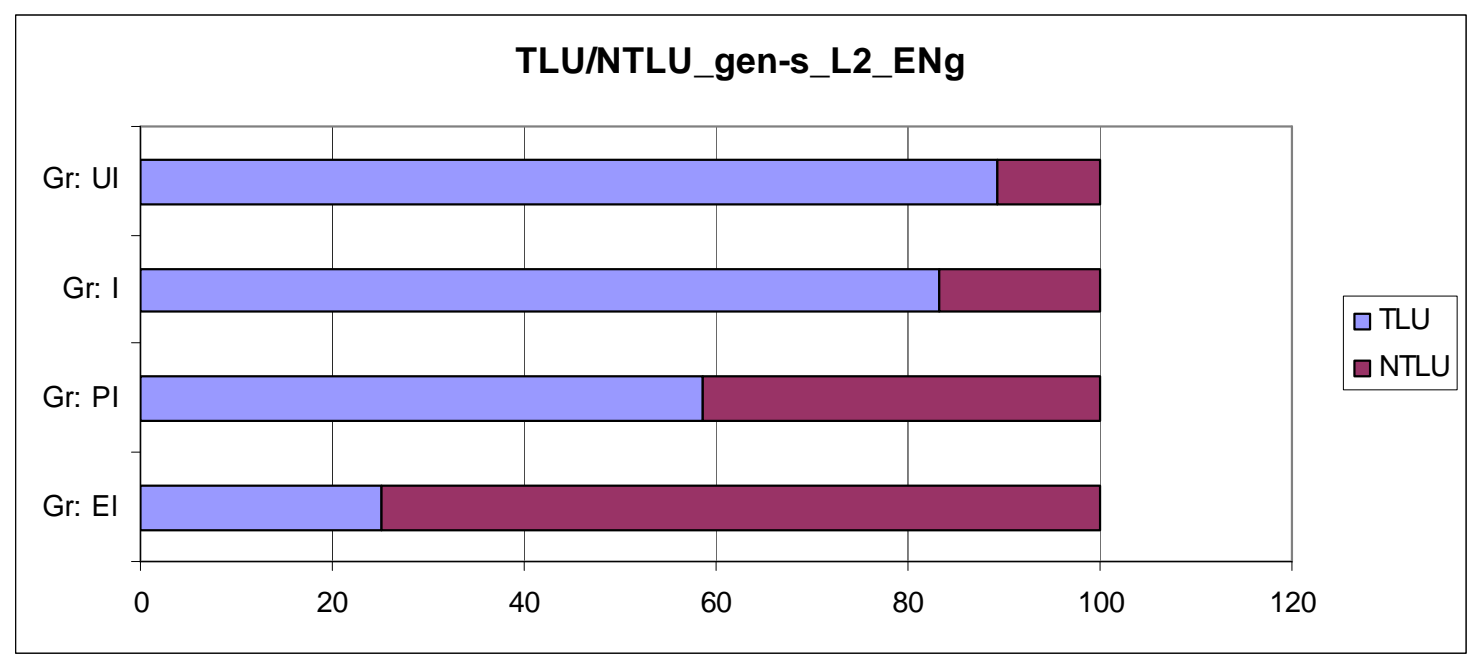

Figure 13: TLU/NTLU of the possessive $-s$ by L2 learners of English (sentence transformation task)

As we can see the accurate use of the possessive $-\boldsymbol{s}$ (i.e., TLU) correlates with the learner's proficiency level. That is, the higher the student's proficiency level the more accurate the use of the possessive $-s$. We should remind here that we constructed our sentence transformation task in such a way that both the synthetic ( $-s$ possessor) and the analytic ( $P P$ ) forms could be used. That enabled us to secure equal possibilities of use for each of the forms and thus diminish the possible effects of the instrument used. For more details we refer the reader to the corresponding section (5.3.4).

However, in order to determine whether this correlation also displays a preference of the high proficiency students for the 
synthetic genitive $-s$ form (as seen in the TLU rates) and the opposite tendency of the low proficiency learners, we should further analyse the data. Indeed, if we observe the types of NTLU we can see that the majority of NTLU cases exhibited by all four groups do not belong to what we classified as PP. The results are shown in Table 27 .

\begin{tabular}{|l|c|c|c|c|}
\hline & Gr: El & Gr:PI & Gr:I & Gr:UI \\
\hline NTLU_Type & $75 \%$ & $41,4 \%$ & $16,7 \%$ & $10,8 \%$ \\
$(\mathrm{n}=81)$ & $(\mathrm{n}=263)$ & $(\mathrm{n}=101)$ & $(\mathrm{n}=20)$ \\
\hline Underuse & $77,8 \%$ & $35,9 \%$ & $18,8 \%$ & $75 \%$ \\
\hline Misuse & $22,2 \%$ & $64,1 \%$ & $81,2 \%$ & $25 \%$ \\
\hline Overuse & $0 \%$ & $0 \%$ & $0 \%$ & $0 \%$ \\
\hline \hline Misuse_Type & $\mathrm{N}=18$ & $\mathrm{~N}=118$ & $\mathrm{~N}=82$ & $\mathrm{~N}=5$ \\
\hline Misselection & $22,2 \%$ & $28 \%$ & $34,1 \%$ & $0 \%$ \\
\hline Misrealisation & $27,8 \%$ & $34,7 \%$ & $41,5 \%$ & $60 \%$ \\
\hline Wrong-unclassified & $50 \%$ & $37,3 \%$ & $24,4 \%$ & $40 \%$ \\
\hline
\end{tabular}

Table 27: NTLU types of the genitive $-s$

\begin{tabular}{|l|c|c|}
\hline Group & TLU & NTLU: PP \\
\hline Gr:EI & $25 \%$ & $2,7 \%$ \\
\hline Gr:PI & $58,6 \%$ & $12,54 \%$ \\
\hline Gr:I & $83,3 \%$ & $27,72 \%$ \\
\hline Gr:UI & $89,2 \%$ & $0 \%$ \\
\hline
\end{tabular}

Table 28: Relative frequency of the possessive $-s$ and the $P P$ as possession expressions

The data in Tables 27 and 28 clearly show that the misselection type, that is, the use of the periphrastic possession structure $(P P)$ is significantly low.

According to these data we should say that our hypothesis is disconfirmed, that is, learners at all levels show a clear preference for the synthetic (genitive -s) form of the possession structure in English. In the same line we can argue that the low accuracy rates observed in the initial proficiency 
level groups are not due to the students' preference for the use of the analytic form for the expression of possession.

The last comment we would like to make here regards the relation between our findings and Rosenbach's (2005) study, i.e., we want to contrast L2 English learners vs. English natives on the use of the synthetic genitive $-s$ morpheme vs. the possessive $P P$ analytic structure. In Figure 3 above we showed Rosenbach's (2005) findings on the frequency of the genitive -s among native speakers of English. According to that, native speakers prefer the use of the genitive $-s$ when the possessor is an animated entity. In our study's task all possessors were animated entities and the students showed a clear preference for the use of the possessive $-s$. That tendency cannot be explained by an L1 transfer hypothesis. The subjects of our study were native speakers of Spanish which displays a different possession structure. In Spanish one can express possession either by means of the possessive pronouns (e.g. He leido todos sus libros), which would be the synthetic form, or through a prepositional phrase (e.g. Este es el coche de María), which would obviously reflect the analytic form. English, on the other hand, has two synthetic forms. One is the possessive $-s$ which has no equivalent in the Spanish possessive system. The other, that is, the possessive pronouns, is found in both the English and the Spanish system of possession. However, as we already mentioned in sections 2.2 .1 and 5.3.4, possessive pronouns were included in the given sentences. Hence the only common possession form that was still available for the students to use in the task was the periphrastic form (i.e., the prepositional phrase). But we saw that the students preferred the use of the synthetic possessive $-s$ instead. Therefore the L1 transfer explanation is rejected in this case. Nonetheless, we cannot suggest that the possessor's characteristic as an animated entity is what triggered the use of the genitive $-s$ by our learners of L2 English. We can say that our findings imply such a correlation, but in order to make a positive statement in this regard we should check the whole spectrum of possibilities and thus 
include also inanimate entities and distinguish between neutral and long/short. As we mentioned in section 2.2.1, we did not include a similar distinction in our study, but we consider that our findings could be used in a future research that would also contain data in relation to inanimate and neutral or long/short possessors. Regarding this issue we refer the reader to the relevant discussion presented in sections 7.4 and 7.5 .

After having analysed the expression of possession in L2 English, we shall move to our $3^{\text {rd }}$ study: the expression of possession in L3 German via the genitive $-s$ morpheme and via other structures. Recall that a full account of the German system of possession is given in section 2.2.2.

\subsection{Possessive structures in I3 German}

In this section we wish to explore the use of each of the possession structures in German by students who learn German as a third language. As we mentioned in section 2.2.2 in German there are structural restrictions as to which type of possession structure one can use. Furthermore, in German there are four ways of expressing possession. The first is, as in English and Spanish, the possessive pronouns (e.g. Das ist sein Auto; lit.: This is his car). In keeping with our choice in the case of English, we decided to include the possessive pronouns in the given sentences of the transformation task in German. This enabled us to follow a similar tagging scheme in English and in German and thus allowed us to make comparisons. Additionally, it helped us check whether there is or not an L2 English influence on the acquisition of the L3 German possession system, but to this we will return later.

Before proceeding to the presentation of our findings, we should mention our principal aims:

(i) First we wish to check the general preferences of the L3 German learners in relation to the synthetic and the analytic forms for expressing possession. 
(ii) Then we would like to compare these results to the relative frequency of the possessive $-s$ and the $P P$ in L2 English (see study no. 2 in the previous section).

(iii) Finally, we intend to determine whether there is or not an influence of the I2 English on the acquisition of the I3 German.

The majority of our subjects $(77,6 \%)$, were learning English as an L2. The remaining 22,4\% either did not mention any other L2 or mentioned that they were learning a different L2. In most of these cases, that is, at least regarding the young subjects of the remaining $22,4 \%$, we believe that they have gone through the process of learning English as a foreign language, at school for example. Nevertheless, since we cannot know whether they meant that they are not currently learning or that they have never learnt English as foreign language, we decided to exclude these samples from the last subsection of our third study.

In order to study the tendencies in the use of the synthetic and the periphrastic possession structures by L3 German learners, we should compare the TLU and the "NTLU: misuse: misselection" accuracy rates for each proficiency level. Table 29 displays the relevant information as resulted from the analysis of our raw data. These represent the accuracy rates of the two synthetic forms of possession in German, i.e. the possessive $-s$ and the genitive case, as well as the accuracy rates of the periphrastic form, that is, the PP. Note that the percentage has been calculated on the basis the total number of oc that appeared in each group. A detailed description of the TLU and NTLU rates along with their chart and a full account of the NTLU types are displayed in Appendix 9.11.3.1. 


\begin{tabular}{|l|l|llll|}
\hline Group & TLU & NTLU: & misuse: & misselection: & PP \\
\hline $\begin{array}{l}\text { Elementary } \\
\text { (Gr:El) }\end{array}$ & $5,8 \%$ & $94,2 \%:$ & $85,8 \%:$ & $89,7 \%:$ & $40,2 \%$ \\
\hline $\begin{array}{l}\text { Pre- } \\
\text { intermediate } \\
\text { (Gr:PI) }\end{array}$ & $14,1 \%$ & $85,9 \%:$ & $83,6 \%:$ & $83,9:$ & $59,6 \%$ \\
\hline $\begin{array}{l}\text { Intermediate } \\
\text { (Gr:I) }\end{array}$ & $12,7 \%$ & $87,3 \%:$ & $85,5 \%:$ & $96,2 \%:$ & $70,6 \%$ \\
\hline $\begin{array}{l}\text { Upper- } \\
\text { intermediate } \\
\text { (Gr:UI) }\end{array}$ & $41,7 \%$ & $58,3 \%:$ & $100 \%:$ & $50 \%:$ & $71,4 \%$ \\
\hline
\end{tabular}

Table 29: Relative frequency of the synthetic and the analytic possessive forms in L3 German learners' language

The third column in Table 29 presents the accuracy rates of the NTLU, the "NTLU:misuse", the "NTLU:misuse:misselection", and finally the "NTLU:misuse:misselection:PP". So, for example, in the case of the elementary level group, these data mean that in relation to all the obligatory contexts (OC) for the expression of possession, the students of the elementary group presented a $94,2 \%$ of NTLU, out of which the $85,8 \%$ were cases of misuse. That is, the remaining $14,2 \%$ represents other types of NTLU such as underuse or the so-called SNOC. Then, the $89,7 \%$ out of this $85,8 \%$ of "NTLU:misuse" reflects the misselection type which includes both the use of the $P P$ and the use of the possessive $-s$ in contexts where a different possession form was required (for more details on our tagging scheme for L3 German see section 5.4.4 part 3). We decided not to tag this as a case of SNOC because these reflect OC for a possession structure. The mistake lies in the choice of the particular form of possession expression (possessive $-s$ ) in those occasions where the corresponding structural restrictions allow the use of either the genitive case or the PP. If we had included it in the SNOC we would have erroneously distorted the calculation of the SOC, which we will be using for the L2 English (study no. 2 above) and L3 German (this study, no. 3) comparison later. Finally, the $40,2 \%$ of the misselection cases represents the use of the PP. 
This is the full analysis of the percentages presented in Appendix 9.11.3.1. Note that displaying just the 40,2\% of the PP use would be misleading since it is not estimated on the basis of the total number of possession expression OC. However, since it is difficult to reach a conclusion from these percentages, we have transformed the PP use percentage into a rate based on the overall OC. The rates were calculated following the aforementioned process for every group and therefore represent the percentage of $P P$ occurrences in the corresponding obligatory contexts. We present the results in the following table.

\begin{tabular}{|c|c|c|}
\hline Group & $\begin{array}{c}\text { TLU: genitive 's \& } \\
\text { genitive case (in } \% \text { ) }\end{array}$ & NTLU: PP (in $\%)$ \\
\hline $\begin{array}{l}\text { Elementary } \\
\text { Gr:El }\end{array}$ & 5,8 & 29,16 \\
\hline $\begin{array}{l}\text { Pre-intermediate } \\
\text { Gr:PI }\end{array}$ & 14,1 & 35,89 \\
\hline $\begin{array}{l}\text { Intermediate } \\
\text { Gr:I }\end{array}$ & 12,7 & 50,70 \\
\hline $\begin{array}{l}\text { Upper-intermediate } \\
\text { Gr:UI }\end{array}$ & 41,7 & 20,83 \\
\hline
\end{tabular}

case and the $P P$ in the L3 German learners' language

In Table 30 we can see that in general the accurate use of the $\boldsymbol{P P}$ has not obtained very high rates, as they are 50\% or below. Nevertheless, these rates are still higher than the equivalent rates of the TLU. Only the upper-intermediate group obtained higher accuracy rates in the use of the synthetic forms of possession expression (genitive $-s$ and genitive case). Yet, the difference between the use of the synthetic and the analytic forms at this level is significantly lower than the corresponding difference in the other three levels. This can be clearly appreciated in Figure 14 . 


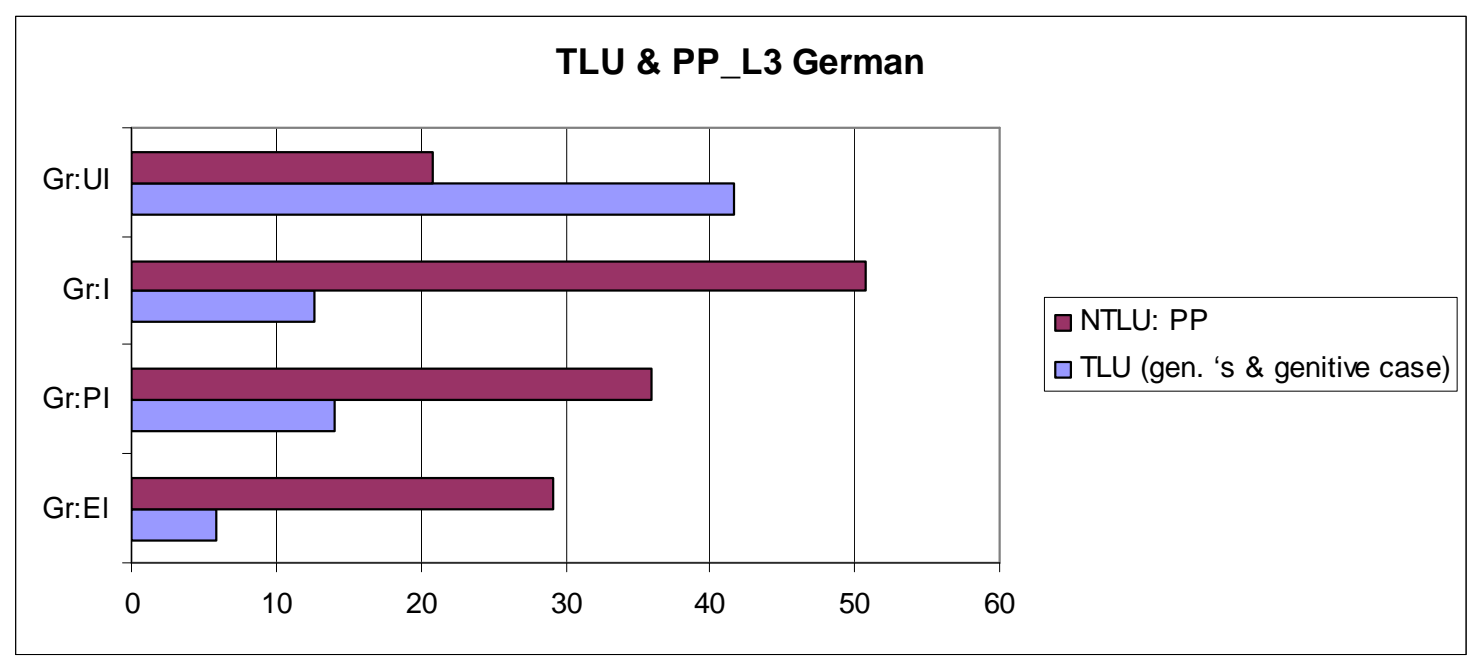

Figure 14: Relative frequency of the s-genitive (TLU), the genitive case (TLU) and the of-genitive (NTLU:PP)

Based on the accuracy rates obtained for the s-genitive and the genitive case on the one hand, and those obtained for the ofgenitive on the other, we can claim that in general the I3 learners of German show a preference for the use of the analytic form. However, explaining this preference on grounds of an L1 transfer would be a mistake for two reasons. First, because the of-genitive structure may be part of the possession expressions in our subjects' L1 Spanish, but it also forms part of their L2 English. This implies that I1 transfer cannot account for the I3 German data here. Second, because the overall percentage of the periphrastic form of possessive expression is low in our data. Additionally, the preference shown in Figure 14 is determined only in relation to the TLU cases, but that does not mean that the PP is the learners' first choice when it comes to possession expression in German. The remaining percentages in each level represent the cases where the genitive $-s$ has been used incorrectly. We shall deal with these rates later when we will be examining the influence of the L2 English on the L3 German.

We should now pass to our second question that refers to the comparison of relative frequency of the synthetic and the analytic forms of possession in both I2 English and L3 German. We have decided to use the experimentally elicited L2 English data (see study no. 2 in the previous section) in order to avoid 
possible interferences of the instrument. In the following table we present the data for both the L2 English and the L3 German.

\begin{tabular}{|c|c|c||c|c|}
\hline & \multicolumn{2}{|c||}{ TLU } & \multicolumn{2}{c|}{ NTLU: PP } \\
\hline Group & L2_Eng & L3_Ger & L2_Eng & L3_Ger \\
\hline Gr: $:$ I & 25 & 5,80 & 3,7 & 29,16 \\
\hline Gr:PI & 58,6 & 14,10 & 5,1 & 35,89 \\
\hline Gr: I & 83,3 & 12,70 & 4,6 & 50,7 \\
\hline Gr:UI & 89,2 & 41,70 & 0 & 20,83 \\
\hline
\end{tabular}

Table 31: Accuracy rates for the use of the synthetic and the analytic forms of possession expression in L2 English and L3 German

Based on the data displayed in Table 31 we can argue that the use of the synthetic form (genitive morphology) is more extended among the learners of L2 English than among the learners of L3 German. In the same line, the use of the periphrastic form ( $P P$ structure) in L2 English displays very low rates. In comparison to this, the use of the $P P$ made by $L 3$ learners of German is significantly higher. That could probably be explained by the fact that in English there are no structural restrictions and thus the achievement of the TLU of the genitive $-s$ is much easier for the learners. On the contrary, the various structural restrictions posed in the use of each of the possession forms in German probably has a negative interference in students' accuracy rates.

Before we set about checking whether there is or not an L2 influence on L3 acquisition, we should clarify where this influence, if it exists, should appear. As we mentioned in section 2.2.1, English has two ways of expressing possession, namely the synthetic and the analytic. The former is constructed by means of the possessive pronouns or the genitive $-s$. The analytic form is constructed by means of the prepositional phrase. In German, on the other hand, there are also two ways of expressing possession, that is, the inflectional and the 
periphrastic. The inflectional possession expression in German includes the possessive pronouns, the genitive $-s$ and the genitive case. The latter is the only formal feature that English lacks. Furthermore, in German the use of the genitive $-s$ is restricted in those cases where the possessor is expressed by means of either a proper name or a kinship term (see section 2.2.2 for more details). English, on the contrary, does not pose such restrictions to the use of the possessive -s. As we saw briefly in section 2.2.1 various factors have been suggested as a possible explanation of the native speakers' tendency to use one possessive form over the other. But there are no rules that allow or prohibit the use of each of the possessive forms except for the relative order of the possessor and the possessum (i.e., the $\mathrm{PR}>\mathrm{PM}$ or the $\mathrm{PM}>\mathrm{PR})$. For more details in this respect we refer the reader to our sections $2.2,2.2 .1$ and 2.2 .2 . So, the only differences in the possession expression systems in English and in German are the two extra features described above that we find in the German possession. These are the genitive case and the structural restrictions regarding the choice of the possession form. In relation to the first, we could say that the use of other possession structures in those occasions where the genitive case is required would imply an influence of the L2 English. Nonetheless, this is not a sound assumption, since all the OC for the genitive case in German are also the OC for the $P P$ (see section 2.2.2). Therefore, the only area where we can look for a possible influence is the use of the genitive $-s$ in those structures where either a genitive case or a $P P$ is allowed. As we explained when we described our tagging process, we called these cases "NTLU: misuse: misselection: possessive -s" in order to distinguish them from the cases where a genitive $-s$ was the correct choice.

Before presenting our results we should highlight that we have included in our task the OC for all the forms of the possession expression. Additionally, we have excluded, as we said in the beginning of this subsection, those samples where the subjects did not expressively said that they were or had been at some 
point in their lives learning English. The relevant results of the remaining samples are displayed in the following table. The whole description of the statistic features for this sub-group of L3 German learners can be found in Appendix 9.11.3.2.

\begin{tabular}{|c|c|c||c|c|}
\hline & \multicolumn{2}{|c||}{ TLU } & \multicolumn{2}{c|}{ NTLU } \\
\hline Group & gen_s & gen-case & PP & Pos. -s \\
\hline Gr:EI & 5,3 & 0 & 28,07 & 43,85 \\
\hline Gr:PI & 7,5 & 7,5 & 28,78 & 28,78 \\
\hline Gr:I & 6,25 & 8,3 & 35,41 & 27,08 \\
\hline Gr:UI & - & - & - & - \\
\hline
\end{tabular}
case, the of-genitive and the misused possessive $-s$ in the language of L3 German learners with L2 English

In the above table we can see that the accurate use of the three forms of possession expression (i.e., the genitive $-s$, the genitive case, and the $P P$ ) correlates with the proficiency level. In the same vein, we observe that the use of the $P P$ is lower than the wrong use of the possessive $-s$ at the elementary level. The same rates are equal in the pre-intermediate level, and in the intermediate level the use of the $P P$ is higher than the inaccurate use of the possessive $-s$.

However, what we find even more interesting, is the fact that the rates of the inaccurate use (i.e. the use in the wrong contexts) of the possessive $-s$ is significantly higher not only compared to the accuracy rates for each of the synthetic forms, i.e. the genitive $-s$ and the genitive case, but also in relation to the overall TLU rates for both synthetic forms. That is, the genitive -s morpheme is most frequently used by our L3 German learners in the wrong contexts (i.e., wrong according to the structural restrictions imposed in German). That can only be explained by the influence of their L2 English where these structural restrictions do not exist and hence the use of the possessive $-s$ would not be wrong in the corresponding contexts. Indeed, this tendency of the wrong use of the genitive $-s$ 
correlates negatively with the proficiency level. That is, the less proficient the student the higher the L2 influence.

Our results correspond to the findings of previous studies on the role of the L2 in the acquisition of the L3 syntax that we presented in section 3.3. Additionally, our findings confirm our initial hypothesis that there will be an $\mathbf{L} \mathbf{2}$ influence especially in initial stages. In that aspect, we agree with the hypothesis put forth by Ringbom (1987) that claimed that background languages exert a high influence when the L3 proficiency level is low (see section 3.3).

The L1 transfer cannot explain these data since in our subjects' L1 the genitive-s feature does not exist. The fact that their L2 does not restrict the use of the genitive $-s$ in those cases where the $\mathrm{PR}=$ proper name/kinship term explains the learners' tendency to incorrectly extend the use of the genitive $-s$ without considering the possessor. Accordingly, we argue that the Cumulative Enhancement Model (CEM, Flynn et al. 2004) is not supported by our study. The CEM suggests that all previously learnt languages can be transferred in the L3 acquisition, when there is a structural overlap in two of the languages involved. In our case there is a structural overlap between the possession expression systems in L1 Spanish and L3 German on the one hand and L2 English and L3 German on the other hand. However, as we commented above based on the data displayed in Table 31, the use of the structural overlap between L2 English and L3 German, i.e. the genitive $-s$, is more extended than the structural overlap found in L1 Spanish and L3 German, i.e. the PP. To that we should add that the $P P$ as a possession expression is actually common in all three languages. Even so, our subjects did not seem to prefer that structure, but rather the one that was shared only by the L2 and the L3.

The Typological Primacy Model (TPM, Rothman, 2010) states that according to economy of acquisition the most similar, typologically, language becomes the source for transfer, 
independently of the language being an L1 or an L2. Based on our data we could argue in favour of this model since English is a Germanic language and seems to be the source of influence. However, we believe that such an assumption would be erroneous for two reasons. The first reason why a confirmation of the TPM would be inaccurate if based on our study's results is the special case that English presents as a language. English is indeed a Germanic language, but it is also one that has been extensively influenced by Romance languages especially in terms of its lexicon. Now, if we consider that in initial stages learners do not apply rules but rather assimilate chunks of language, as the declarative/procedural model suggests and our findings confirm (for more details see section 6.1), then we can argue that in these initial stages learners do not conceive the morphosyntactic similarities between two languages simply because they do not analyse the target language's morphological and syntactic properties. Additionally, in our case, similarities in language can be found between our subjects' L1 and L3 as well as between our subjects' L2 and L3. Yet only the L2 influence seems to be particularly high in initial stages. Second, and most importantly, we cannot accept the TPM as an explanatory model of our study's results because our data do not contrast various L1s and L2s which are, typologically speaking, similar or dissimilar to our L3 German. In that sense, our study lacks data in order to reach a clear conclusion in relation to the TPM model. Therefore, we should not argue in favour or against the TPM model on the grounds of this study.

The final hypothesis that has been proposed in relation to the L2 transfer in the acquisition of an L3 is known as the I2 status hypothesis (Williams and Hammarberg, 1998). The underpinning idea is that in L3 acquisition there is an L2 transfer due to the subject's "[...] desire to suppress L1 as being 'non-foreign' and to rely rather on an orientation towards a prior L2 as a strategy to approach the L3" (Hammarberg, 2001:36-37). We believe that this model can be proposed as the explanatory factor of our L3 German learners' extended use of 
the genitive $-s$ in non-obligatory for these possession structure contexts. Indeed, this model is the only that manages to account for our L3 German subjects' preference for the genitive $-s$ even though the $P P$ was common in all three languages (L1_Spanish, L2_English, L3_German). 


\section{Conclusions}

After having presented our data and commented on the results of each of our three studies, we shall now introduce the conclusions that can be reached regarding the studies' questions and hypotheses presented in section 4. In this chapter we will also proceed with the distinction of three sections each of which corresponds to one of our project's studies. In this line of thought, section 7.1 deals with the questions and hypotheses of our first study that regards the morphemes' accuracy rates obtained by our L2 English subjects in our picture description task (corpus). Accordingly, section 7.2 presents our conclusions in relation to the use of the possessive -s as revealed by our data from both the learner corpus and the experimentally elicited learner language (sentence transformation task). Finally, in section 7.3 we regard the importance and the implications of the use of the various possessive structures in German by our L3 German learners.

\subsection{Study I: MOS \& Learner Corpus in L2 English}

In relation to our first question, which referred to the possibility that the proficiency level can stand as an explanatory factor for the development of morphology in L2 English, our study provides evidence that the proficiency level is in general a covariate of accuracy order. In the same line, we can argue that the average order of accuracy appears after the very initial stages of proficiency. In this respect we agree with Muñoz's (2006) findings.

Our first hypothesis was that accuracy in use would not imply acquisition of the corresponding functor. In order to confirm that we needed to show that there are functors for which the accuracy rates are lower in higher proficiency levels. This 
hypothesis was confirmed, since the grouping of our subjects on the basis of their proficiency level enabled us to successfully observe the U-shape pattern of development of the past irregular functor.

Our second hypothesis was that we would find a similar pattern of morphemes accuracy order for each proficiency level. This hypothesis was also confirmed as shown in Figure 10 (section 6.1). Additionally, our findings are similar to those suggested by Muñoz (2006) for those subjects that had a proficiency level beyond the elementary one. Our findings do not conform to Dulay and Burt's (1974) and Krashen's (1977) average orders, although they do display some similarities.

Our second question contemplated the possible explanatory value that Andersen's (1978) and Hawkins' (2001) pattern could have for the results of our study in relation to the verb-related morphemes. In that respect, our study confirms that Andersen's (1978) and Hawkins' (2001) pattern can explain the development of the verb-related morphemes studied in our project. In the same line, we can argue that our third hypothesis was confirmed. The slight difference in order found in our pre-intermediate group in comparison to Hawkins' (2001) pattern is explained by the SLA process and the function of the subjects' interlanguage (IL).

\section{2 study II: Genitive -s in L2 English}

In relation to this project we formulated one question and two hypotheses. The question we posed in this respect was the influence of the data elicitation method on the results. Accordingly, we wished to check the validity of Krashen's claim that naturally occurred language will display the order of acquisition which will be different to the order of learning. The latter, following Krashen, should appear in tasks that trigger the subject's formal knowledge, such as the discretepoint grammar tests. Indeed, our findings yield a clear influence of the research instrument on the final results. They also confirm the claim that the accuracy orders found in 
learners' language elicited naturally will be different to the corresponding orders found in experimentally elicited learner language. In that vein, our first hypothesis that the accuracy rates for the possessive $-s$ obtained through our corpus task would be lower than the corresponding rates found in the data collected through our experiment (sentence transformation task) is confirmed. This, we believe, could imply that Krashen's distinction between acquisition and learning is supported.

Our second hypothesis regarding the relative frequency of the genitive $\boldsymbol{- s}$ by L2 English learners was that they would show a clear preference towards the use of the analytic form (PP) especially in initial stages, over the synthetic form (genitive -s morpheme). Our data disconfirmed this hypothesis, since they display high rates of use of the synthetic possession expression, that is, of the possessive $-s$. In the same vein, we find a correlation between our L2 English learners' relevant choice and the native speakers' preference as suggested by Rosenbach (2005). However, we would need more data in order to confirm such correspondence. On the other hand, our study's data provide some evidence that $\mathbf{L} 1$ transfer cannot stand alone as an explanatory model of the SLA/FLA processes.

\section{3 study III: Possessive structures in I3 German}

In this part we formulated one hypothesis and one question. The latter relates to the relative frequency of the inflectional and the periphrastic forms of possession expression in both L2 English and L3 German. Based on the comparison of our data we were prompted to say that the synthetic form of possession expression is used more often by L2 English learners, whereas the analytic form of possession expression is used more often by L3 German learners. Indeed, what we found was that the analytic form was used more often than the synthetic forms in the corresponding OC. 
Bearing on our hypothesis for this study, we should repeat our initial claim that the use of the possession expressions by L3 German learners would display an L2 English influence especially in initial stages. Indeed, this hypothesis was confirmed by our data. The highest frequency rates were achieved in relation to the use of the genitive $-s$ but in wrong contexts, according to the structural restrictions of the German possessive system, which reveals an L2 English transfer, since in the English system of possession allows these restrictions do not exist. The lack of structural restrictions that is found in English was reproduced in the samples of our subjects' L3 German. The model that we consider most likely to account for this phenomenon is the so-called $\mathbf{L} 2$ status hypothesis. The Typological Primacy Model (TPM), although we believe that is not a valid explanatory model for our findings due to the reasons we exposed in section 6.3, cannot actually be rejected since in our study we have not included various and typologically distant background languages.

\subsection{Limitations of the study}

We hold that this study could be improved in various aspects. First, the participation of more students, especially from the elementary and upper-intermediate proficiency levels, would have allowed for a more precise description of the morpheme accuracy orders in each proficiency level. In the same vein it would have enabled us to compare our MOS results with previous studies that include data from younger learners.

Time limitations prevented us from considering additional information such as the subjects' onset age and the actual exposure to the target language. These are data that we have in our possession since relevant questions were included in our learner's profiles. However, we did not manage to take this information into consideration when we grouped our participants. Therefore we had to consider only the proficiency level when we separated our subjects into different groups. 
Additionally, we would like to have tested our students' proficiency level based on an oral test as well. When we were correcting the written tests we came across some cases in which two students were put in the same level although one was just two points above the minimum required for that level, whereas the other was just two points below the minimum required for the next level. We therefore believe that an oral test would have clarified these edge cases.

Furthermore, our study would have been improved if we had included extra means of data elicitation. We believe that a recording of spontaneous conversations would have enabled us not only to make more accurate comparisons between our data and the findings of previous studies, but also to investigate the differences between completely naturally produced and clinically elicited language.

In relation to the frequency of use of the genitive $-s$ in English we suggest that further study should be conducted including all other types of possessors. That would make possible a comparison between L2 English learners' use of the various possession forms and native speakers' relevant preferences. Furthermore, although we tried to limit the instrument's influence on our results, a different elicitation task that would result in more authentic language would be desirable, provided that it would ensure a sufficient number of OC for the genitive $-s$.

Finally, we would like to have been able to include more information on the influence of various background languages on the acquisition of a new foreign language. For this we should have collected data of various and typologically distant first and second/foreign languages and then compare the learners' results in the production of L3 language.

\subsection{Avenues for future research}


In this final section we would like to suggest some possible lines for future research according to the findings but also the limitations of the present studies.

In the same line, we would argue that future MO studies should be conducted taking into consideration additional information with regard to the subjects' background. In our study we have regarded the subjects' proficiency level, but we consider that it is possible and desirable to further analyse our data as to include the subjects' onset age, exposure to TL and other relevant information found in our learner profiles.

Additionally, we believe that, for a better understanding of the morpheme acquisition process, future research should include various data elicitation instruments, which we did in our study, but only in relation to one of the functors at issue, namely the genitive $-s$.

Regarding the study of the developmental pattern of individual morphemes, the genitive $-s$ in our case, we understand that further research should be carried out including additional elicitation tasks designed for the production of the functor under examination. This, as we mentioned in the previous section, is a highly demanding activity since it should aim to the designing of an instrument that would ensure not only that the specific morpheme is used in sufficient occasions, but also that the learner language produced will be as natural as possible.

Perhaps a more realistic future project regarding the use of the various possessive forms by $\mathbf{L} 2$ English learners can be proposed, in which various types of possessors (e.g., animate vs. inanimate, etc.) would be included. This would allow the researcher to study L2 English learners' preferences and compare them to the corresponding ones shown by L1 English speakers. In our understanding this type of comparison would provide us with some enriching insights bearing on the relation between the L1 and the foreign language (FL) acquisition processes. 


\begin{abstract}
Finally, we consider that further research should be conducted in the direction of the influence that background FL may exert on the acquisition of a new target language. This field of research is relatively new and, although a number of relevant studies have already been conducted, we understand that there is still much to be discovered. Nevertheless, it is of particular interest for the SLA research since it can indeed provide us with useful information and thus shed light on the actual process of language acquisition. In line with this thought, we trust that the introduction of learner corpora in this type of research would provide the SLA researcher with important information regarding the various aspects of language (e.g. the strategies adopted bearing on the functional use of language, the acquisition of FL pragmatics, etc.), and hence enable us to obtain a more holistic view of foreign language acquisition.
\end{abstract}




\section{References}

Andersen, R.w. 1978. 'An implicational model for second language research.' Language Learning, 28: 221-282.

Archer, D., P. Rayson, A. Wilson and A. McEnery (eds.) 2003. Proceedings of the Corpus Linguistics. Lancaster: UCREL.

Bailey, N., C. Madden and S. D. Krashen 1974. 'Is there a natural sequence in adult second language learning?' Language Learning, 24: 235-243.

Bardel, C. and Falk, Y. 2007. 'The role of the second language in the third language acquisition: the case of Germanic syntax.' Second Language Research, 23:459-484.

Brown, R. 1973. A First Language: The Early Stages. Cambridge, Mass: Harvard University Press.

Brown, H. D., C. Yorio and R. Crymes (eds.) 1977. On TESOL '77: Teaching and Learning English as a Second Language. Trends in Research and Practice. Washington, DC: TESOL.

Brown, J.D. 1983. 'An exploration of morpheme group interactions' in Bailey, K., Long, M., and Peck, S.(eds.) Second Language Acquisition Studies. Rowley, MA: Newbury House.

Butters, R.R. 2001. 'Grammatical Structure' in Algeo J. (ed.) English in North America. Cambridge: Cambridge University Press. 325-339

Cook, v. 1993. Linguistics and Second Language Acquisition. New York: St. Martin's Press.

Corder, S.P. 1976. 'The study of interlanguage' in Proceedings of the Fourth International Conference of Applied Linguistics Volume 3: Techniques in Applied Linguistics. Oxford: Oxford University Press.

de Villiers, J. and P. de Villiers. 1973. 'A cross-sectional study of the acquisition of grammatical morphemes in child speech.' Journal of Psycholinguistic Research, 2: 267-278.

De Angelis, G. 2005b. 'Interlanguage transfer of function words.' Language Learning, 55: 379-414. 
Dentler, s. 2000. Deutsch und English - das gibt immer Krieg [German and English - there is always a war]. In Dentler, S., Hufeisen, B. and Lindemann, B.(eds.) Tertiär und Drittsprachen. Projekte und empirische Untersuchungen. [Tertiary Languages. Projects and empirical research.] Tübingen: Stauffenburg Verlag: 77-97.

Díaz Negrillo, A. 2007. A Fine-Grained Error Tagger for Learner Corpora. Unpublished PhD Thesis. University of Jaen.

Dulay, н. C. and M. K. Burt. 1973. 'Should we teach children syntax?' Language Learning, 23: 245-258.

Dulay, H. C. and M. K. Burt. 1974b. 'Natural sequences in child second language acquisition.' Language Learning, 24 : 37-53.

Eisenbeiß, $\mathbf{S}$. et al. 2009. 'Learning to encode possession.' in McGregor, W. (ed.) The expression of possession. Berlin: Mouton de Gruyter. 143-212.

Ellis, R. 1987. 'Interlanguage variability in narrative discourse: Style shifting in the use of the past tense.' Studies in Second Language Acquisition 11: 305- 328 .

Ellis, R. 1994. The Study of Second Language Acquisition. Oxford: Oxford University Press.

Ellis, R. and G. Barkhuizen 2005. Analysing Learner Language. Oxford: Oxford University Press.

Fathman, A. 1975. 'The relationship between age and second language productive ability.' Language Learning, 25: 245253.

Flyn, s. 1987. A parameter setting model of L2 Acquisition: Experimental Studies in Anaphora. Dordrecht: Reidel.

Flyn, s. et al. 2004. 'The cumulative-enhancement model of language acquisition: comparing adults' and children's patterns of development first, second and third language acquisition of relative clauses.' International Journal of Multilingualism 1(1): 3-16.

Gass, S. 2001. 'Sentence matching: a re-examination.' Second Language Research, 17:421-441.

Goldschneider, $\boldsymbol{J}$. and R. Dekeyser 2001. 'Explaining the "Natural Order of L2 Morpheme Acquisition" in English: A meta- 
analysis of multiple determinants.' Language Learning, $51(1): 1-50$

Granger, S. 2004 'Computer learner corpus research: current status and future prospects.' in Connor and Upton (eds.), 123-145.

Granger, s. 2008. 'Learner corpora.' in Lüdeling and Kytö (eds.), 259-275.

Granger, s. 2009 'The contribution of learner corpora to second language acquisition and foreign language teaching.' in Aijmer, K. (ed.) Corpora and Language Teaching. Amsterdam: John Benjamins. 13-33.

Gilquin, G., \& Gries, S. T. 2009 'Corpora and experimental methods: a state-of-the-art review'. Corpus Linguistics and Linguistic Theory, $5(1), 1-26$.

Hammarberg, B. 2001. 'Roles of L1 and L2 in L3 production and acquisition.' In Cenoz, J., Hufeisen, B. and Jessner, U. (eds.) Cross-linguistic Influence in Third Language Acquisition: Psycholinguistic Perspectives. Clevedon: Multilingual Matters. 21-41.

Haspelmath, M., 2002. Understanding Morphology. Oxford: Oxford University Press.

Hawkins, J.A. 1994. A performance theory of order and constituency. Cambridge: Cambridge University Press.

Hawkins, R. 2001. Second Language Syntax. A Generative Introduction. Oxford: Blackwell.

Hawkins, R. and Lozano, C. 2006. 'Second Language Acquisition of Phonology, Morphology, and Syntax' in Brown, K.(ed.) The Encyclopaedia of English Language and Linguistics (2 ${ }^{\text {nd }}$ edition). London: Elsevier. 67-74.

Heine, B. 1997. Possession: Cognitive Sources, Forces and Grammaticalization. New York: Cambridge University Press.

Housen, A. 2002. 'A corpus-based study of the L2 acquisition of the English verb system, in Granger, S., Hung, J. and Petch-Tyson, S.(eds.) Computer Learner Corpora, Second Language Acquisition and Foreign Language Teaching. Amsterdam: John Benjamins. 77-116. 
Kachru, Y. 2003. 'On definite reference in world Englishes.' World Englishes, $22(4): 497-510$.

Klein, E. 1995. 'Second versus third language acquisition: Is there a difference?' Language Learning, 45: 419-465.

Krashen, S. 1977. 'Some issues relating to the monitor model.' in Brown, Yorio and Crymes (eds.), TESOL' 77: 144-158. TESOL, Washington, DC.

Krashen, S. 1977. 'The Monitor Model for adult second language performance.' In: Burt, M., Dulay, H., and Finocchiaro, M. (eds). Viewpoints on English as a Second Language. New York: Regents Publishing.

Krashen, s. 1978. "Is the "Natural Order" an artefact of the bilingual syntax measure?' Language Learning, $28(1)$ : 187191 .

Krashen, S., Sferlazza, V., Feldman, L. and Fathman, A. 1976. 'Adult performance on the SLOPE test: More evidence for a natural sequence in adult second language acquisition.' Language Learning, 26: 145-151.

Kjarsgaard, M. 1979. The order of English morpheme category acquisition by Vietnamese children. Unpublished PhD Thesis. Arizona State University, Phoenix.

Kwon, E. Y. 2005. 'The natural order of morpheme acquisition: A historical survey and discussion of three putative determinants.' Working Papers in TESOL Applied Linguistics, $5 / 1: 1-20$.

Larsen -Freeman, D.E. 1975. 'The acquisition of grammatical morphemes by adult ESL students.' TESOL Quarterly, 9:409419

Larsen -Freeman, D.E. 1976. 'An explanation for the morpheme acquisition order of second language learners.' Language Learning, 26:125-134.

Larsen -Freeman, D.E., \& Long, M.H. 1975. An Introduction to second language acquisition research. New York: Longman

Lightbown, P. 1983. 'Exploring relationships between developmental and instructional sequences in L2 acquisition' in Selinger H.B. and Long M.H. (eds.) Classroom 
Oriented Research in Second Language Acquisition. Rowley, MA : Newbury House. 217-245.

Lozano, C. and Mendikoetxea, A. (forthcoming 2012). 'Learner corpora and second language acquisition: the design and collection of CEDEL2.' In Ballier, N., Díaz-Negrillo, A. and Thompson, P.(eds.) Automatic Treatment and Analysis of Learner Corpus Data. Amsterdam: John Benjamins.

Lozano, C., \& Mendikoetxea, A. (forthcoming 2013). 'Corpus and experimental data: subjects in second language research'. In L. Degand \& S. Granger (Eds.), Corpora and Language in Use. Louvain: Presses universitaires de Louvain.

Lüdeling, A. and M. Kytö (eds.) 2008. Corpus Linguistics. An International Handbook. Vol. 1. Berlin: Mouton de Gruyter.

Mackey, A. and S. Gass 2012. Research Methods in Second Language Acquisition: A Practical Guide. London: Wiley-Blackwell.

Makino, T. 1979. English morpheme acquisition order of Japanese secondary school students. Unpublished PhD Thesis. University of New Mexico, Albuquerque.

Matteini, s. 2007. On the morphosyntactic acquisition of the German DP by Italian adult L2 learners: Possessive constructions, Noun placement and inflectional morphology on nominal modifiers. Unpublished PhD Thesis. University of Firenze.

Matteini, s. 2009. 'L2 strategies of morphological variability in the morphosyntactic acquisition of German DPs' in Actes du colloque Acquisilyon 09. Available at (http://www.ciscl.unisi.it/doc/doc_pub/proceedings_acquisil yon09.pdf).

Mayer, M. 1969. Frog, Where are You? New York: Dial Press.

Mendikoetxea, A., \& Lozano, C. (forthcoming 2013). 'Conceptual and methodological interfaces in SLA research: triangulating corpus and experimental data in L2 SubjectVerb and Verb-Subject alternations.' (S. De Knop \& F. Meunier, Eds.) Corpus Linguistics and Linguistic Theory [Special issue on Learner corpus research, cognitive linguistics and second language acquisition]. 
McEnery, A. M. 2003. 'Corpus linguistics' in Mitkov (ed.), 448463 .

McEnery, T. and A. Hardie 2012. Corpus Linguistics: Method, Theory and Practice. Cambridge: Cambridge University Press.

McEnery, A. M. and A. Wilson 2001. Corpus Linguistics. Edinburgh: Edinburgh University Press.

McEnery, A. M., R. Xiao and Y. Tono 2006. Corpus-based Language Studies. London: Routledge.

McGregor, w. 2009. 'Introduction' in McGregor, W. (ed.) The expression of possession. Berlin: Mouton de Gruyter. 1-13.

Muñoz, C. 2006. Age and the Rate of Foreign Language Learning. Clevedon, Buffalo: Multilingual Matters.

Norris, J. and Ortega, I. 2001. 'Does type of instruction make a difference? Substantive findings from a meta-analytic review' in Ellis, R.(ed.) Form-Focused Instruction and Second Language Learning. Malden, MA: Blackwell.

o'Donnell, M. 2009. 'The UAM Corpus Tool: Software for corpus annotation and exploration.' in Callejas et al. (eds.), 1433-1447.

Perkins, K. and Larsen-Freeman, D. 1975. 'The effect of formal language instruction on the order of morpheme acquisition.' Language Learning, 25 (2) : 237-243.

Pica, T. 1983. 'Adult acquisition of English as a second language under different conditions of exposure.' Language Learning, 33:465-497.

Pienemann, M. 1998. Language Processing and Second Language Development: Processability Theory. Amsterdam: John Benjamins.

Quirk, R. et al. 1985. A Comprehensive Grammar of the English Language. London:Longman.

Ringbom, H. 1987. The Role of the First Language in Foreign Language Learning. Clevedon: Multilingual Matters.

Rosenbach, A. 2007. 'Animacy versus weight as determinants of grammatical variation in English.' Language 81(3): 613-644.

Rothman, J. 2010. 'On the typological economy of suntactic transfer: word order and high/low attachment preference in relative clause interpretations in L3 Brazilian 
Portuguese.' International Review of Applied Linguistics in Language Teaching, 48: 245-275.

Rothman, $\boldsymbol{J}$ and Abrelli-Amaro, J. 2010. 'What variables condition syntactic transfer? A look at the L3 initial state.' Second Language Research, 26:189-218.

Rosansky, E. 1976. 'Methods and morphemes in second language acquisition research.' Language Learning, $26(2)$ : 409-425.

Seidlhofer, B. 2004. 'Research Perspectives on Teaching English as a lingua franca.' Annual Review of Applied Linguistics, $24: 209-239$.

Sinclair, J. 1996. EAGLES. Preliminary Recommendations on Corpus Typology. Available from (http://www.ilc.cnr.it/EAGLES/corpustyp/corpustyp.html) .

Stauble, A.M. 1984. 'A comparison of a Spanish-English and a Japanese-English second language continuum: Negation and verb morphology.' In R. Andersen (ed.), Second languages: $A$ cross-linguistic perspective. Rowley, MA: Newbury House.

Taylor, J.R. 1996. Possessives in English. Oxford: Oxford University Press.

Tono, Y. 2000. 'A computer learner corpus based analysis of acquisition' in Burnard and McEnery (eds.), 123-133.

Tono, Y. 2002. The Role of Learner Corpora in SLA Research and Foreign Language Teaching: The Multiple Comparison Approach. Unpublished PhD Thesis.Lancaster University, UK.

Tono, Y. 2003. 'Learner corpora: design, development and applications' in Archer, Rayson, Wilson and McEnery (eds.), 800-809.

Tono, Y. 2005. Corpus-based SLA Research: State-of-the-Art of Learner Corpus Studies. Tokio:Kurosio Publishers.

Ullman, M. 2001. 'The neural basis of lexicon and grammar in first and second language: the declarative/procedural model.' Bilingualism: Language and Cognition, 4: 105-122.

Ullman, M. 2005. 'A cognitive neuroscience perspective on second language acquisition: declarative/procedural model.' In Sanz, C.(ed.) Mind and Context in Adult Second Language Acquisition. Methods, Theory and Practice. Washington, DC: Georgetown University Press. 141-178. 
Van de Gratts, I. Corver, N. and R. Van Hout. 2000. 'Conservation of Grammatical Knowledge: on the acquisition of possessive noun phrases by Turkish and Moroccan learners of Dutch'. Linguistics, $38(2): 221-314$.

Wagner, J. 2005. 'Acquisition of Grammatical Morphemes in English as a Foreign Language Learners' Available at (http: //www. ielanguages.com/documents/papers/Masters\%20semi nar.pdf)

Willemse, P., Davidse, K. and Heyvaert, I. 2009. 'English possessives as reference-point constructions and their function in the discourse.' in McGregor, W.(ed.) The expression of possession. Berlin: Mouton de Gruyter. 13-50

Williams, S. and Hammarberg, B. 1998. 'Language switches I L3 production: Implications of a polyglot speaking model.' Applied Linguistics, 19:295-333.

Zobl, H. and $\boldsymbol{J}$. Liceras 1994. 'Functional categories and the acquisition orders.' Language Learning, 44(1) : 159-180. 


\section{Appendices}

\subsection{Learner Profile for L2 English and for I3 German}

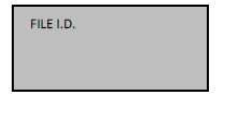

Fecha:

\section{INFORMACIÓN PERSONAL}

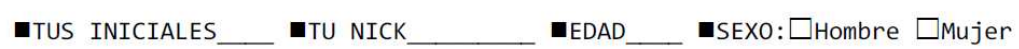

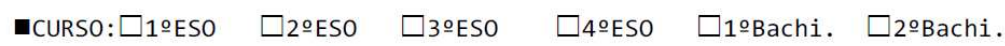

$\square$ PCPI $\square$ Grado administrativo $\square$ otro

-INSTITUTO DONDE ESTÁS ESTUDIANDO:

\section{INFORMACIÓN LINGÜÍSTICA}

- Lengua materna: $\square$ español $\square$ otra (indicar):

- Lengua materna de tu padre: $\square$ español $\square$ otra (indicar):

- Lengua materna de tu madre: $\square$ español $\square$ otra (indicar):

- Lengua(s) que hablas en casa: $\square$ español $\square$ otras (indicar):

Edad a la que empezaste a aprender inglés

¿Cuál crees tú que es tu nivel de inglés?

\begin{tabular}{l|l|l}
\hline SPEAKING: & LISTENING: & READING:
\end{tabular}

|l|l $\quad$ WRITING:

\begin{tabular}{l|l|l|l} 
DPrincipiante bajo (A1) & $\square$ Principiante bajo (A1) & $\square$ Principiante bajo (A1) & WPrincipiante bajo (A1)
\end{tabular}

Intermedio bajo (B1) $\quad$ Intermedio bajo (B1) $\quad$ Intermedio bajo (B1)

\begin{tabular}{l|l|l|l}
$\square$ Intermedio alto (B2) & $\square$ Intermedio alto (B2) & $\square$ Intermedio alto (B2) & $\square$ Intermedio bajo (B1) \\
\hline Intermedio alto (B2)
\end{tabular}

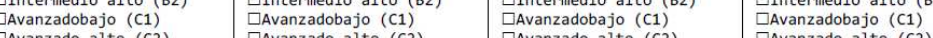

\begin{tabular}{l|l|l} 
DAvanzado alto (C2) & $\square$ Avanzado alto (C2) & $\square$ Avanzado alto (C2) \\
\hline
\end{tabular}

¿¿Estás aprendiendo otro idioma además del inglés? $\square$ sí $\square$ No Si tu respuesta es SÍ, ¿Cuál?

- Nota del curso pasado (a rellenar por el profesor de inglés):

\section{EXPOSICIÓN LINGÜÍSTICA}

- ¿Has hecho alguna estancia en un país de habla inglesa? $\square$ sí $\square$ No Si tu respuesta es SÍ, ¿dónde?

¿Cuándo?

¿Cuántas semanas o meses estuviste allí?

घ ¿Has estudiado o estudias inglés fuera del instituto? $\square$ sí $\square$ No Si has contestado SÍ, ¿en qué año y cuánto tiempo (semanas/meses)?

- ¿Haces algo fuera del colegio relacionado con el inglés? (ej: ver películas en inglés, leer internet en inglés, etc.) $\square$ sí $\square$ No

Especifica:

¿Estás en algún programa de bilingüismo en el Instituto? $\square$ sí $\square$ No Si tu respuesta es SÍ, ¿en qué curso empezaste el bilingüismo? ¿Qué asignaturas bilingües tienes?

¿Cuántas horas semanales de inglés tienes en esas asignaturas?

Consentimiento: $\square$ marca aquí para dar el consentimiento de que tus datos sean usados con fines de investigación sobre el aprendizaje del inglés. Esto No es un examen. Todos tus datos serán anónimos y tratados confidencialmente. Gracias por tu colaboración. 


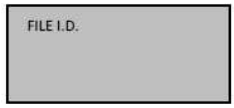

Fecha:

\section{INFORMACIÓN PERSONAL}

-TUS INICIALES

-TU NICK

- EDAD

घSEX: $\square$ Hombre $\square$ Mujer

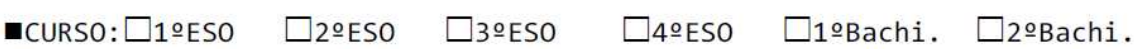

$\square$ PCPI $\square$ Grado administrativo $\square$ otro

- Centro DONDE ESTÁS ESTUDIANDO:

\section{INFORMACIÓN LINGÜISTICA}

- Lengua materna:

$\square$ español $\square$ otra (indicar):

- Lengua materna de tu padre: $\square$ español

$\square$ otra (indicar):

- Lengua materna de tu madre: $\square$ español

$\square$ otra (indicar):

- Lengua(s) que hablas en casa: $\square$ español $\square$ otras (indicar):

Edad a la que empezaste a aprender alemán

¿ ¿Cuál crees tú que es tu nivel de alemán?

Sprechen:

口Principiante bajo (A1)

DPrincipiante alto (A2)

$\square$ Intermedio bajo (B1)

$\square$ Intermedio alto (B2

$\square$ Avanzadobajo (C1)

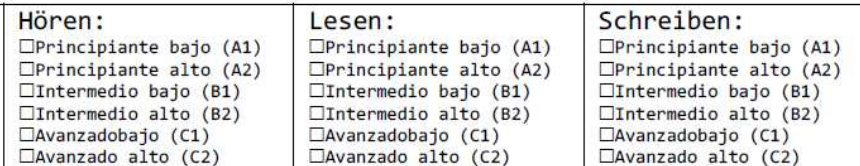

- ¿Estás aprendiendo otro idioma además del alemán? $\square$ sí $\square$ No Si tu respuesta es SÍ, ¿Cuál?

- Nota del curso pasado (a rellenar por el profesor de alemán):

\section{EXPOSICIÓN LINGÜÍSTICA}

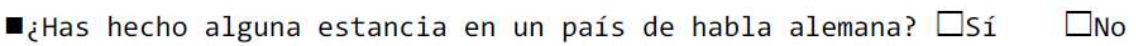
Si tu respuesta es SÍ, ¿dónde?

¿cuándo?

¿Cuántas semanas o meses estuviste allí?

- ¿Has estudiado o estudias alemán fuera del instituto? $\square$ sí $\square$ No Si has contestado SÍ, ¿en qué año y cuánto tiempo (semanas/meses)? Note that this question was included only in the learner profile given to the secondary education students of IES Padre Suarez

- ¿Haces algo fuera del colegio relacionado con el alemán? (ej: ver películas en alemán, leer internet en alemán, etc.) $\square$ sí $\square$ No

Especifica:

Consentimiento: $\square$ marca aquí para dar el consentimiento de que tus datos sean usados con fines de investigación sobre el aprendizaje del inglés. Esto No es un examen. Todos tus datos serán anónimos y tratados confidencialmente. Gracias por tu colaboración. 


\subsection{Proficiency test: L2 English}

\section{English}

\section{Written test}

- Choose the best answer for each question.

Stop when the questions become too difficult.

Spend no more than 40 minutes on the test.

\begin{tabular}{|c|c|c|c|}
\hline 1 & $\begin{array}{l}\text { Where } \\
\text { I'm from Russia. } \\
\begin{array}{ll}\text { A you are } & \text { B you }\end{array}\end{array}$ & c & are you \\
\hline & $\begin{array}{l}\text { We have house in Moscow. } \\
\begin{array}{ll}A \text { any } & B \text { a }\end{array}\end{array}$ & c & an \\
\hline & $\begin{array}{l}\text { I have two } \\
\begin{array}{ll}A \text { sons } & \text { a boy and a girl. } \\
B \text { daughters }\end{array}\end{array}$ & C & children \\
\hline 4 & $\begin{array}{l}\text { I work in a } \\
\begin{array}{ll}\text { A hospital } & \text { I'm a doctor. }\end{array}\end{array}$ & c & supermarket \\
\hline & $\begin{array}{l}\text { This is my brother. } \\
\begin{array}{ll}\text { A Her } & \text { B His }\end{array}\end{array}$ & c & He's \\
\hline & $\begin{array}{l}\text { five people in my family. } \\
\text { A They are }\end{array}$ & c & There are \\
\hline & $\begin{array}{l}\text { I get up } \\
\begin{array}{ll}A \text { for } & \text { o'clock in the morning. }\end{array}\end{array}$ & c & in \\
\hline & $\begin{array}{l}\text { I like apples, but I } \\
\text { A don't like }\end{array}$ & c & do like \\
\hline & $\begin{array}{lc}\text { Excuse me, } & \text { speak French? } \\
\text { A do you } & \text { B you do }\end{array}$ & c & you \\
\hline & $\begin{array}{l}\text { How much are } \\
\begin{array}{ll}\text { A this } & \text { shoes? } \\
B \text { these }\end{array}\end{array}$ & $c$ & that \\
\hline
\end{tabular}

Unglismited Placement test Written test

11 Where are my glasses? They're the table.
A at
$B$ on
$C$ in

12 My sister tennis very well.

$\begin{array}{lll}A & \text { plays } & \text { B play playing }\end{array}$

13

I usually go to work __t train.

$A$ on $B$ with

c by

14

I don't see my parents very often they live in South Africa.

15 Rosie stayed B but C because

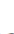
$A$ in home yesterday afternoon.

6 Last night 1 $B$ at $C$ to
A went
$B$ did go
C was

to the cinema.

17 The is quite expensive but the food there is excellent.
A film
B restaurant
c book

18 Do you want to listen to music or TV?

A see

B look

G watch

19 were you at the weekend?
A wis in Scotland.
A when
B where
C What

20

Yes, it was fun.
A Did
B were
C Had

21
A Maria
B Marias
c Maria's

22 Bob will meet

at the airport.

A us

B we

C our

23 I'm going to a concert tonight.

B Are 

A could I

25
A money
B rent
is too expensive for $m e$.

26

Excuse me, how do

to the bus station?

A come

27

Do you sell stamps?

Yes, we do. How

$A$ any

Co you want?

Sorry I'm so late.

That's
A OK
B great

c arrive

29

l'd like

milk in my coffee, please.

A some

$B$ any

30

a bus stop near my flat.

$$
\text { B Here's C There's }
$$

31 Is this a good time to talk? Sorry, no. 1 dinner.
A cook
$B$ am cooking
C cooking

32 I think cycling is more dangerous driving.
$A$ as
B like
C than

$3: 3$

We going to the theatre next Saturday.

$A$ will $B$ do $C$ are

34
A Let's
c Shall they

35

Kamal has got a holiday home near __ sea.
A a
B the
c some

Ennlisimited Placement test Written test

36 If you've got a headache, you A should

B did

C had

37
A Have you B Are you ever been to New York?

C Did you

38 I only get about five hours' sleep a night That's not
A renough
B lot
C too much

39 Did Amina finish the report? No. She it tomorrow
A finishes
$B$ is going to finish
C finished

40 Paula loves working with children.
A very
$B$ really
C much

41 Is Ottawa the capital of Canada? I think
$A$ is
B yes
C so
D right

42 We never a television when I was a child.
A have had
$B$ hadn't
C had
D didn't have

43 We paid the restaurant bill
A to
B with
$C$ on
D by

44 The last time

Joanna was in Paris.
A have seen
B saw
C see
D was seeing

45 If you money from a friend, you should always pay it back promptly.
A borrow
$B$ earn
C spend
$D$ lend

46 Can I make myself a cup of coffee? Of course. You_to ask.
A haven't
B mustn't
C needn't
D don't have

47 a lot of sport in my free time.
A do
$B$ practise
C make
$D$ exercise

48 anywhere interesting recently?
A Do you go
B Have you been

C Are you going

D Will you go

Unglish United Placement test Written test 


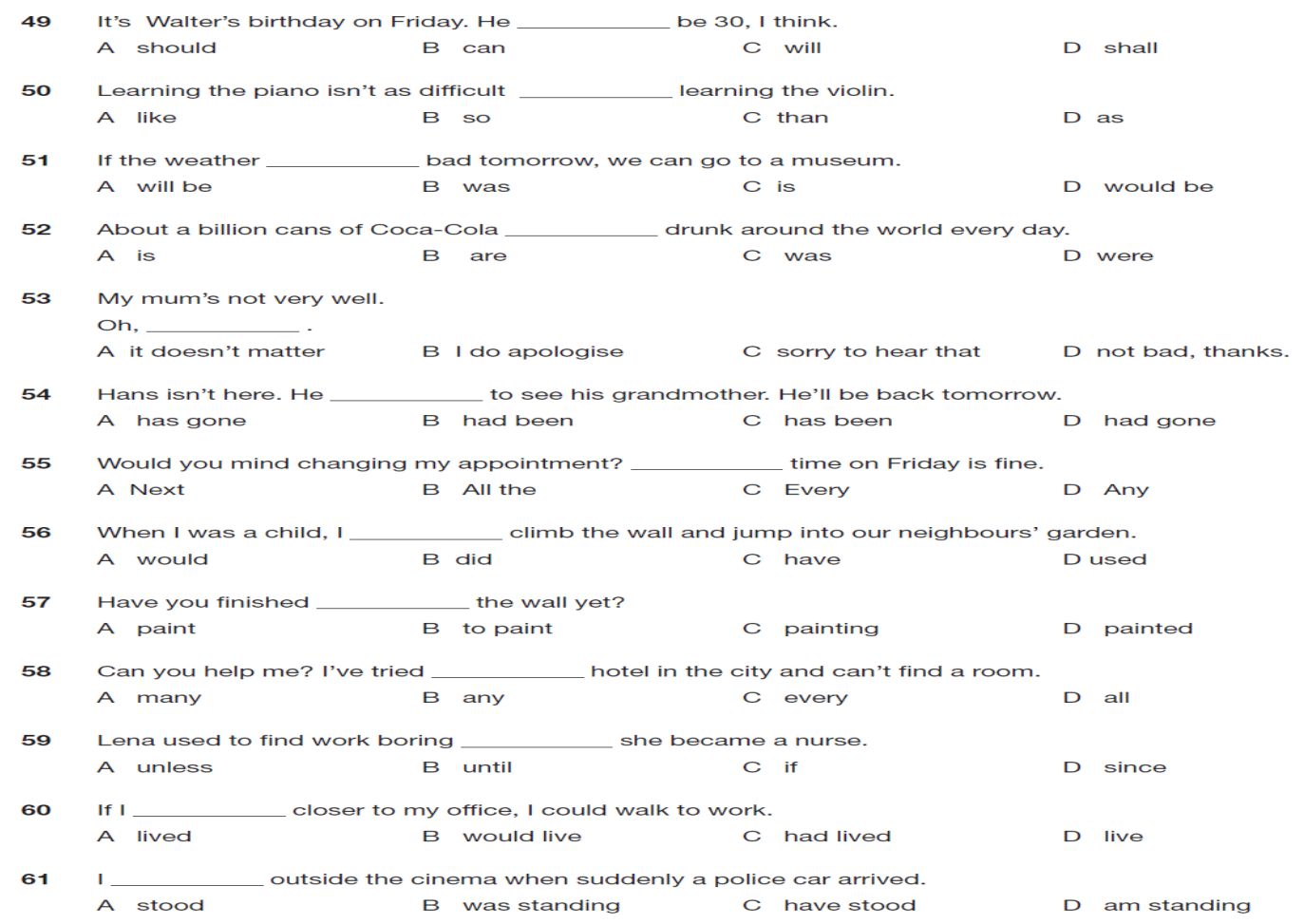

Englishited Placement test Written test

62 Shall we go to The Riceboat for dinner? It be fully booked. They're sometimes busy on a Monday.
A will
B may
C can
D must

63 We've come back from a trip to India. It was amazing.
A already
B yet
C just
D only

64 I've got to be at work in five minutes. Don't worry, I __ you a lift if you want.
A give
$B$ am giving
C 'll give
D 'm going to give

65 My doctor advised me more exercise.
A take
B taking
C having taken
D to take

66 I couldn't up with the noise in the city, so we moved to the countryside.
A put
B live
C set
D take

67 There's no name on this dictionary.

It be mine then. Mine's got my name on the front.
A might not
B mustn't
c won't
D can't

68 Julia married since she was 20 .
$A$ is
B was
C has been
$D$ is being

69

Don't worry if I

late tonight. I'm going to the gym after work.
A am
B will be
C would be
D was

7o I've got a terrible headache, and it won't go away. Have you tried___some aspirin?
A to take
B take
C took
D taking

71 Boxing is a sport requires a lot of speed and fitness.
A it
$B$ that
c what
D where

72 Jon_working on this project for a couple of months so he hasn't made much progress yet.
A is only
$B$ has only been
C was only
D had only been

$73 \quad$ I was wondering I could ask you some questions. Sure, go ahead.
A what
$B$ if
C that
D how 
What clothes should I pack for a trip to Boston?

Well, it depends_the time of year that you go.
$A$ on
$B$ with
C up
$D$ to

75 I've finished this salad and I'm still hungry. I___ ordered something more filling.
A must have
C should have
D may have

Do you ever ask your neighbours to do favours ___ you?
A for
$B$ to
C with
D about

over time.
A alike
B same
c like
D equal

78 I don't know how much this card casts. The price label's
A gone
B taken
c done
D come

79 Ben got the job because he_a very good impression at his interview.
A made
B did
C put
D took

80 Salsa music always me of my trip to Cuba.
A remembers
$B$ realises
C recognises
D reminds

81

to be picking Tom up at the station but l've lost my keys.
A am supposed
$B$ am requested
C am intended
D am obliged

82 How about going to Calours nightclub? There's no I'm going there. It's awfull
A hope
B way
C time
D opportunity

83 By the age of 18,1

not to go to university.
A had decided
B decided
C have decided
D was deciding

84 I'm afraid your car___ repaired before next week.
A hasn't been
B wasn't
C wouldn't be
D can't be

85 The amount of organically grown food on sale has_enormously in recent years.
A raised
B lifted
C increased
$\mathrm{D}$ built

86 Can you believe it? A woman has been

for hacking into the computer of her online virtual husband.
A accused
B suspended
C arrested
D suspected

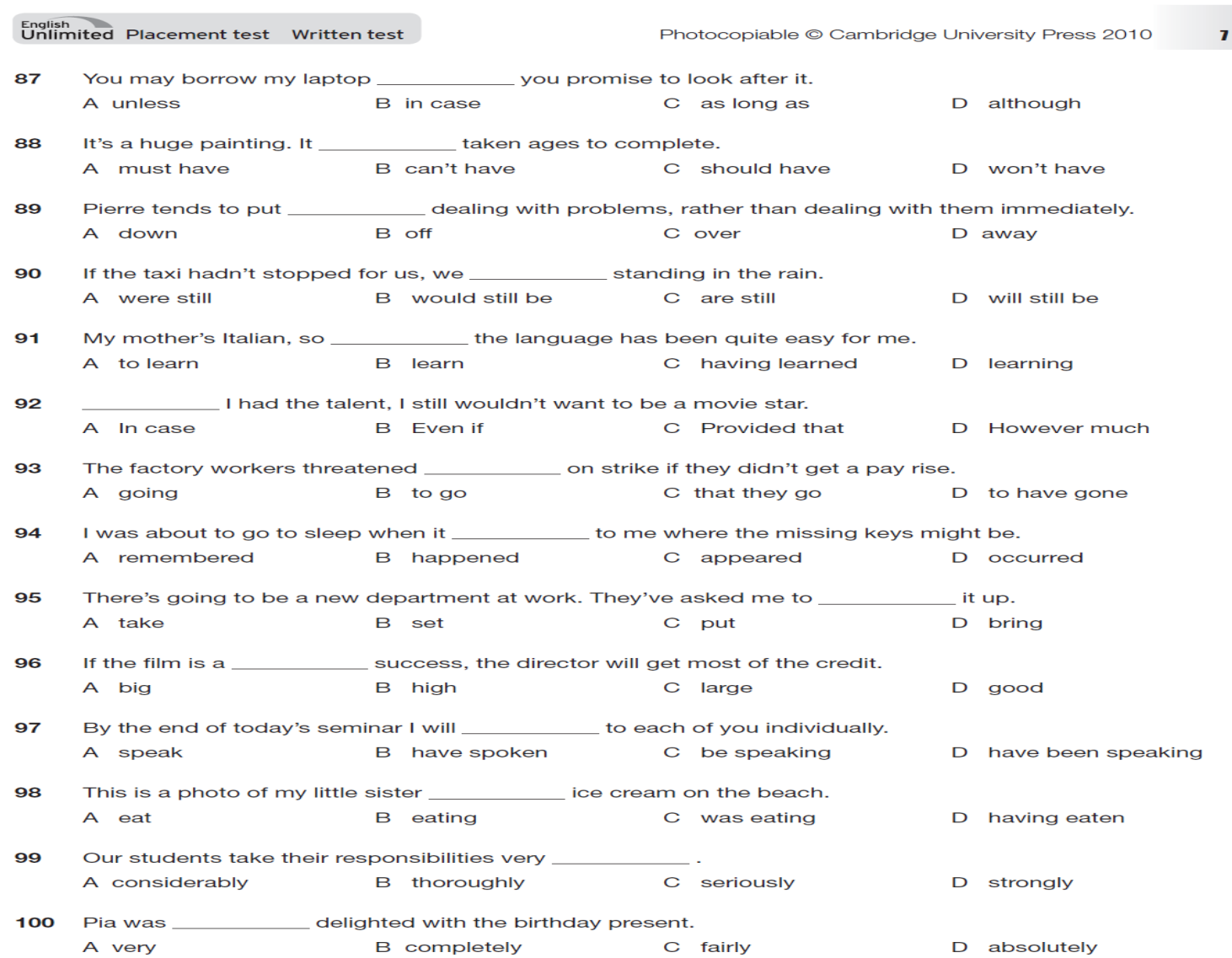




\section{English}

\section{Unlimited Placement test}

\section{Teacher's guide}

This placement test is designed to help teachers decide at which level of English Unlimited new students should be placed.

The test contains:

- 120 written multiple-choice questions, 20 at each level from Starter to Advanced (covering CEF levels A1 to C1). The questions focus on the language taught across the six levels of English Unlimited.

- an oral placement test, designed to be used in conjunction with the written test. The questions in this test are linked to the goals in the English Unlimited coursebooks, which in turn are based on the CEF 'can-do' statements. The oral test is designed to be flexible. This should allow teachers to get an overview of students' speaking ability in order to 'fine-tune' their assessment of the correct level at which to place students.

- keys and tables for interpreting scores.

\section{Written test procedure}

1 Ask the student to start at the beginning of the written test and stop when the questions become too difficult. Allow 30-40 minutes for the test.

2 Mark the test and use the table below to place the student provisionally at one of the six levels of English Unlimited.

3 Use the oral placement test to confirm or adjust this placement (see Oral test procedure below).

\begin{tabular}{|l|l|l|l|l|l|l|}
\hline & Starter & Elementary & $\begin{array}{l}\text { Pre- } \\
\text { intermediate }\end{array}$ & Intermediate & $\begin{array}{l}\text { Upper } \\
\text { Intermediate }\end{array}$ & Advanced \\
\hline $\begin{array}{l}\text { Written } \\
\text { test score }\end{array}$ & $0-15$ & $16-35$ & $36-55$ & $56-75$ & $76-95$ & $96+$ \\
\hline
\end{tabular}


Prueba de Nivel de Alemán Nivel Básico 1 A1 Grammatik- und Wortschatztest 1.- Tobias kommt _-_-_-_-_-_-_-_- Berlin.
a) von b) aus c) in

2.- Am Morgen fahre ich mit

a) der b) den c) dem

3.- Das Kind Tobias.

a) heißt b) bin c) hei $\beta$ e 4.- Mein Mann in Berlin.

a) arbeite b) wohnst c) arbeitet

5.- Wir reisen oft Bahn.

a) bei b) mit c) mit der

6. Morgens trinke ich Kaffee.

a) keinen b) nicht c) kein

7.- Tobias ____________ immer sehr schnell.

a) sprecht b) spreche c) spricht

8.- Sonntags _-________ ich um 9.30

a) stehe/- b) aufstehe/- c) stehe/auf

9.- Jeden Tag haben wir vier

a) Uhren b) Stunden c) Stunde

10.- Auf dem Tisch gibt es drei

a) Buch b) Bücher c) Heft

11.- Am Wochenende

a) ich nicht lerne b) lerne ich nicht c) nicht ich lerne

12.- Heute habe ich

a) nicht Zeit b) Zeit nicht c) keine Zeit

13 . du nach Hause?

a) Kommt b) Kommst c) Kommen 14 .Sie bitte!

a) Wartet b) Warten c) Warte 15. Ich verstehe dich nicht. a) Sprichst du b) Sprechen sie c) Sprich 16.- Lekeitio liegt

a) $a n$ b) am c) ans

17 . August fahren wir nach Deutschland.

a) $\mathrm{Am} \mathrm{b}$ ) Im c) -

18. - Ich bin

a) in b) am c) -

19.- Das Bild hängt an 1983 geboren.
a) die b) das
c) der

20.- Ich habe

a) dein b) deinen c) deiner

21. - Maria hat schon

a) seine b) ihre c) deine

22 . - Ich

a) habe b) bin c) ist

23. - Tobias hat Pasta

a) kochen b) gekocht c) kocht

24.- Wir haben unsere Bücher

a) vergisst b) vergesst c) vergessen

25.- Ich muss zum Arzt

a) gehen b) gegangen c) geht bitte lauter! Meer. 
26.- Hier man nicht rauchen. Es ist verboten.

a) muss b) kann c) darf

27.- Komm zu mir,

a) wenn du willst! b) wenn willst du! c) wenn du will!

\section{Prueba de Nivel de Alemán Nivel Básico 2 A2}

\section{Grammatik- und wortschatztest}

1.- Hans _-_-_-_- eigentlich Ingenieur werden. Aber er ist Mechaniker geworden.

a) möchte b) wollte c) will

2.- Die Chefin hat mit Sekretärin gesprochen .

a) ihrer b) ihrem c) seiner

3.-Ich möchte in einem Land leben,

schöne Landschaften hat.

a) der b) den c) das

4.- Deine Mutter hat angerufen. Du früh nach Hause kommen.

a) magst b) sollst c) willst

5.- Heute Morgen haben wir

in der Firma verabschiedet.

von unseren Kollegen

a) uns b) einander c) es

6.- Beate ist ein bisschen größer _-_-_- ihre Zwillings chwester.

a) ob b) wie c) als

7.- Peter hat die Prüfung bestanden. wir heute eine Party bei ihm.

a) Denn b) Deshalb c) Obwohl

8.- Die Frau mit dem von Frank.

Kleid ist die schwester

a) roten b) rotem c) rotes

9. - _-_ ich mein studium abgeschlossen habe, war ich schon 30 .

a) Wenn b) Wann c) Als

10.- Du, ich brauche deinen Wagen. Würdest du

leihen?.

a) er mir b) mir es c) ihn mir

11. - In _____ Monat fahre ich nach Berlin.

a) ein b) einen c) einem

12.- _-____ ich keine zigaretten mehr rauche, atme ich viel besser.

a) Als b) Nach c) Seit

13. - sie haben

a) $\operatorname{sich}$ b) ihr c) ihnen

14.- Ich habe meinen Laptop mitgebracht,

feiern Text lesen kannst.

a) deshalb b) denn c) damit

15.- Mein Vater interessiert sich sehr Politik

a) $\mathrm{an} b)$ für c) von

16.- Ich muss mit dem Arzt einen Termin

a) vereinbaren b) verbinden c) verbleiben

17. - Ich habe mich sehr

deine Einladung gefreut.

a) vor b) mit c) über

18. - Ich weiß nicht, Peter meine E-mail bekommen hat.
a) wenn
b) dass
C) $\mathrm{ob}$ 
19.- Ich habe meine Brille auf den Tisch und jetzt ist sie nicht mehr da.
a) gelegen b) gelegt c) gelogen
$20 .-$ Wochenende haben wir Zeit uns zu erholen.
a) $\mathrm{Am}$ b) An c) An die
21.- Der Freund, wollte, hat einen Unfall gehabt.
a) den b) von dem c) mit dem

22.- _-____ ich mit der Arbeit fertig bin, gehe ich zu meinen Freunden.

a) Als b) Wenn c) Wann

23.- _-_____ weiß, warum er uns so belogen hat.

a) Alle b) Keiner c) Jeden

24.- Gestern ______ ich keine billige Eintrittskarte für die oper besorgen.

a) konnte b) mochte c) sollte

25.- Die Lehrerin hat das Kind gelobt,

es hat eine sehr schöne Geschichte geschrieben.

a) damit b) deshalb c) denn

26.- Das Wochenende haben wir _______ dem Land verbracht.
a) auf b) in c) an

27. - Ist ______ in Ordnung? Du siehst müde aus.

a) alle b) alles c) etwas

28 . Das Auto

a) hat b) bin c) wird

29.- _-____ Sie mir bitte sagen, wo ich meinen Laptop anschließen kann?
a) Konnten
b) Könnten
c) $\mathrm{H} \ddot{\mathrm{t} t \mathrm{ten}}$

Prueba de Nivel de Alemán Nivel Intermedio 1 B 1.1

\section{Grammatik- und wortschatztest}

1. - Karl, ......... Freundin im siebten Monat schwanger ist, hat gestern seine Arbeit verloren.
a) deren b) seine c) dessen

2. - "Ich bin sehr ........ deiner Meinung interessiert."

a) $\mathrm{an}$ b) $\mathrm{für}$ c) $\operatorname{von}$

3. - Eine Woche ......... er seinen Führerschein gemacht hatte, hatte er bereits seinen ersten Unfall.

a) seitdem b) nachdem c) seit

4. - Sie versucht es immer wieder auf ......... Weise, aber dieses Mal wird es nicht funktionieren.
a) ihrer b) derselben c) dieselbe

5. - "Lass die Tasche ruhig liegen. Du ........ sie nicht wegzuräumen. "

a) brauchst b) musst c) verstehst

6. - "Kannst du mir mal sagen, ........ . du Angst hast?"

a) vor wen b) wovor c) was

7. - "Ich bin wütend ........ Klaus, weil er nicht mit mir ausgehen will."
a) wegen
b) $f \ddot{i r}$
c) auf

8. - "........ ich enttäuscht von ihm bin, bin ich doch seine Freundin."

a) Trotzdem b) Deswegen c) Obwohl

9. - ........ einer Arbeit im väterlichen Betrieb wählte er einen Lehrberuf bei der stadtverwaltung. 
a) An b) Statt c) In

10. - "Wenn sie noch nicht hier sind, dann sind sie bestimmt wieder den ......... Weg gefahren."

a) weitesten b) größten c) stundenlangen

11. - "Er ist wieder einmal zu spät gekommen, ....... wir ohne ihn anfangen mussten."

a) warum b) zumal c) so dass

12. - "Das ist der Kollege, ........ ich dir erzählt habe."

a) von dem b) über den c) wovon

13. - Letzten Sommer in Hamburg hat María ......... Deutsch gesprochen."

a) viel b) viele c) mehrere

14. - ......... länger man übt, ......... besser klappt es dann.

a) Je / desto b) Zwar / aber c) Sowohl / als auch

15. - Es ist Herbst, da verlieren die Bäume ihre .....................

a) $\ddot{A} s t e$ b) Büsche c) Blätter

16. -.......... bezahlen 3 Euro Eintritt, Kinder unter 16 Jahren die Hälfte.

a) Eltern b) Große c) Erwachsene

17. - Die Sekretärin klebte den Brief zu und warf ihn

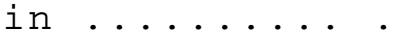

a) die Mailbox b) den Briefkasten c) die Post

18. - Mein Computer hat eine Maus, einen Monitor und

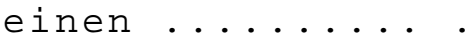

a) Schreiber b) Laser c) Drucker

19. - Zum Kaffee essen die Müllers gerne ein stück .....................

a) Brötchen b) Teigware c) Kuchen

20. - "Ich war schon in Lateinamerika und Asien." - "Dann

bist du aber schon viel.........."

a) gefahren b) gegangen c) gereist

21. - Die Brücke trägt nur 5 Tonnen......... dürfen sie nicht benutzen.

a) Fahrräder b) Fußgänger c) LKWs

22. - Diese Informationen möchte ich auf einer CD ...................

a) lagern b) speichern c) liegen

23. - Den Sommer möchten wir bei unseren ....... in London verbringen.

a) Bekanntem b) Bekannten c) Bekannte

24. - Der Postbote konnte den Brief nicht zustellen, weil Herr Braun die........ falsch notiert hatte.

a) Bankleitzahl b) Postleitzahl c) Postnummer

25. - In der Eile hatte Peter ganz vergessen einzupacken. Jetzt musste er so ins Bett gehen.

a) den Schlafanzug b) das Schlafhemd c) die Nachthose

26. - Seit ich sport treibe, funktioniert mein ........ besser.

a) Blutlauf b) Blutsystem c) Kreislauf

27. - Um endlich eine nette Partnerin zu finden, hat Klaus in der sektion "Lonely Hearts" seiner Lokalzeitung ............ aufgegeben.

a) eine Werbung b) eine Anzeige c) einen Hinweis 
28. - Petra möchte ihrer Mutter beim Tischdecken helfen und hat schon einmal die ........ aus der schublade geholt.

a) Dosenöffner b) Bestecke c) Kochlöffel

Prueba de Nivel de Alemán Nivel Intermedio 2 B 1.2 Grammatik- und Wortschatztest

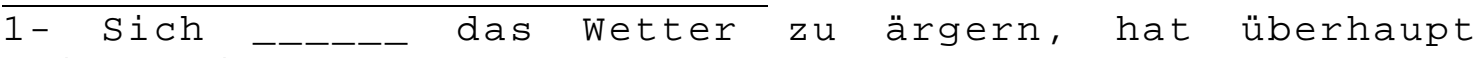
keinen Sinn.
a) auf
b) $\mathrm{an}$
c) über

$2-\operatorname{Er}$ das

Essen seiner Frau mit dem seiner Mutter.

a) vergeht b) vergibt c) vergleicht

3- Ich habe _-___ in dieser Sache getäuscht.

a) $\mathrm{mich}$ b) $\mathrm{mir}$ c) es

4- _-_____ eines Maschinenschadens kam die U-Bahn heute Morgen verspätet an.

a) Trotz b) Während c) Wegen

5 - Es ist verboten einen Wagen

a) zu überholen b) überholen c) überzuholen

6- _-_-_- sie den chef sprechen konnte, war schon die Kündigung eingetroffen.

a) Bevor b) Wenn c) Nachdem

7- Die Arbeitslosigkeit müsste

a) bekämpfen b) bekämpft werden c) bekämpft worden

8- Nur wenige Menschen haben einen so guten Geruchssinn, sie vermuten.

a) wie b) als c) da

9- • - _-_-__ sie den ganzen Tag arbeitet, hat sie immer noch zeit für ihre alte Tante.

a) Dennoch b) Deshalb c) Obwohl

10- Sie dürfen nicht alles durch eine

Brille sehen.

a) rosa b) rote c) schwarze

11-Die _-_____ Zeitung berichtet von einer ganz aktuellen Entwicklung.

a) heutliche b) heutige c) heuzutage

12 - Wenn Sie einen _______ suchen, rufen sie uns umgehend an.

a) Beschäftigung b) Nebenjob c) Stelle

13- Auch mit deiner Hilfe hätte ich nichts

a) gemacht können b) machen gekonnt c) machên können.

14 - Der Opersänger lernt Deutsch, er interessiert sich für deutsche Komponisten.

a) denn b) da c) darum

$15-$ Wir müssen uns Klima anpassen .

a) an das b) an den c) am

16- Im verlassenen Dorf sind Häuser

a) vertragen b) verfallen c) verzogen

17- Die studentin hat ein stipendium _-_____-_, um in Deutschland ihre Doktorarbeit schreiben zu können.

a) beantragt b) beworben c) bestellt

18 - Die studenten, die Prüfung gut gelungen ist, sind zufrieden.

a) denen b) die c) dessen

$19-$

diesem Wetter bleiben wir lieber zu Hause. 
a) Mit b) Während c) Bei

20- Ein Angestellter, der nicht pünktich ist,

a) werde entlassen b) wäre entlassen c) wird entlassen 21- Die _-______ des Fußballspiels beginnt um 19:00 Uhr.

a) Niederlassung b) Übertragung c) Veröffentlichung 22 - Hätte ich

a) ja b) $\operatorname{mal}$ c) bloß

23- Das Buch soll ein_______ Publikum erreichen können.

a) weites b) breites c) braves

24- _-_-_ der Computer kaputt ging, hatte ich nur die Hälfte meiner Arbeit gespeichert.

a) Wenn b) Wann c) Als

25- Er konnte eine vom Lehrer ________ Frage nicht beantworten.

a) gestellte b) gestellten c) gestellter $26-$ ihrer Mühe hat sie keine guten Ergebnisse bekommen.

a) Infolge b) Trotz c) Dank

27-Die Teilnahme der Demo war gefährlich.

a) $a u f$ b) in c) an

$28-\operatorname{Er}$ ist eine sehr

Person, die immer bereit zu helfen ist.

a) hilfsbedürftige b) hilflose c) hilfsbereite 


\subsection{Elicitation of Learner Language: Picture Composition Task}

\section{FROG WHERE ARE YOU?}

Glossary: Dog (perro), frog (rana), boy (niño), bed (cama), vase (vaso), floor (suelo), look at (mirar a), smell (oler), day (día), night (noche), sleer (dormir), escape (escapar), worried (preocupado), look for (buscar), shout (gritar), forest (bosque), bee (abeja), rock (roca), hold (sostener), branch (rama) deer (ciervo), drop (caer), push (empujar), fall (caer), river (río), water (agua), trunk (tronco), find (encontrar), family (familia), leave (dejar), hand (mano) and wave qoodbve (decir adios).

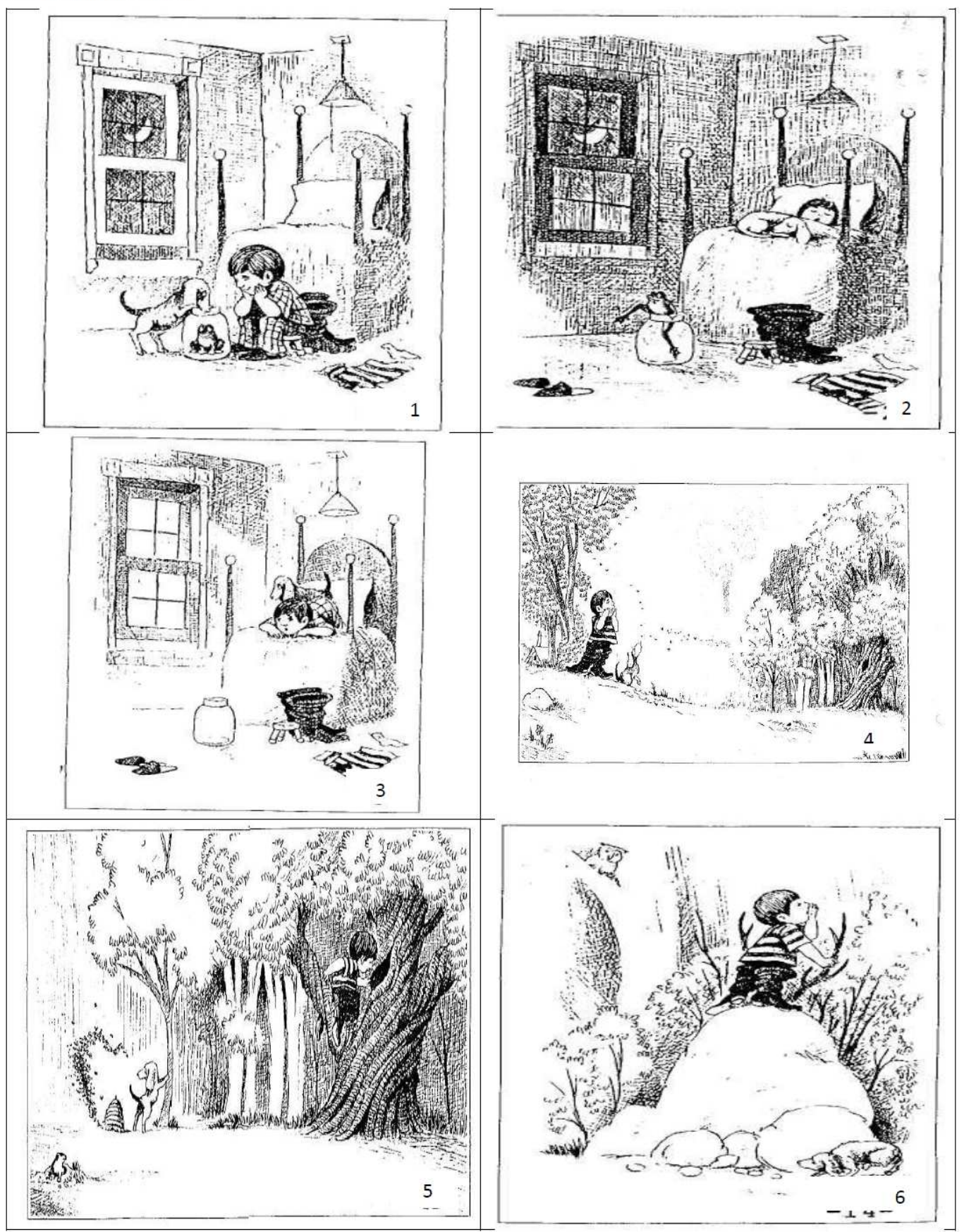



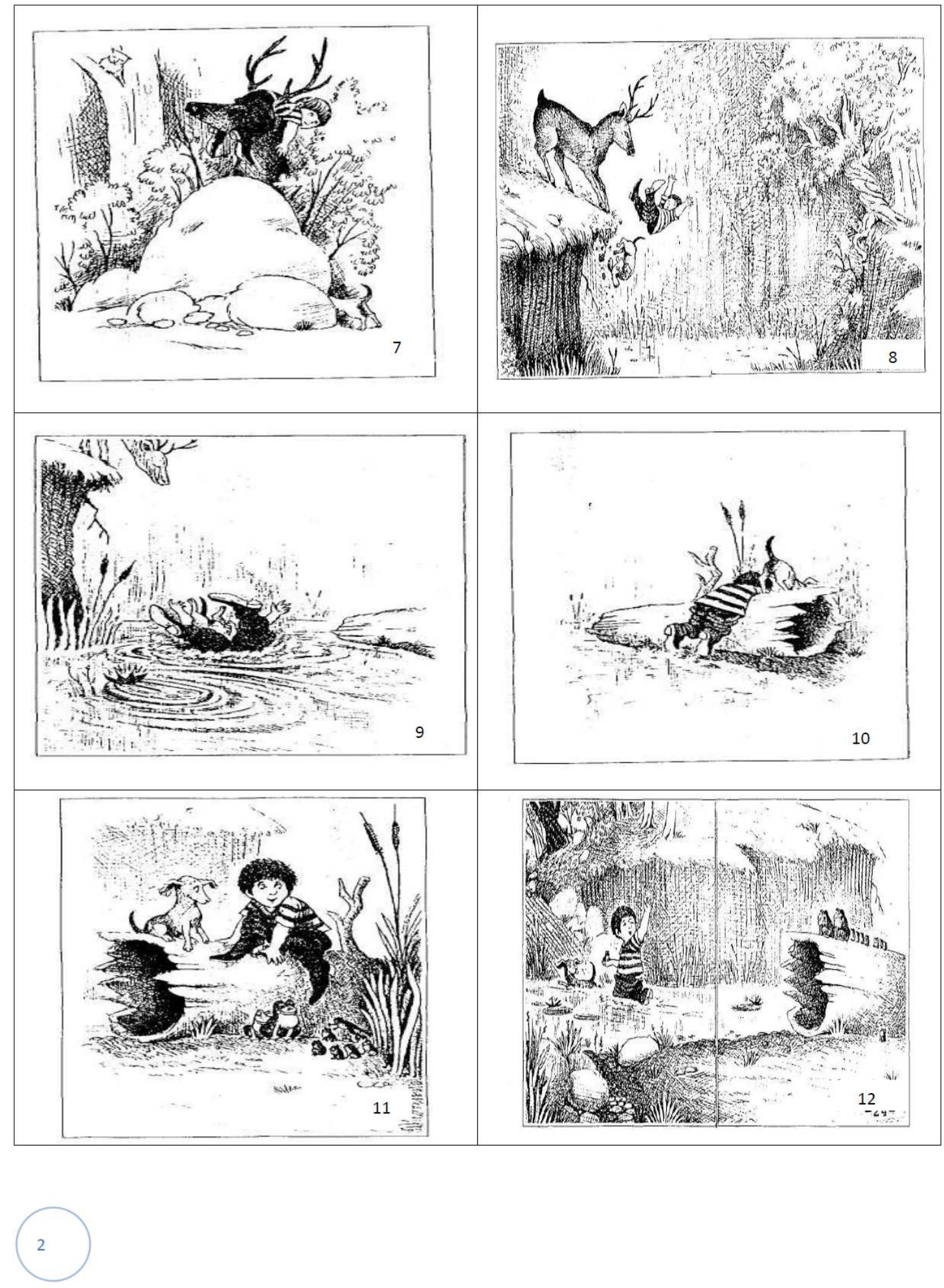

Pictures reproduced by Mayer (1969), with permission of the author/artist and publisher. 


\subsection{Experimental Elicitation of Learner Language: Sentence Transformation Task: English \& German}

Rewrite the sentences below replacing the underlined words with the words in brackets.

\section{A. English:}

1. This is his car. (my father)

2. Her sister fell off the swing. (Maria)

3. Their shoes are in the locker. (boys)

4. Their toys were left out in the rain. (children)

5. Her computer was broken. (woman)

6. His truck was dirty. (man)

B. German:

1. Das ist sein Auto. (mein Vater)

2. Ihre Schwester fiel von der Schaukel. (Maria)

3. Ihre Schuhe sind im Schrank. (Jungen)

4. Ihre Spielzeuge blieben im Regen draußen liegen. (Kinder)

5. Ihr Computer/Rechner war kaputt. (Frau)

6. Sein LKW war schmutzig/dreckig. (Mann) 


\subsection{Transcription Template}

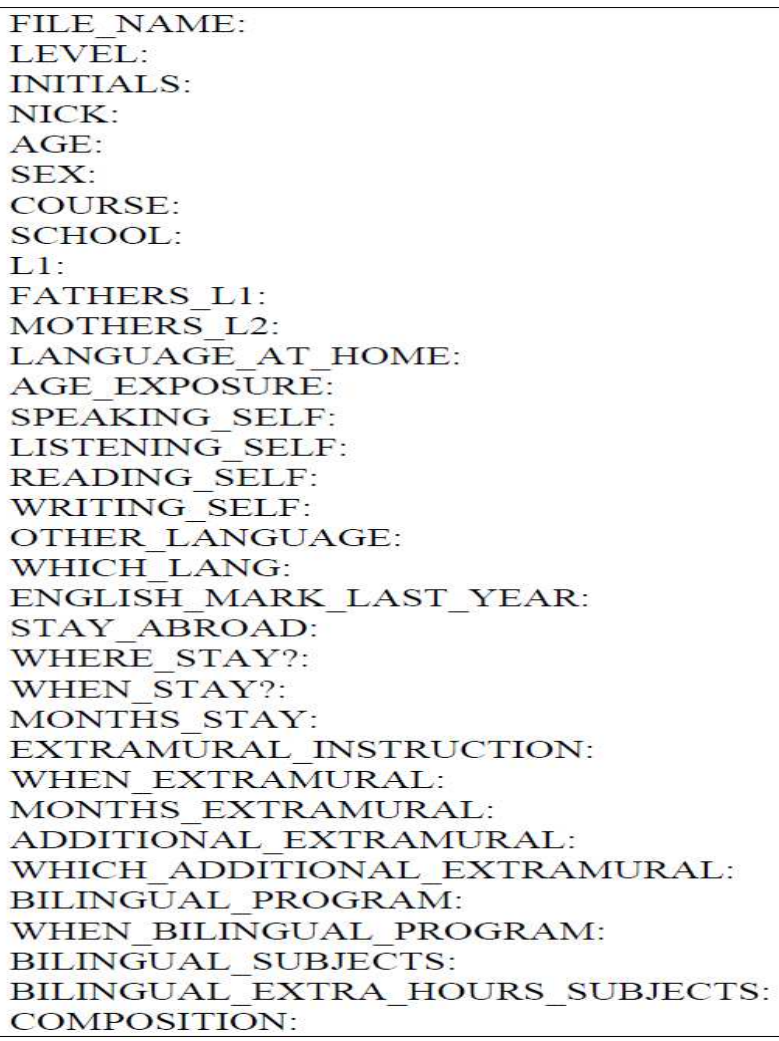

\subsection{Examples}

\subsubsection{Learner Corpus Transcribed File}

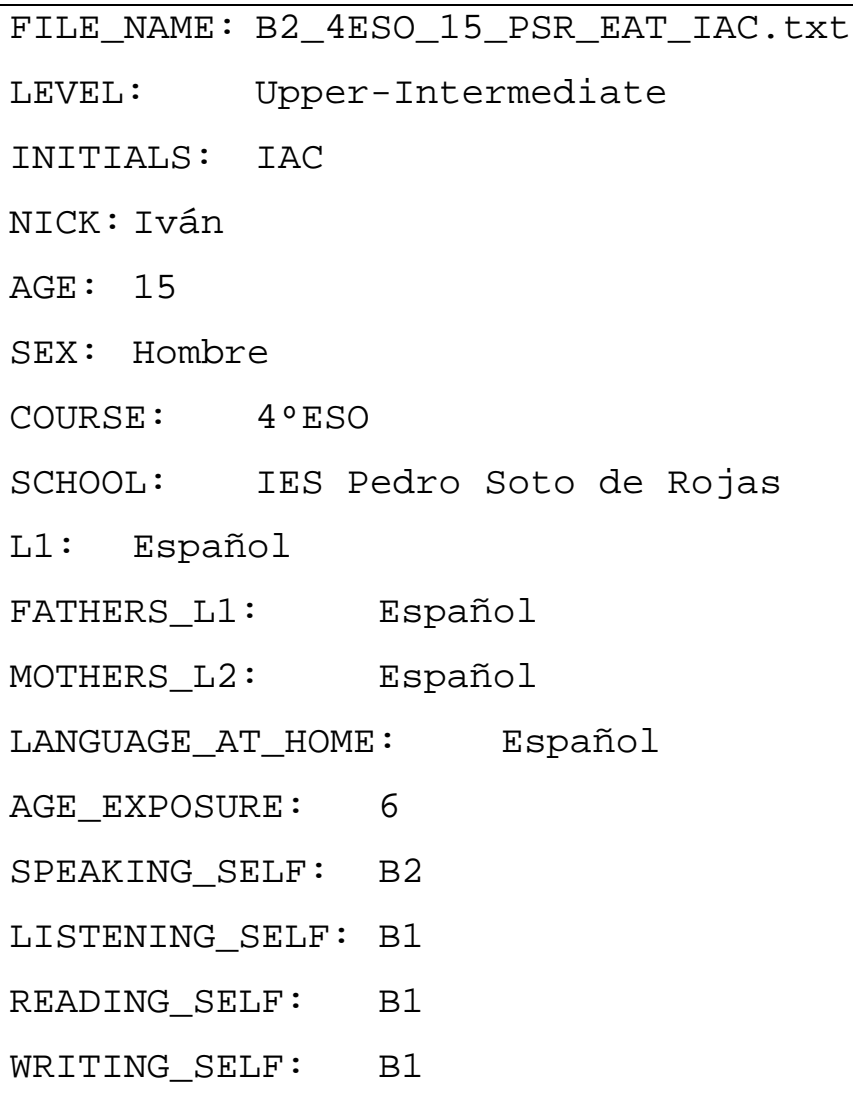




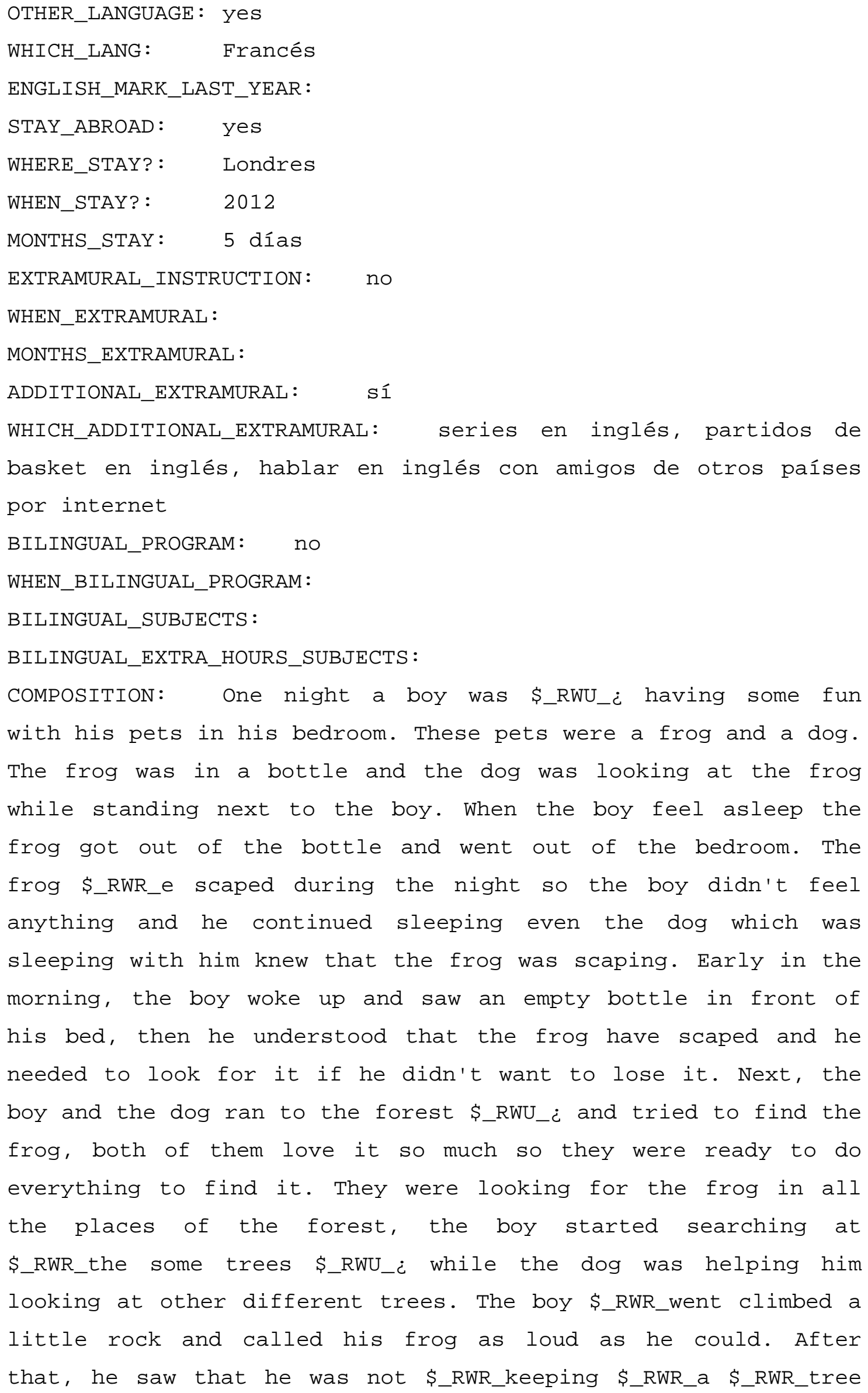


holding a branch to maintain his equilibrium, he was holding a deer! Then, the deer pushed him down the mountain and the boy dropped with his dog. The boy and the dog fell \$_RWU_i in the water, but they didn't suffer any injury or hurt. They returned to loonk for the frog pulling a trunk that they found next to them. When they got on the trunk, they could see a family of little frogs where the dog were looking for was. The boy caught his frog and then, \$_RWU_i all of them \$_RWU_i went back home. The boy and his dog felt very happy and they wave goodbye to the frog family.

\subsubsection{Sentence Transformation Transcribed File English}

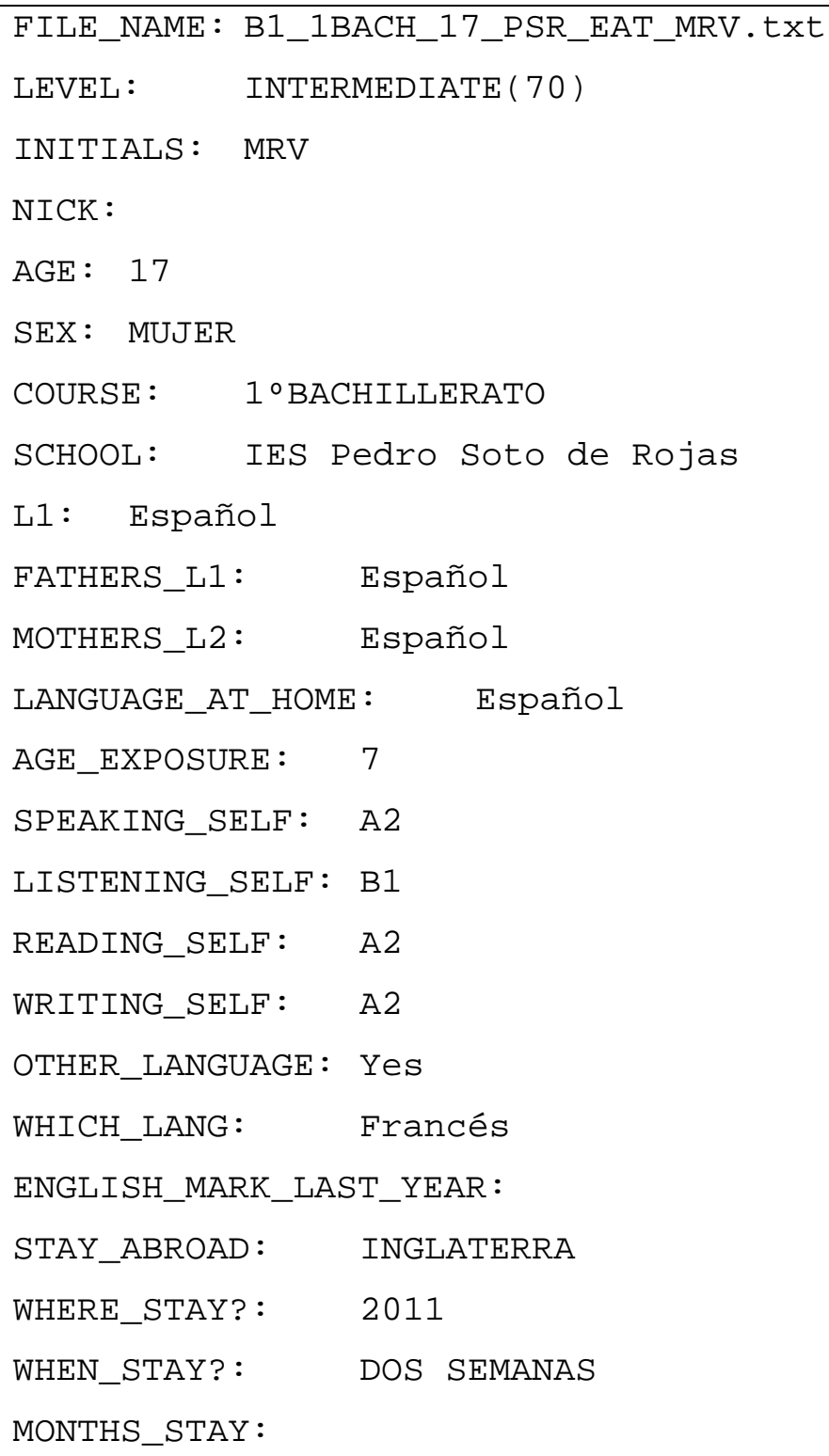




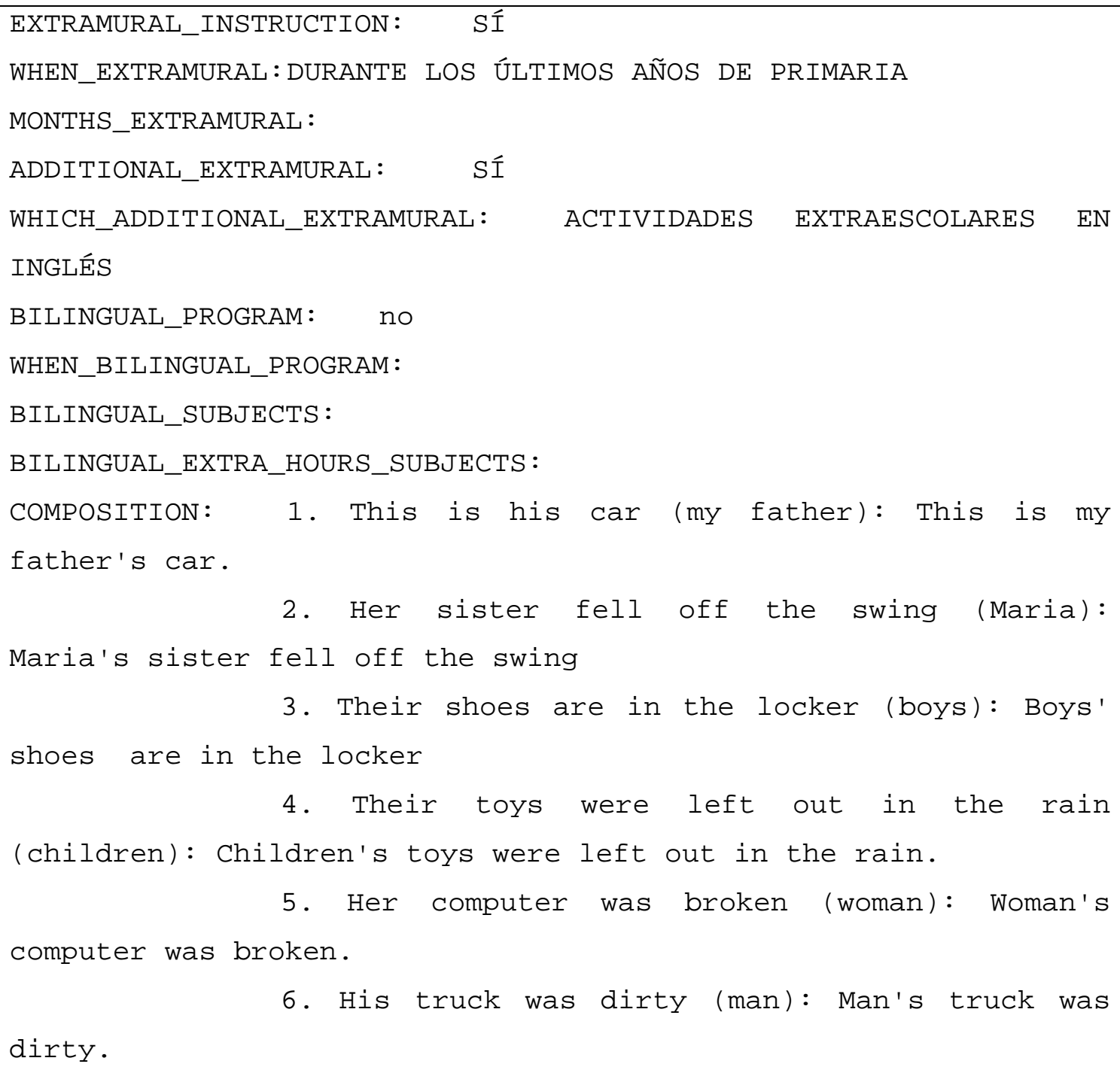

\subsubsection{Sentence Transformation Transcribed File German}

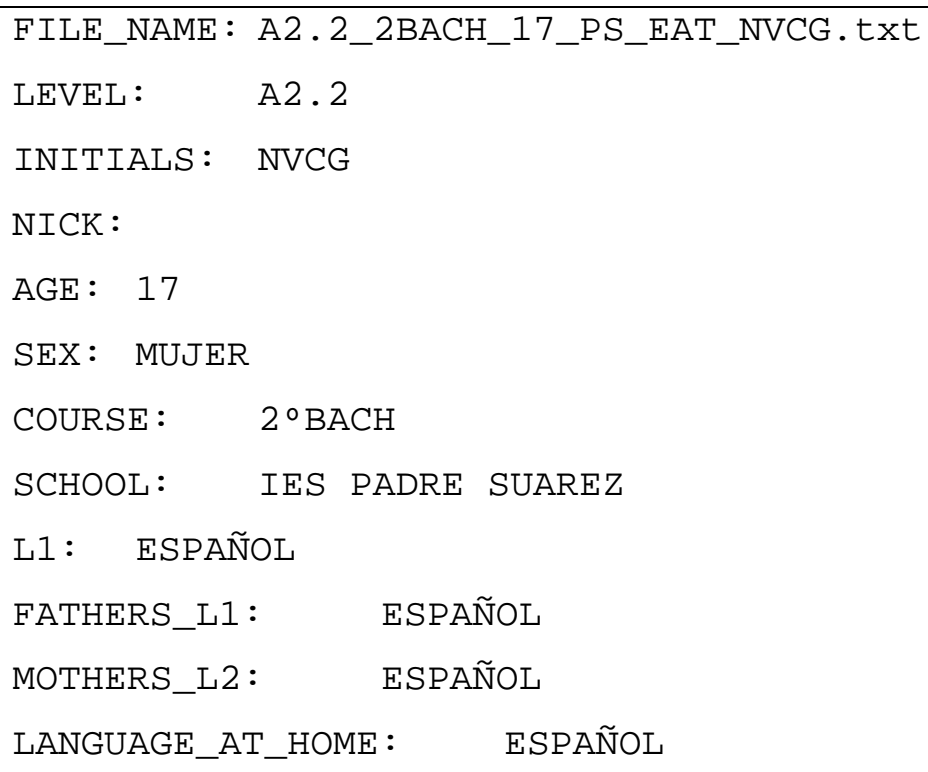




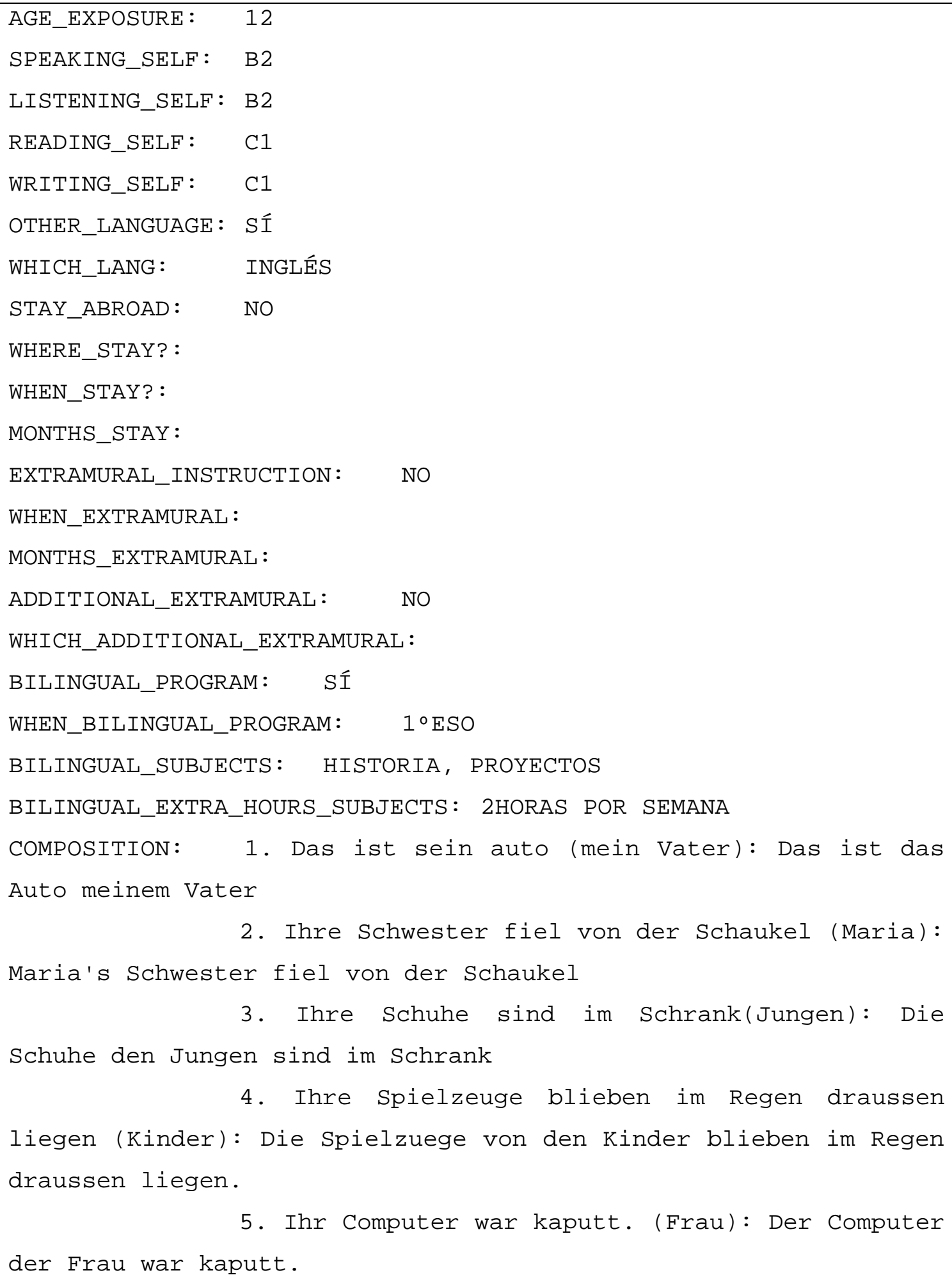

5. Ihr Computer war kaputt. (Frau): Der Computer der Frau war kaputt. 


\begin{abstract}
WHEN_EXTRAMURAL: NO
MONTHS EXTRAMURAL: NO

ADDITIONAL_EXTRAMURAL: YES

WHICH_ADDITIONAL_EXTRAMURAL: READING SCIENTIFIC ARTICLES

BILINGUAAL_PROGRAMM:YES

WHEN_BILINGUAL_PROGRAM: 2010

BILINGUAL SUBJECTS: SOCIAL SCIENCES, MATHS

BILINGUAL_EXTRA_HOURS_SUBJECTS: 6

COMPOSITION: A boy called $\bar{C}$ harles was in his bedroom with his pets: a dog c: was sleeping when his frog escaped from its glass. The next day, Charles \& his worried. They went to the forest to search it very quickly. Firstly, they saw in a tre searched behind a rock but it wasn't there. There, there was an enormous beer th Afterwards, they left from the water and they saw a trunk on the land. Behind it, th the three arrived home very happy. Charles never forget this accident and now he

$\langle\langle\langle\rangle\rangle$ lgnore Delete Other Action... Save Close llelp VG

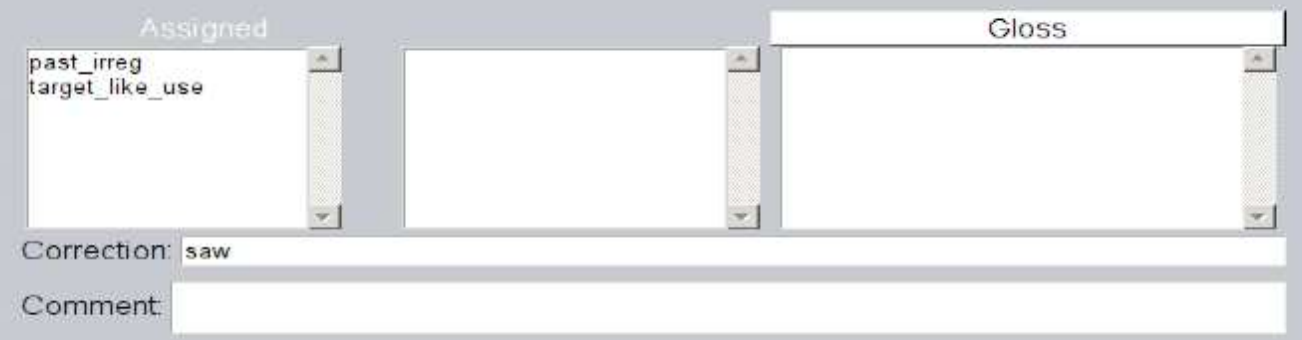

9.9 Tagging Manual: Learners' correction tagging scheme

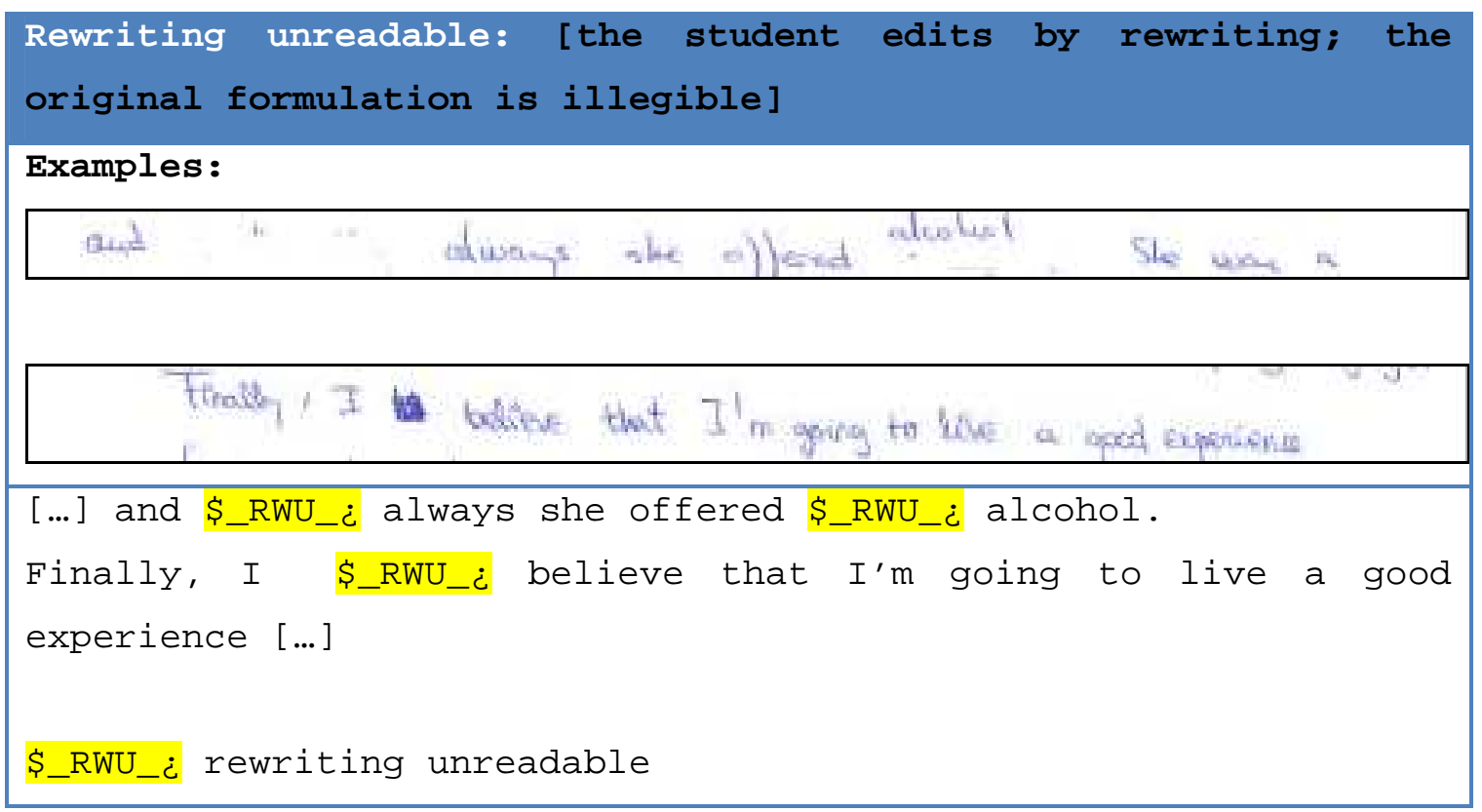


Rewriting readable: [the student edits by rewriting; the original formulation is legible]

Example:

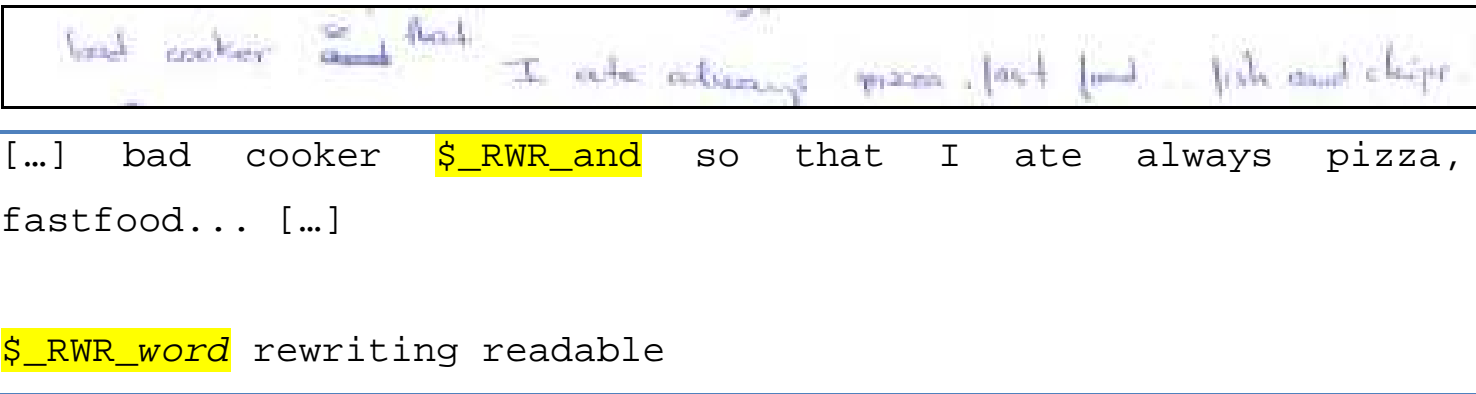

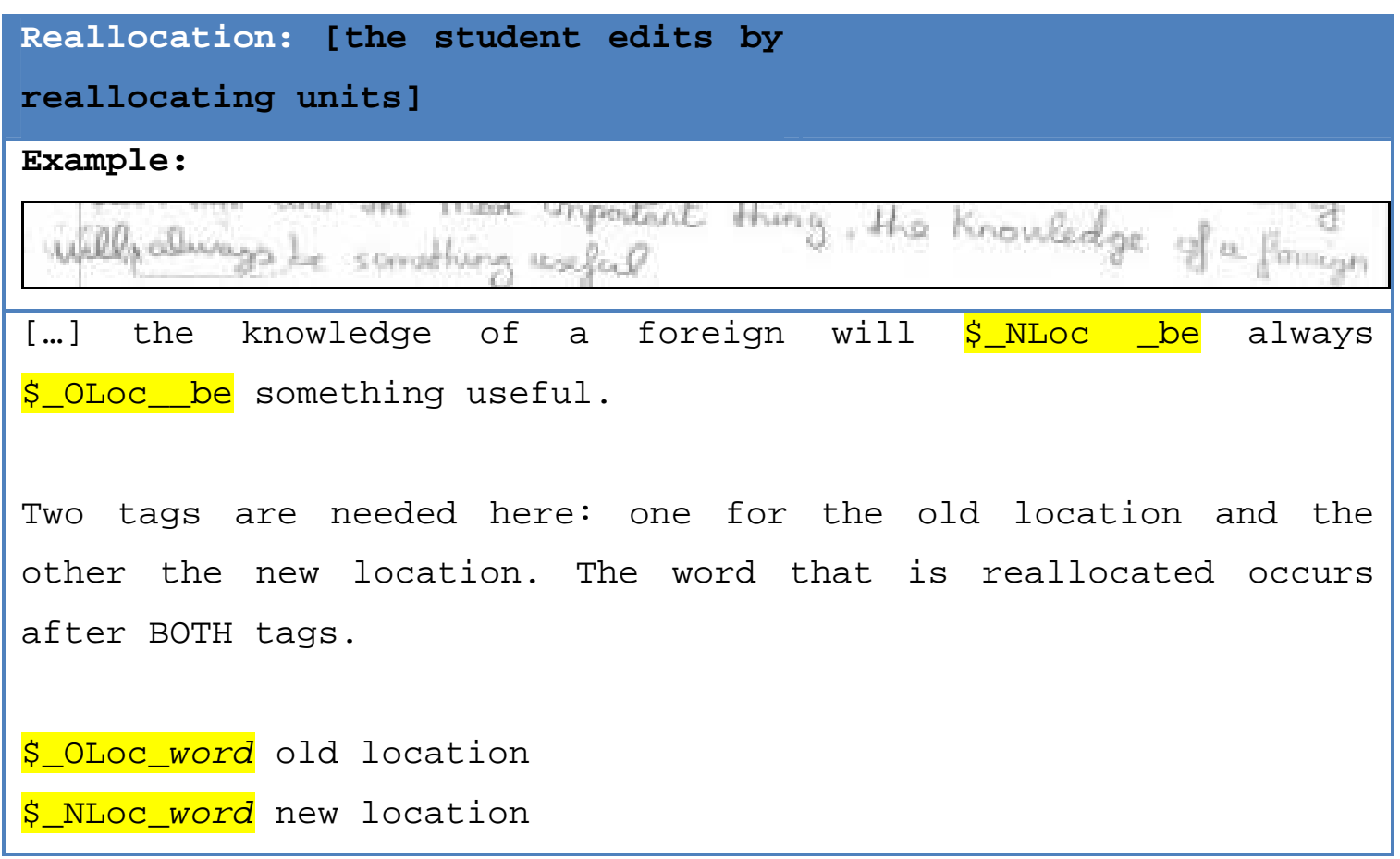

\section{Iate insertion: [the student edits by inserting new units]}

\section{Example:}

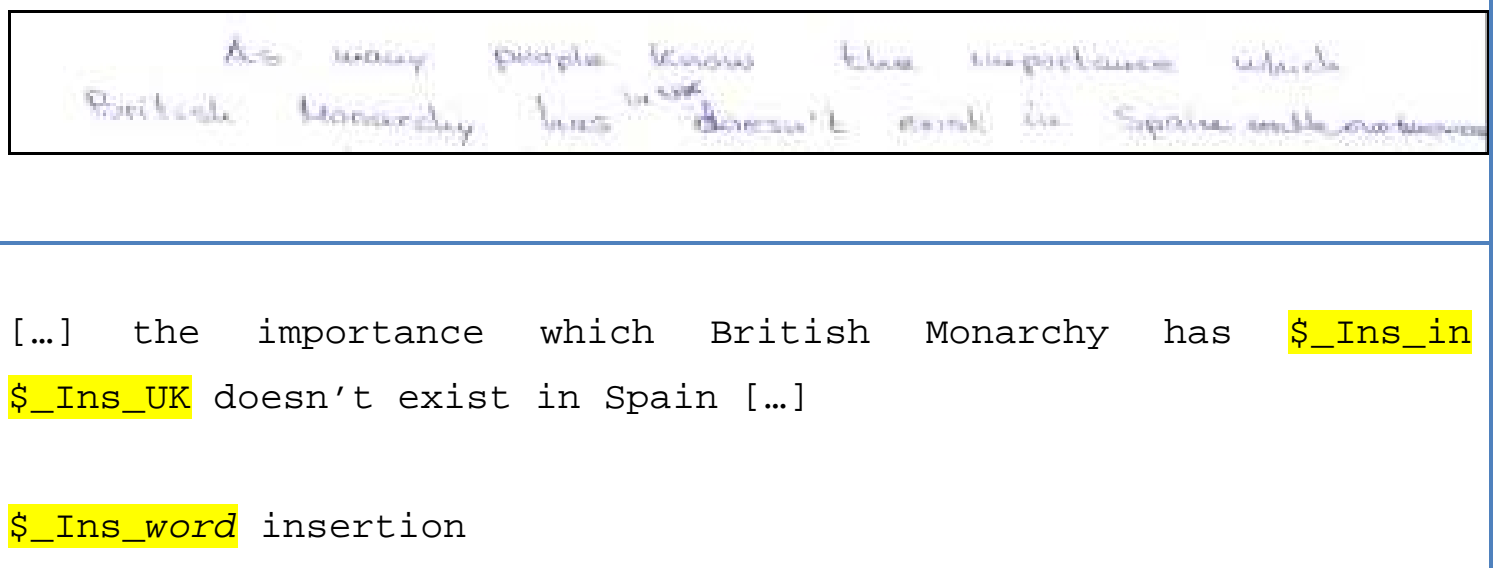


Unreadable: [the student's writing is unintelligible]

Example :

\$_UNR_i unreadable 


\subsection{Tagging Manual: MOS Project}

Morpheme tagging scheme for Past regular

\begin{tabular}{|c|c|c|c|}
\hline \multicolumn{3}{|c|}{ OC: Past reg (Peter walked yesterday) } & S: Supplied form \\
\hline \multicolumn{2}{|c|}{$\begin{array}{l}\text { Target-like Use } \\
\text { (correct form supplied) }\end{array}$} & & Peter walked yesterday \\
\hline \multirow[t]{3}{*}{$\begin{array}{l}\text { Non-target- } \\
\text { like Use }\end{array}$} & Underuse & & Peter walk__ yesterday \\
\hline & \multirow[t]{2}{*}{ Misuse } & $\begin{array}{l}\text { Misselection } \\
\text { (form exists) }\end{array}$ & Peter walking yesterday \\
\hline & & $\begin{array}{l}\text { Misrealisation } \\
\text { (form does not } \\
\text { exist) }\end{array}$ & $\mathbf{n} / \mathbf{a}$ \\
\hline \multicolumn{3}{|c|}{ OC: ing (Peter is walked $[=$ walking]) } & SNOC \\
\hline & & $\begin{array}{l}\text { Overuse } \\
\text { (correct form } \\
\text { supplied but in } \\
\text { NOC) }\end{array}$ & Peter is walked \\
\hline
\end{tabular}

Morpheme tagging scheme for Past Irregular

\begin{tabular}{|c|c|c|c|}
\hline \multicolumn{3}{|c|}{ OC: Past irreg (Peter stole yesterday) } & S: Supplied form \\
\hline \multicolumn{2}{|c|}{$\begin{array}{l}\text { Target-like Use } \\
\text { (correct form supplied) }\end{array}$} & & Peter stole yesterday \\
\hline \multirow[t]{4}{*}{$\begin{array}{l}\text { Non-target- } \\
\text { like Use }\end{array}$} & $\begin{array}{r}\text { Underuse } \\
\text { (no form } \\
\text { supplied) }\end{array}$ & & Peter steal__ yesterday \\
\hline & \multirow{3}{*}{$\begin{array}{l}\text { Misuse } \\
\text { (incorrect } \\
\text { form } \\
\text { supplied) }\end{array}$} & $\begin{array}{l}\text { Misselection } \\
\text { (form exists) }\end{array}$ & Peter stealing yesterday \\
\hline & & \multirow[t]{2}{*}{$\begin{array}{l}\text { Misrealisation } \\
\text { (form does not } \\
\text { exist) }\end{array}$} & Peter stealed yesterday \\
\hline & & & Peter stoled yesterday \\
\hline \multicolumn{3}{|c|}{$O C: 3^{\text {rd }}$ sing (Peter never stole $[=$ steals $]$ ) } & SNOC \\
\hline & & $\begin{array}{l}\text { Overuse } \\
\text { (correct form } \\
\text { supplied but in } \\
\text { NOC) }\end{array}$ & Peter never stole \\
\hline
\end{tabular}


Morpheme tagging scheme for Third person singular $-s$

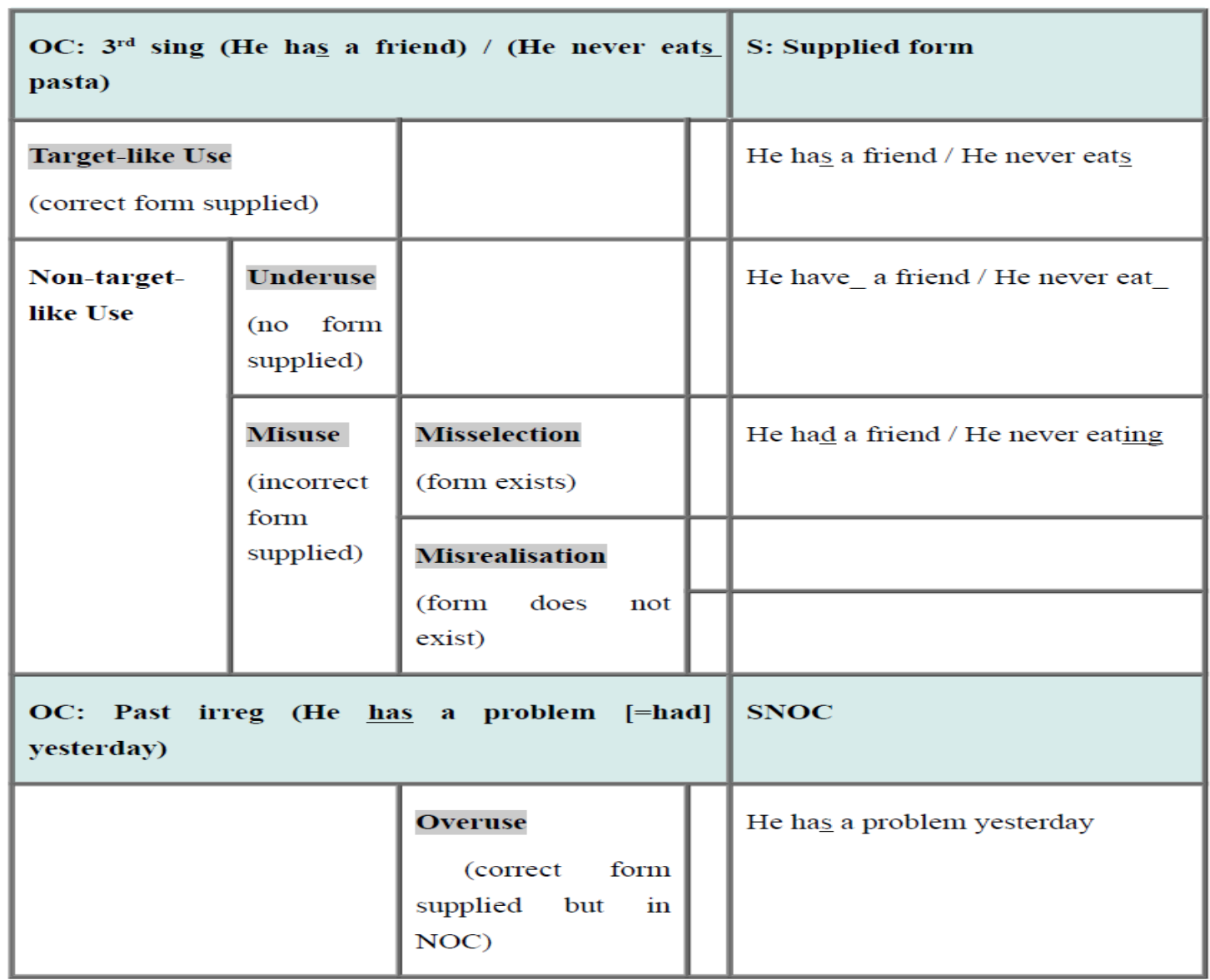

Morpheme tagging scheme for Present progressive -ing

\begin{tabular}{|c|c|c|c|}
\hline \multicolumn{3}{|c|}{ OC: Progressive (Peter is swimming) } & S: Supplied form \\
\hline \multicolumn{2}{|c|}{$\begin{array}{l}\text { Target-like Use } \\
\text { (correct form supplied) }\end{array}$} & & Peter is swimming \\
\hline \multirow[t]{3}{*}{$\begin{array}{l}\text { Non-target- } \\
\text { like Use }\end{array}$} & $\begin{array}{l}\text { Underuse } \\
\text { (no form } \\
\text { supplied) }\end{array}$ & & Peter is swim \\
\hline & \multirow{2}{*}{$\begin{array}{l}\text { Misuse } \\
\text { (incorrect } \\
\text { form } \\
\text { supplied) }\end{array}$} & $\begin{array}{l}\text { Misselection } \\
\text { (form exists) }\end{array}$ & Peter is swims \\
\hline & & $\begin{array}{l}\text { Misrealisation } \\
\text { (form does not }\end{array}$ & n.a. \\
\hline \multicolumn{3}{|c|}{ OC: $3^{\text {rd }}$ sing (Peter swimming $[=$ swims $]$ every day) } & SNOC \\
\hline & & $\begin{array}{l}\text { Overuse } \\
\text { (correct form } \\
\text { supplied but in } \\
\text { NOC) }\end{array}$ & swimming \\
\hline
\end{tabular}


Morpheme tagging scheme for Copula Be

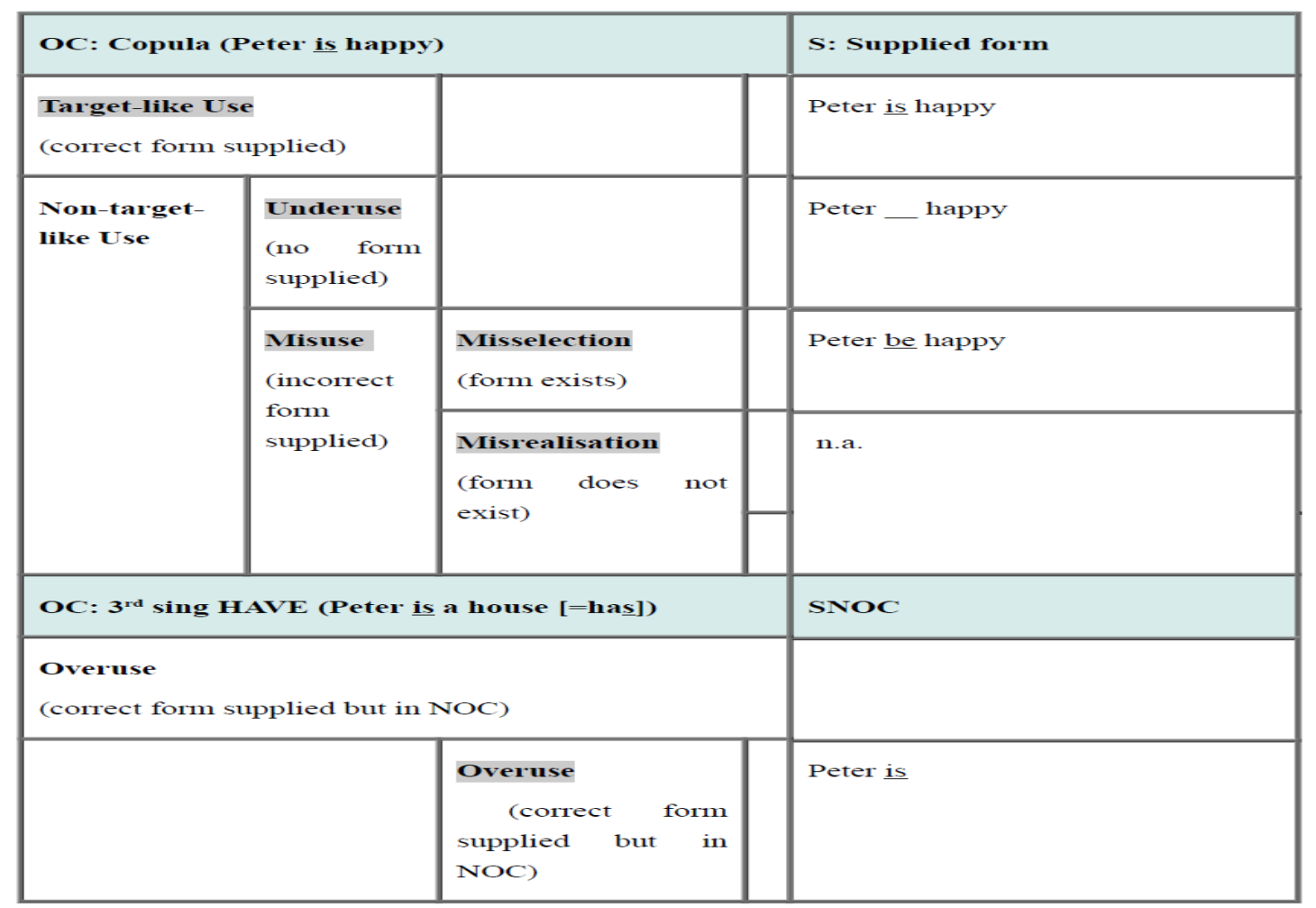

Morpheme tagging scheme for Auxiliar Be

\begin{tabular}{|c|c|c|c|}
\hline \multicolumn{3}{|c|}{ OC: Aux BE (Peter is swimming) } & S: Supplied form \\
\hline \multicolumn{3}{|c|}{$\begin{array}{l}\text { Target-like Use } \\
\text { (correct form supplied) }\end{array}$} & Peter is swimming \\
\hline \multirow[t]{3}{*}{$\begin{array}{l}\text { Non-target- } \\
\text { like Use }\end{array}$} & $\begin{array}{l}\text { Underuse } \\
\text { (no form } \\
\text { supplied) }\end{array}$ & & Peter ___ swimming \\
\hline & \multirow[t]{2}{*}{$\begin{array}{l}\text { Misuse } \\
\text { (incorrect } \\
\text { form } \\
\text { supplied) }\end{array}$} & $\begin{array}{l}\text { Misselection } \\
\text { (form exists) }\end{array}$ & Peter be swimming \\
\hline & & $\begin{array}{l}\text { Misrealisation } \\
\text { (form does not } \\
\text { exist) }\end{array}$ & n.a. \\
\hline \multicolumn{3}{|c|}{ OC: $\operatorname{aux~HAVE~(Peter~is~left~[=has])~}$} & SNOC \\
\hline & & $\begin{array}{l}\text { Overuse } \\
\text { (correct form } \\
\text { supplied but in } \\
\text { NOC) }\end{array}$ & Peter is left \\
\hline
\end{tabular}


Morpheme tagging scheme for Indefinite article

\begin{tabular}{|c|c|c|c|}
\hline \multicolumn{3}{|c|}{ OC: Indefinite article (A friend of mine came) } & S: Supplied form \\
\hline \multicolumn{2}{|c|}{$\begin{array}{l}\text { Target-like Use } \\
\text { (correct form supplied) }\end{array}$} & & A friend of mine \\
\hline \multirow[t]{4}{*}{$\begin{array}{l}\text { Non-target- } \\
\text { like Use }\end{array}$} & $\begin{array}{l}\text { Underuse } \\
\text { (no form } \\
\text { supplied) }\end{array}$ & & _ friend of mine \\
\hline & \multirow{3}{*}{$\begin{array}{l}\text { Misuse } \\
\text { (incorrect } \\
\text { form } \\
\text { supplied) }\end{array}$} & $\begin{array}{l}\text { Misselection } \\
\text { (form exists) }\end{array}$ & The friend of mine \\
\hline & & \multirow{2}{*}{$\begin{array}{l}\text { Misrealisation } \\
\text { (form does not } \\
\text { exist) }\end{array}$} & \\
\hline & & & \\
\hline \multicolumn{3}{|c|}{ OC: generic (I like a pasta $[O]$ ) } & SNOC \\
\hline & & $\begin{array}{l}\text { Overuse } \\
\qquad \text { (correct form } \\
\text { supplied but in } \\
\text { NOC) }\end{array}$ & I like a pasta \\
\hline
\end{tabular}

Morpheme tagging scheme for Possessive -s

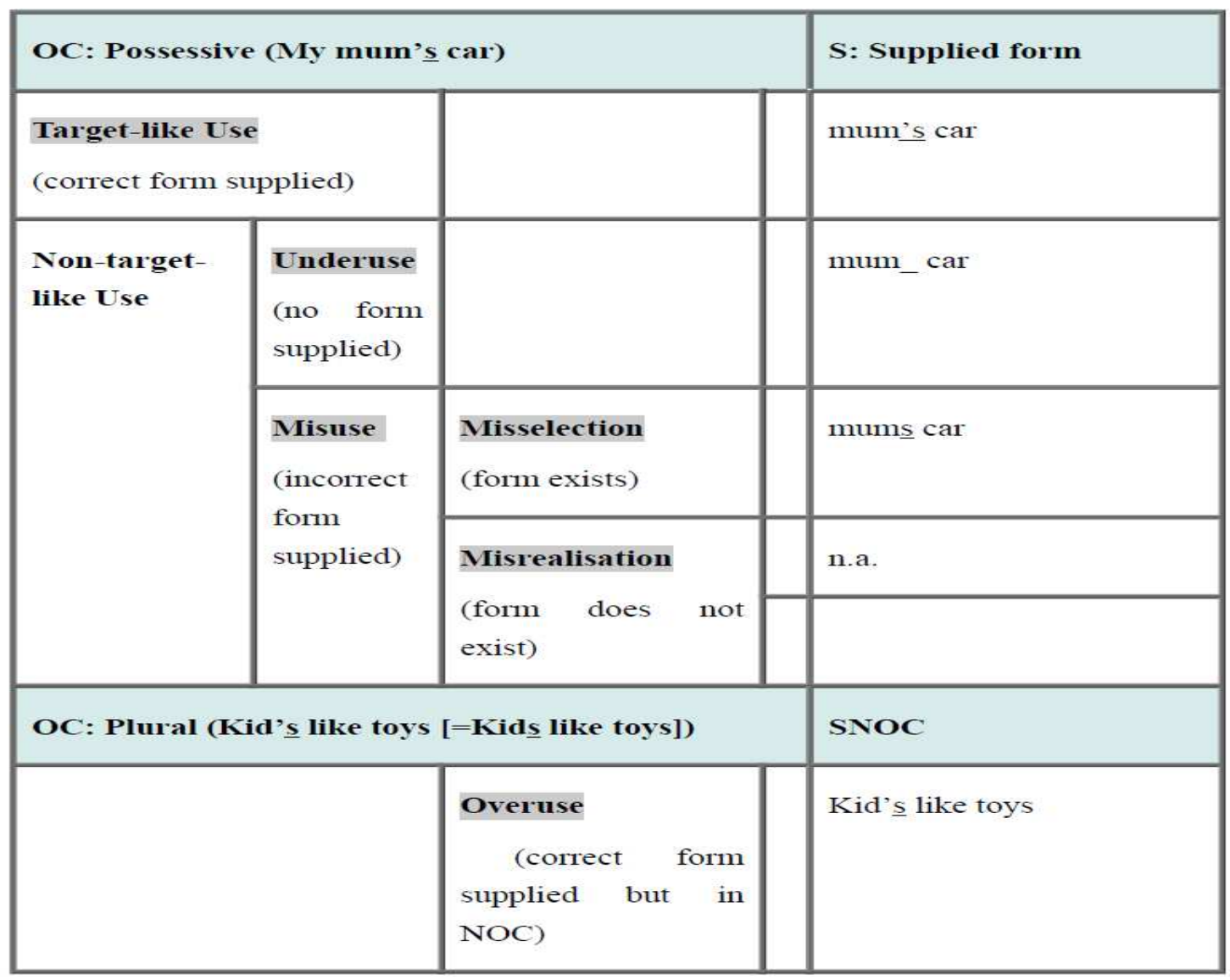


9.11.1 Part I: MOS \& Learner Corpus

9.11.1.1 Specific Descriptive Statistics (grouping criterion: proficiency level)

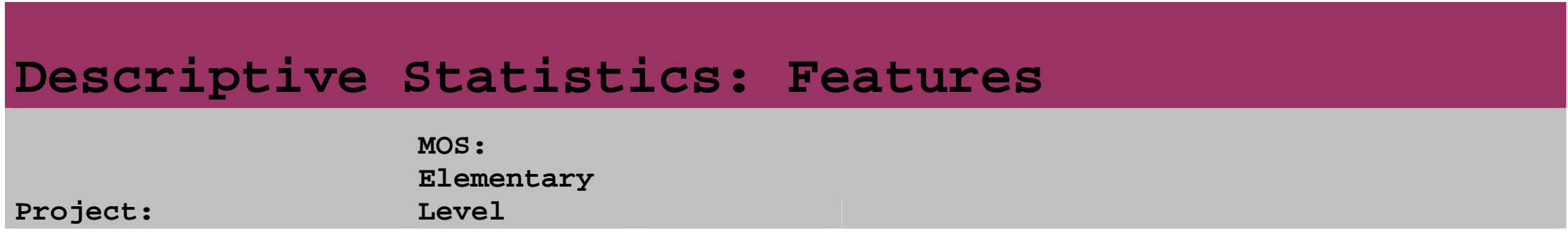

Feature

Percent

$\mathrm{N}$

PAST_REG-TYPE

$N=13$ 


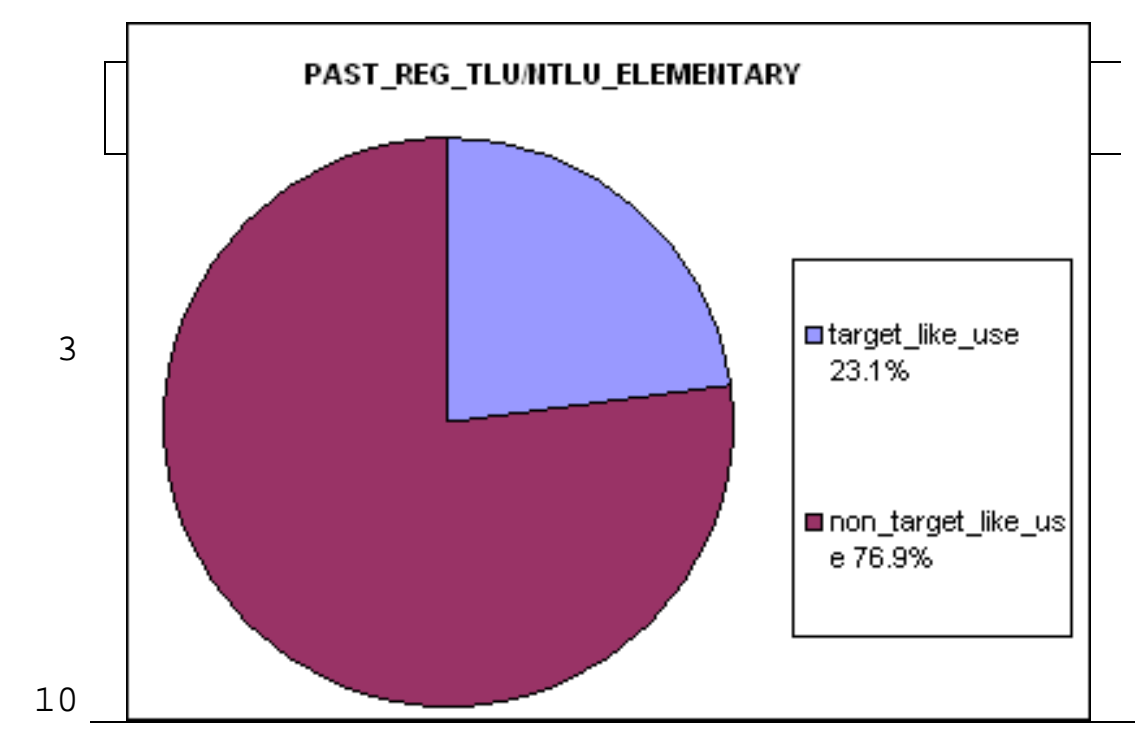

NON_TARGET_LIKE_USE-TYPE

$\mathrm{N}=10$

\section{underuse}

$60.0 \%$

misuse

$40.0 \%$

$0.0 \%$

$0.0 \%$

unclassified

MISUSE-TYPE

misselection

misrealisation

$25.0 \%$

$75.0 \%$ 


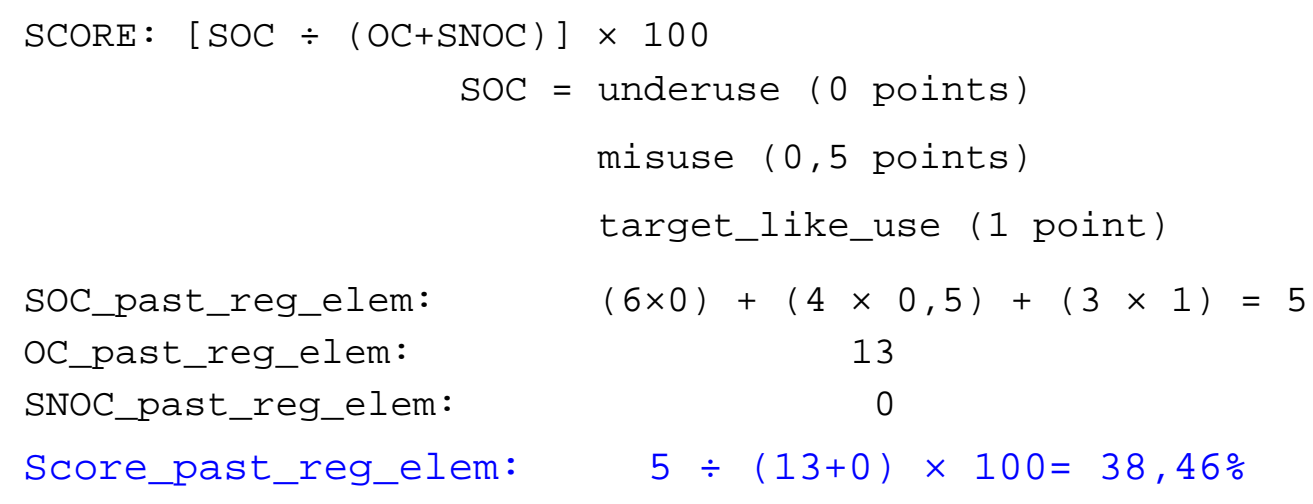


non_target_like_use

NON_TARGET_LIKE_USE-TYPE

underuse

misuse

overuse (snoc)

unclassified

MISUSE-TYPE

misselection

misrealisation
$43.8 \%$

$56.2 \%$

$55.6 \%$

$22.2 \%$

$22.2 \%$

$0.0 \%$

$0.0 \%$

$100.0 \%$

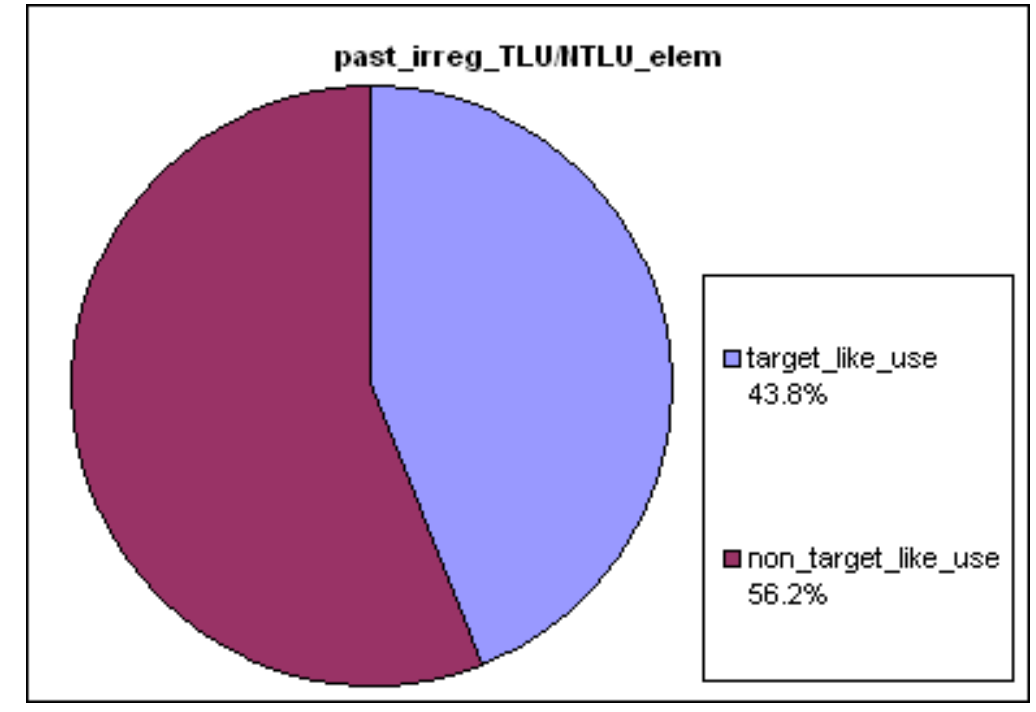

$\mathrm{N}=9$

5

2

0

$\mathrm{N}=2$

0

SCORE : $[\mathrm{SOC} \div(\mathrm{OC}+\mathrm{SNOC})] \times 100$

SOC $=$ underuse $(0$ points $)$ misuse $(0,5$ points $)$ 


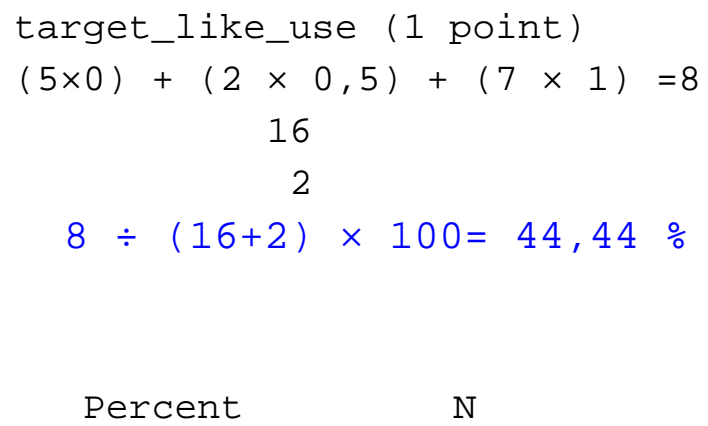

Percent

N

\section{SG_TYPE}

$N=15$

15

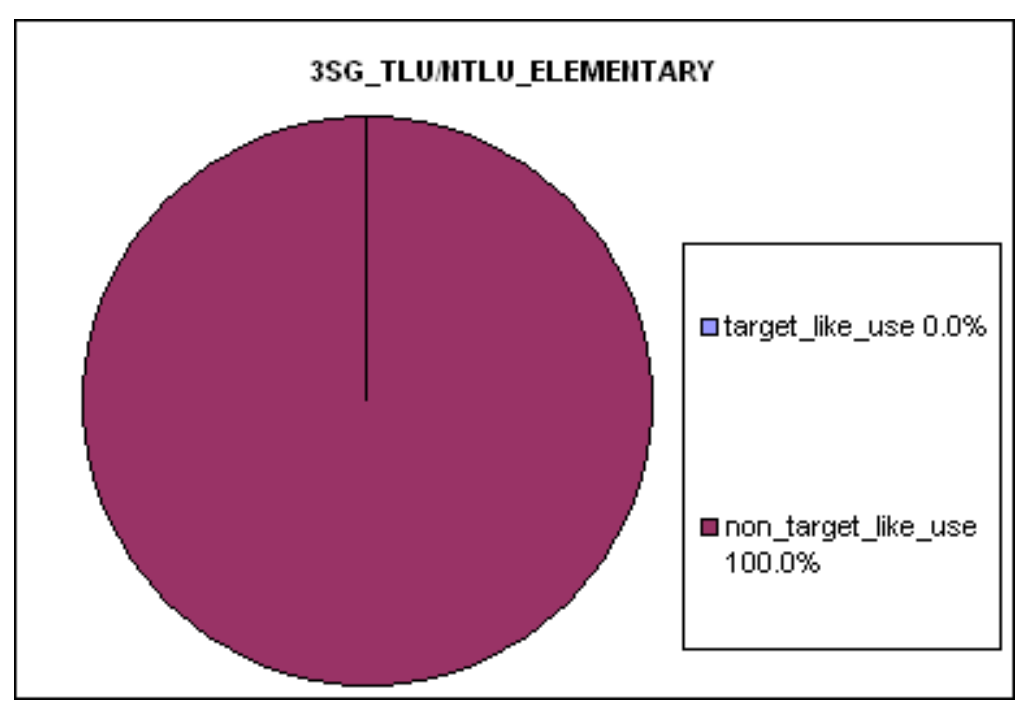

$\mathrm{N}=15$

13

2 


$\begin{array}{lrr}\text { overuse (snoc) } & 0.0 \% & 0 \\ \text { unclassified } & 0.0 \% & 0 \\ \text { MISUSE-TYPE } & & \mathrm{N}=2 \\ \text { misselection } & 0.0 \% & 0 \\ \text { misrealisation } & 100.0 \% & 2\end{array}$

SCORE : $[\mathrm{SOC} \div(\mathrm{OC}+\mathrm{SNOC})] \times 100$

$\mathrm{SOC}=$ underuse $(0$ points $)$ misuse $(0,5$ points $)$ target_like_use ( 1 point)

SOC_3SG_elementary: OC_3SG_elementary: SNOC_3SG_elementary: Score_3SG_elem:

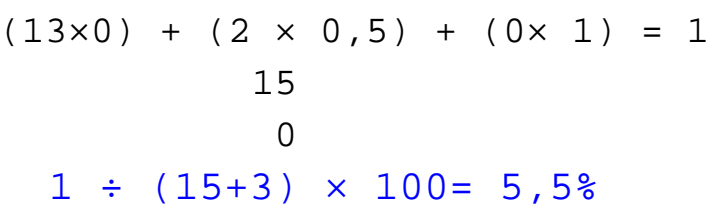

Feature

Percent

$\mathrm{N}$ 


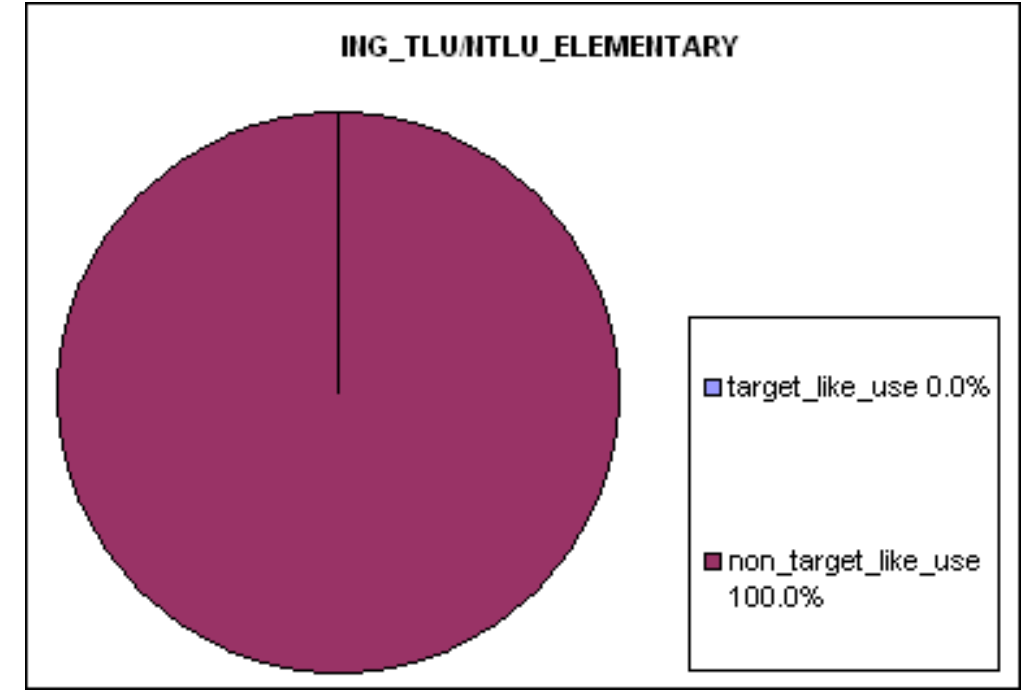

NON_TARGET_LIKE_USE-TYPE

$\mathrm{N}=5$

underuse

$0.0 \%$

$80.0 \%$

misuse

$20.0 \%$

$0.0 \%$

unclassified

$0.0 \%$

misselection

$100.0 \%$

$100.0 \%$

misrealisation

SCORE : $[\mathrm{SOC} \div(\mathrm{OC}+\mathrm{SNOC})] \times 100$

SOC $=$ underuse $(0$ points $)$

misuse $(0,5$ points $)$

target_like_use (1 point) 
SOC_ING_elementary: OC_ING_elementary:

SNOC_ING_elementary:

Score_ING_elem:

Feature

$B E \_C O P \_T Y P E$

target_like_use

non_target_like_use

NON_TARGET_LIKE_USE-TYPE

underuse

misuse

overuse (snoc)

unclassified

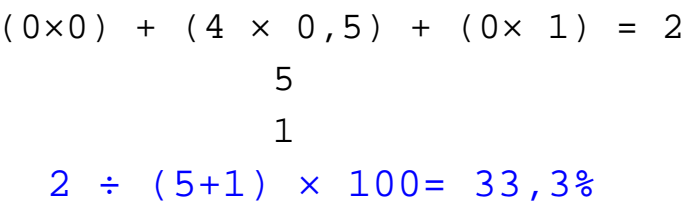

Percent

$\mathrm{N}$

$N=8$

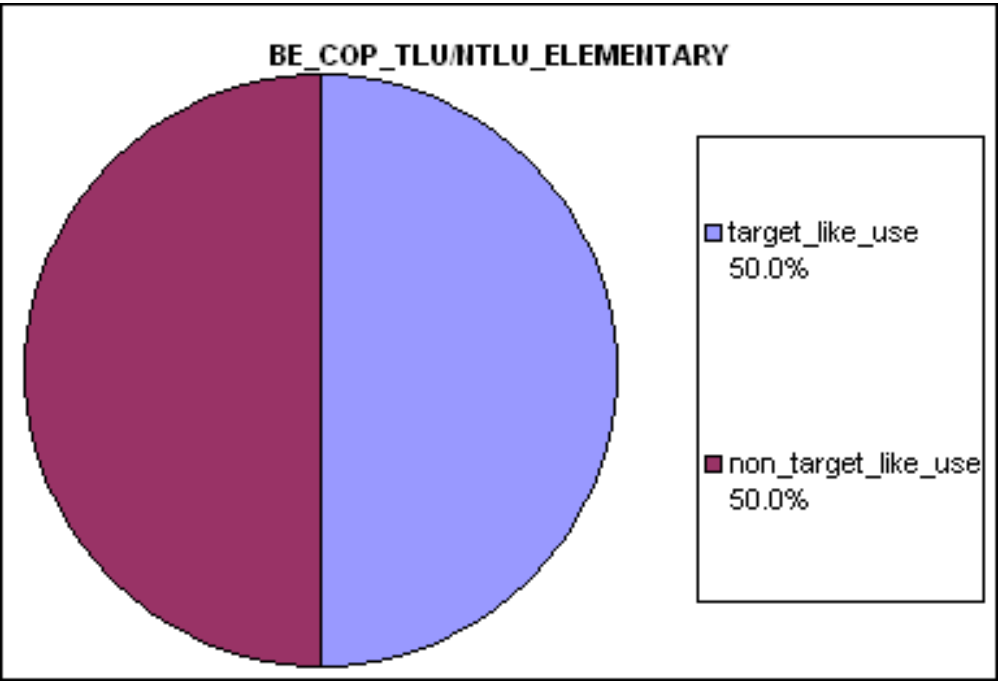

$\mathrm{N}=4$

$0.0 \%$

$100.0 \%$

$0.0 \%$

$0.0 \%$
4

4

0

0 
MISUSE-TYPE

misselection

$0.0 \%$

$\mathrm{N}=4$

misrealisation

$100.0 \%$

0

SCORE $:[$ SOC $\div(\mathrm{OC}+\mathrm{SNOC})] \times 100$

$\mathrm{SOC}=$ underuse $(0$ points $)$

misuse $(0,5$ points $)$

target_like_use (1 point)

SOC_BE_COP_elementary:

OC_BE_COP_elementary:

$(0 \times 0)+(4 \times 0,5)+(4 \times 1)=6$

SNOC_BE_COP_elementary:

\section{8}

Score_BE_COP_elem:

$6 \div(8+0) \times 100=75 \%$

Feature

Percent

N

BE_AUX_TYPE

$N=7$ 
BE_AUX_TLU/ITLU_ELEMEITTARY

NON_TARGET_LIKE_USE-TYPE

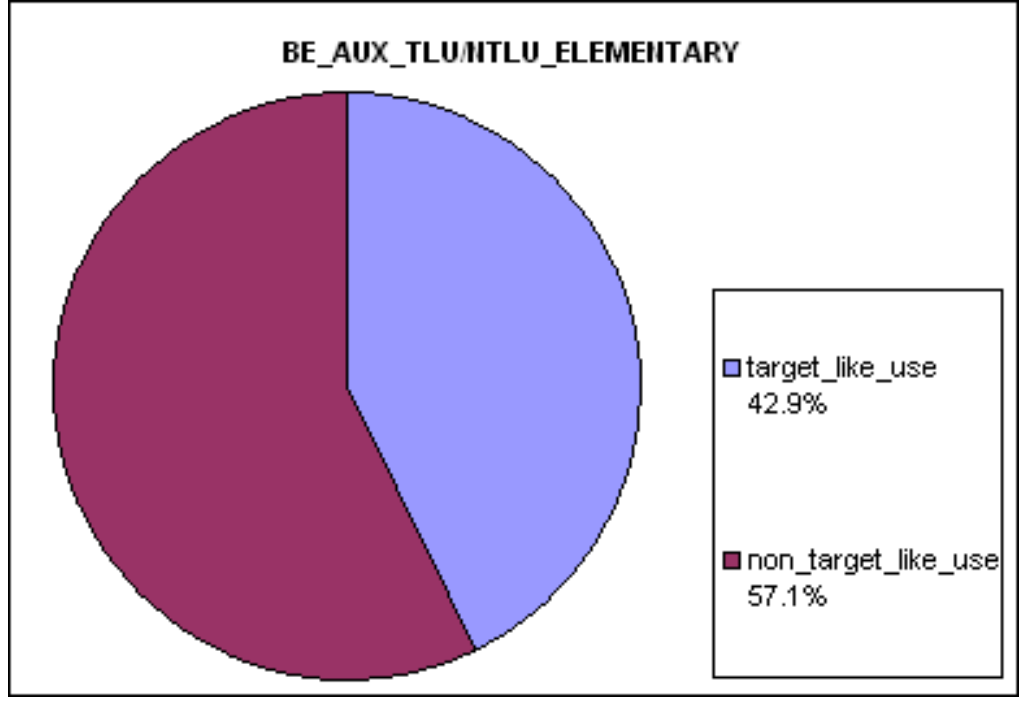

underuse

$\begin{array}{rr}50.0 \% & \mathrm{~N}=4 \\ 0.0 \% & 2 \\ 50.0 \% & 2 \\ 0.0 \% & 0 \\ 0.0 \% & \mathrm{~N}=0 \\ 0.0 \% & 0 \\ & 0\end{array}$

overuse (snoc)

unclassified

$0.0 \%$

misselection

misrealisation

SCORE : $[\mathrm{SOC} \div(\mathrm{OC}+\mathrm{SNOC})] \times 100$

SOC $=$ underuse $(0$ points $)$

misuse $(0,5$ points $)$

target_like_use (1 point) 
SOC_BE_AUX_elementary: OC_BE_AUX_elementary:

SNOC_BE_AUX_elementary: Score_BE_AUX_elem:

\section{Feature}

\section{PLU_TYPE}

non target like use

NON_TARGET_LIKE_USE-TYPE underuse

misuse

overuse (snoc)
$(2 \times 0)$

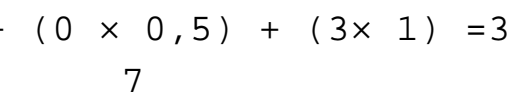

$3 \div(7+2) \times 100=33,3 \%$

Percent

N

$N=5$

$100.0 \%$

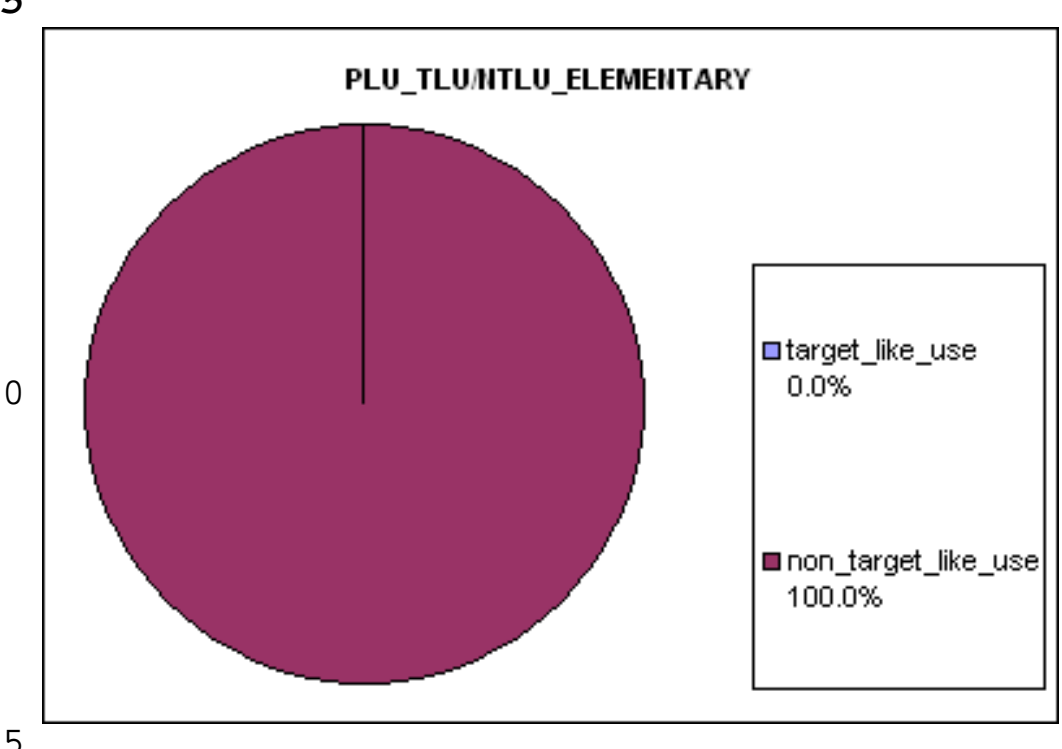

$\mathrm{N}=5$

$80.0 \%$

$0.0 \%$

$20.0 \%$

1 


$\begin{array}{lcr}\text { Unclassified } & 0.0 \% & 0 \\ \text { MISUSE-TYPE } & & \mathrm{N}=0 \\ \text { misselection } & 0.0 \% & 0 \\ \text { misrealisation } & 0.0 \% & 0\end{array}$

SCORE: $[\mathrm{SOC} \div(\mathrm{OC}+\mathrm{SNOC})] \times 100$

SOC $=$ underuse $(0$ points $)$

misuse $(0,5$ points $)$

target_like_use (1 point)

SOC_PLU_elementary:

OC_PLU_elementary:

SNOC_PLU_elementary:

Score_PLU_elem:

$(4 \times 0)+(0 \times 0,5)+(0 \times 1)=0$

$0 \div(5+1) \times 100=0 \%$

Feature

Percent

$\mathrm{N}$

ART_TYPE

$N=60$ 
target_like_use

non_target_like_use

NON_TARGET_LIKE_USE-TYPE

underuse

misuse

overuse (snoc)

unclassified

MISUSE-TYPE

misselection

misrealisation
$56.7 ㅇ$

$43.3 \%$

$15.4 \%$

$61.5 \%$

$23.1 \%$

$0.0 \%$

$93.8 \%$

$6.2 \%$
ART_TLU/ITLU_ELEMEITTARY

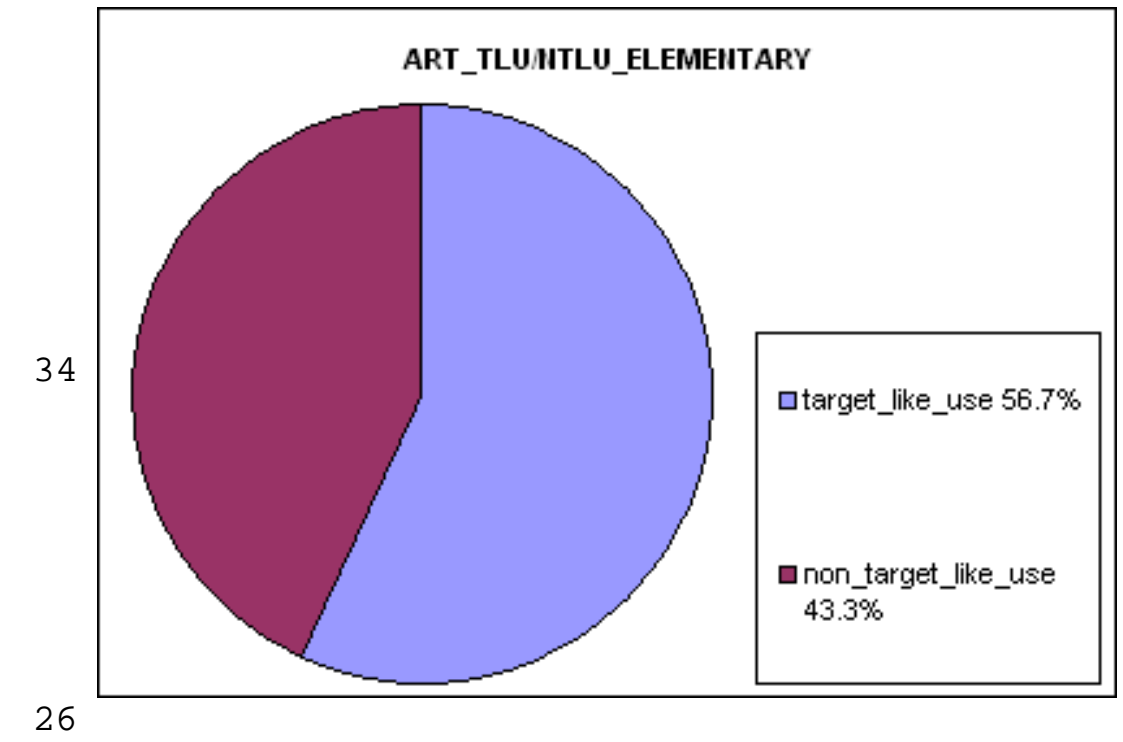

$N=26$

4

16

6

$\mathrm{N}=16$

15

1

SCORE: $[\mathrm{SOC} \div(\mathrm{OC}+\mathrm{SNOC})] \times 100$

$\mathrm{SOC}=$ underuse $(0$ points $)$

misuse $(0,5$ points $)$

target_like_use (1 point) 
SOC_ART_elementary: OC_ART_elementary:

SNOC_ART_elementary:

Score_ART_elem:

Feature

\section{POS_TYPE}

non target like use

NON_TARGET_LIKE_USE-TYPE underuse

misuse

overuse (snoc)

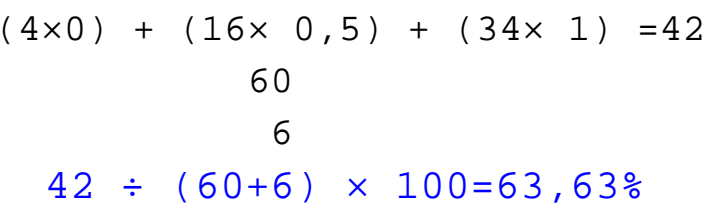

Percent

N

$16.7 \frac{\circ}{\circ}$

$83.3 \frac{\circ}{\circ}$

$40.0 \%$

$40.0 \%$

$20.0 \%$

\section{$N=6$}
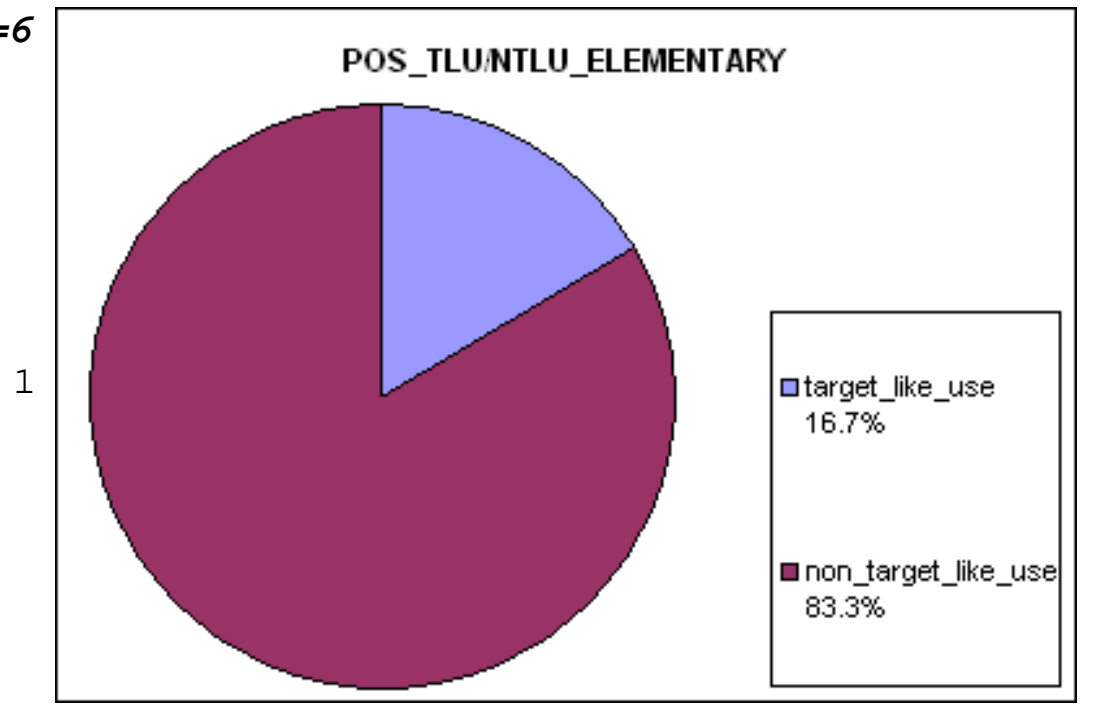

$\mathrm{N}=5$

2 


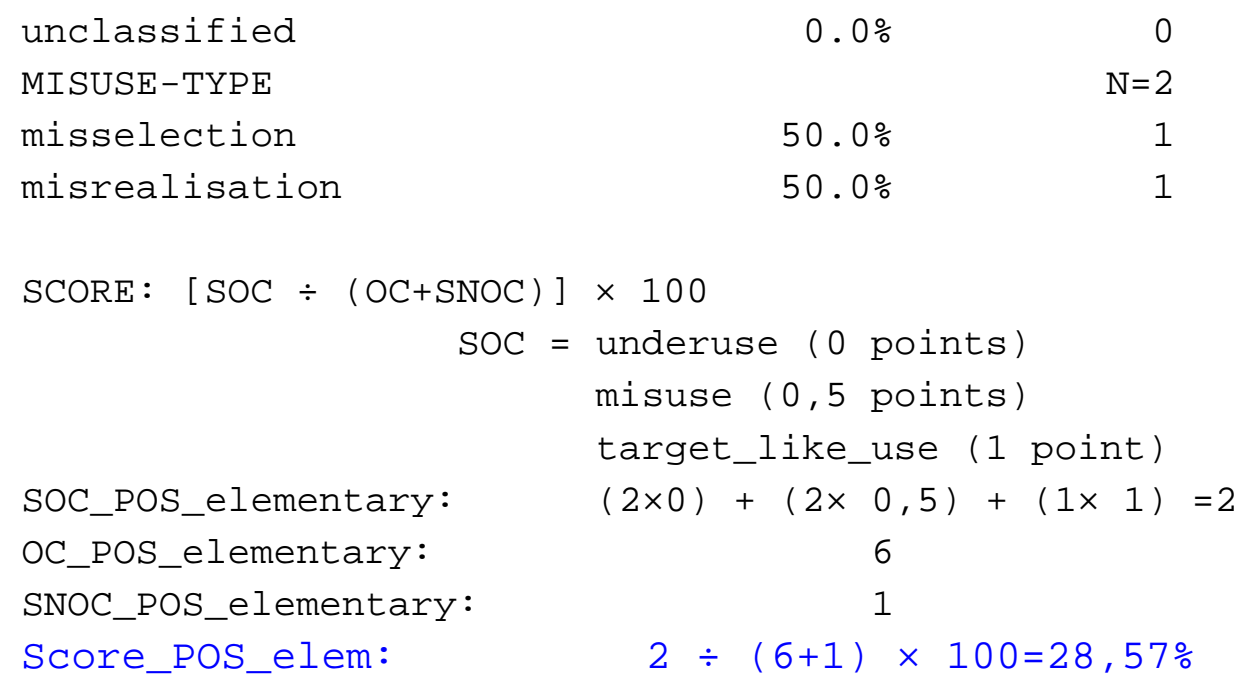


MOS : Pre-

Intermediate

Project:

Feature

\section{PAST_REG-TYPE}

target_like_use

non_target_like_use

NON_TARGET_LIKE_USE-TYPE

underuse

misuse

overuse (snoc)

unclassified
Level

Percent

N

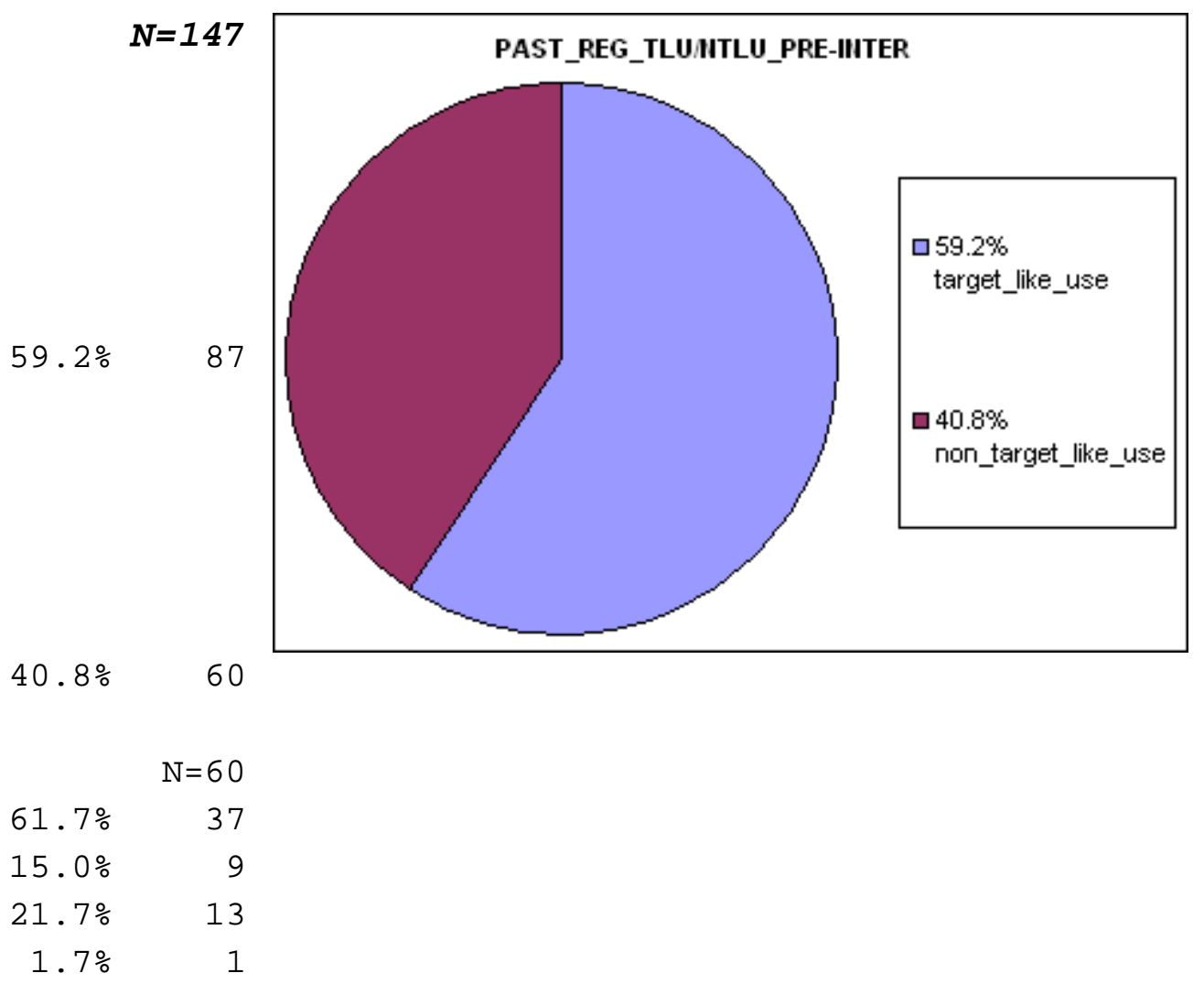


MISUSE-TYPE

misselection

misrealisation

SCORE : $[\mathrm{SOC} \div(\mathrm{OC}+\mathrm{SNOC})] \times 100$

$\mathrm{SOC}$

SoC_past_reg_pre-intermediate:

oC_past_reg_pre-intermediate:

SNOC_past_reg_pre-intermediate:

Score_past_reg_pre-inter:

Feature

PAST_IRREG-TYPE
$\mathrm{N}=9$

$33.3 \%$

$66.7 \%$ 


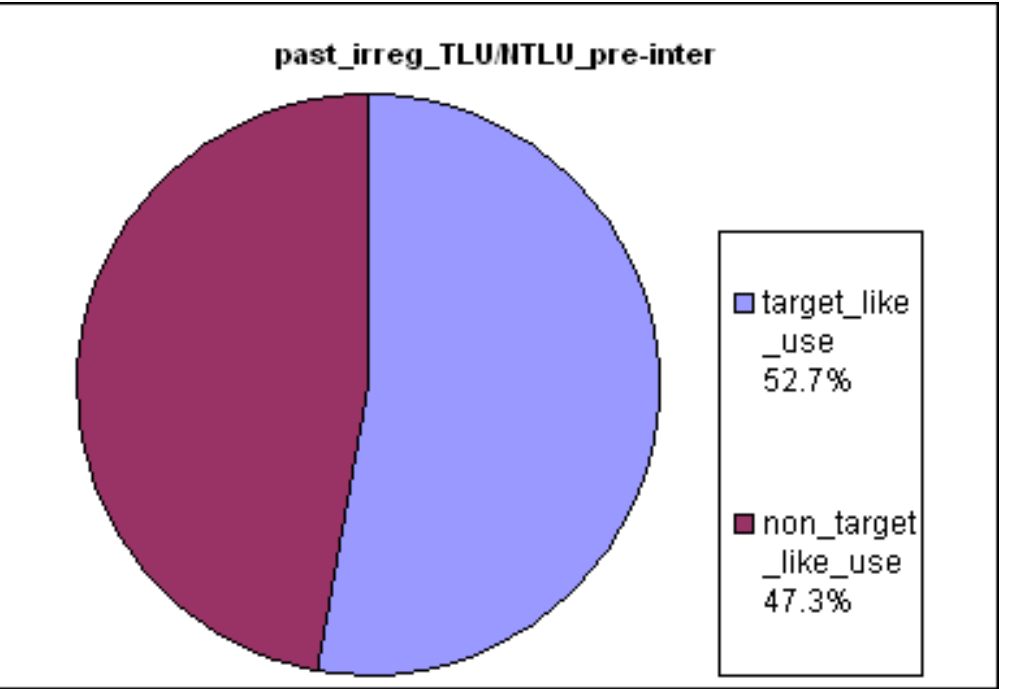

NON_TARGET_LIKE_USE-TYPE

$31.4 \%$

misuse

$18.6 \% 13$

eruse (snoc)

$0.0 \%$

MISUSE-TYPE

misselection

$4.5 \% \quad 1$

misrealisation

$95.5 \%$

21

SCORE : $[\mathrm{SOC} \div(\mathrm{OC}+\mathrm{SNOC})] \times 100$

SOC $=$ underuse $(0$ points $)$ misuse $(0,5$ points

target_like_use (1 point) 
Soc_past_irreg_pre-

intermediate:

oC_past_irreg_pre-intermediate:

SNOC_past_irreg_pre-

intermediate:

Score_past_irreg_pre-inter:

Feature

3SG_TYPE

target_like_use

non_target_like_use

NON_TARGET_LIKE_USE-TYPE

underuse

misuse

overuse (snoc)

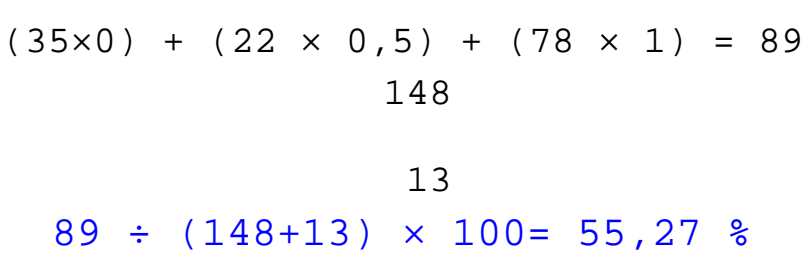

Percent

$\mathrm{N}$

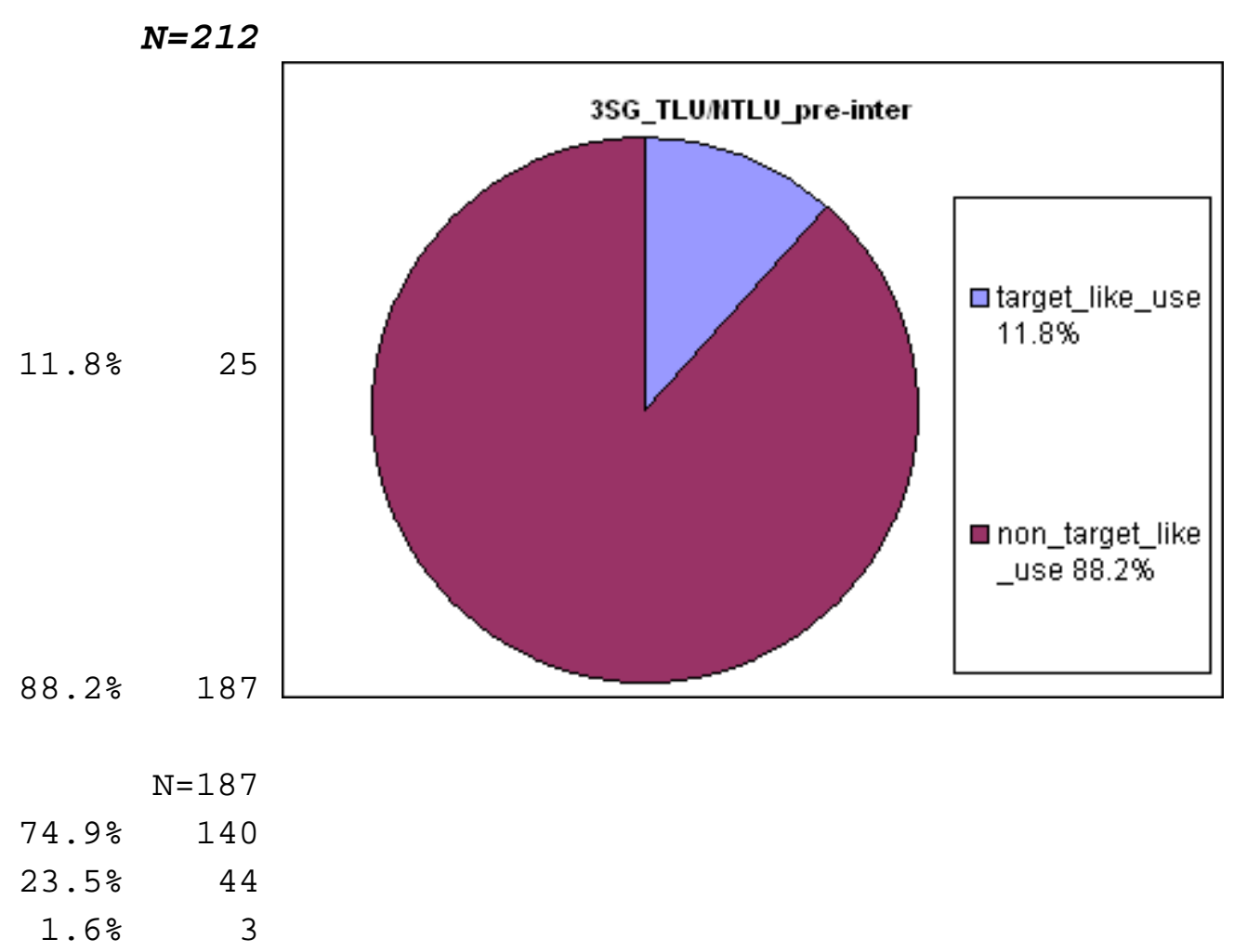


unclassified

MISUSE-TYPE

misselection

misrealisation

SCORE : $[\mathrm{SOC} \div(\mathrm{OC}+\mathrm{SNOC})] \times 100$

SOC $=$ underuse $(0$ points $)$

misuse $(0,5$ points $)$

target_like_use ( 1 point)

$(140 \times 0)+(44 \times 0,5)+(25 \times 1)=47$

212

3

SNOC 3SG_pre-intermediate:

Score_3SG_pre-inter:
$68.2 \% 30$

$31.8 \% 14$
Eeature

ING_TYPE
Percent

$\mathrm{N}$

$N=74$ 


\section{ING_TLUNTLU_PRE-INTER}

NON_TARGET_LIKE_USE-TYPE

$\begin{array}{rr} & \mathrm{N}=40 \\ 35.0 \% & 14 \\ 32.5 \% & 13 \\ 32.5 \% & 13 \\ 0.0 \% & 0 \\ 7.7 \% & \mathrm{~N}=13 \\ 92.3 \% & 12\end{array}$

SCORE : $[\mathrm{SOC} \div(\mathrm{OC}+\mathrm{SNOC})] \times 100$

SOC $=$ underuse $(0$ points $)$ misuse $(0,5$ points $)$

target_like_use (1 point) 
SOC_ING_pre-intermediate: OC_ING_pre-intermediate:

SNOC_ING_pre-intermediate: Score_ING_pre-inter:

\section{Feature}

\section{BE_COP_TYPE}

target_like_use

non target like use

NON_TARGET_LIKE_USE-TYPE

underuse

misuse

overuse (snoc)

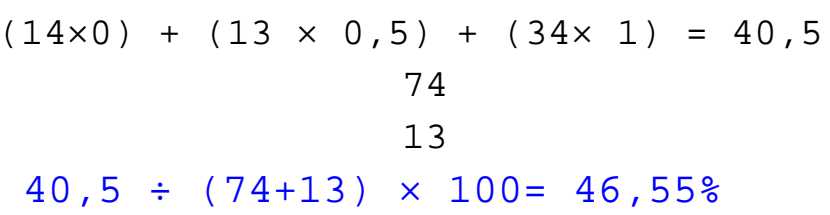

Percent

$\mathrm{N}$

$89.0 \%$

$11.0 \%$

$\begin{array}{rr} & N=8 \\ 37.5 \% & 3 \\ 62.5 \% & 5 \\ 0.0 \% & 0\end{array}$

65

$=8$

0

\section{$\square 89.0 \%$}

target_like_use

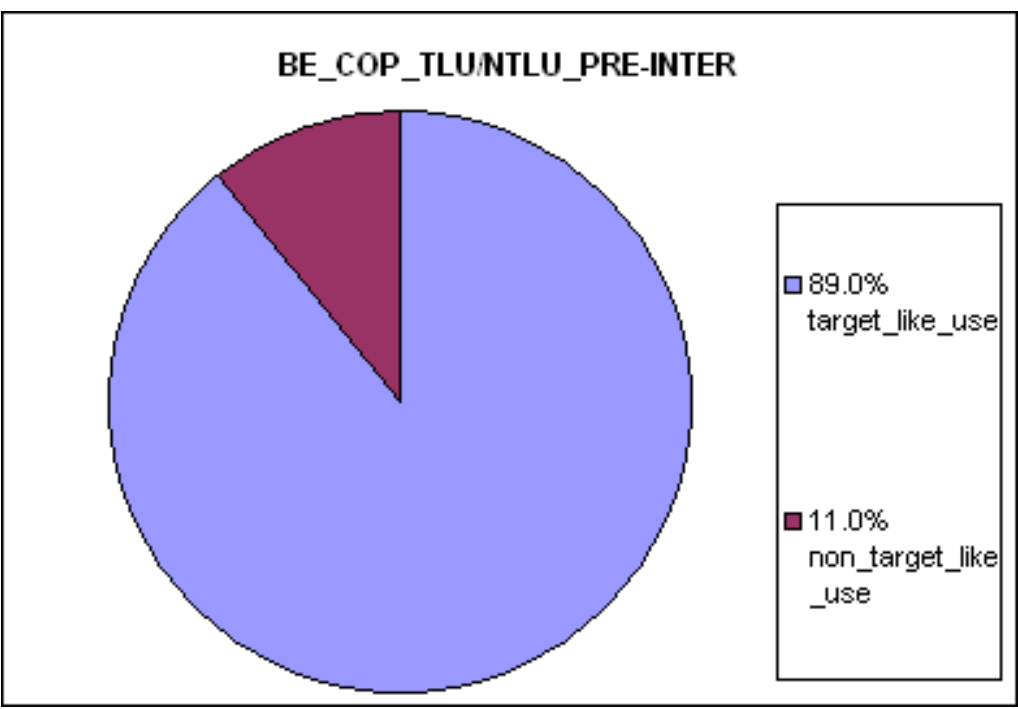


unclassified

MISUSE-TYPE

misselection

misrealisation

\section{$0.0 \% \quad 0$}

$\mathrm{N}=5$

$0.0 \% \quad 0$

$100.0 \% \quad 5$

SCORE: $[\mathrm{SOC} \div(\mathrm{OC}+\mathrm{SNOC})] \times 100$

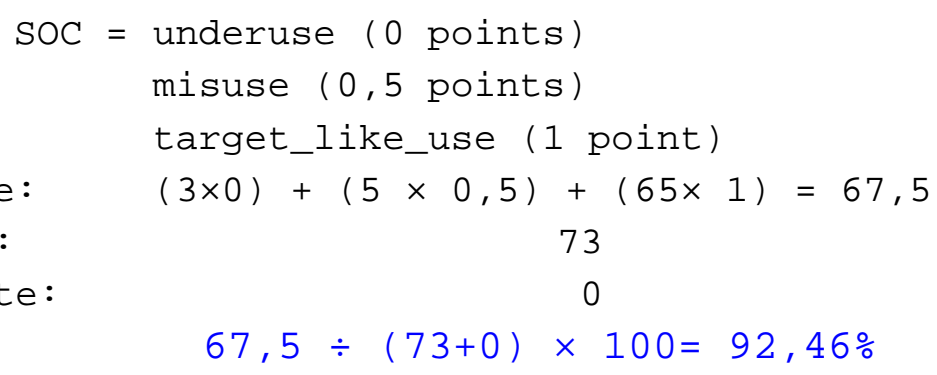

73

0

$67,5 \div(73+0) \times 100=92,46 \%$

SOC_BE_COP_pre-intermediate:

SNOC_BE_COP_pre-intermediate:

Score_BE_COP_pre-inter:

Feature

Percent

$\mathrm{N}$

BE_AUX_TYPE

$\mathbf{N}=\mathbf{7 0}$ 


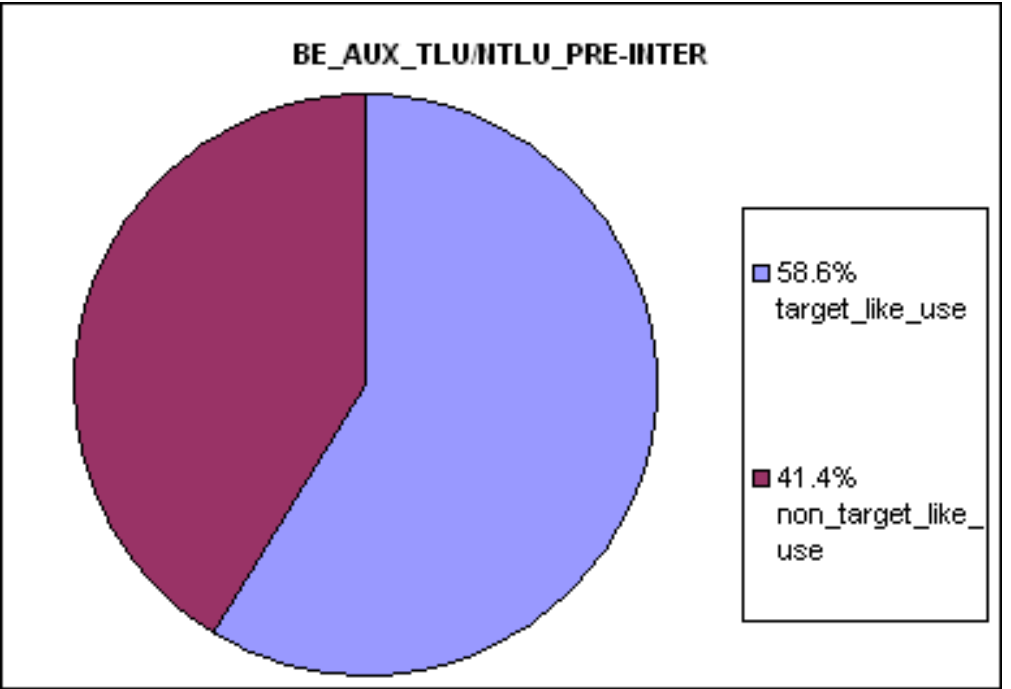

NON_TARGET_LIKE_USE-TYPE

misuse

$13.8 \%$

$13.8 \%$

$72.4 \%$

$0.0 \%$

unclassified

overuse (snoc)

MISUSE-TYPE

misselection

$0.0 \%$

misrealisation

$100.0 \%$

21

0

SCORE : $[\mathrm{SOC} \div(\mathrm{OC}+\mathrm{SNOC})] \times 100$

SOC $=$ underuse $(0$ points $)$ misuse $(0,5$ points $)$

target_like_use (1 point) 
SOC_BE_AUX_pre-intermediate: OC_BE_AUX_pre-intermediate: SNOC_BE_AUX_pre-intermediate: Score_BE_AUX_pre-inter:

\section{Feature}

\section{PLU_TYPE}

target_like_use

non_target_like_use

NON_TARGET_LIKE_USE-TYPE

underuse

misuse

overuse (snoc)

unclassified

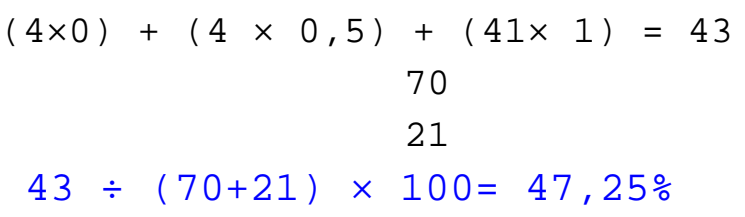

Percent

$\mathrm{N}$

$N=63$

$76.2 \%$

48

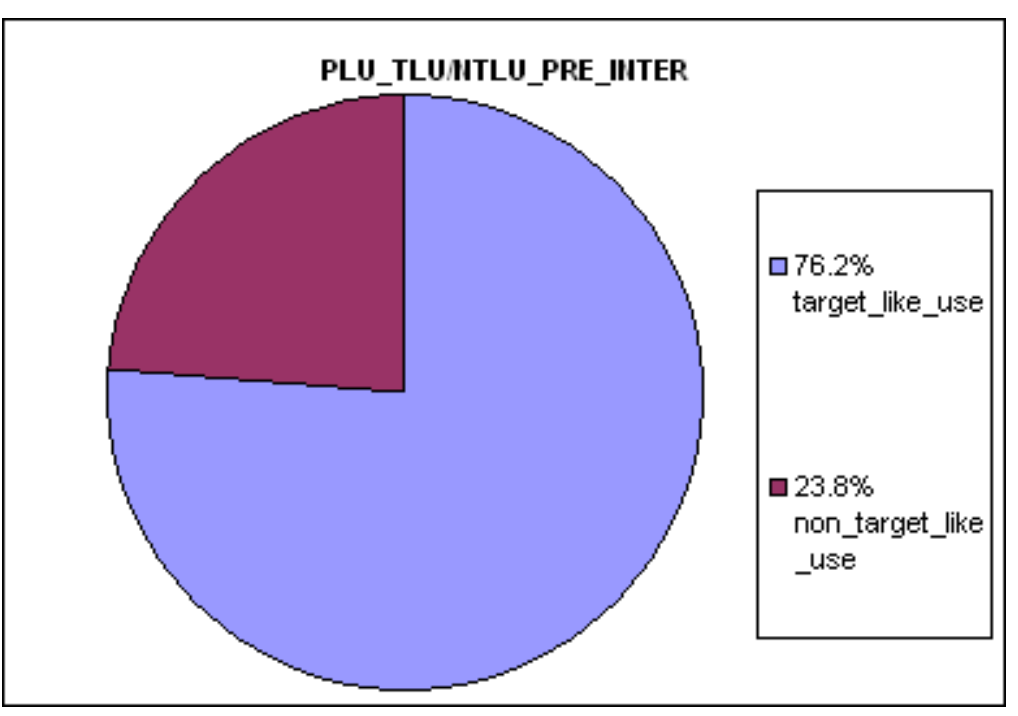

$\mathrm{N}=15$

$33.3 \% 5$

$6.7 \% 1$

$60.0 \% 9$

$0.0 \% \quad 0$ 
MISUSE-TYPE

misselection

misrealisation

SCORE : $[\mathrm{SOC} \div(\mathrm{OC}+\mathrm{SNOC})] \times 100$

SOC_PLU_pre-intermediate:

OC_PLU_pre-intermediate:

SNOC_PLU_pre-intermediate:

Score_PLU_pre-inter:

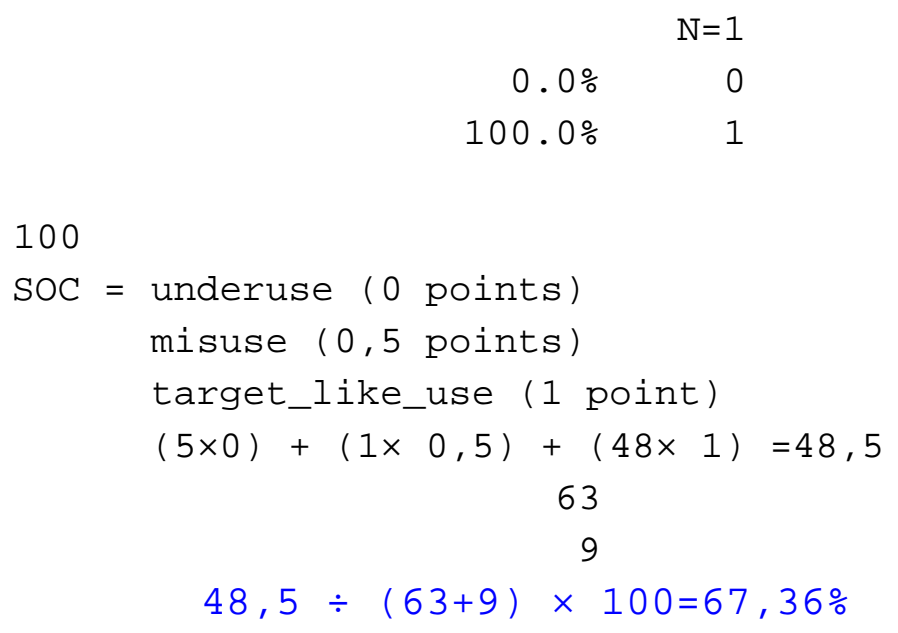

SOC

Feature

Percent

$\mathrm{N}$

ART_TYPE

$N=628$ 


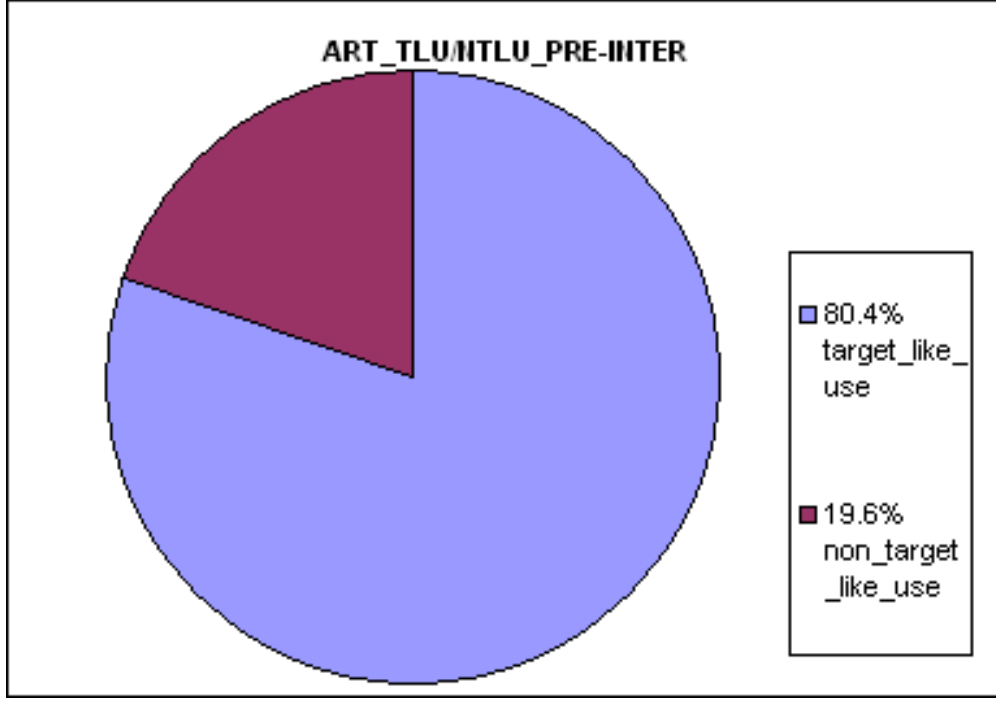

NON_TARGET_LIKE_USE-TYPE

misuse

$61.8 \% \quad 76$

overuse (snoc)

$14.6 \%$

unclassified

$0.0 \% \quad 0$

MISUSE-TYPE

$\mathrm{N}=76$

misselection

$89.5 \%$

misrealisation

$10.5 \%$

8

SCORE : $[\mathrm{SOC} \div(\mathrm{OC}+\mathrm{SNOC})] \times 100$

SOC $=$ underuse $(0$ points $)$

misuse $(0,5$ points

target_like_use (1 point) 
SOC_ART_pre-intermediate: OC_ART_pre-intermediate:

SNOC_ART_pre-intermediate: Score_ART_pre-inter:

Feature

\section{POS_TYPE}

target_like_use

non target like use

NON_TARGET_LIKE_USE-TYPE

underuse

misuse

overuse (snoc)
$(29 \times 0)+(76 \times 0,5)+(505 \times 1)=543$

628

18

$543 \div(628+18) \times 100=84,05 \%$

Percent

$\mathrm{N}$

$N=31$

$16.1 \%$

5

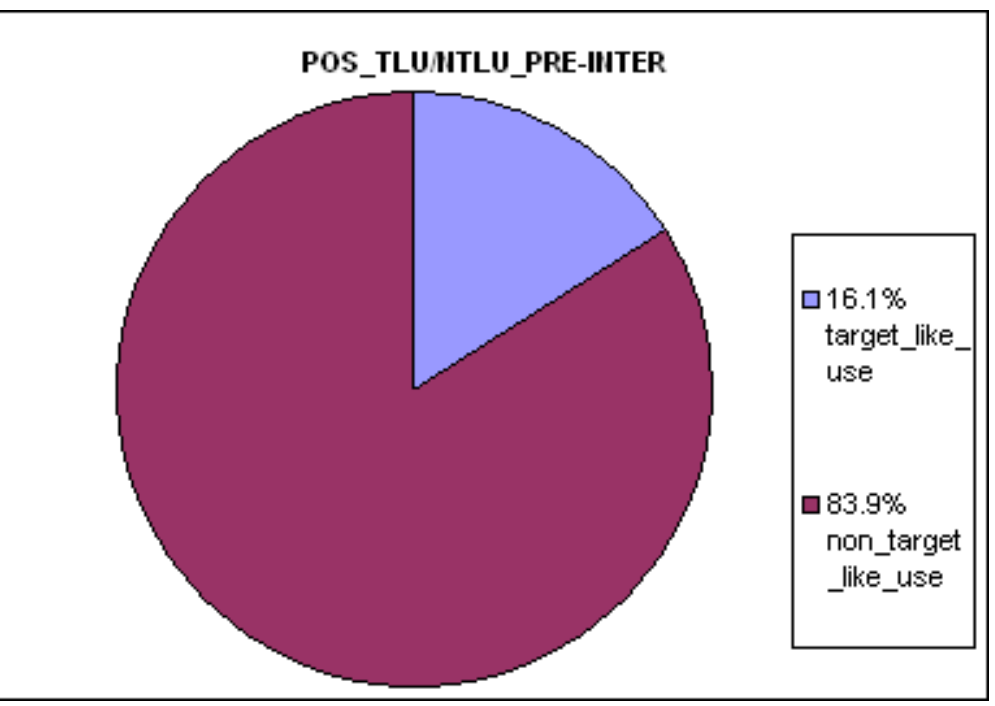

$83.9 \%$

26

$\mathrm{N}=26$

$0.0 \% 0$

$96.2 \% \quad 25$

$3.8 \% 1$ 
unclassified

MISUSE-TYPE

misselection

misrealisation

SCORE : $[\mathrm{SOC} \div(\mathrm{OC}+\mathrm{SNOC})] \times 100$

$\mathrm{SOC}=$ underuse $(0$ points $)$

misuse $(0,5$ points $)$

target_like_use ( 1 point)

$(0 \times 0)+(25 \times 0,5)+(5 \times 1)=17,5$

OC POS pre-intermediate:

SNOC_POS_pre-intermediate:

Score_Pos_pre-inter:

$\begin{array}{rr}0.0 \% & 0 \\ 76.0 \% & 19 \\ 24.0 \% & 6\end{array}$

5

$17,5 \div(31+5) \times 100=48,61 \%$ 


\section{MOS :}

Intermediate

Project:

\section{Feature}

PAST_REG-TYPE

target_like_use

non_target_like_use

NON_TARGET_LIKE_USE-TYPE

underuse

misuse

overuse (snoc)

unclassified

MISUSE-TYPE

\section{Level}

Percent

$\mathrm{N}$

$N=217$

$72.4 \%$

$27.6 \%$

60

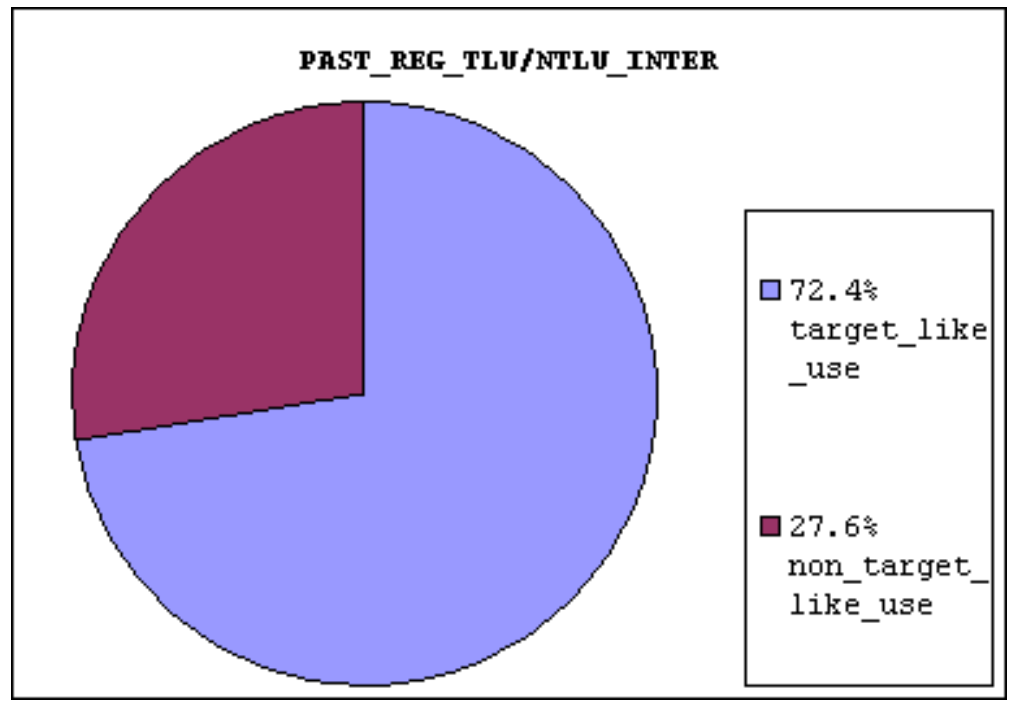

$\mathrm{N}=60$

$73.3 \%$

$10.0 \%$

$15.0 \%$

$1.7 \%$ 
misselection

misrealisation
$16.7 \%$

$83.3 \%$

\section{1}

SCORE : $[\mathrm{SOC} \div(\mathrm{OC}+\mathrm{SNOC})] \times 100$

SOC $=$ underuse $(0$ points $)$

misuse $(0,5$ points $)$

target_like_use (1 point)

SoC_past_reg_intermediate:

oC_past_reg_intermediate:

SNOC_past_reg_intermediate:

Score_past_reg_inter:

$(44 \times 0)+(6 \times 0,5)+(157 \times 1)=160$

217

$160 \div(217+9) \times 100=70,79 \circ$
Feature

PAST_IRREG-TYPE
Percent

$\mathrm{N}$

$N=255$ 


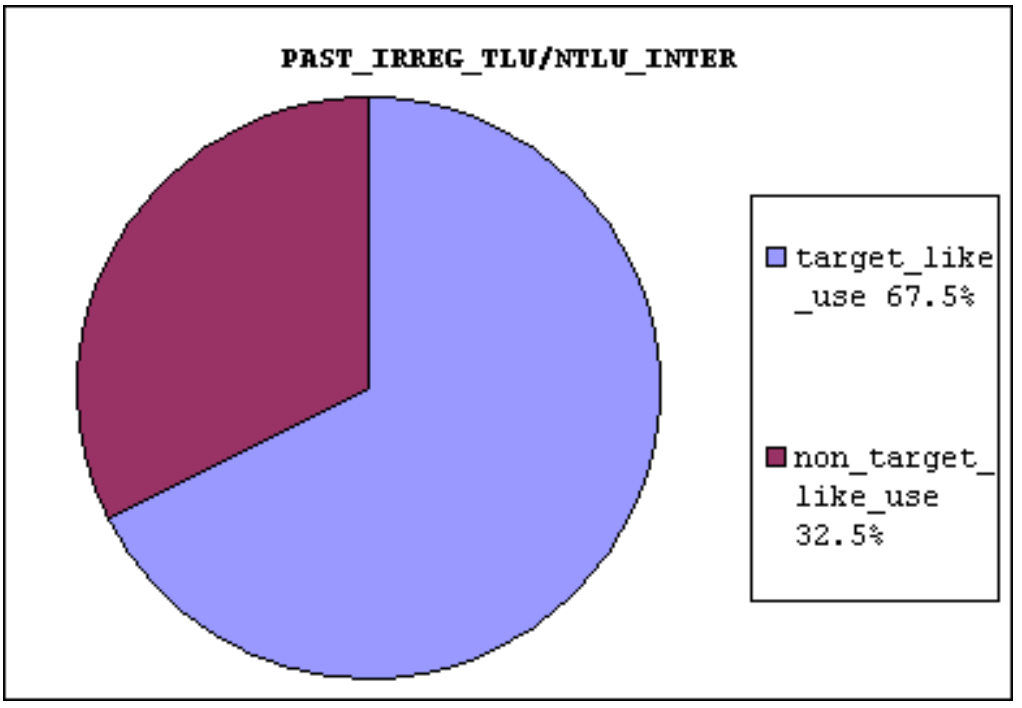

NON_TARGET_LIKE_USE-TYPE $\mathrm{N}=83$

\section{underuse}

$\begin{array}{rr}51.8 \% & 43 \\ 37.3 \% & 31 \\ 9.6 \% & 8 \\ 1.2 \% & 1\end{array}$

overuse (snoc)

unclassified

$1.2 \%$

MISUSE-TYPE

misselection

misrealisation

SCORE : $[\mathrm{SOC} \div(\mathrm{OC}+\mathrm{SNOC})] \times 100$

SOC $=$ underuse $(0$ points $)$

misuse $(0,5$ points

target_like_use (1 point)

SoC_past_irreg_intermediate:

$(43 \times 0)+(31 \times 0,5)+(172 \times 1)=187,5$ 
oC_past_irreg_intermediate:

SNOC_past_irreg_intermediate:

Score_past_irreg_inter:

Feature

3SG_TYPE

target_like_use

non_target_like_use

NON_TARGET_LIKE_USE-TYPE

underuse

misuse

overuse (snoc)

unclassified

MISUSE-TYPE
$187,5 \div(255+8) \times 100=71,29 \div$

Percent

$\mathrm{N}$

$N=73$

$17.8 \%$

$82.2 \%$

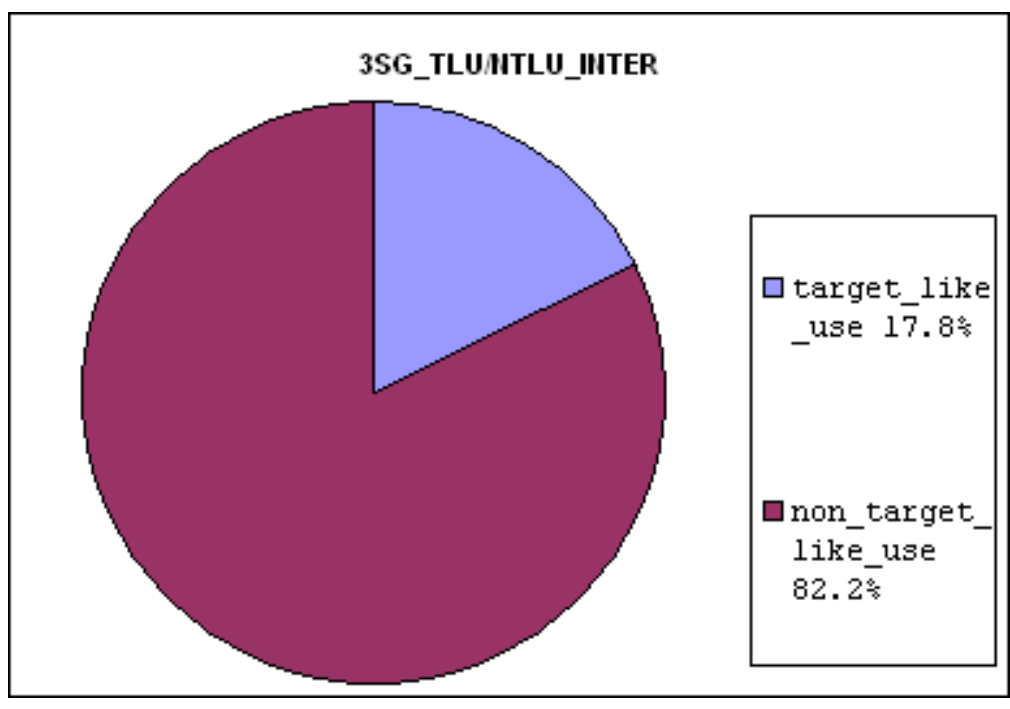

60

$\mathrm{N}=60$

$81.7 \% \quad 49$

$5.0 \% \quad 3$

$13.3 \% \quad 8$

$0.0 \% \quad 0$

$\mathrm{N}=3$ 
misselection

misrealisation
$66.7 \%$

$33.3 \%$

SCORE : $[\mathrm{SOC} \div(\mathrm{OC}+\mathrm{SNOC})] \times 100$

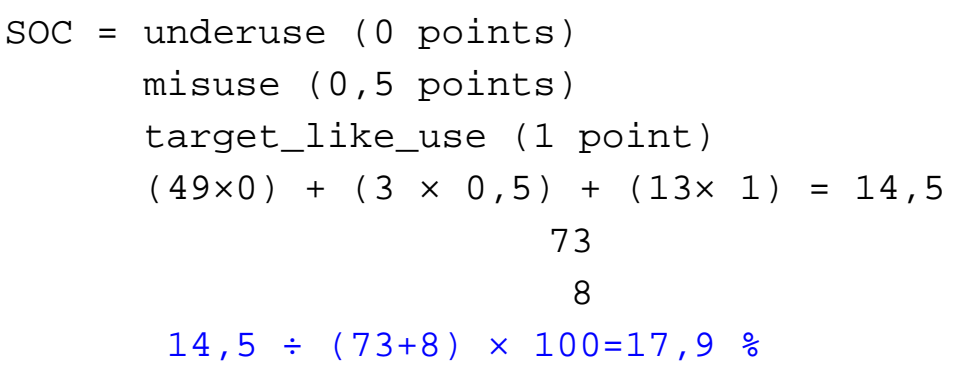




\section{ING_TYPE}

target_like_use

non_target_like_use

NON_TARGET_LIKE_USE-TYPE

underuse

misuse

overuse (snoc)

unclassified

MISUSE-TYPE

misselection

misrealisation
$84.9 \%$

$15.1 \%$

18.2

$36.4 \%$

$45.5 \%$

$0.0 \%$

$50.0 \%$

$50.0 \%$
IIIG_TLU/ITLU_IITER

$N=73$

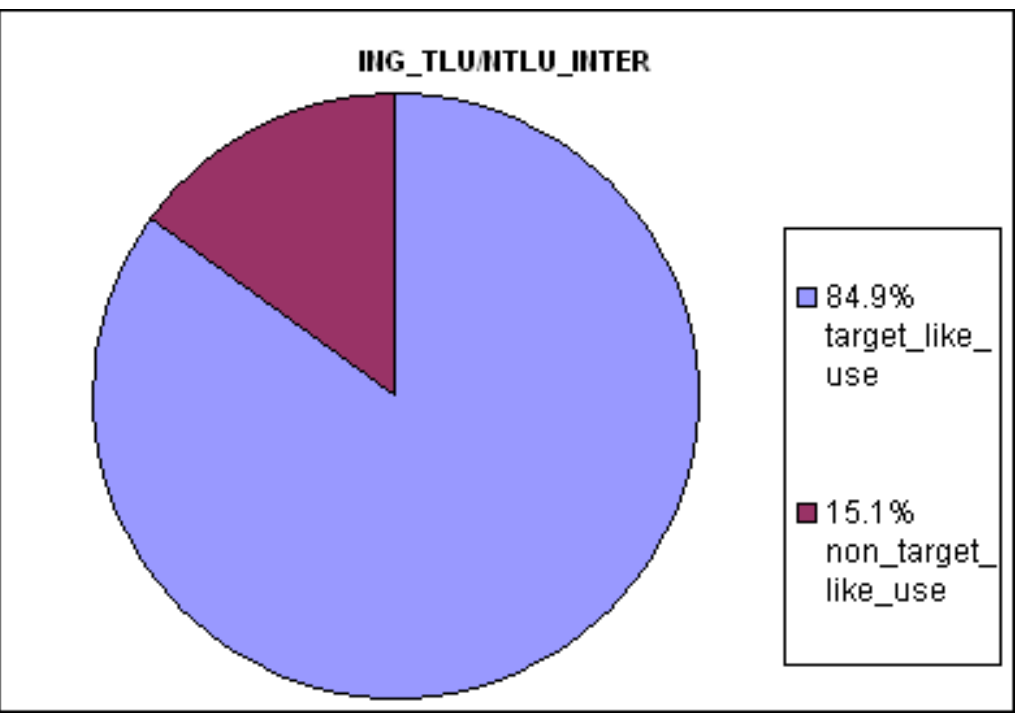

11

$\mathrm{N}=11$

2

4

5

0

$\mathrm{N}=4$

2

SCORE : $[\mathrm{SOC} \div(\mathrm{OC}+\mathrm{SNOC})] \times 100$

SOC $=$ underuse $(0$ points $)$ 
SOC_ING intermediate:

OC_ING_intermediate:

SNOC_ING_intermediate:

Score_ING_inter:

Feature

BE_COP_TYPE

target_like_use

non_target_like_use

NON_TARGET_LIKE_USE-TYPE

underuse

misuse misuse $(0,5$ points $)$

target_like_use ( 1 point)

$(2 \times 0)+(4 \times 0,5)+(62 \times 1)=64$

73

5

$64 \div(73+5) \times 100=$

$82,05 \%$

Percent

\section{$N=81$}

$91.4 \%$

$8.6 \%$

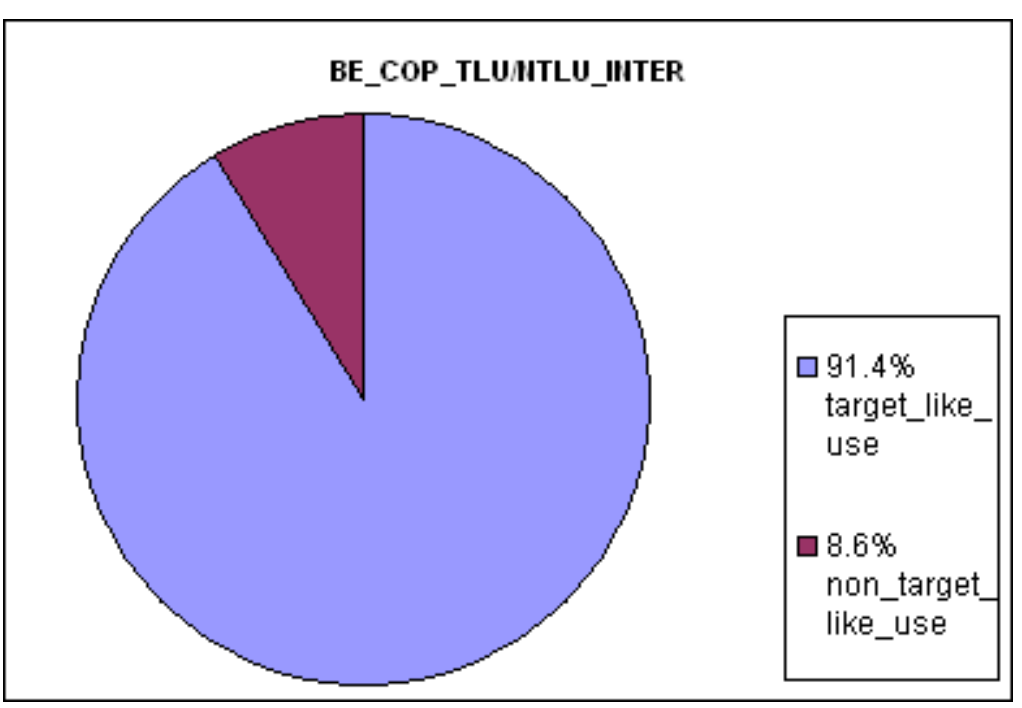

$\mathrm{N}=7$

$0.0 \%$

$100.0 \%$

0 
overuse (snoc)

unclassified

MISUSE-TYPE

misselection

misrealisation

$\begin{array}{rr}0.0 \% & 0 \\ 0.0 \% & 0 \\ & \mathrm{~N}=7 \\ 0.0 \% & 0 \\ 100.0 \% & 7\end{array}$

SCORE : $[\mathrm{SOC} \div(\mathrm{OC}+\mathrm{SNOC})] \times 100$

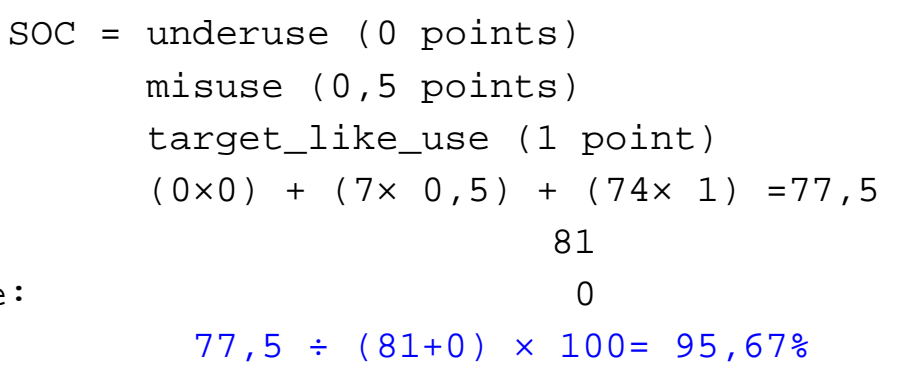

$77,5 \div(81+0) \times 100=95,67 \%$

OC BE_COP intermediate:

SNOC_BE_COP_intermediate:

Score_BE_COP_inter:
Feature

BE_AUX_TYPE
Percent

$\mathrm{N}$

$N=59$ 


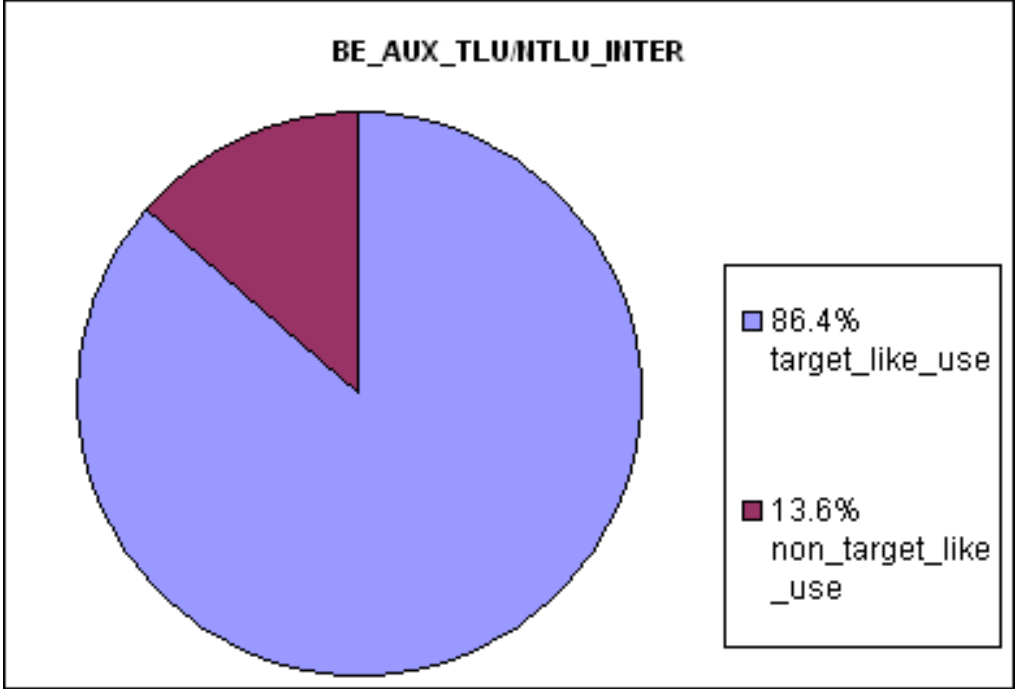

NON_TARGET_LIKE_USE-TYPE

$$
\mathrm{N}=8
$$

$12.5 \%$

$12.5 \%$

$75.0 \%$

$0.0 \%$

unclassified

MISUSE-TYPE

misselection

$\mathrm{N}=1$

misrealisation

$0.0 \% \quad 0$

SCORE : $[\mathrm{SOC} \div(\mathrm{OC}+\mathrm{SNOC})] \times 100$

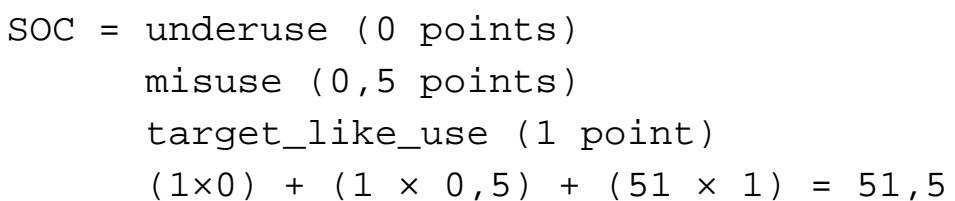


OC_BE_AUX_intermediate:

SNOC_BE_AUX_intermediate:

Score_BE_AUX_inter:

\section{Feature}

PLU_TYPE

target_like_use

non_target_like_use

NON_TARGET_LIKE_USE-TYPE

underuse

misuse

overuse (snoc)

unclassified

MISUSE-TYPE

$51,5 \div(59+6) \times 100=79,23 \div$

Percent

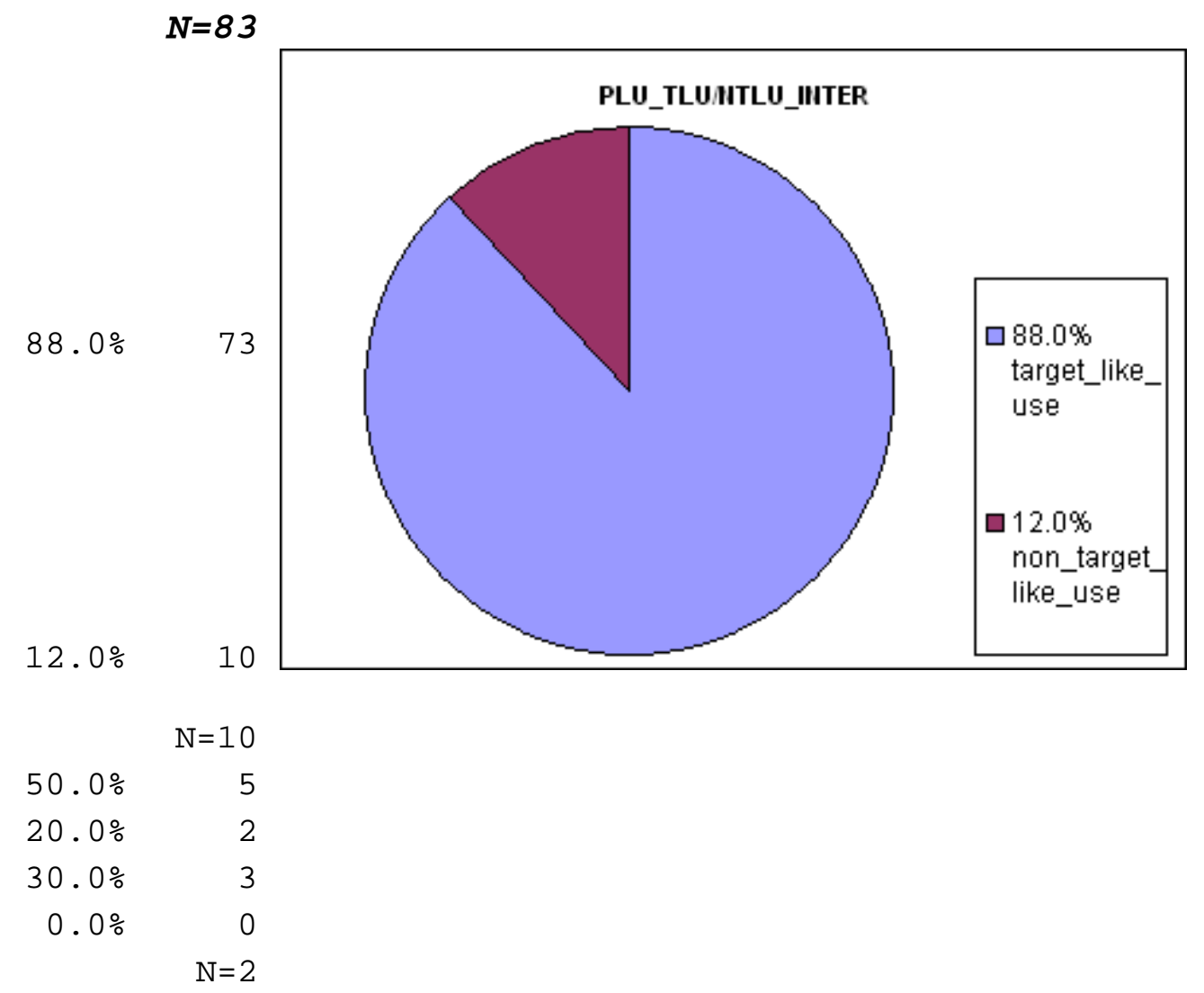


misselection

misrealisation

SCORE: $[\mathrm{SOC} \div(\mathrm{OC}+\mathrm{SNOC})] \times 100$

SOC $=$ underuse $(0$ points $)$

misuse $(0,5$ points $)$

target like_use (1 point)

SOC_PLU_intermediate:

OC_PLU_intermediate:

SNOC_PLU_intermediate:

Score_PLU inter:
$0.0 \%$

$100.0 \%$ 
ART_TYPE

target_like_use

non_target_like_use

NON_TARGET_LIKE_USE-TYPE

underuse

misuse

overuse (snoc)

unclassified

MISUSE-TYPE

misselection

misrealisation

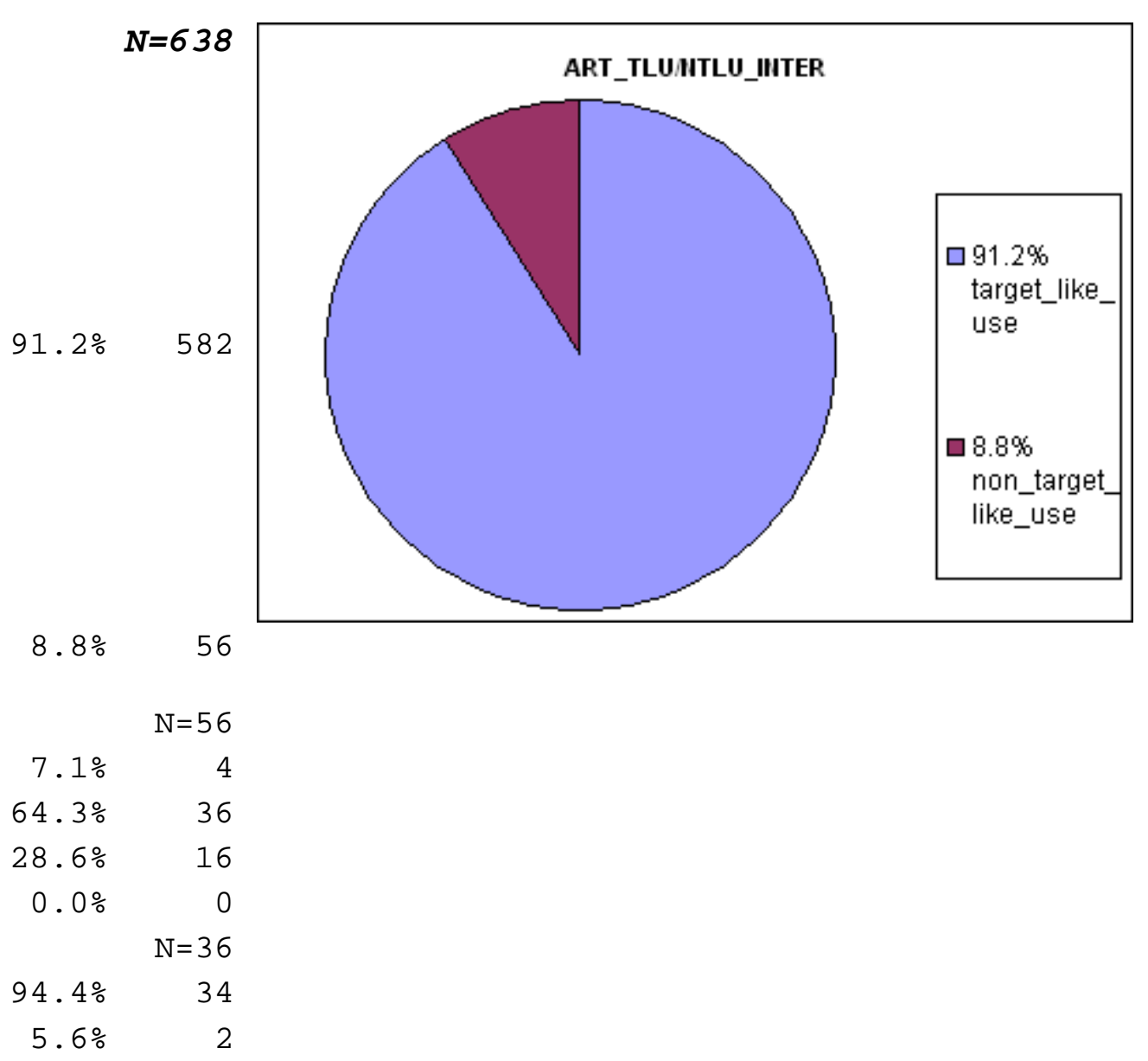

SCORE : $[\mathrm{SOC} \div(\mathrm{OC}+\mathrm{SNOC})] \times 100$

SOC $=$ underuse $(0$ points $)$ 
SOC_ART intermediate: OC_ART_intermediate:

SNOC_ART_intermediate:

Score_ART inter:

Unit :

\section{Feature}

\section{POS-TYPE}

misuse $(0,5$ points $)$

target_like_use (1 point)

$(4 \times 0)+(36 \times 0,5)+(582 \times 1)=600$

638

16

$600 \div(638+16) \times 100=91,74 \%$

POS : pos

Percent

$N=33$

non_target_like_use target like use
$39.4 \%$

$60.6 \%$

\section{POS_TLU/ITLU IIITER}

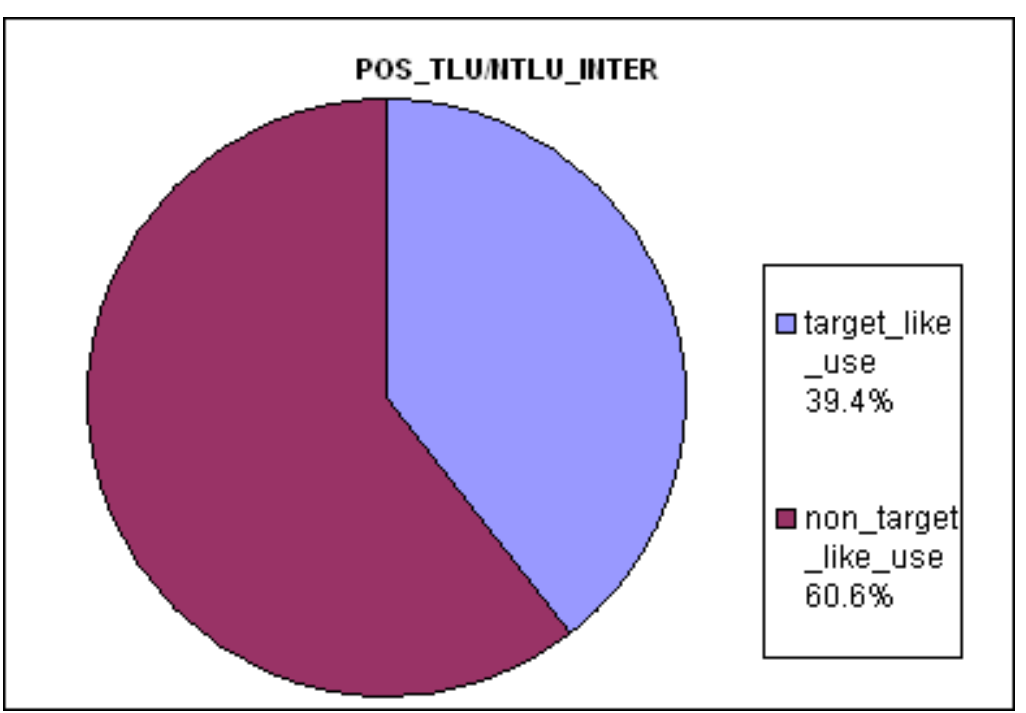


NON_TARGET_LIKE_USE-TYPE

$$
\text { underuse }
$$

misuse

$\mathrm{N}=20$

$$
15.0 \%
$$

3

$75.0 \%$

overuse (snoc)

$10.0 \%$

2

SCORE : $[$ SOC $\div(\mathrm{OC}+\mathrm{SNOC})] \times 100$

$$
\begin{aligned}
& \text { SOC }=\text { underuse }(0 \text { points }) \\
& \text { misuse }(0,5 \text { points }) \\
& \text { target_like_use }(1 \text { point }) \\
& (3 \times 0)+(15 \times 0,5)+(13 \times 1)=20,5 \\
& 33 \\
& 2 \\
& 20,5 \div(33+2) \times 100=58,57 \%
\end{aligned}
$$




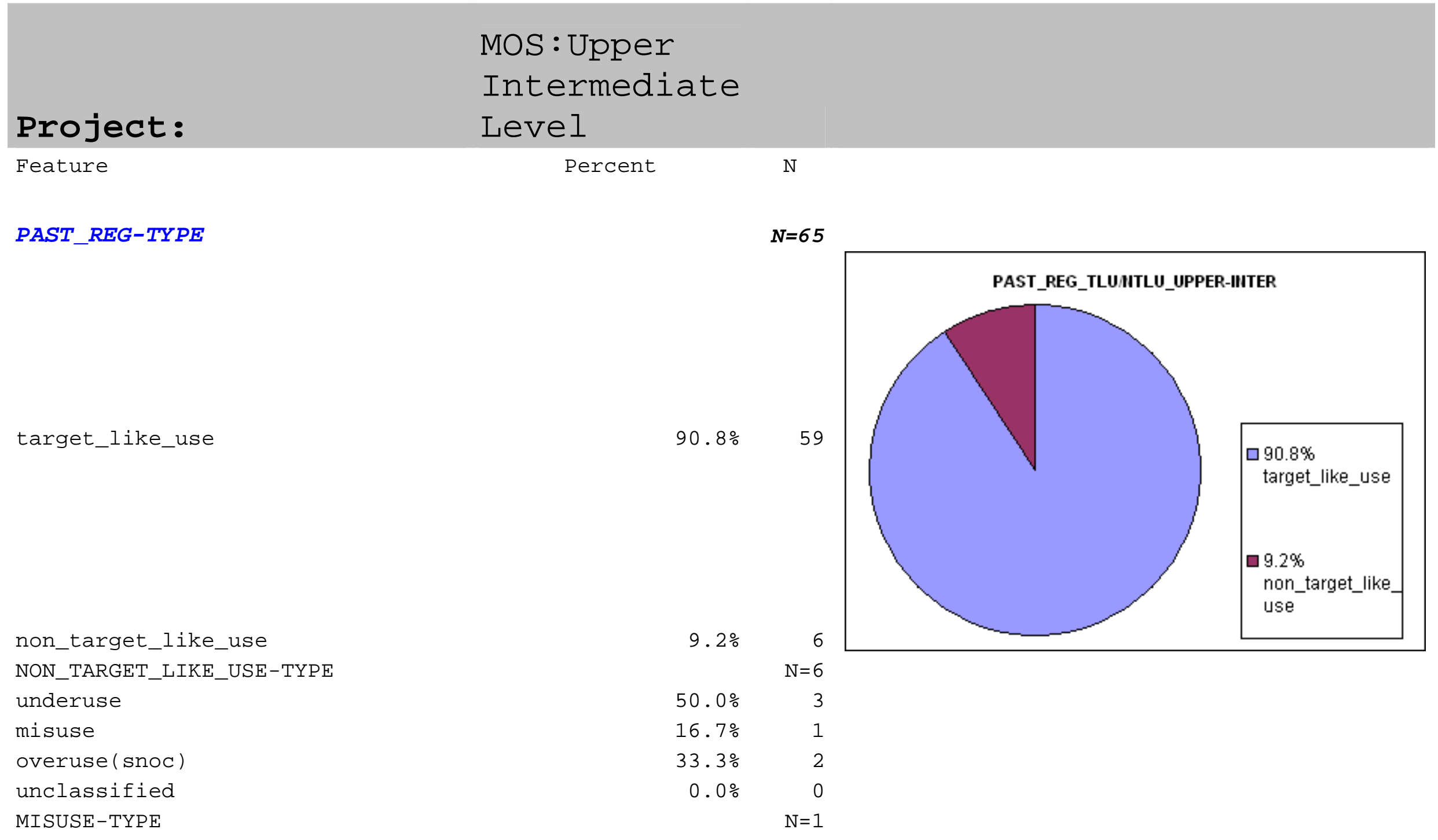


misselection

misrealisation
$100.0 \%$

$0.0 \%$

SCORE: $[\mathrm{SOC} \div(\mathrm{OC}+\mathrm{SNOC})] \times 100$

SOC $=$ underuse $(0$ points $)$

misuse $(0,5$ points)

target_like_use (1 point)

SoC_past_reg_upper-intermediate:

OC_past_reg_upper-intermediate:

SNOC_past_reg_upper-intermediate:

Score_past_reg_upper-inter:

Feature

PAST_IRREG-TYPE
Percent

$\mathrm{N}$

$N=65$ 
$89.2 \%$

non target like use

NON_TARGET_LIKE_USE-TYPE

underuse

misuse

overuse (snoc)

unclassified

MISUSE-TYPE

misselection

misrealisation

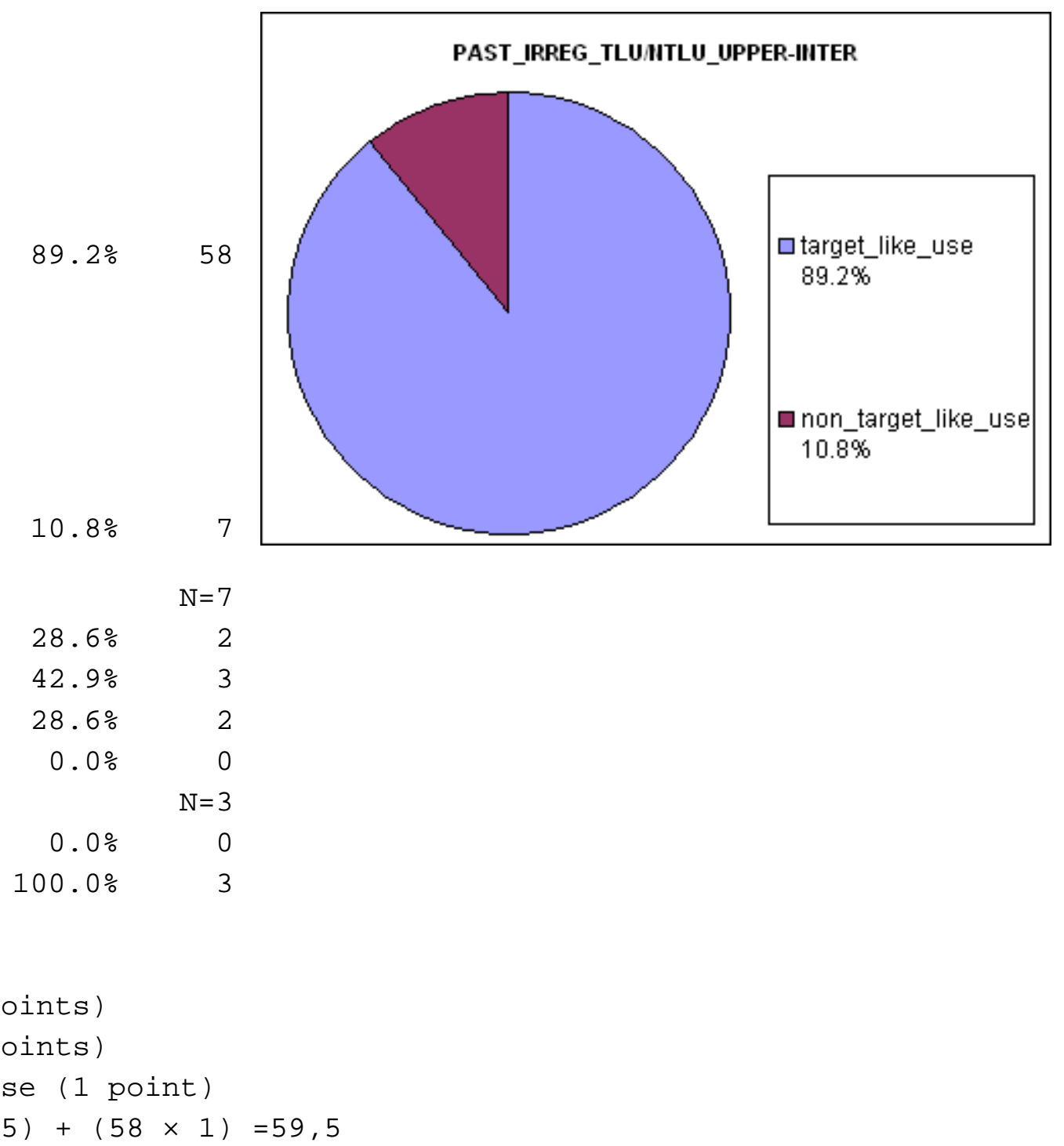


intermediate:

OC_past_irreg_upper-intermediate:

SNOC_past_irreg_upper-

intermediate:

Score_past_irreg_upper-inter:

\section{Feature}

\section{SG_TYPE}

target_like_use

non_target_like_use

NON_TARGET_LIKE_USE-TYPE

underuse

misuse

overuse (snoc)

unclassified

\section{5}

2

$59,5 \div(65+2) \times 100=88,80 \div$

Percent

$\begin{array}{rr} & \boldsymbol{N}=1 \\ 0.0 \% & 0 \\ & \\ 100.0 \% & 1 \\ & \\ & \\ 0.0 \% & 0 \\ 0.0 \% & 0 \\ 100.0 \% & 1 \\ 0.0 \% & 0\end{array}$

$\mathrm{N}$

$=1$

$=1$

0

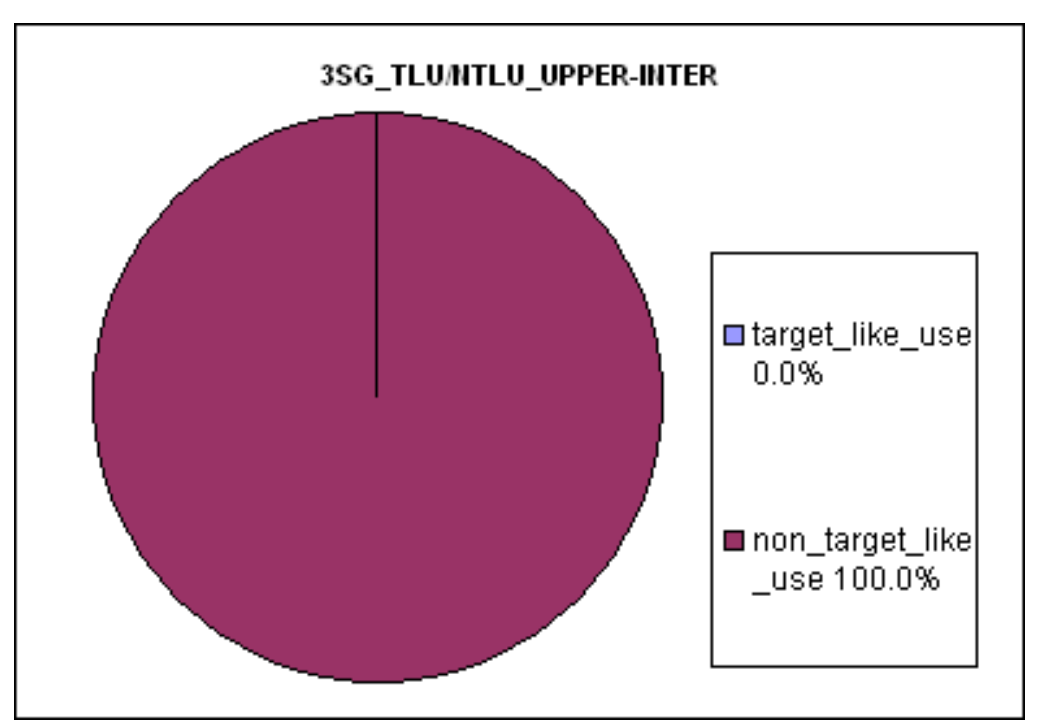


MISUSE-TYPE

misselection

$0.0 \%$

misrealisation

$0.0 \%$

SCORE : $[\mathrm{SOC} \div(\mathrm{OC}+\mathrm{SNOC})] \times 100$

SOC $=$ underuse $(0$ points $)$

misuse $(0,5$ points $)$

target_like_use (1 point)

SOC_3SG_upper-intermediate:

OC_3SG_upper-intermediate:

$(0 \times 0)+(0 \times 0,5)+(0 \times 1)=0$

SNOC_3SG_upper-intermediate:

Score_3SG_upper-inter:

1

$0 \div(1+1) \times 100=0 \div$ 
NON_TARGET_LIKE_USE-TYPE

$\begin{array}{rr}0.0 \% & 0 \\ 0.0 \% & 0 \\ 100.0 \% & 1 \\ 0.0 \% & 0 \\ 0.0 \% & 0 \\ 0.0 \% & 0\end{array}$

underuse

misuse

overuse (snoc)

unclassified

MISUSE-TYPE

misselection

$0.0 \%$

misrealisation

\section{IIIG_TLU/ITLU_UPPER-IIITER}

32

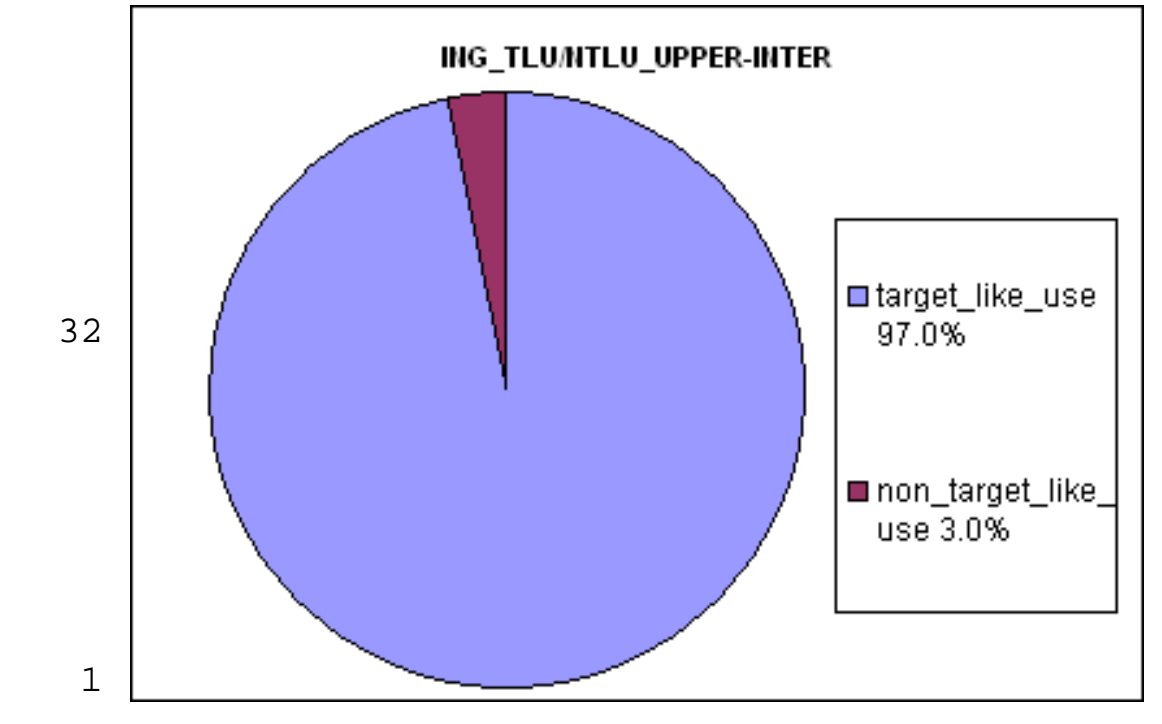

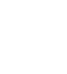

SCORE $:[S O C \div(O C+S N O C)] \times 100$

SOC $=$ underuse $(0$ points $)$

misuse $(0,5$ points $)$

target_like_use (1 point)

SOC_ING_upper-intermediate:

$(0 \times 0)+(0 \times 0,5)+(32 \times 1)=32$ 
OC_ING_upper-intermediate:

SNOC_ING_upper-intermediate:

Score_ING_upper-inter:

Feature

BE_COP_TYPE

target_like_use

non_target_like_use

NON_TARGET_LIKE_USE-TYPE

underuse

misuse

overuse (snoc)

unclassified

MISUSE-TYPE

$32 \div(33+1) \times 100=94,11 \div$

Percent

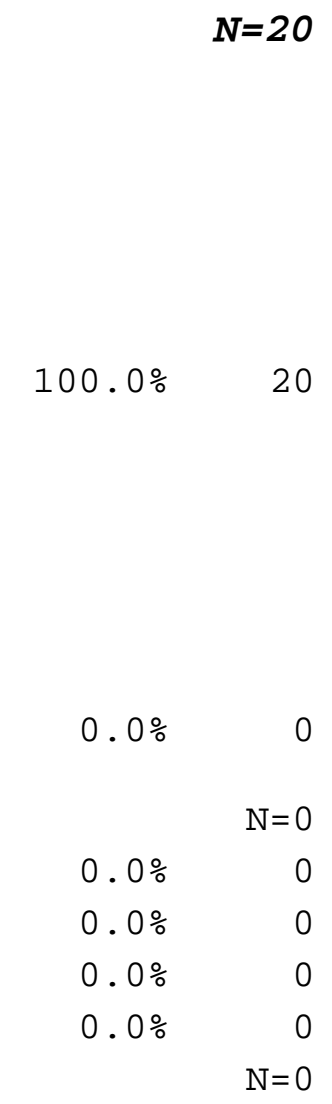


misselection

misrealisation

\section{$0.0 \%$}

$0.0 \%$

SCORE : $[\mathrm{SOC} \div(\mathrm{OC}+\mathrm{SNOC})] \times 100$

SOC $=$ underuse $(0$ points $)$

misuse $(0,5$ points) target_like_use (1 point)

SOC_BE_COP_upper-intermediate: OC_BE_COP_upper-intermediate: SNOC_BE_COP_upper-intermediate: Score_BE_COP_upper-inter:

Feature

BE_AUX_TYPE
Percent

$\mathrm{N}$

$N=28$ 
NON_TARGET_LIKE_USE-TYPE

$\begin{array}{lr}0.0 \% & \mathrm{~N}=0 \\ 0.0 \% & 0 \\ 0.0 \% & 0 \\ 0.0 \% & 0 \\ 0.0 \% & \mathrm{~N}=0 \\ 0.0 \% & 0\end{array}$

\section{underuse}

misuse

overuse (snoc)

unclassified

MISUSE-TYPE

misselection

$0.0 \%$

misrealisation

SCORE : $[\mathrm{SOC} \div(\mathrm{OC}+\mathrm{SNOC})] \times 100$

SOC $=$ underuse $(0$ points $)$

misuse $(0,5$ points $)$

target_like_use (1 point)

SOC_BE_AUX_upper-intermediate: 
OC_BE_AUX_upper-intermediate: SNOC_BE_AUX_upper-intermediate: Score_BE_AUX_upper-inter:

\section{Feature}

\section{PLU_TYPE}

target_like_use

non_target_like_use

NON_TARGET_LIKE_USE-TYPE

underuse

misuse

overuse (snoc)

unclassified

MISUSE-TYPE

$28 \div(28+0) \times 100=100 \div$

Percent

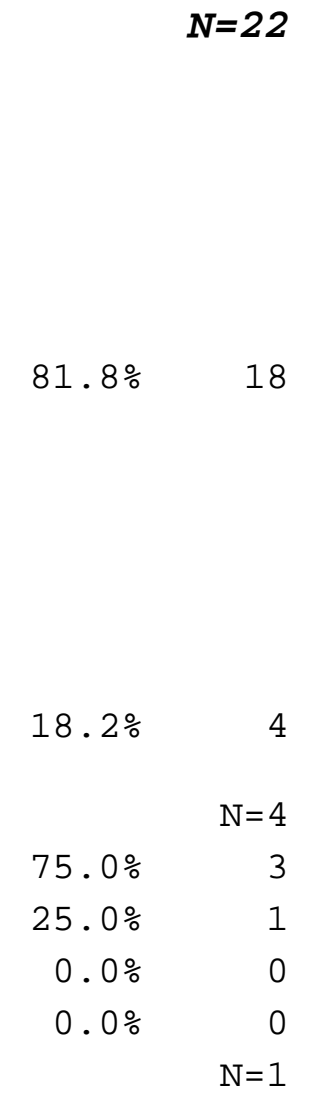


misselection

misrealisation
$0.0 \%$

$100.0 \%$

SCORE : $[\mathrm{SOC} \div(\mathrm{OC}+\mathrm{SNOC})] \times 100$

SOC $=$ underuse $(0$ points $)$

misuse $(0,5$ points $)$

target_like_use (1 point)

SOC_PLU_upper-intermediate:

OC_PLU_upper-intermediate:

SNOC_PLU_upper-intermediate:

Score_PLU_upper-inter:

Feature

ART_TYPE
Percent

$\mathrm{N}$

$N=129$ 


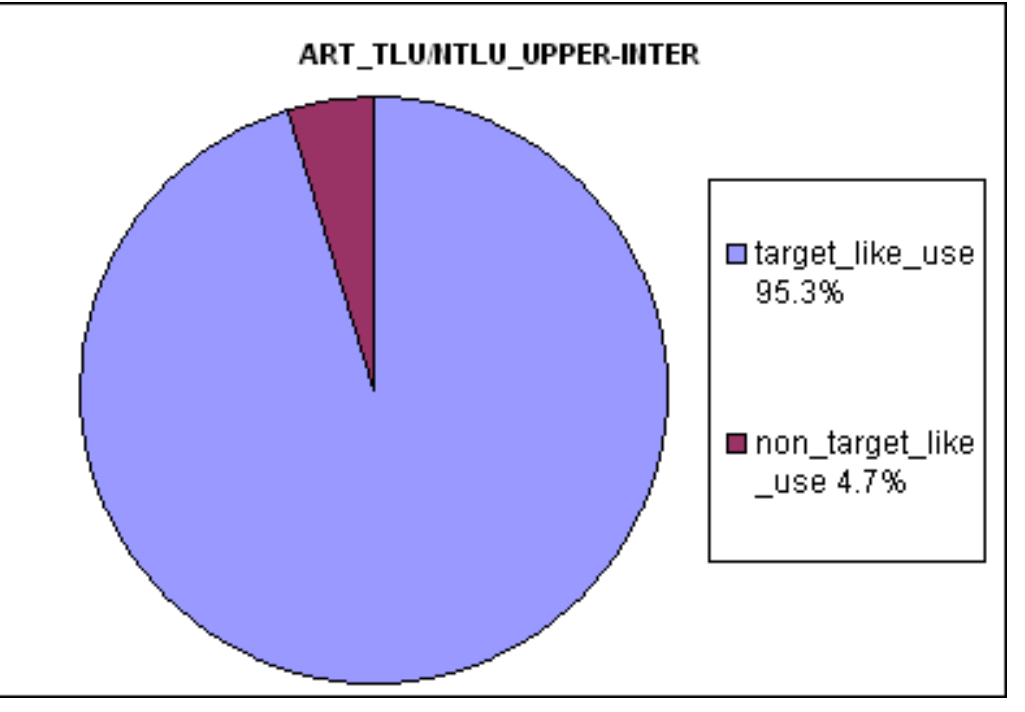

non_target_like_use

$4.7 \%$

$=6$

NON_TARGET_LIKE_USE-TYPE

$0.0 \% \quad 0$

underuse

misuse

$83.3 \%$

$16.7 \%$

$0.0 \%$

unclassified

$\mathrm{N}=5$

ISUSE-TYPE

$100.0 \%$

$0.0 \%$

misrealisation

SCORE $:[S O C \div(O C+S N O C)] \times 100$

SOC $=$ underuse $(0$ points $)$

misuse $(0,5$ points $)$

target_like_use (1 point)

SOC_ART_upper-intermediate:

$(0 \times 0)+(5 \times 0,5)+(123 \times 1)=125,5$ 
OC_ART_upper-intermediate:

SNOC_ART_upper-intermediate:

Score_ART_upper-inter:

\section{Feature}

\section{POS_TYPE}

target_like_use

non_target_like_use

NON_TARGET_LIKE_USE-TYPE

underuse

misuse

overuse (snoc)

unclassified

MISUSE-TYPE

$125,5 \div(129+1) \times 100=96,53 \%$

Percent

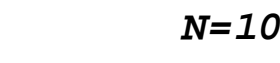

$60.0 \%$

$16.7 \%$

$66.7 \%$

$16.7 \%$

$0.0 \%$

$\mathrm{N}=6$

1

4

0

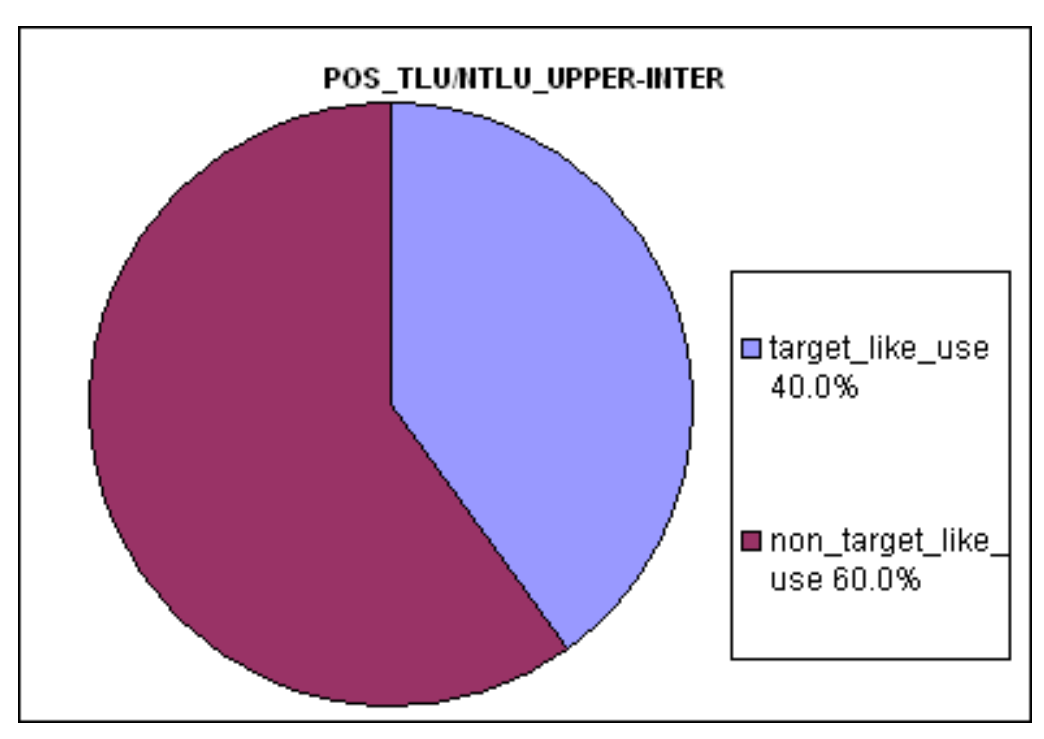

$\mathrm{N}=4$ 
misselection

misrealisation
$25.0 \%$

$75.0 \%$

SCORE : $[\mathrm{SOC} \div(\mathrm{OC}+\mathrm{SNOC})] \times 100$

SOC $=$ underuse $(0$ points $)$

misuse $(0,5$ points

target_like_use (1 point)

$(1 \times 0)+(4 \times 0,5)+(4 \times 1)=6$

10

1

$6 \div(10+1) \times 100=54,54 \%$ 
9.11.1.2 General Descriptive Statistics (grouping criterion: none)

\section{Descriptive Statistics: Features}

\section{MOS : ALL \\ PROF ICIENCY}

Project: LEVELS

Feature

PAST_REG-TYPE

target_like_use

non_target_like_use

NON_TARGET_LIKE_USETYPE
Percent

$\mathrm{N}$

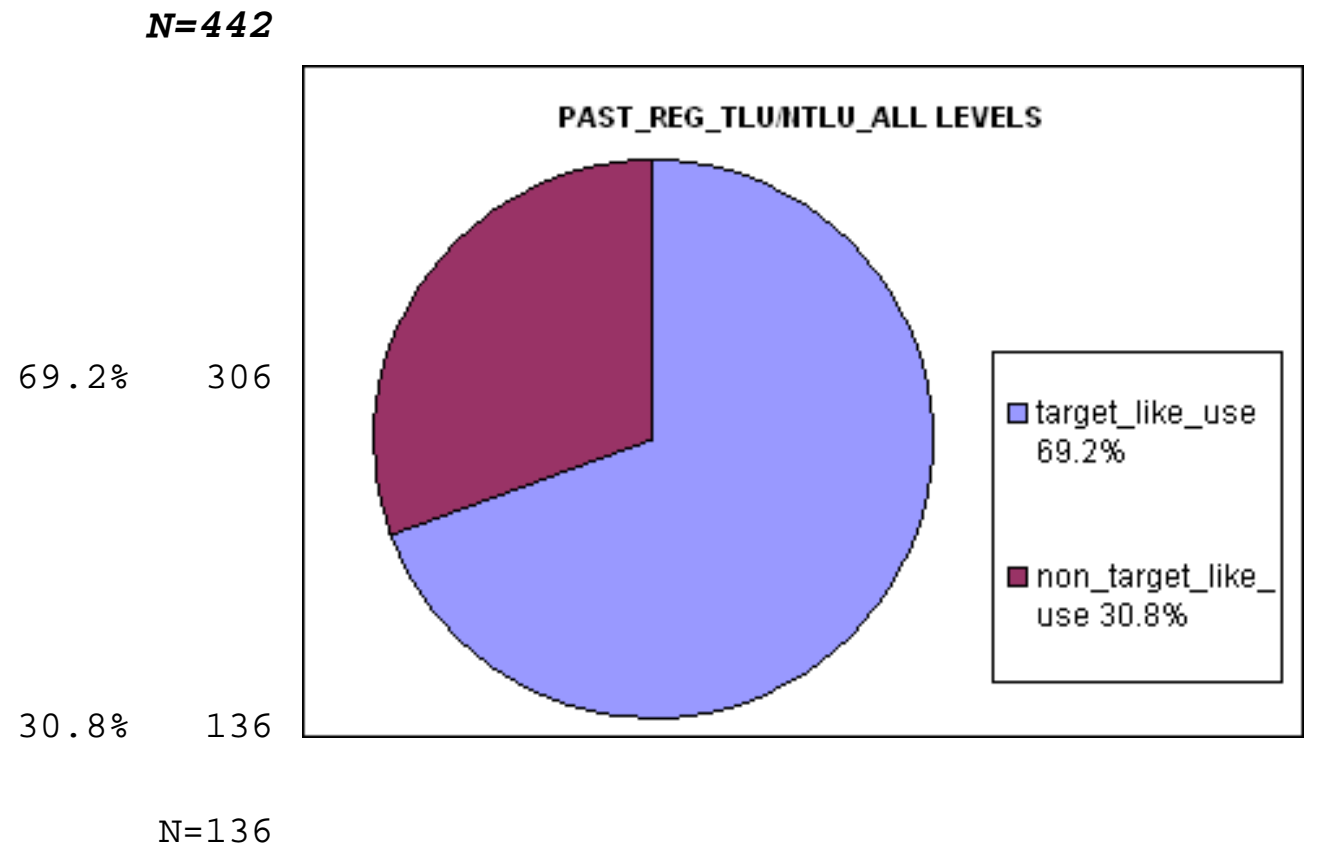




\begin{tabular}{|c|c|c|c|}
\hline underuse & $66.2 \%$ & 90 & \\
\hline misuse & $14.7 \%$ & 20 & \\
\hline overuse (snoc) & $17.6 \%$ & 24 & \\
\hline unclassified & $1.5 \%$ & 2 & \\
\hline MISUSE-TYPE & & $\mathrm{N}=20$ & \\
\hline misselection & $30.0 \%$ & 6 & \\
\hline misrealisation & $70.0 \%$ & 14 & \\
\hline $\begin{array}{r}\text { SCORE : }[\mathrm{SOC} \div(\mathrm{OC}+\mathrm{SNOC} \\
\text { SOC }=\end{array}$ & $\begin{array}{l}\text { C) }] \times 100 \\
\text { underuse }(0 \text { points }) \\
\text { misuse }(0,5 \text { points }) \\
\text { target_like_use }(1 \text { poir }\end{array}$ & & \\
\hline SOC_past_reg: & $(90 \times 0)+(20 \times 0,5)+$ & $(306 \times 1)$ & $=31$ \\
\hline oC_past_reg: & 442 & & \\
\hline SNOC_past_reg: & 24 & & \\
\hline Score_past_reg: & $316 \div(442+24) \times 100=$ & $67,81 \%$ & \\
\hline
\end{tabular}

Feature

Percent

$\mathrm{N}$

PAST_IRREG-TYPE

$N=478$ 
target_like_use

non_target_like_use NON_TARGET_LIKE_USETYPE

\section{underuse}

misuse

overuse (snoc)

unclassified

MISUSE-TYPE

misselection

misrealisation

SCORE : $[\mathrm{SOC} \div(\mathrm{OC}+\mathrm{SNOC})] \times 100$

SOC $=$ underuse $(0$ points $)$

misuse $(0,5$ points $)$

target_like_use ( 1 point)

SOC_past_irreg:

oC_past_irreg:

$65.7 \%$

$34.3 \%$

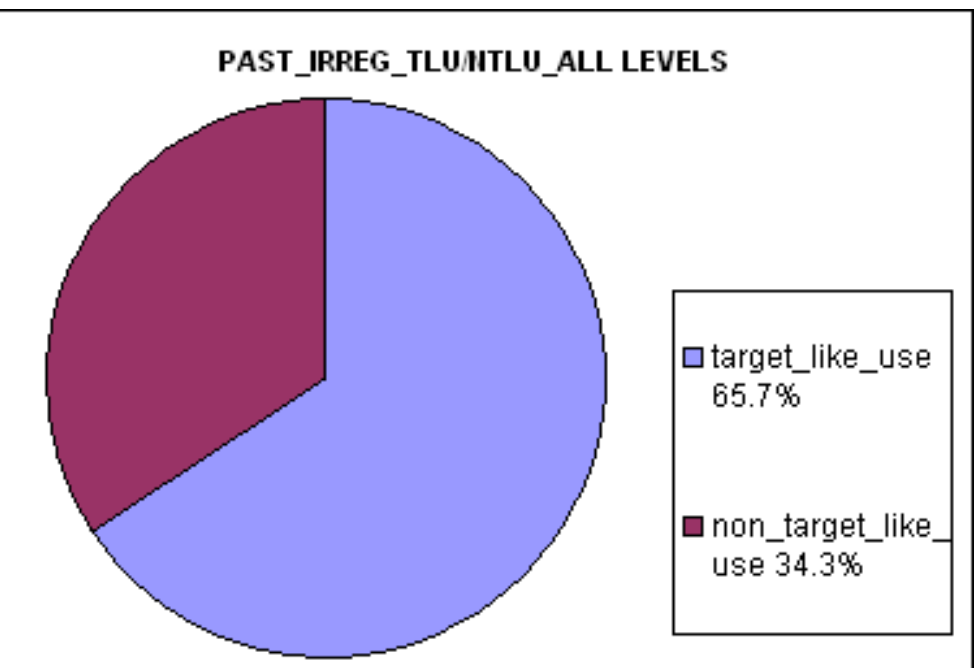

$\mathrm{N}=164$

$51.2 \% \quad 84$

$34.1 \% 56$

$14.6 \% 24$

$0.0 \% \quad 0$

$10.7 \% 6$

$89.3 \% 50$ 
SNOC_past_irreg:

Score_past_irreg:

Feature

\section{SG-TYPE}

target_like_use

non_target_like_use

NON_TARGET_LIKE_USE-

TYPE

underuse misuse

overuse (snoc)
Percent

$\mathrm{N}$

$N=301$

$12.6 \%$

$87.4 \%$

263

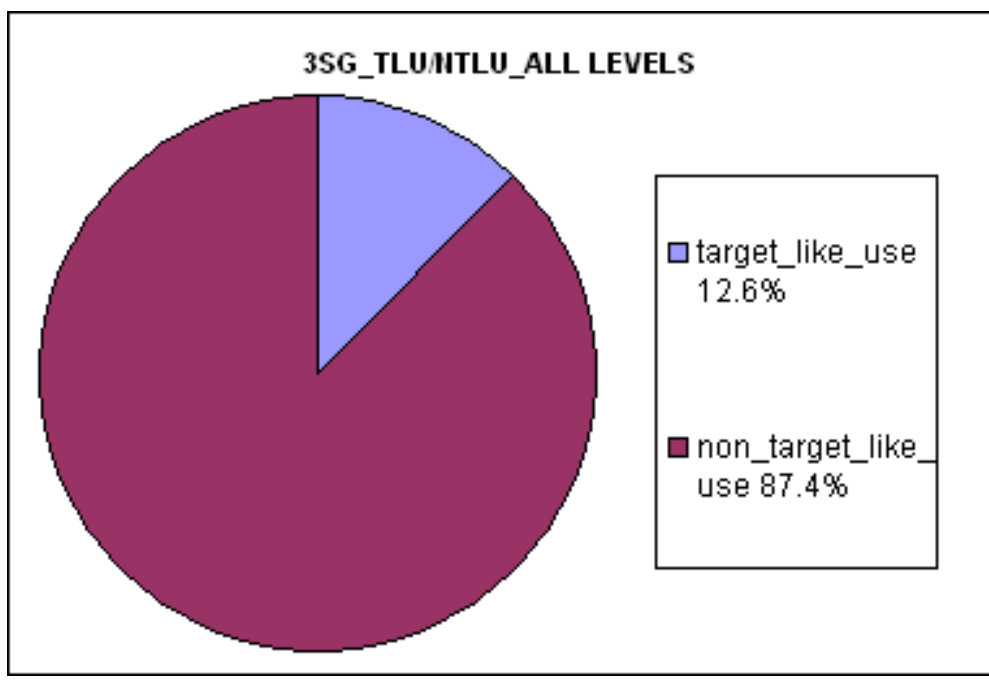

$\mathrm{N}=263$

$76.8 \% 202$

$18.6 \% \quad 49$

$4.6 \%$

12 


$\begin{array}{crr}\text { unclassified } & 0.0 \% & 0 \\ \text { MISUSE-TYPE } & & \mathrm{N}=49 \\ \text { misselection } & 65.3 \% & 32 \\ \text { misrealisation } & 34.7 \% & 17\end{array}$

SCORE: $[\mathrm{SOC} \div(\mathrm{OC}+\mathrm{SNOC})] \times 100$

$\mathrm{SOC}=$ underuse $(0$ points $)$

misuse $(0,5$ points $)$

target_like_use ( 1 point)

SOC_3sg:

OC_3sg:

$(202 \times 0)+(49 \times 0,5)+(38 \times 1)=62,5$

SNOC_3sg:

301

Score_3sg:

12

$62,5 \div(301+12) \times 100=19,96 \%$

Feature

\section{ING-TYPE}

Percent

$\mathrm{N}$

$N=185$ 
target_like_use

non_target_like_use NON_TARGET_LIKE_USETYPE

\section{underuse} misuse overuse (snoc) unclassified MISUSE-TYPE

misselection misrealisation SCORE : $[\mathrm{SOC} \div(\mathrm{OC}+\mathrm{SNOC})] \times 100$

SOC $=$ underuse $(0$ points $)$ misuse $(0,5$ points $)$ target_like_use (1 point)

SOC_ing: oC_ing:

$69.2 \%$

$30.8 \%$

185

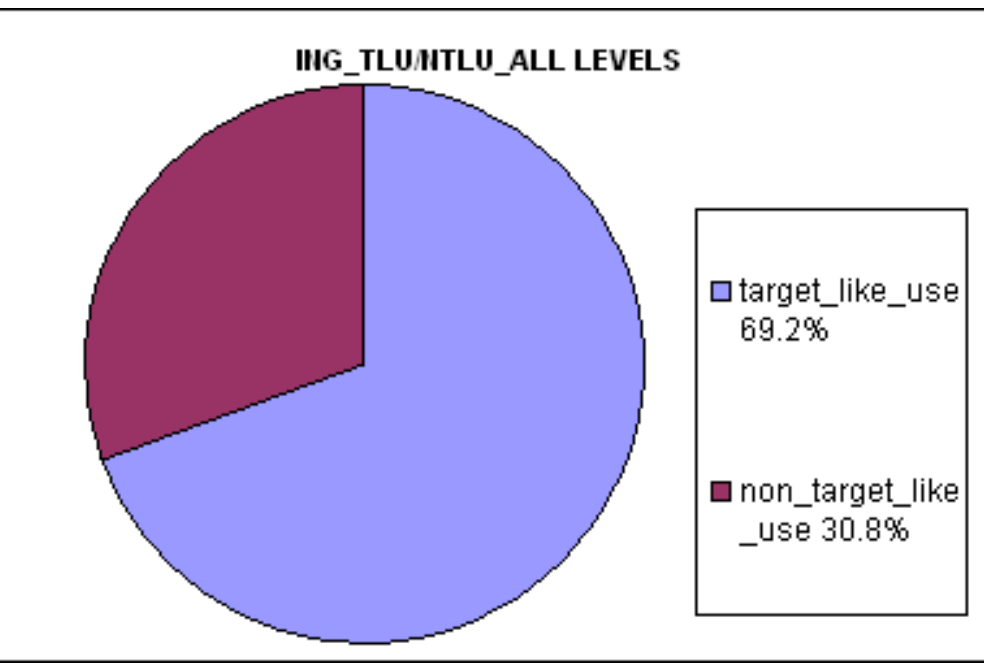

$\mathrm{N}=57$

$28.1 \% \quad 16$

$36.8 \% 21$

$35.1 \% \quad 20$

$0.0 \% \quad 0$

$\mathrm{N}=21$

$14.3 \% 3$

$85.7 \% \quad 18$

$(16 \times 0)+(21 \times 0,5)+(128 \times 1)=138,5$ 
SNOC_ing:

Score_ing:

Feature

$B E \_C O P-T Y P E$

target_like_use

non_target_like_use

NON TARGET_LIKE_USETYPE

$$
\begin{array}{r}
\text { underuse } \\
\text { misuse } \\
\text { overuse (snoc) } \\
\text { unclassified }
\end{array}
$$

MISUSE-TYPE
20

$138,5 \div(185+20) \times 100=67,56 \%$

Percent

$\mathrm{N}$

$N=182$

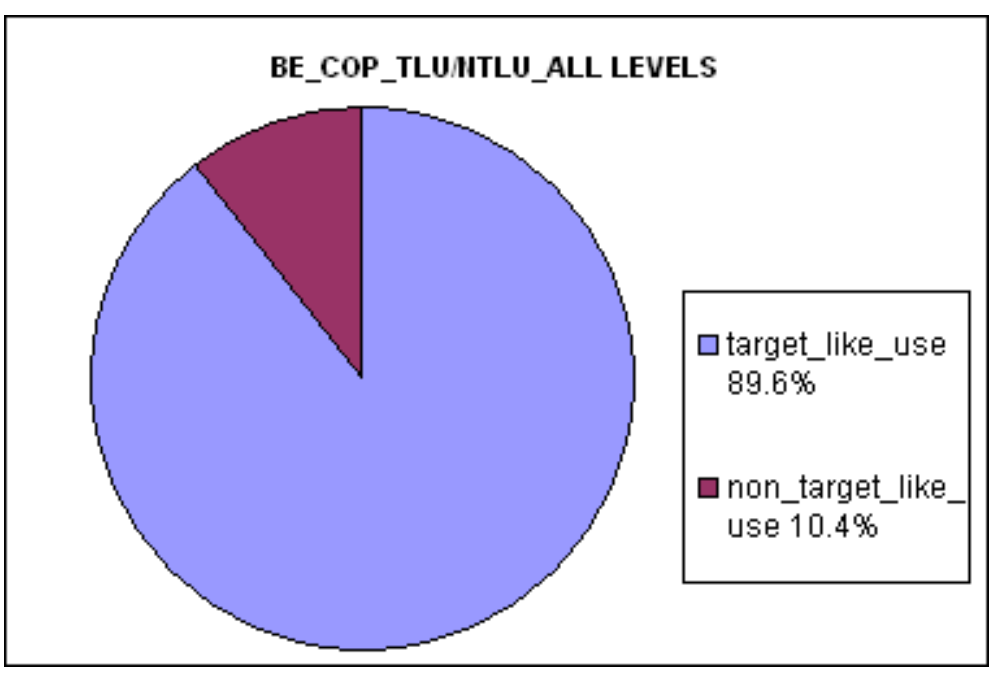

$\mathrm{N}=19$

$15.8 \% 3$

$84.2 \% \quad 16$

$0.0 \% \quad 0$

$0.0 \% \quad 0$ 
misselection

$0.0 \% \quad 0$

misrealisation

$100.0 \%$

16

SCORE : $[\mathrm{SOC} \div(\mathrm{OC}+\mathrm{SNOC})] \times 100$

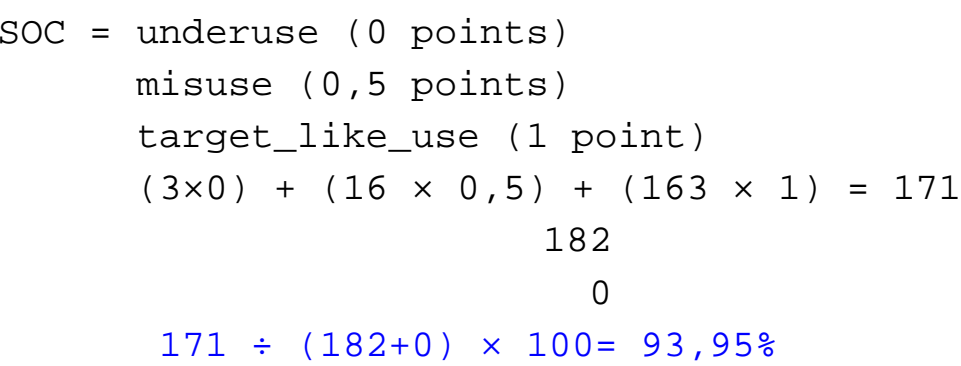

Feature

Percent
$\mathrm{N}$

\section{$N=164$}

\section{$B E \_A U X-T Y P E$}




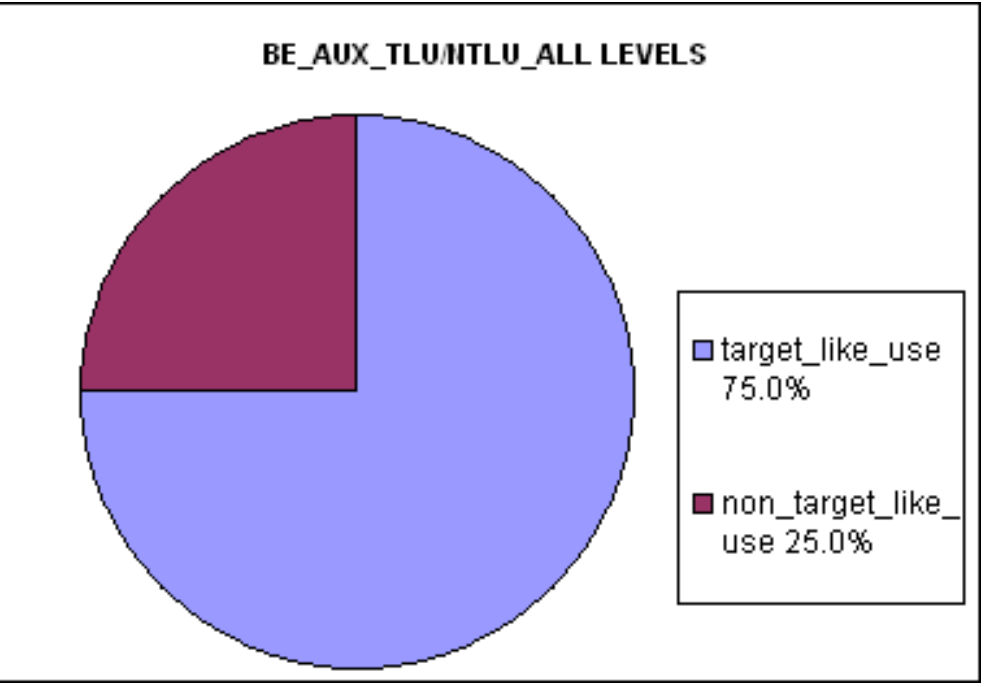

NON_TARGET_LIKE_USETYPE

underuse
misuse
overuse (snoc)
unclassified
MISUSE-TYPE
misselection
misrealisation

misrealisation

$(\mathrm{OC}+\mathrm{SNOC})] \times 100$

SOC $=$ underuse $(0$ points $)$

misuse $(0,5$ points $)$

target_like_use (1 point)

SOC_be_aux:

OC_be_aux:

$\mathrm{N}=41$

$17.1 \%$

$12.2 \% 5$

$70.7 \% \quad 29$

$0.0 \% \quad 0$

$0.0 \% \quad 0$

$100.0 \% 5$

164 
SNOC_be_aux:

Score_be_aux:

Feature

\section{PLU-TYPE}

target_like_use

non_target_like_use NON_TARGET_LIKE_USETYPE

$$
\begin{array}{r}
\text { underuse } \\
\text { misuse } \\
\text { overuse (snoc) } \\
\text { unclassified }
\end{array}
$$

MISUSE-TYPE
29

$125,5 \div(164+29) \times 100=65,02 \%$
N

$N=173$

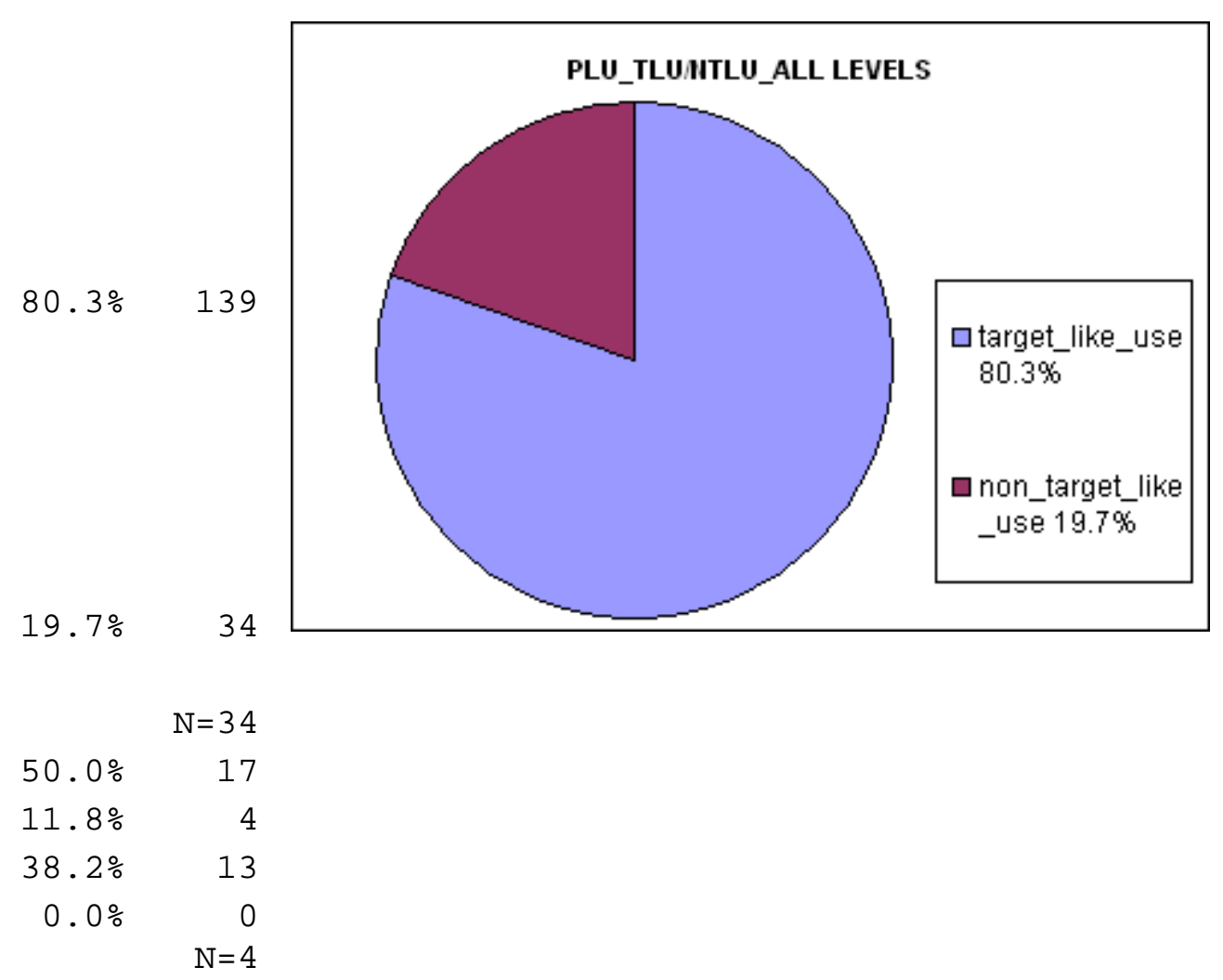


misselection

$0.0 \% \quad 0$

misrealisation

$100.0 \%$

SCORE: $[\mathrm{SOC} \div(\mathrm{OC}+\mathrm{SNOC})] \times 100$

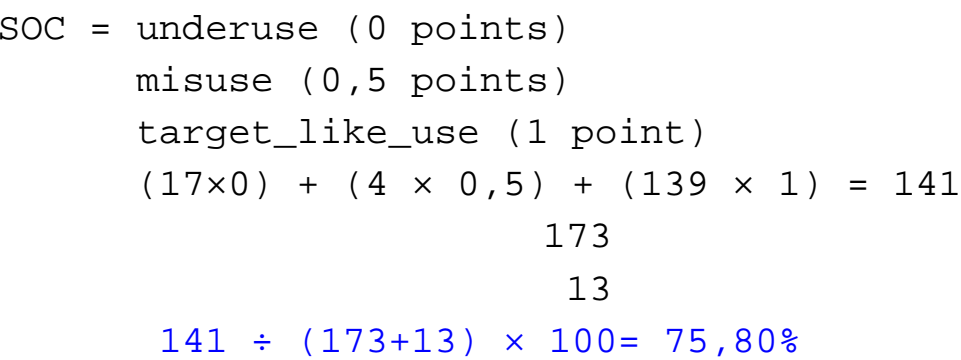

$141 \div(173+13) \times 100=75,80 \%$

Feature

\section{ART-TYPE}

$\mathrm{N}$

$N=1455$ 
target_like_use

non_target_like_use NON_TARGET_LIKE_USETYPE

\section{underuse}

misuse

overuse (snoc)

unclassified

MISUSE-TYPE

misselection

misrealisation
$85.5 \%$

$14.5 \%$

211

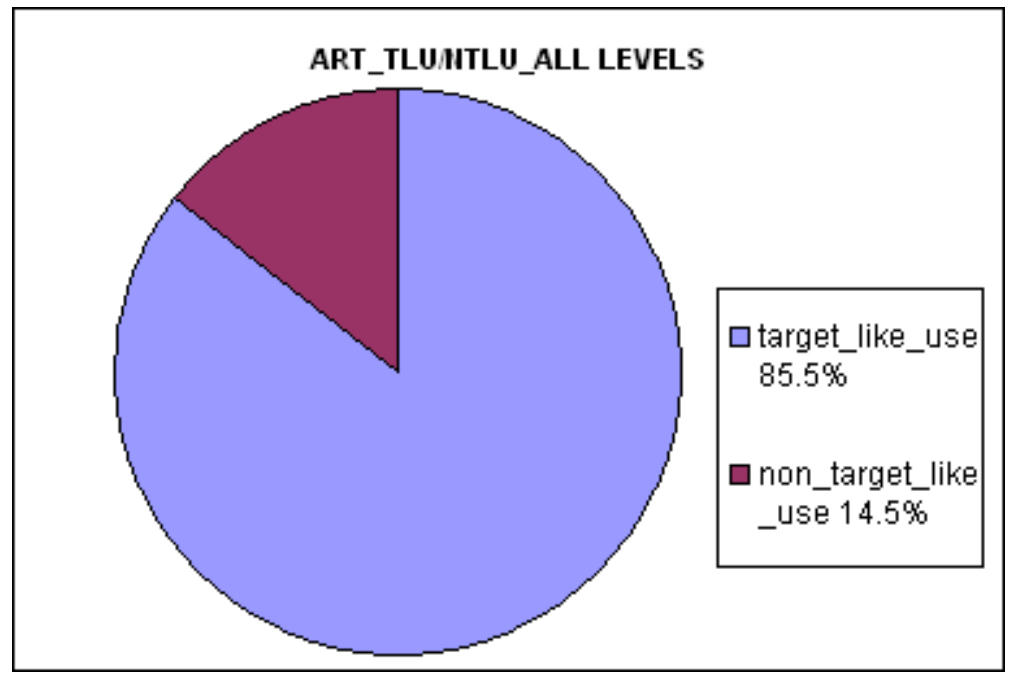

$\mathrm{N}=211$

$17.5 \% \quad 37$

$63.0 \% 133$

$19.4 \% 41$

$0.0 \% \quad 0$

$\mathrm{N}=133$

$91.7 \% \quad 122$

SCORE : $[\mathrm{SOC} \div(\mathrm{OC}+\mathrm{SNOC})] \times 100$

$\mathrm{SOC}=$ underuse $(0$ points $)$

misuse $(0,5$ points $)$

target_like_use (1 point)

SOC_art:

$(37 \times 0)+(133 \times 0,5)+(1244 \times 1)=1310,5$

oc_art: 
SNOC_art:

score_art:

Feature

\section{POS-TYPE}

target_like_use

non_target_like_use NON_TARGET_LIKE_USETYPE

underuse

$$
\text { misuse }
$$

overuse (snoc)

$$
\text { unclassified }
$$

MISUSE-TYPE
41

$1310,5 \div(1455+41) \times 100=87,60 \%$
Percent

$\mathrm{N}$

$N=80$

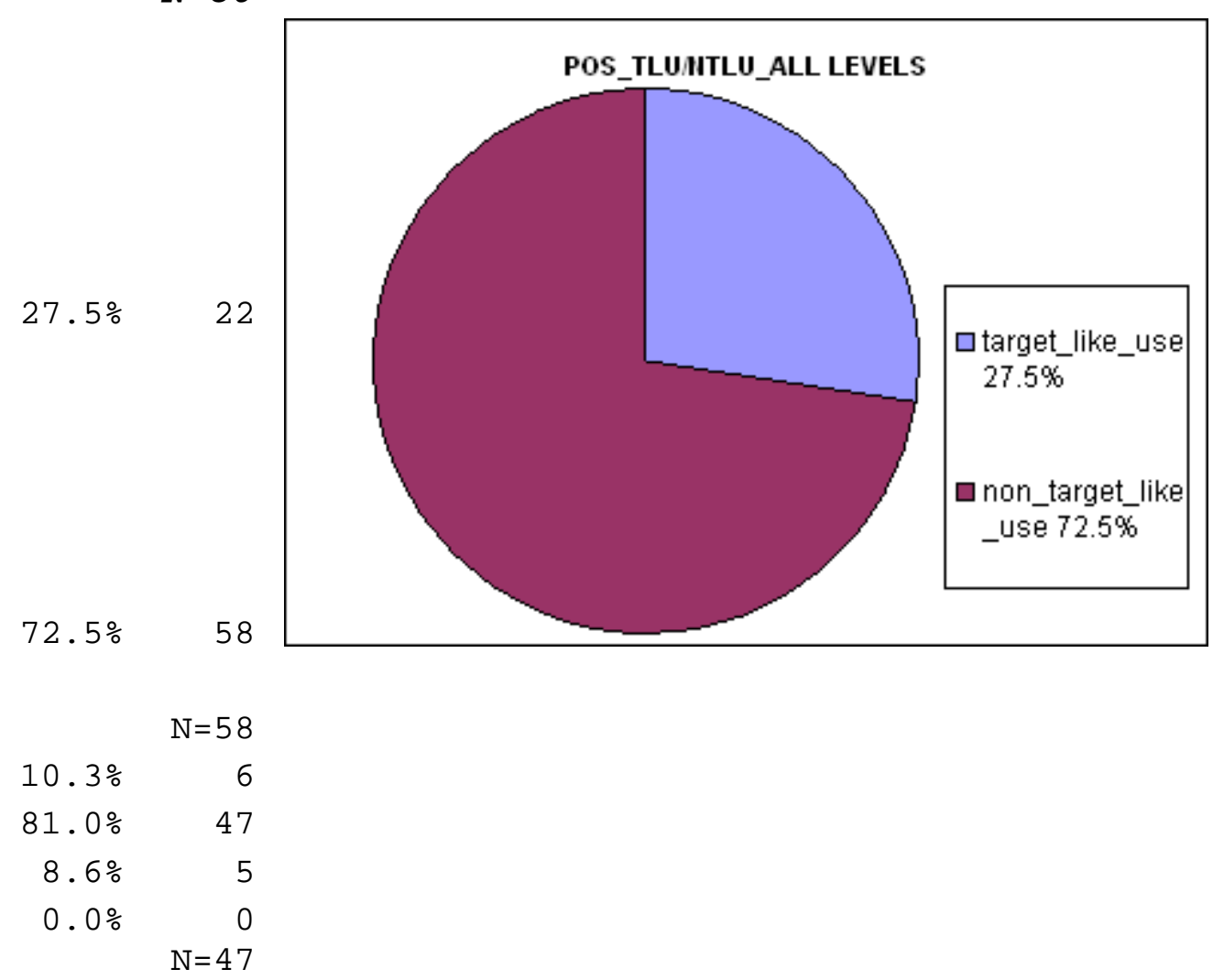


misselection

$70.2 \%$

33

misrealisation

$29.8 \%$

14

SCORE : $[\mathrm{SOC} \div(\mathrm{OC}+\mathrm{SNOC})] \times 100$

SOC $=$ underuse $(0$ points $)$

misuse $(0,5$ points $)$

target_like_use ( 1 point)

SOC_pos:

oC_pos:

$(6 \times 0)+(47 \times 0,5)+(22 \times 1)=45,5$

SNOC_pos:

80

Score_pos:

$45,5 \div(80+5) \times 100=53,52 \%$ 
9.11.2 Part II: The use of the possessive -s by L2 English learners: an experimentally elicited data study

\section{Descriptive Statistics: Features}

possessive -

Project

$\mathrm{S}$

\section{Elementary Level}

Feature

POS-TYPE
Percent

$N=108$ 
target_like_use

non_target_like_use

NON_TARGET_LIKE_USE-TYPE

underuse

misuse

overuse-(snoc)

UNDERUSE-TYPE

blank

no-'/-'s

MISUSE-TYPE

misselection

misrealisation

wrong-unclassified

SCORE $:[S O C \div(\mathrm{OC}+\mathrm{SNOC})] \times 100$

$\mathrm{SOC}=$ underuse $(0$ points $)$

$\mathrm{N}=81$

$\mathrm{N}=63$

$\mathrm{N}=18$
POS-S_TLU/ITLU_ELEM

$75.0 \%$

81

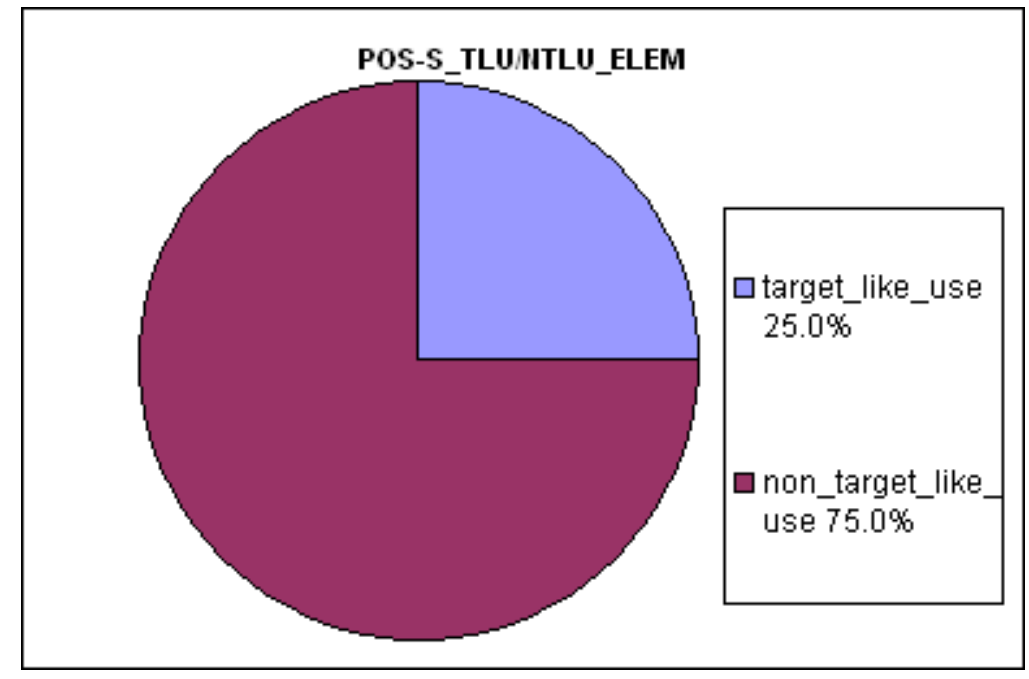

$77.8 \% 63$

$22.2 \% 18$

$0.0 \%$

$41.3 \div \quad 26$

$58.7 \% 37$

$22.2 \%$

$27.8 \% 5$

$50.0 \% 9$ 


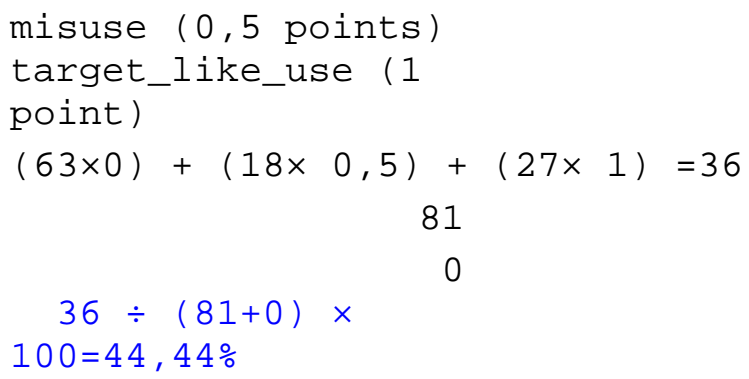

Pre-intermediate Level

Feature

POS-TYPE
Percent

non_target_like_use
$N=636$

target_like_use

$58.6 \%$

373

$41.4 \%$

263
$\mathrm{N}$

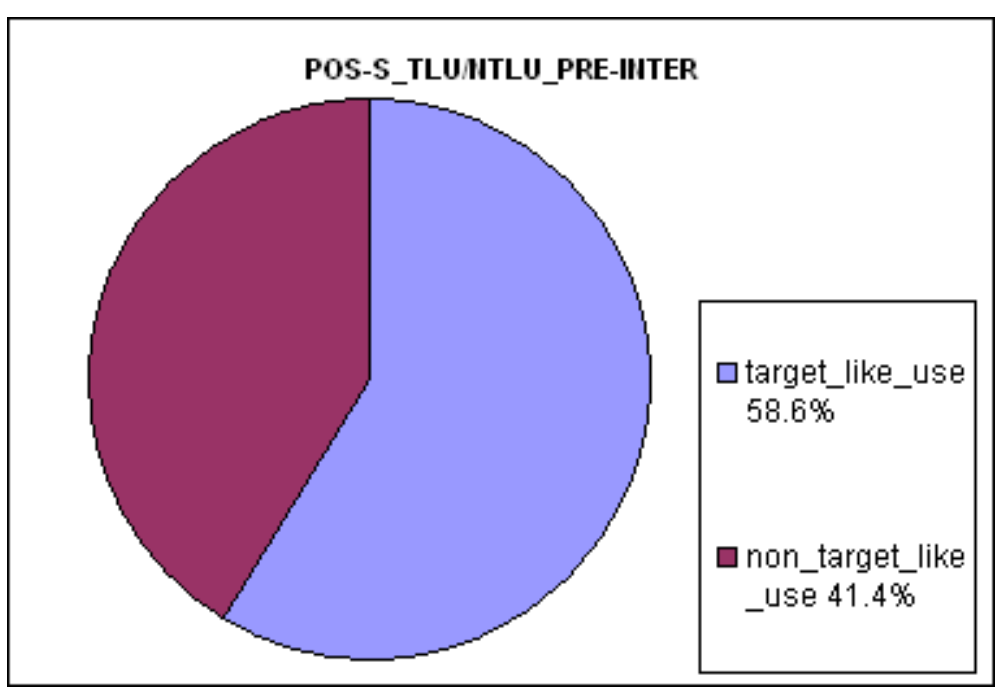




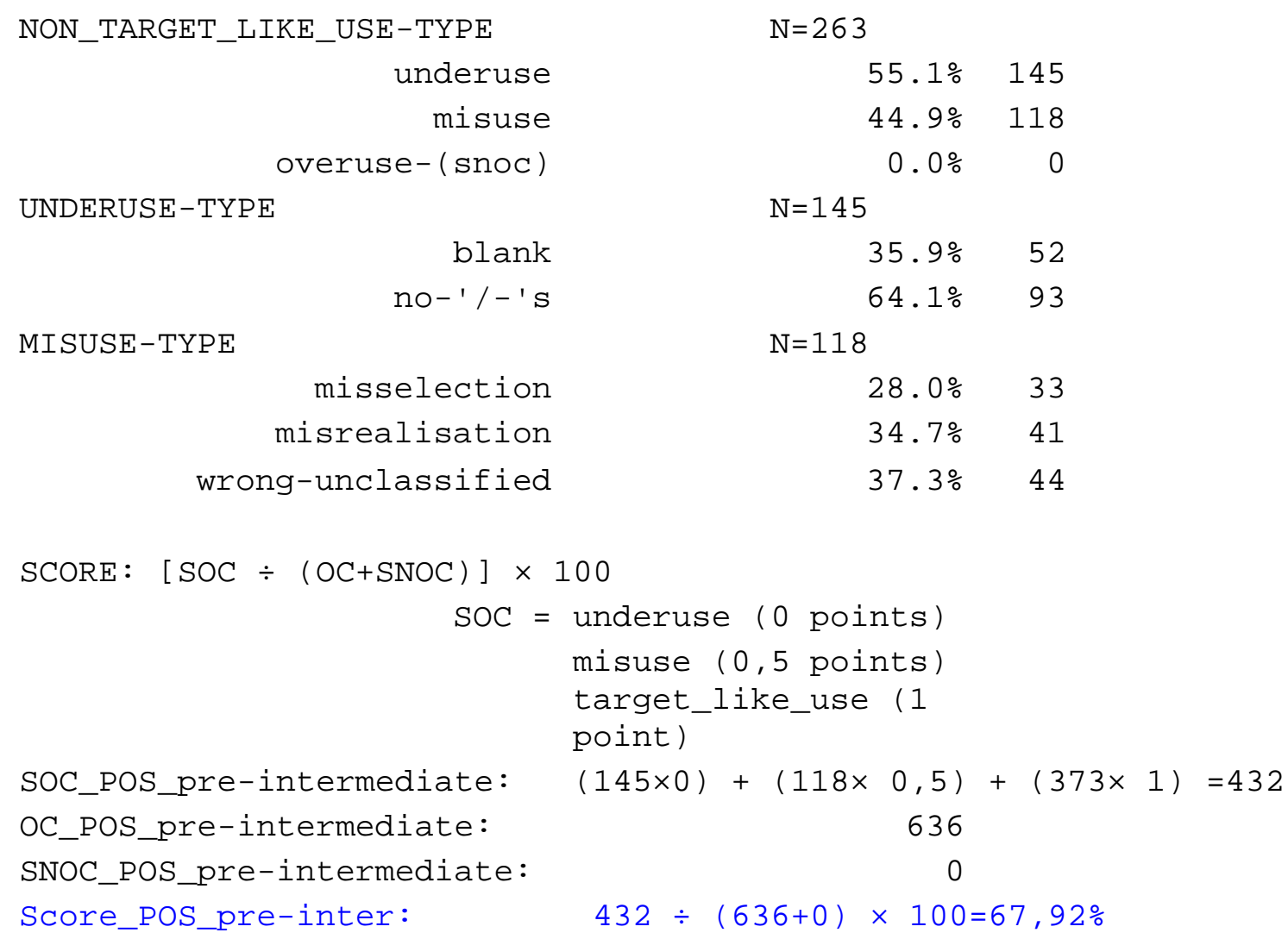

\section{Intermediate Level}




\section{POS-TYPE}

target_like_use

non target like use

NON_TARGET_LIKE_USE-TYPE

underuse

misuse

overuse-(snoc)

UNDERUSE-TYPE

blank

$$
\text { no-'/-'s }
$$

MISUSE-TYPE

misselection

misrealisation

wrong-unclassified

\section{$N=606$}

$83.3 \frac{\circ}{\circ}$

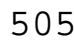

$16.7 \%$

101

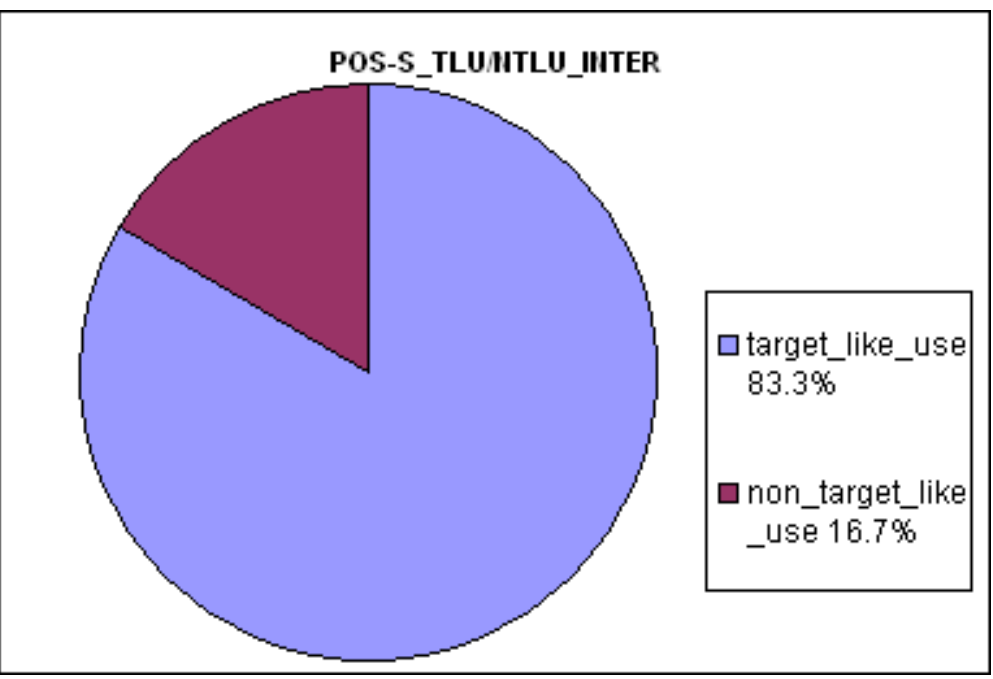

$\mathrm{N}=101$

$18.8 \% 19$

$81.2 \% \quad 82$

$0.0 \% \quad 0$

$\mathrm{N}=19$

$21.1 \% 4$

$78.9 \% \quad 15$

$\mathrm{N}=82$

$34.1 \% 28$

$41.5 \% 34$

$24.4 \% 20$ 


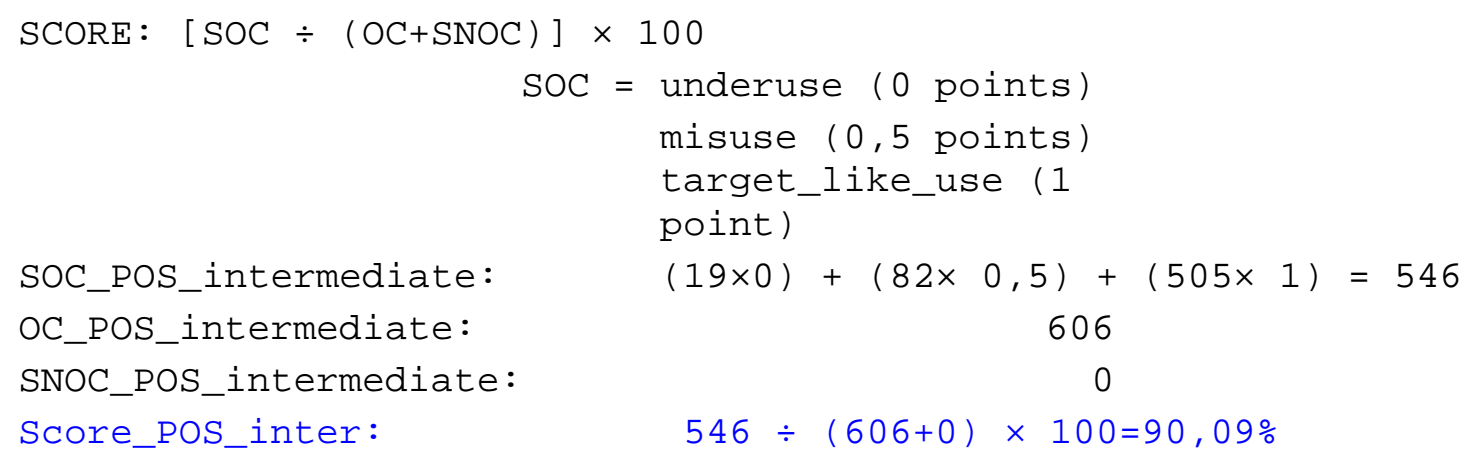

\section{Upper-intermediate Level}

Feature

Percent
$N=186$

POS-TYPE 
target_like_use

non_target_like_use

NON_TARGET_LIKE_USE-TYPE

underuse

misuse

overuse-(snoc)

UNDERUSE-TYPE

blank

$$
\text { no-'/-'s }
$$

MISUSE-TYPE

misselection misrealisation wrong-unclassified

SCORE $:[\mathrm{SOC} \div(\mathrm{OC}+\mathrm{SNOC})] \times 100$
POS-S_TLU/ITLU_UPPER-IIITER

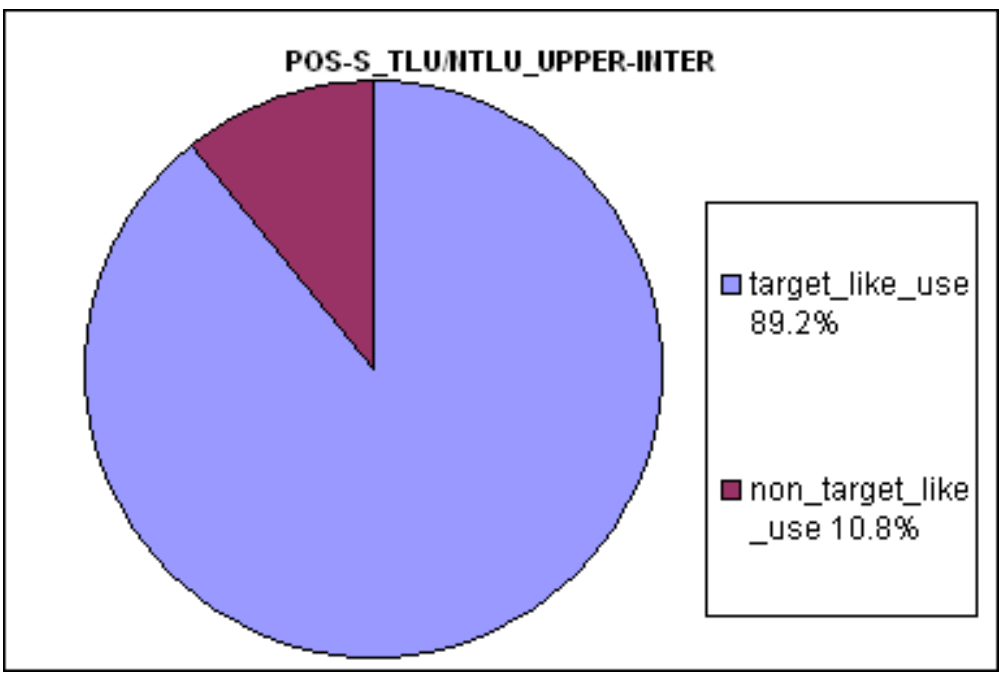

$\mathrm{N}=20$

$75.0 \% 15$

$25.0 \% 5$

$0.0 \% \quad 0$

$\mathrm{N}=15$

$40.0 \div 6$

$60.0 \% 9$

$\mathrm{N}=5$

$0.0 \% \quad 0$

$60.0 \% 3$

$40.0 \% \quad 2$

SOC $=$ underuse $(0$ points $)$ 
SOC_POS_upper-

intermediate:

OC_POS_upper-intermediate:

SNOC_POS_upper-

intermediate:

Score_POS_upper-inter:

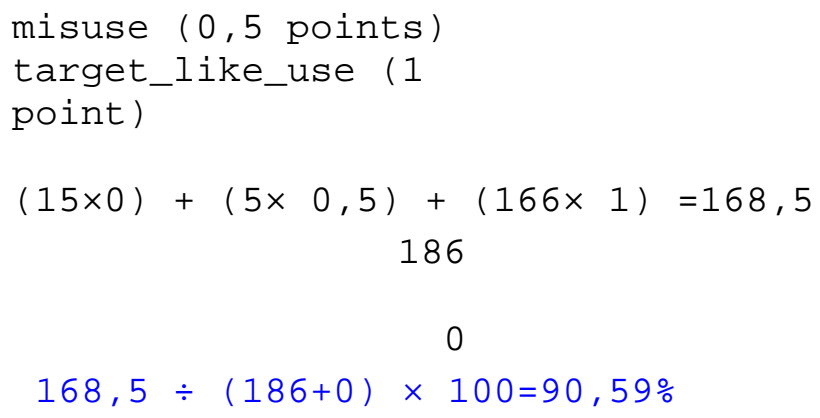

9.11.3 Part III: The use of the possessive structures by I3 German learners: an experimentally elicited data study

9.11.3.1 The relative frequency of the various possession constructions in German by I1 Spanish learners

Descriptive Statistics: Features

$\begin{array}{ll}\text { Project } & \text { genitive_ } \\ \text { German }\end{array}$

\section{Elementary Level}


non_target_like_use TARGET_LIKE_USE-TYPE

-s-possessor-construction genitive-case NON_TARGET_LIKE_USE-TYPE

underuse misuse overuse-(snoc) UNDERUSE-TYPE

blank

MISUSE-TYPE
Percent

$N=120$

$4.2 \% 113$

$\mathrm{N}=7$

$100.0 \% \quad 7$

$0.0 \% \quad 0$

$\mathrm{N}=113$

$14.2 \% \quad 16$

$85.8 \% 97$

$0.0 \% \quad 0$

$\mathrm{N}=16$

$100.0 \% 16$

$\mathrm{N}=97$

\section{GEII_GERMAII_TLU/ITLU_ELEM}

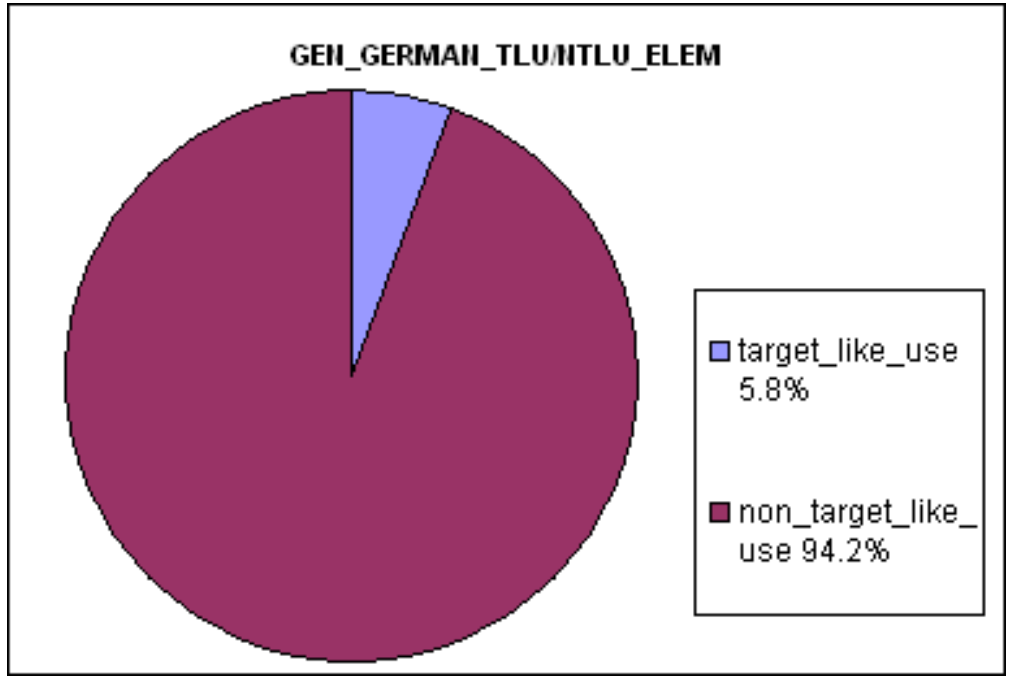

7$$
6
$$

0

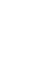


misselection

misrealisation

wrong-unclassified

MISSELECTION-TYPE

MISREALISATION-TYPE

wrong-genitive-form
$89.7 \%$
$2.1 \%$
$8.2 \% 8$

$\mathrm{N}=87$

$40.2 \% \quad 35$

$59.8 \% 52$

$\mathrm{N}=2$

$100.0 \% \quad 2$

$0.0 \% \quad 0$

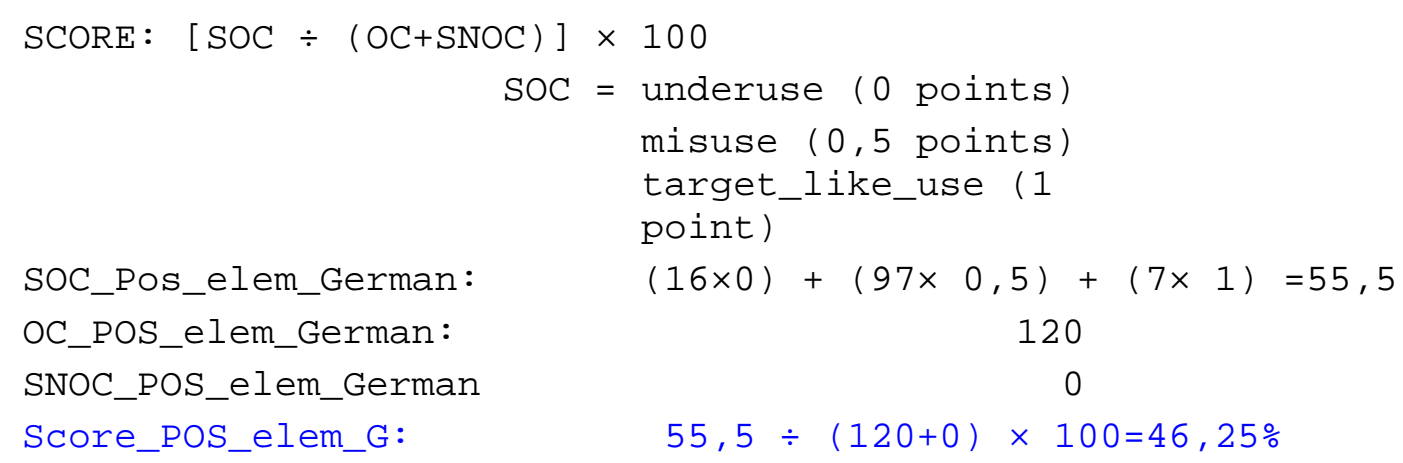

\section{Pre-intermediate Level}

Feature

POS-TYPE
Percent 
non_target_like_use TARGET_LIKE_USE-TYPE

-s-possessor-costruction genitive-case NON_TARGET_LIKE_USE-TYPE

\section{underuse}

misuse

overuse-(snoc)

UNDERUSE-TYPE

blank

MISUSE-TYPE

misselection misrealisation wrong-unclassified MISSELECTION-TYPE

$\mathrm{pp}$

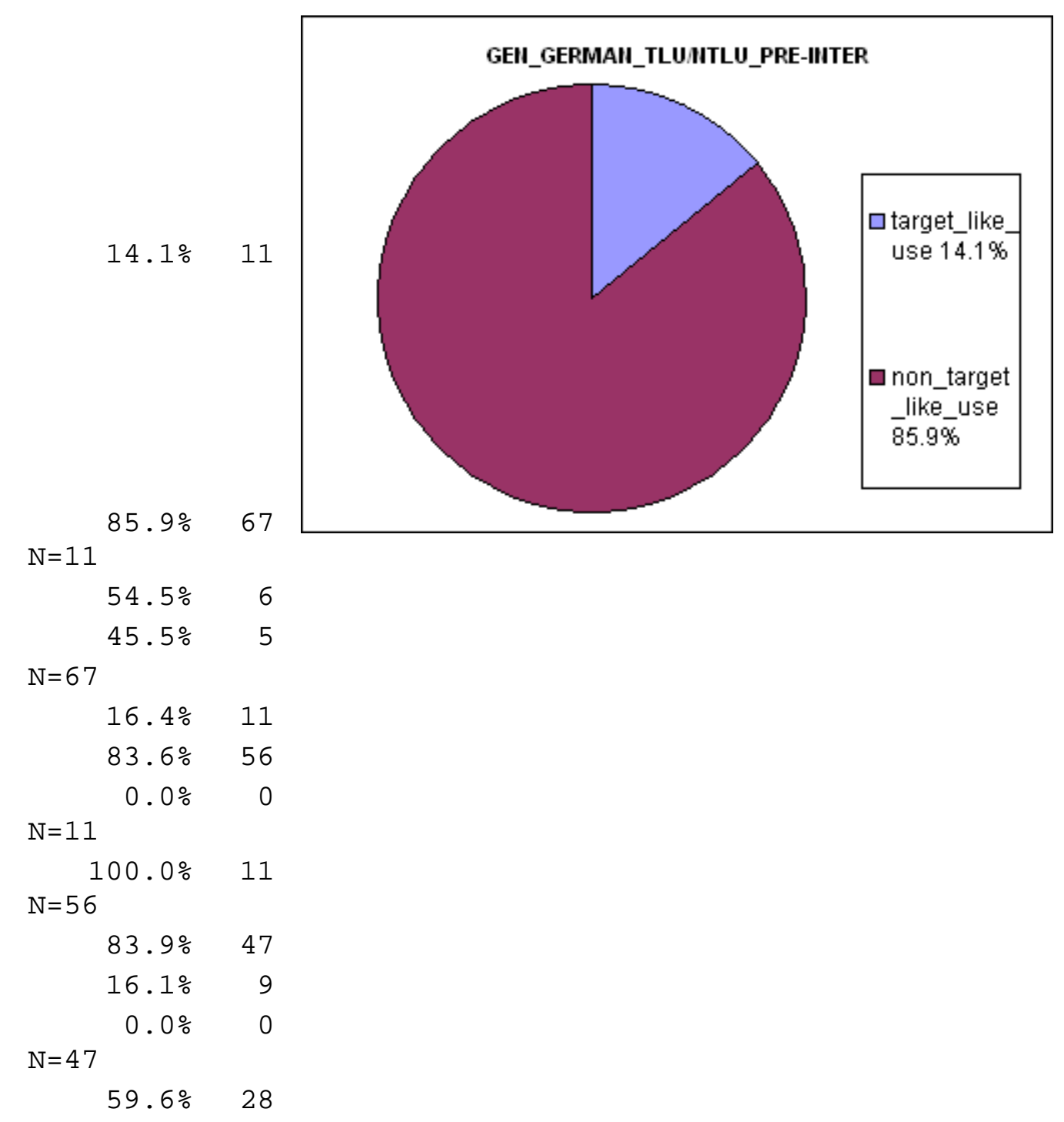


possessive--s

MISREALISATION-TYPE

wrong-genitive-form
$40.4 \% \quad 19$

$\mathrm{N}=9$

$44.4 \% \quad 4$

SCORE : $[\mathrm{SOC} \div(\mathrm{OC}+\mathrm{SNOC})] \times 100$

$\mathrm{SOC}=$ underuse $(0$ points $)$ misuse $(0,5$ points $)$ target_like_use (1 point)

SOC_Pos_pre-inter_German: OC_POS_pre-inter_German:

SNOC_POS_pre-inter_German

Score_POS_pre-inter_G:

\section{Intermediate Level}

Feature

Percent

POS-TYPE

$N=71$ 
target_like_use

non_target_like_use TARGET_LIKE_USE-TYPE

-s-possessor-costruction genitive-case NON_TARGET_LIKE_USE-TYPE

underuse misuse overuse-(snoc) UNDERUSE-TYPE

$$
\begin{array}{rr}
\text { MISUSE-TYPE } & \text { blank } \\
\text { misselection } \\
\text { misrealisation } \\
\text { wrong-unclassified }
\end{array}
$$
MISSELECTION-TYPE
$12.7 ㅇ$

\section{9}

$87.3 \%$

62

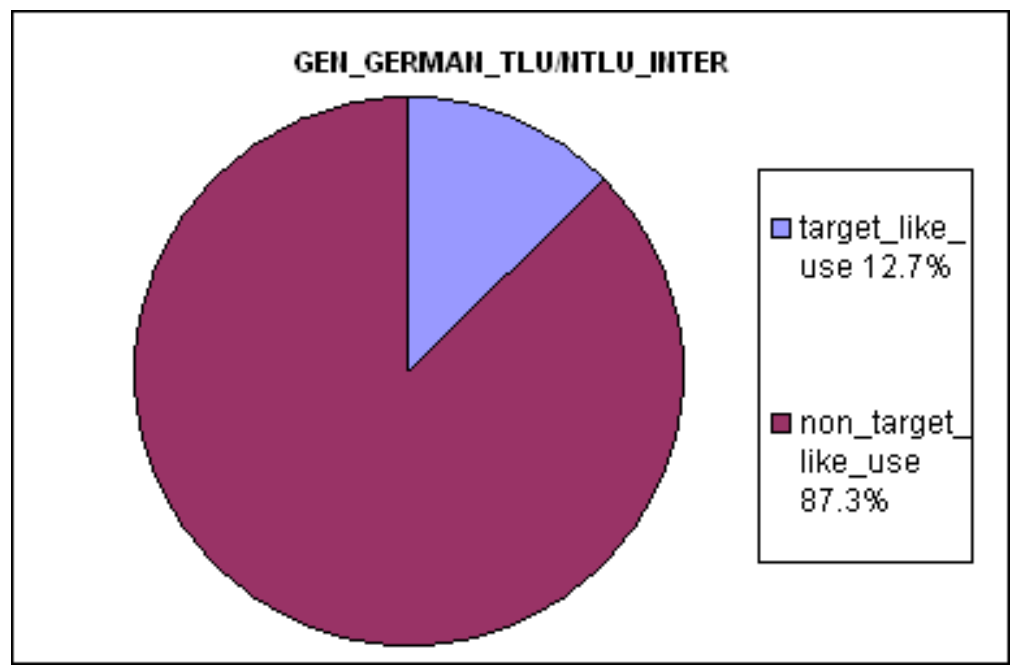

$\mathrm{N}=9$

$44.4 \% 4$

$55.6 \% 5$

$\mathrm{N}=62$

$14.5 \% 9$

$85.5 \% 53$

$0.0 \% \quad 0$

$\mathrm{N}=9$

$100.0 \% 9$

$\mathrm{N}=53$

$96.2 \% 51$

$1.9 \% \quad 1$

1. $9 \% 1$

$\mathrm{N}=51$

$70.6 \% 36$ 


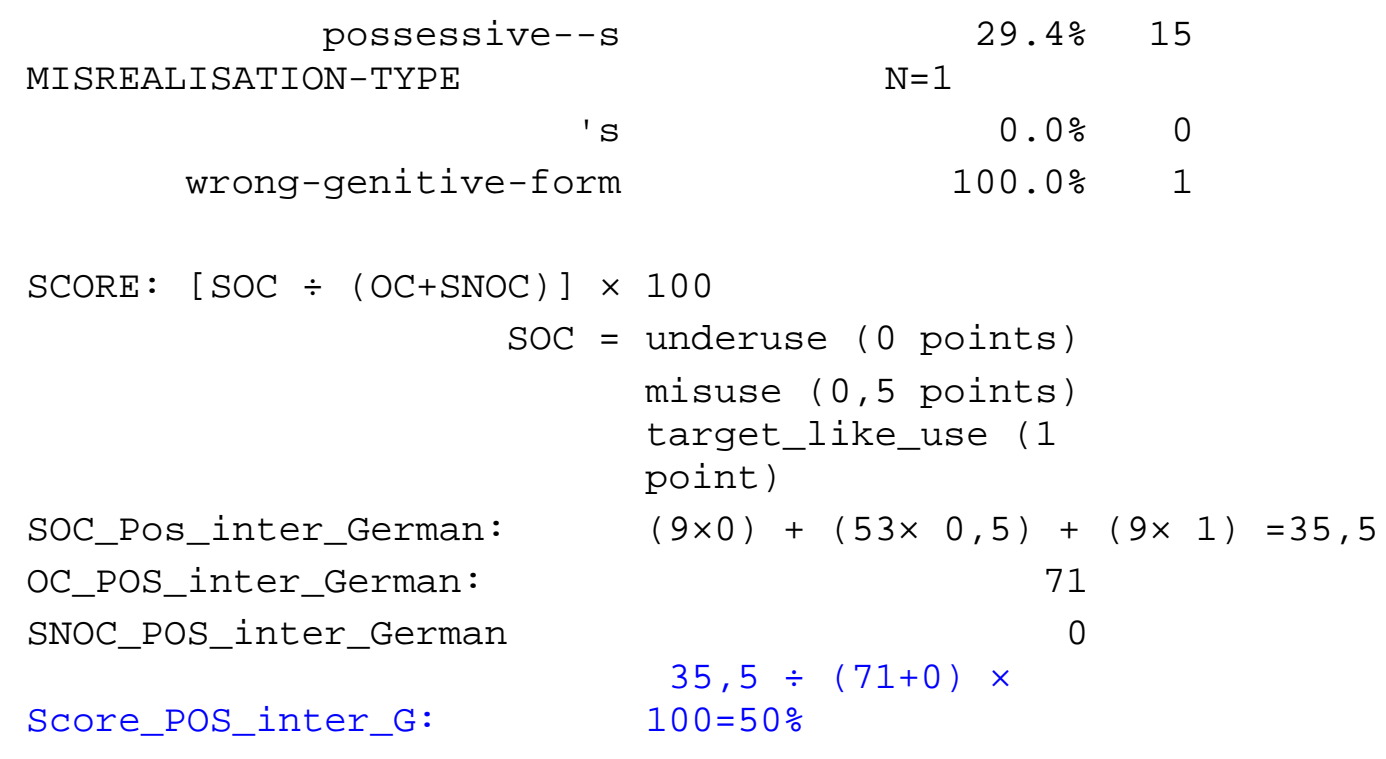

\section{Upper-intermediate Level}

Feature

Percent
$N=24$

POS-TYPE$$
N=24
$$ 
target_like_use

non_target_like_use TARGET_LIKE_USE-TYPE

-s-possessor-costruction genitive-case NON_TARGET_LIKE_USE-TYPE

underuse misuse overuse-(snoc) UNDERUSE-TYPE

blank MISUSE-TYPE

misselection misrealisation wrong-unclassified MISSELECTION-TYPE

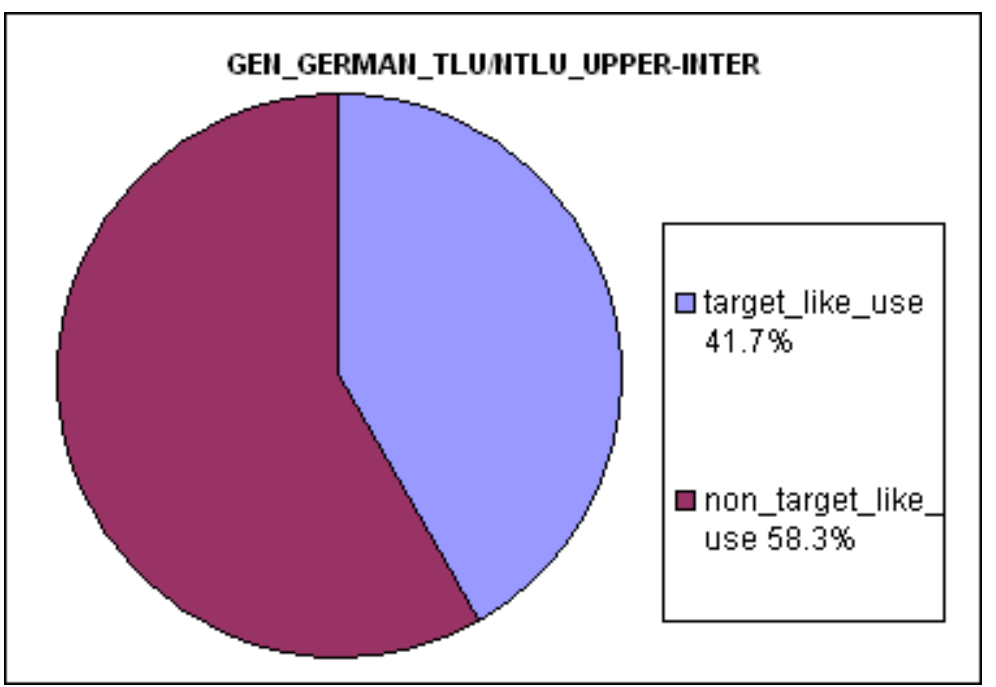

$\mathrm{N}=10$

$10.0 \% \quad 1$

$90.0 \% 9$

$\mathrm{N}=14$

$0.0 \% \quad 0$

$100.0 \% \quad 14$

$0.0 \% \quad 0$

$\mathrm{N}=0$

$0.0 \% \quad 0$

$\mathrm{N}=14$

$50.0 \% 7$

$28.6 \% 4$

$21.4 \% 3$

$\mathrm{N}=7$

$71.4 \% 5$ 
possessive--s

MISREALISATION-TYPE

wrong-genitive-form
$28.6 \%$

$\mathrm{N}=4$

$25.0 \% \quad 1$

SCORE: $[\mathrm{SOC} \div(\mathrm{OC}+\mathrm{SNOC})] \times 100$

SOC $=$ underuse $(0$ points $)$

misuse $(0,5$ points $)$

target_like_use (1

SOC_Pos_upper-

inter_German:

OC_POS_upper-

inter_German:

point)

SNOC_POS_upper-

inter_German

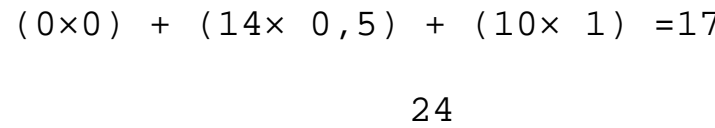


9.11.3.2 The relative frequency of the various possession constructions in German by L1 Spanish and L2 English learners

\section{Descriptive Statistics: Features}

\section{Project: Genitive German_L1 Spanish_L2 English}

\section{Elementary Level}

Feature

POS-TYPE

target_like_use

non_target_like_use

TARGET_LIKE_USE-TYPE

-s-possessor-construction

genitive-case

NON_TARGET_LIKE_USE-TYPE

underuse

misuse

overuse-(snoc)

UNDERUSE-TYPE

blank

MISUSE-TYPE
Percent

$\mathrm{N}$
$N=114$

$5.3 \%$

$94.7 \%$

6

108

$N=6$

$100.0 \%$

$0.0 \%$

0

$\mathrm{N}=108$

$14.8 \% 16$

$85.2 \%$

$0.0 \%$

$\mathrm{N}=16$

$100.0 \%$

$\mathrm{N}=92$
92

0

16 
MISREALISATION-TYPE

$\mathrm{N}=2$

$100.0 \%$

\section{Pre-intermediate Level}

\section{Feature}

\section{POS-TYPE}

target_like_use

non_target_like_use

TARGET_LIKE_USE-TYPE

-s-possessor-costruction

genitive-case

NON_TARGET_LIKE_USE-TYPE

$$
\begin{array}{r}
\text { underuse } \\
\text { misuse } \\
\text { overuse-(snoc) }
\end{array}
$$

Percent

\section{$N=66$}

$15.2 \%$

$84.8 \%$

$\mathrm{N}=10$

$50.0 \%$

$50.0 \%$

$\mathrm{N}=56$

$16.1 \%$

$83.9 \%$

$0.0 \%$
5

10

56

9

47 
UNDERUSE-TYPE

blank

MISUSE-TYPE

misselection misrealisation

wrong-unclassified

MISSELECTION-TYPE

$\mathrm{pp}$

MISREALISATION-TYPE

possessive--s

wrong-genitive-form

\section{Intermediate Level}

Feature

Percent

POS-TYPE

target_like_use non_target_like_use

TARGET_LIKE_USE-TYPE

-s-possessor-costruction

genitive-case

NON_TARGET_LIKE_USE-TYPE

underuse
$\mathrm{N}=9$

$100.0 \% 9$

$\mathrm{N}=47$

$80.9 \% 38$

$19.1 \%$

$0.0 \%$

$\mathrm{N}=38$

$50.0 \%$

$50.0 \%$

$\mathrm{N}=9$

$44.4 \%$

$55.6 \%$

\section{$N=48$}

$14.6 \%$

$85.4 \%$

$\mathrm{N}=7$

$42.9 \%$

3

$57.1 \%$

$\mathrm{N}=41$

$22.0 \%$ 
UNDERUSE-TYPE

blank

MISUSE-TYPE

misselection

misrealisation

wrong-unclassified MISSELECTION-TYPE

pp

MISREALISATION-TYPE

possessive--s

's
$\mathrm{N}=9$

$100.0 \%$

$\mathrm{N}=32$

$93.8 \%$

$3.1 \%$

$3.1 \%$

$\mathrm{N}=30$

$56.7 \%$

$43.3 \%$

$\mathrm{N}=1$

$0.0 \%$

$100.0 \%$
9

30

1

1

17

13

0

1 